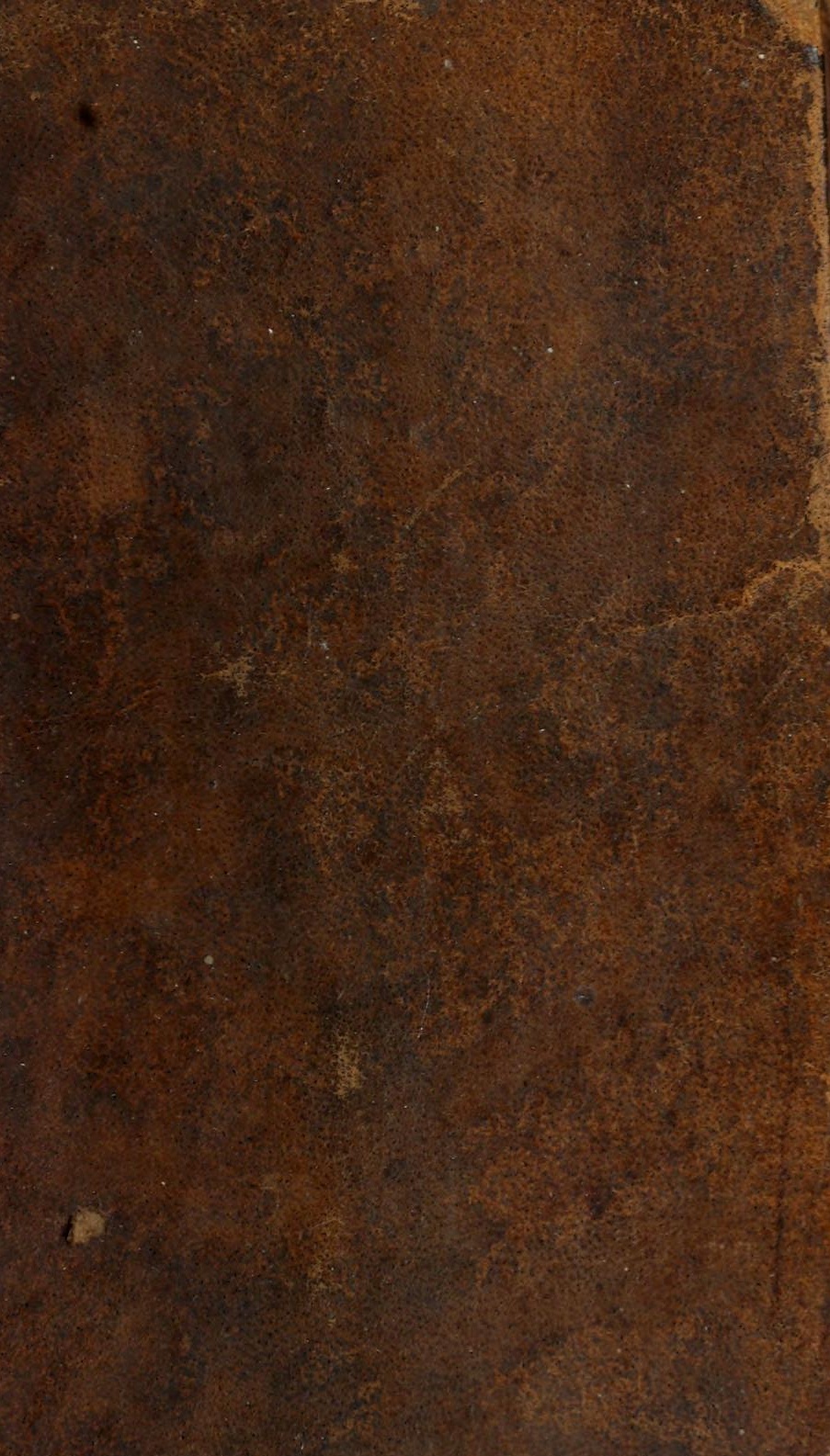




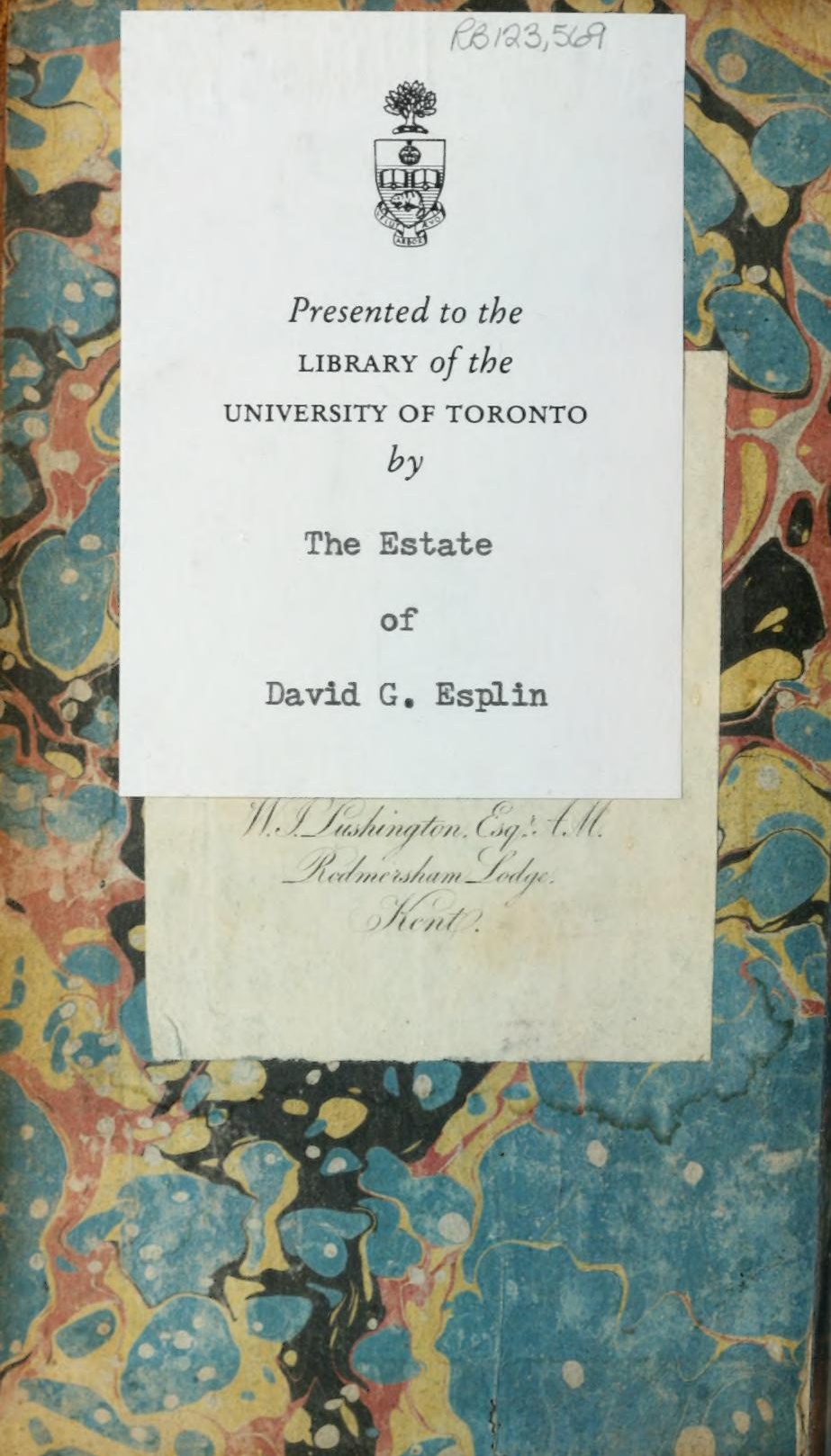




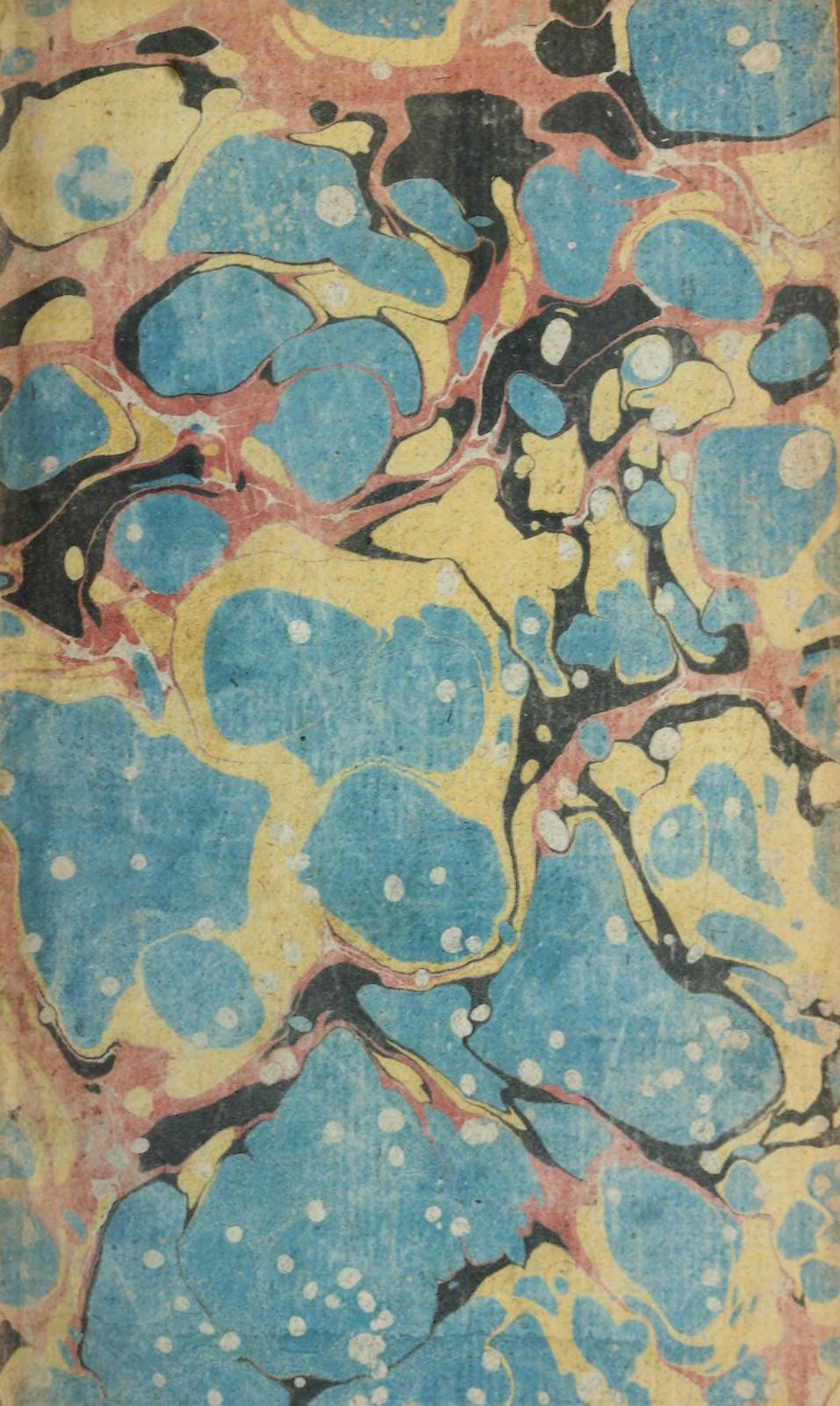




Digitized by the Internet Archive in 2010 with funding from University of Ottawa 

Ton.VIII.Part.2.

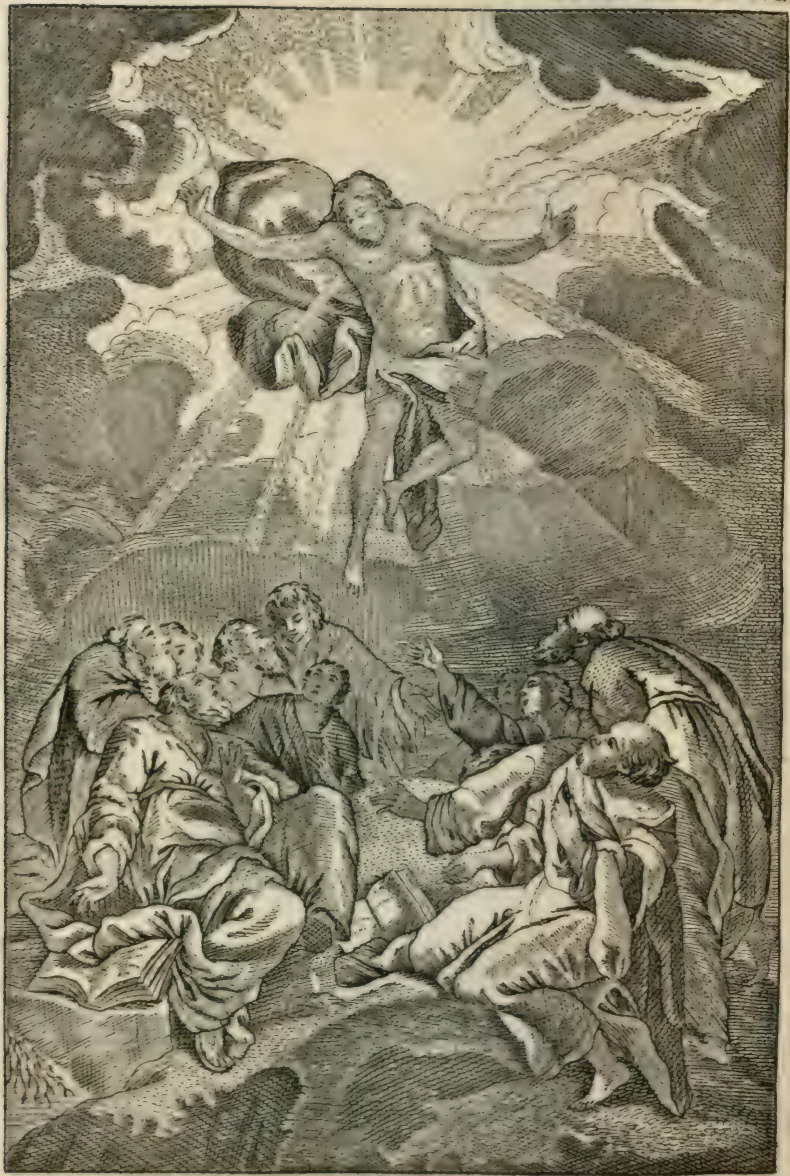

de Boubers fiulp.

$$
\text { Lexécution de la Promesse }
$$

Parune Ambassade inmortelle qui devoit porter la parole et la porte encore a toutes les Nations Matt.28:1g et 20. Marc16:15. 


\section{LE SPECTACLE}

D E

LA NATURE。

TOME HUITIEME.

Seconde Partie. 
criato fandes

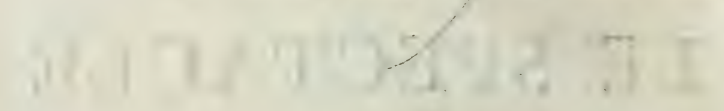

$.73 U 1 A 7 \AA \quad \Lambda J$ 


\section{LE SPECTACLE}

D E

L A NATURE.

TOME HUITIEME,

Contenant ce qui regarde

L'HOMME EN SOCIÉTÉ.

AVEC DIEU.

SECONDE PARTIE.

NOUVELLE ÉDITION.

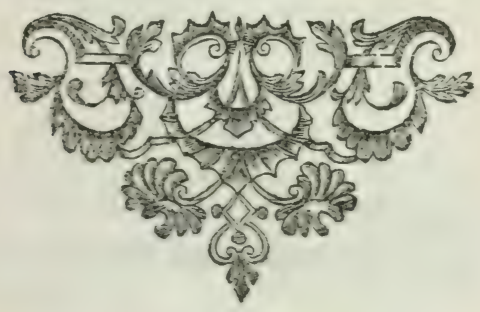

\section{A P A R I S,}

Chez les Freres Estiense, rue S. Jacquics, ì la Vertu.

\section{D C C. L X X I.}

Ayes approbation Es Privilege du Rat. 


\subsection{J142 II ir.}

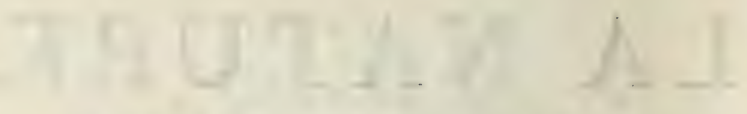

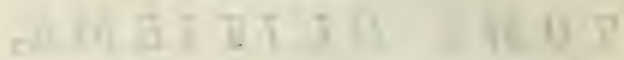

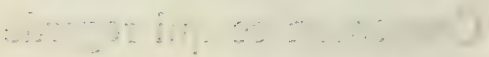

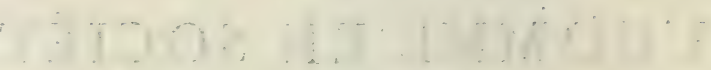

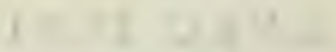

$$
\begin{aligned}
& 31 \times \cdot 6707 \cdot 1231 \\
& \text { Do: }
\end{aligned}
$$

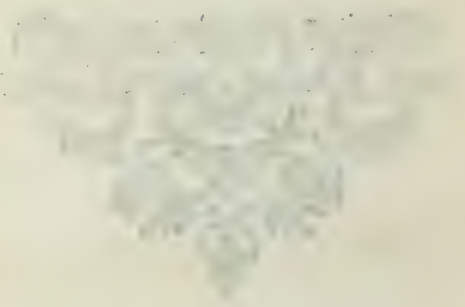

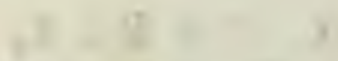

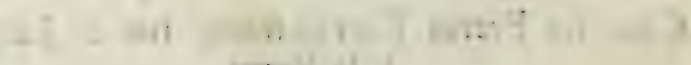

$$
\begin{aligned}
& \text { It: }+1,1
\end{aligned}
$$

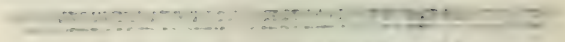

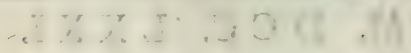

$$
\begin{aligned}
& \cdots+\cdots+\cdots
\end{aligned}
$$




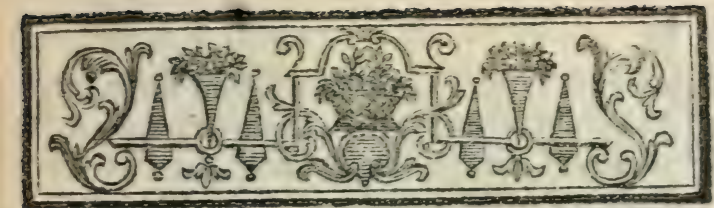

\section{LE SPECTACLE \\ D E}

\section{LA NATURE.}

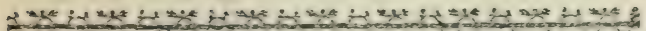

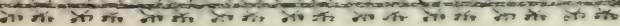

$$
\underset{D E}{S \mathrm{U} I \mathrm{~T}}
$$

LA DEMONSTRATION É V A N GÉ L I Q UE.

\section{CHAPITRE PREMIER.}

Examen de l'Aliiance Chrétionne par la preuve commune de tous les Traités.

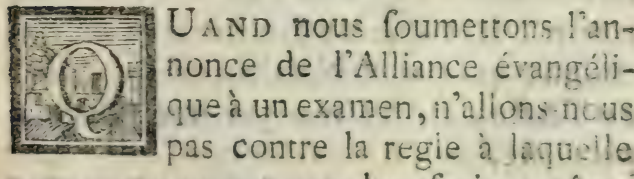
nous avons vu que tous les efprits, mêne Tome VIII. Part. II. A 
Q LE SPECTACLE

LA DS les plus éclairés, devoient être foumis? zoxerr. Nous ne fommes point contraires à nousw.mol mêmes. Comme il y a un examen plein d'arrogance \& d'illufion, il y en a un qui eft jufte \&r conforme à notre état. Aucun efprit n'a droit de rejetter, ou de difcuter jar des railonnements, ce qui eft l'œuvre d'une volonté différente de la fienne, \& à plus forte raifon ce qui eft l'œurre de la libre volonté de Dieu. Mais il n'y a point d'efprit qui, pour agir raifonnablement à l'égard de ce fait, n'ait droit \& obligation de s'en affurer par les preuves teftimoniales autoriées parmi les hommes. On n'examine point fi un tel, qui vivoit du temps de Louis XIII, a dû, ou n'a pas dû avantager une branche de fa famille, fans faire mention des autres. Moins encore fe prétend-on dégagé de fa difpofition teftamentaire par cette raifon, qu'on ne la croit pas faite avec affez d'équité ou d'intelligence. Il n'y a ici qu'une démarche raifonnable: c'eft' d'exa miner fi cet homme qui étoit maitre de fon bien, en a difpofé : \& on s'en affure tant par la copie de l'inltrument de donation, que par le Notaire, confervateur de l'Acte, en un mot'par une fuffifante publicité.

C'ut 'encore la conduite qu'on tient 


\section{DE LA NATURE.}

¿ l'égard des propofitions que viennent LA DEfuire les Envoyés d'une Puiffance étran- Mronstr. gere, \& à l'égard des ordonnances d'une tranigers compagnie d'hommes délégués pour régler la police, la juftice, ou les finances. On demande sils font autorifés, \& l'on s'en inftruit par les témoignages non-fúpects qui leur font rendus. Cette conduite qui contente les moindres efprits, n'a jamais été rejettée des efprits les plus élevés: elle leur eft même également néce?faire, parce qu'ils chercheroient en vain dans leur raifon ce qui n'en eft point provenu, \& ce qui ne peut s'y trouver.

Mais s'il n'y a que cette voie pour favoir ce qui ne dépend point de nous, \& pour vérifier fur-tout la réalité d'une Anbaflade qui s'offre à traiter avec nous; c'eft donc aufii l'unique procédé qui convienne daus l'examen de l'envoi de Jefus-Chrift, \&r de fes Difciples. Laiffons à part le Traicé $\&$ les paroles dont ils fe difent porteurs; voyons leurs pouvoirs: nous pourrions nous méprendre fans l'examen du Traicé, \& il ne peur qu'être digne de tous nos refpects, fi leurs pouvoirs font divins. Or l'examen des pouvoirs eft ailé : c'eft un procédé ordinaire, \& nous y fommes faits. Les regles s'en trouvent dans la fociété. La million des Apôtres eft-elle 


\section{LE SPETACLE}

LA DÉ-connue? les attendoit-on? ont-ils des MONSTR. lettres de créance? produifent-ils des ÉVANGEL. témoignages fatisfaifants?

s.estémoi- Il y a deux fortes de témoignages, ceceffaires. Jui que nous nous rendons à nous-mêmes, \& celui qu'on nous rend. Le premier, qu'on peut appeller le témoignage perfonnel, eft recevable à proportion des bonnes qualités de celui quile rend. Mais en général le témoignage qu'on fe rend à foi-même, s'il eft feul, eft une foible preuve; parce que les déguifements de I'amour-propre infpirent une jufte défiance. Il n'en eft plus de même, quant à ce premier témoignage il s'en joint un autre naturellement plus digne de foi. C'elt le témoignage extéricur, le témoignage paffif, qu'on reçoit de dehors, ou celui que les hommes rendent à d'autres hommes de les connoître pour gens fans reproche, ou de les avoir trouvé véridiques dans un rapport; ou d'avoir appris par des moyens non-fufpects, qu'ils font chargés d'une commiffion qui les doit faire écouter.

Ce témoignage extéricur eft fort \& valide a proportion du nombre \& des bonnes qualités des perfonnes qui le rendent foit aux auteurs d'une action, foit aux portcurs d'une commiflion. J'ajoute que 


\section{DE L A Nature. 5}

ce témoignage devient convainquant à $L A D$ L proportion des circonftances qui a ppuient MoNsTr. les dépofitions des rémoins d'un événe- Ĺvarcis ment, ou qui donnent à une commiffion la notoriété reguife, \& de commun uíage. Le concours de ces diverfes indications d'une même chofe éloignée de nous par la diftance du lieu, ou du temps, devient pour nous tout auffi für que le rapport de nos yeux, ou la vue de l'objer. Et fi nous y prenons garde, les rapports même de nos yeux \& de tous nos fens, ne font que des témoignages rendus à l'excellence \& aux qualités des objets qui font hors de nous. Nous ne connoiffons point le foleil en lui-mêne, ni par aucun examen que nous ayons fair de fa nature. Comment nous y prendrions-nous pour faire un pareil examen? C'eft la perfévérance \& l'uniformité des rapports de nos yeux \& de tout notre corps qui nous affure de la préfence \& du pouvoir du foleil. C'eft de même la perfévérance \& l'uniformité des rapports gu'on nous fait d'un Parlement ézabli à Paris, qui nous détermine à y porter nos afiaires fans crainte de méprife. Cette notoriéré, fondée fur la multitude des circonfitances, \& fur la qualité des témoignages extérieurs, eft la plus grande cercitude

$$
\text { A iij }
$$




\section{LE SPECTACLE}

LA DÉ- que thomme puiffe defirer pour rég!cr fa monstr. conduite. Quelle fera donc fa fécurité \& zanger. fa reconoiflance, fi Dieu a rendu le miniftere qui lui apporte l'alliance du falut nuffi durable \& auffi notoire que l'eft le miniftere confié par la République de Venife à fon Sénat, ou par les ProvincesUnies à leurs Etats-Généraux?

N'entreprenons pas cependant de le prouver, fans avoir pris d'abord dans la fociété une idée nette \& fâtre de ces témoignages extérieurs, dont le défaut décele ceux qui s'arrogent un pouvoir qu'ils n'ont pas, \& dont l'exhibition montre ceux qui en font vraiment revêtus. Ce moyen de certitude eft facile, \& il nous met dans le plus parfait repos.

T.e defaut Trois Politiques, je le fuppofe, après de túmoi- avoir médité fur la conjoncture des affii-
gnazes, preuves du dếăt de pellvoirs. res de l'Europe, en cette année 1748 , fe font mis en tête de former chacun à part \& de faire recevoir un fyftême d'arrangeinent général, qui réglera par des compenfations équitables le partage des Princes \& le fort des Peuples de notre Continent. Tous trois montrent du génie, \& ont eu communication de quelques bons Mémoires qui expofent les intérêts, ou même les intentions des Puifrances. Cclles-ci fo font déja expliqueées par leurs 


\section{DE LA NATURE.}

Aģents, \& ont envoyé leurs Plénipoten- LA DE. tiaires à un Congrès. Il y a plufieurs ar- moxsta. ticles convenus, dont les Peuples ont bravitib. pris connoiffance. On confent en bien des lieux à recevoir le Traité qui met fin à une guerre ruineufe.

Mais Martin, l'un de nos trois Politiques, n'en eft point content, \& y veut changer différents articles. Jean y fait de nouvelles réformes; \& Faufte va encore plus loin. Celui-ci conferve les termes du Traité, \& y fubftitue des fens auxquels on ne penfoit pas, des fens tout différents de ceux qu'un ufage univerfel y avoit attachés: en forte que ce qui dans l'ulage fignifioit un Roi, n'eft plus dans fon explication qu'un premier Miniftre; ce qui figuifioi: un héritier, un propriétaire, n'eft plus qu'un ufufruicier, ainfi du refte. Le Traité de la forte fe trouve tout diffésent de ce qu'on avoit cru.

Tous trois d'ailleurs fe difent mécontents des Envoyés qui avoient commiflion de fuire l'accommodement, ou de fignifier les volontés de leurs Maîtres. Ils les accufenc de prévention, \& de défauts par lefquels ils prétendent la commifion anéantie. Et comme ils croient micux entendre les matieres, nos trois raifonneurs fe 


\section{8 LE SPE C T A C L E}

LA Ds-mettent lans façon à la place de l'Ambar* nistr. Aade. Ils ferout les Plénipotentiaires.

s VANGER. Pour fe procurer cependant une apparence de commiffion, une ombre d'autoricé, ils vont jufqu'à établir un principe fort fingulier pour l'avenir, qui eft que qunnd un Peuple fera mécontent des Ambalindeurs d'une Cuur étrangere, il peut les doftituer, \& choifir dans fon propre corps des fujers quil les remplacent. Ainfi l'Aingleterre mécontente de l'Ambaffadeurd'Lepagne, peut le renvoyer, donner cetre qualité à Nylord Harrington, \&c linftruire bien \& duement des réfolutions de la Cour de Madrid.

Si cette conduice eft extraordinaire, la raifon dont ils l'autorifent ne l'eft pas moins. Toute fociété, difenc-ils, eft en droit de fe choifir elle-même les Miniftres néccffaires à fa confervation. Elle peut done nommer les Envoyés d'une autre Puiffance, les choifir elle-même, \& les prendre où elle veur, même chez elle.

Martin, Jean, \& Faufte couvrent la bizarrerie de ces nouveautés par un air d'érudition \& d'affurance. Ils en impofent, \& trouvent quelques partifans que Ia feduction des raifonnements, ou l'amour de l'indépendance échaufe en leur 


\section{DE I A. N. A T U R E.}

faveur. Mais le refte de l'Europe les laiffe la Déo dire \& battre l'air; parce que n'ayanc Mosista. reçu des Puiflances aucuns pouvoirs pour ÉvANGed. agir, ni aucuns témoignages qui les autorifent, il eft inurile de les entendre: ils n'opéreront rien, n'étant portcurs de rien. Ces trois hommes n'influent pas davantage dans les affaires de l'Europe que trois Nouvelliftes, qui attroupent autour d'eux des auditeurs dans la grande allée des Tuileries, \& qui, la canne à la main, leur tracent leurs idées fur le fable.

Comme il eft aifé de connoîrue ceux qui n'ont ni pouvoirs, ni témoignages, il ne l'eft pas moins de difcerner fans méprife ceux qui en font pourvus.

Ici on ne court rifque de s'égarer, ni Mojens dans les rapports compliqués d'une géo- infaillibles métrie profonde; ni dans la diverfité des notre iš

vues fous lefquelles la méta phýfique peut confidérer une même chofe; ni dans les détours de l'amour-propre \& de l'efpric particulier. La certitude des témoignnges eft communément attachée à des moyens de la plus grande fimplicité, ì une fimple proclamacion, à une prife de polfeffion, à la cérémonie d'une réception. Ceux qui compofent les Congrès pafingers, ou les. Compagnies permanentes, one d'abord prélenté les marques du pouvoir qui les

$$
\text { s } v
$$




\section{Io LESPECTACLE}

LA DL-en a rendu membres. Par la fuice, fans MoNsth. demander l'exhibition de leur premier ÉVANGel. titre, le Pubiic les reconnuit pour ce qu'ils font avec la plus entiere fécurité, \& leur rend lui-même un témoignage fupérieur à tout foupçon. Le moindre doute à cet égard feroit capable de rendre un homme ridicule. On ne fait point de vains raifonnements contre le miniftere public, \&r contre les établiffemencs connus: mais on ségare en des doutes \& en des difcuffions fans fin contre le Minittere évangélique, dont la notoriété eft la même que celle des établiffements humains. Cctte injultice étant très-grande, $\&$ copendani trè-commune, on la fera mieux fentir, en la montrant fous les traits d'une autre qui lui reffemble.

Que penferoit-on d'un habitant de Dicppequi refuferoit de porter fon Process au Parlement de Normandie en vertu de ce railonnement? Pour lier mon affaire à un Tribunal, \& m'cn rendre dépendant, il faut d'abord que je fois perlundé de l'exiftence \& du droit de ce Tribunal. Or ceux qui paffent pour rendre la juftice à Rouen, \& qui prennent la qualicé de Préfidents ou de Confeillers au Purlement de Normandie, n'ont aucun titre légitime pour le faire. Car nos Rois 


\section{DE LA NATURE. II}

n'ont jamais fait un établiffement qui au- LA DÉroit été enciérement contraire à leurs pro- Mossta. pres intérèts. Et qu'y avoit-il de plus con- Ĺvinizi. traire aux intérêts des Rois de France, que d'aliéner la Noblefte d'une Province riche \& maritime, en la dépouillant du dioit honorable \&i de la polfefiion immémoriale où elle étoit de rendre la juitice, pour en revêtir des hommes de Loix? At-on oublié le dépir de ces Seigneurs de Baffe-Normandie, qui favoriferent la defcente des Anglois en France, \& qui vengerent leur mécontentoment perfonnel par l'ébranlement de tout l'Ltar? Ce qu'on nomme Parlenent de Normandie, dérogeant au droit commun \& à la faine politique, eft donc un écablifrenent fabuleux, ou une entreprife infoutenable. Avec cela je voudrois bien favoir fi les Loix quion y fuit font juftes, \& fi elles Tont émanées du fuprême Tribunal de la raifon. Mon parti eft pris : \& je porterai mon procès devanc les plus fentés de l'ancienne Nobleffe de la Province; jomais ailleur's.

Que vous fert-il, diroit-on à cet homme, de difputer contre un fait atiefté des perits \& des grands? penfez-vous y donner atteinte par la liberce de vos doutes? Les premiers Juges délégnés par le Boi 


\section{LESPECTACL 2}

LA D:- qui ont fiégé en $150 \mathrm{I}$ dans ce Parlement, A. UN TR: montrerent leurs Lettres fignées en I 499 SPANelco par Louis XII, avec toutes les marques d'un pouroir légitime \& émané du Trône. C'eft la Nobleffe même, qui pour s'acquitter mieux du fervice militaire, peu compatible avec l'étude des Loix, \& avec Ia longueur des difcuffions, demanda cer énbliffement. Eile le regarda comme un moyen de décharge pour elle, \& de falue pour les Particuliers, dont les intérêts fe décidoient auparavant trop à la légere dans les courtes féances de l'Echiquier.

Depuis ce temps, même fans exiger la vue des Lettres-Patentes de la nouvelle Compagnie, ni la lifte fuivie des Magiftrats qui s'y font fuccédés, tout le Pubilic rend témoignage à ceux d'aujourd'hui qu'ils font les fucceffeurs des précédents. Joignez à ces atteftations la fuite des Réglements fublics \& des Arrêts rendus d'année en année par ce Corps, les bâtiments dont il a toujours été en poffeffion pour exercer les mêmes fonctions, les habits \& toutes les marques de fa dignité, les charges confervées dans certaines famillics, les offices fubalternes, les droits honorifiques, \& les ufages relatifs aux fonctions de la Compagnie : tout en démontre le pouvoir \& la perpćtuité. 
Ce qui diftingue ici l'efpric fupérieur LA DÉd'avec les efprits du commun, n'elt pas noxsm. de pouvoir difputer contre ce qui eft pu- LVANGELs blic \& notoire; mais de fentir mieux que les aurres toute la force de la preuve te?timoniale.

Or cette preure fi courte $\&$ fi décifive dans la fociété pour dilcerner ceux qui font revêtus de pouvoirs légitimes, eft le moyen aufli expéditif que peu furpect auquel Dieu nous renvoie dans l'affaire de l'Alliance qu'il daigne faire avec nous par fon Mefile. Il a confié fes pouvoirs au defcendant d'Abraham, à quilesbéné- Gmef. dictions étoient promifes, $\&$ a communi- $=2: 18$. qué ces bénédictions à tous les Peuples par un miniftere à jamais reconnoirfible, \& toujours environné des marques de la divinité de fa miffion. En forte quue comme c'eft Dieu qui a fait \& montré de loin la Préparation de l'Evangile, c'eft luimême qui en a fuit la Démonftration; \& certe Démonitration cft aufi fimple que calle qui nous affure des établifiements qui fe font dans la fociété.

Si l'Evangile n'étoit qu'une hiftoire, on pourroit le confidérer fous différents points de vue, \& en produire différentes preuves également folides, fans entrer dans la quofition du miniftere porreur des 


\section{LE SPECT A C L E}

LA D-biens promis. Il y auroit, femble-t-il, MONSTR. quelque prudence à s'abftenir d'en parler; ślivigl. parce que dans cetre multicude de fociétés qui ont rejetté le miniftere, ou en onc introduit un nouveau, ou ont rompules liens des Eglifes en rompant ceux du corps facerdotal; cette queftion peut offenfer les efprits, à la réunion defquels nous devons toujours tendre.

Afurément nous n'avons rien de pius à cœur que d’applanir, felon notre poutvoir, les obftacles qui nous féparent, ni rien de plus en horreur que d'avoir bleflé ceux que nous voudrions ramener à la concorde. Mais ce feroit les fervir fort mal, de nous étendre fur ce qui eft infuffifant, \& de fupprimer ce qui eft indifpenfablement néceffaire.

La fin du Traité de l'homme où la fuite des matieres nous a conduit, ne doit pas ĉtre différente de la fin même de l'homme qui eft fon unionavec Dieu. L'Evangile eft pour lui l'hemreufe annonce de cette alliance éternelle à laquelle Dieul'invire. Il étoit en la pleine liberté du Toutpuifant de faire certe invitation.par des Anges, ou par des hommes; comme il l'ćtoit de ne laiffer aucun exercice à notre liberté, en nous fauvant fansaucune invitation. Son choix nous fixe, \&nous n'a- 
vons pas à délibérer fur le moyen de com- LA DÉmunication. Si pour y avoir part il s'agiffoit uniquement d'être convaincu de la ÉVANGEL. réalité de l'Hiftoire évangélique, il y en a cent preuves, \& l'on pourroit choifir. Mais de l'alliance évangélique il n'y en a qu'une, \& c'eft notre bonheur que cetre preuve foit unique, fenfible, \& auffi fatisfaifante pour les efprits les plus fins, qu'intelligible pour les plus bornés. C'eft même ce qui coupe pied aux vaines railleries, à l'érudition déplacée, aux difcuffions qui multiplient les difficultés, plutôt que de les éclaicir. C'eft un faic public, \& fubfitant fous nos yeux, qu'il y a une compagnie d'hommes qui fe dilent chargés par exclufion d'aninoncer à toure Nation la nouvelle du falur.

Or tous ceux qui viennent à nous avec commifion, montrent leurs pouvoirs. Tout fe réduit là. On connoît donc le miniftere évangélique comme tout autre miniftere. La certiude en roule fur ce qui eft de néceffité \& d'ufage dans tous les Traités; fur les moyens très-fimples $\&$ très-palpables par lefquels les hommes fe procurent une juite lécurité dans tout ce qui fe traice entr'eux par des agents.

Le droit de jouir du repos que donne Premicre la ceritude s'acquiert de deux façons, regle de 


\section{I6 LE SPECTAC 2}

LA Dí- \& felon deux maximes du fens commun MoNsTr. qui cranquillifent tous les efprits. La preB́ANGEL. miere regle de fécurité, regle univerfellement reçue, eft que, quand les Envoy és d'une Puifance abfente ont fait connoitre leurs pouvoirs, on peut alors être für des inientions de cette Puiffance, Es ce n'eft que par fes Envoyés quíon peut contracter avec elle. Par une fuite néceffaire de la même maxime, il eft clair çue ceux quii fans une commifion expreffe auroient pris connoiffunce ou copie du Traitéqu'on propofe, ne font pas autorifés pour cela à le dire Envoyés, ni ne peuvent mettre en correfpondance les parties qui voudroient contracter. En un mor, le Traité, foit verbal, foit écrit, n'eft point ce qui fert à faire connoître les Envoyés; mais les Envoyés connus fervenc à garantir le Trairé, \& à communiquer la réalité de l'Alliance.

seconde reile die Livurité.

Tous les hommes fonrufage d'une autre maxime également fimple, que, quand une compagnie de Juges ou d'autres perfonnes qualifices, ne peut fe tranfporitr dans un lieu, fi elle $y$ envoie un de $\int e s$ Membres, avec une commifion préfentée dans la forme qui l'autorife; on traite, on agit aufji flurement avec le Commifionaire gic avec tout le corps qui l'a envoy's 


\section{DE L A N A T URE. IT}

Je n'ai befoin que de la premiere maxime pour démontrer la vérité de l'E-Monstr. vangile aux perfonnes cultivées par l'u- źmugito fage du monde, \& des affaires de la fociété.

Cette maxime qui contente les meilleurs efprits, elt intelligible \& facisaifante pour les plus tornés. Elle les éclaire tous, \& rend leur condition égale.

Je n'ai befoin que d'y joindre la feconde regle pour faire voir aux plus fimples, à ceux, par exemple, qui ne comnoiffent que leur Curé, qu'ils ne doivent pas croire leur condition pire ou moins certaine à l'égard du filut, que celle des perfonnes les mieux infruites.

L'unique affaire des petits \& des grands, eft de fivoir, s'il $y$ a un Apofolat adrefle à toutes les Nations Es à tous les frecles. Mais il ne faut demander ni s'il y en a un, ni s'il n'y en a qu'un, ni où il eft. Deux ambaffades s'entre détruiroient, \& on ne va pas au-devant d'une ambaflade. Il eft feulement vrai que ceus qui en ont entendu parier, ne peuvent railonnablement négliger de la connoître, ni de la recevoir. Mais on n'eft pas en peine de la chercher : c'eft elle qui vient à nous. L'Apoitolat de Jefus-Chrilt s'et mis en marche il y a dix-lept cents 
18 LE SPECTACL

$\mathrm{L}_{\Lambda}$ DÉ-ans. Depuis ce temps-là les Envoyés n'ont moNsTr. ceffé de dire à toures les Nations : Nous ÉVANGer. voici. Ils continuent à nous annoncer la parole de vie, \& à nous montrer les preuves de la mifion dont ils font revêtus. De cette forte les ignorants font inftruits, \& les favants font fixés. Voilà donc la preuve qu'il eft indifpenfable de faire valoir dans un Traité tel que celui-ci; puifque feule elle fuffit à tous, \& que fans elle tous les moyens généraux de prouver le Chriftianifine ne nous rendent pas Chrétiens.

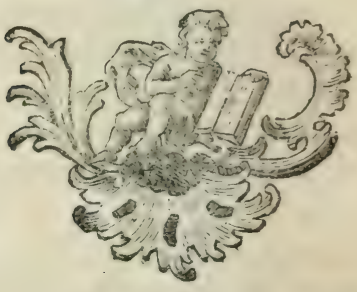




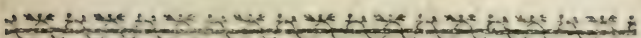

LA DŔMONSTT.

C H A P I T R E II. ÉTACLL。

Les Témoignages rendus au Miniftere Evangélique.

SI j'avois à faire l'hiftoire de la Paix $S$ de Munfter, ou d'Aix-la-Chapelle, je ne produirois pas en nature les pouvoirs des Plénipotentiaires, ni les actes fignés. Je n'en donnerois que des copies, qui par elles-mêmes ne pourroient faire foi, mais qui deviendroient certaines par les témoignages poftérieurs des différentes Cours qui ont reconnu ces Actes, \& des Peuples qui y ont conforméleur conduize. Nous pouvons de même prendre dans les livres des premiers Miniftres de l'Evangile le récit des merveilles par lefquelles le Tour-Puifant a manifefté \& fcellé fon œuvre. Nous n'avons pas befoin de prouver en ce lieuni l'infpiration de ces Livres, ni la réalité des miracles qui ont fervi de lettres de créance aux Ouvriers évangéliques. Ce que nous en affurons n'eft que condicionnel. L'efprit de Dieu s'eft communiqué au Genre-humain, fi les faits font atteftés. Jufqu’à la production de ces témoignages, tout demeure en fufpens. 


\section{LE SPECTACLE}

LA D.́. Mais il ne refte plus de doute ni fur l'oeuMonstr. vre de Dieu, ni fur les Livres qui la rapporEVVANGEL. tent, quand on montre la fociété pleine desatteftations renduesavec examen, avec difcernement, \& en connoiffance de caufe, à l'œuvre, aux Livres évangéliques, \& au miniftere à jamais porteur de l'alliance.

Nous pouvons, felon le langage des premiers Chréciens, partager cette matiere en trois témoignages, qui font celui de l'efprit, celui de l'eau, \& celui du fang.

Les témoignages de l'ceprit, font les caracteres de Divinité par lefyuels l'efpric de Dieu a illuftré fes Euvoyés. Nous ne les avons pas vus : mais ils font remplacés pour nous parles autres témoignages qui les conftatent.

Le témoingnge de l'eau eft celui qui étoit rendu à l'Evangile par le Baptême, \& par lavie nouvelle des premiers Chrétiens. Quoique le premier Baptême des Chrétiens eût acquis par fa nouvelle inftitution un mérite forc différent de celui d'une fimple cérémonie, il rentroit dans l'idée commune de purification. Touse l'Antiquité eft pleine de traits qui nous montrent que ceux qui vouloient changer de vie, ou expier de grands crimes, fe mettoient fous la conduite de quelque Porfonnage refpectable par fa place ois 
par fa doctrine, \& commençoient par LA DL une purification, qui étoit comme la pro- MONsTR. feffion publique de leur renonciation à Évangel. leur vie précédente. Cette purification, nous l'avons vu ailleurs, étoit connue chez les Paiens comme chez les Juifs: \& l'ufage en étoit fi univerfel, qu'on en trouve des exemples fréçuents jufques dans les fables, comme dans celle d'Hercule, qui fut purifié par Eumolpe; a dans celle d'Apollon, qui fur purifié par Carmanor; b de Théfée, qui le fut par les Py- a Paufan. talides; c \& de Bellerophon, qui pour c Platarcb. un meurtre, quoiqu'involontaire, fe fic purifier par Pracus, Roi \& grand Prêtre d'Argos. d

2 Dion. Sicul. lib. 4 , b Pausan.
lib. 10.
c Platarcb.
in Tbeseo.

d Apollo. cor. lib. 2.

Au témoignage de l'eau ou du changement de vie par le Baptême, les premiers Chrétiens ont ajouté celui du fang ou du martyre, le plus fort de tous : \& ces trois témoignages n'en font proprement qu'un. C'eft l'Efprit de vérité qui rend témoignage à l'Evangile, parce que Ia nouvelle vie des Chrétiens \& leur martyre ont fuffifamment conftaté le témoignage des œuvres de l'E prit-Saint, comme les Actes du Parlement \& la perfuafion où eft le Public de l'exiftence de ce Parlement, font pour nous la même chofe que la vue des Lettres de fon établiffe- 


\section{LE SPECTACLE}

In Dé- ment. Ce font trois témoignages qui n’en MoNstr. font qu'un.

GWANGEL.

I.

Le Témoignage de l'Esprit.

Il y avoit des promeffes : on en attendoit l'exécution. Dieu fit paroître enfin le Miniftre de la grande alliance, \& rendit le témoignage le moins équivoque à la Miflion évangélique, par les traits d'un pouvoir fort au-deffus de l'homme, par différents dons, qui de leur nature font fupérieurs ain forces de toutes les intelligences créées, \& qui par leur concours font encore fupérieurs à toutes les illufions imaginables.

Avec la Réfurrection du Sauveur, qui eft la grande preuve du Chriftianifme \& le fondement de l'efpérnnce Chrétienne, l'Eeprit de Dieu a mis en ourre des dons qu'il a diverffifiés felon fes rues. Les uns étoient fpécialement deftinés à lédification de l'Eglife déja formée, comme la fageffe ou la profonde connoiffance des myfteres dont on n'avoit pas encore entendu parler. Telle eft la doctrine toute nouvelle que S. Paul prêche aux Juifs d'Antioche, de Rome, \& de Galatie, fur la deftination de la Loi \& du Sacerdoce d'Aaron, fur l'éloignement que cette Loi metcoit entre 
Jefis-Chrilt, né d'une mere Juive, \& le La DóPeuple Gentil; fur la réunion des deux monstr. Peuples en Jefus-Chrift, mort pour eux írangel. tous, affranchi de la Loi parfa mort, devenu un nouvel homme par fa réfurrection, \& les affociant fans diftinction à tous fes droits. Cette doctrine étoit bien différente de celle que Paul avoit apprife aux pieds du Docteur Gamaliel. Du même genre écoient les révélations fpéciales \& relatives au bien de quelques particuliers, ou d'une Eglife entiere; le difcernement des efprits, \& fur-tout des ouvriers qui s'offroientà la prédication de l'Evangile, les uns de bonne volonté \& par conviction, les autres par intérêt \& avec déguifement. Il y avoit d'autres dons qui tendoient fpécialementà convaincre ceux qui ne connoiffoient pas l'Evangile, ou qui refufoient d'y croire. Nous nous bornerons à rappeller en peu de mots les plus diftingués, ceux qui ont proprement formél'Eglife, en autorifant très-publiquement les Envoyés. Ce fonc le don des guérifons, celui des langues, \& le don de prophétie.

Celui des guérifons, qui de fa nature étoit le plus propre à attirer les yeux par le vif intérêt qu'on y pouvoic prendre, a été aufil le plus univerfel. Il accompagnoit par-tout le Sauveur \& fes Difciples. 


\section{4 LE SPECT ACLE}

I.A Dé- Le fimple attouchement de la robe de monstr. Jefus-Chrift, l'ombre de Pierre, les mouínaval. choirs que la main de Paul avoit touchés, guériffoient fubitement les malades. (a) Ces guérifons miraculeufes fe trouverent fi multipliées \& fi notoires, que les incrédules, tant Juifs que Gentils, jugerent plus commode de les attribuer à la magie, que de nier ce qui étoit public \& univerfel.

Mais cette attribution étoit vuide de fens, \& n'avoit rien d'intelligible que l'aveu des faits. Elle devient ainfi une des preuves du Chriftianifme.

Inutilement croiroit-on en éluder la force, en confondant la doctrine des Chrétiens \& celle des Paiens fur les efprits, \& en tâchanz de répandre für le tout la même incercitude \& le même ridicule. C'eft imirer les Pyrrhoniens, qui jetrent dans la même cathéçorie les fonges de ceux qui dorment, \& la fuire desidées de ceux qui veillent. Mais on laiffe dire les Pyrrhoniens, \& l'on fait la différence qui ie trouve entre veiller \& dormir. On ne s'y méprend pas: ils ne s'y méprennent pas eux-mêmes.

Ce que les Chrétiens admettent fur le miniftere des Anges, \& fur la malignité des efprits déchus de la juftice, eft fondé,

colmme

(2) Hattb. 14:36. Aते. 5:15: Aิ่. 19:12. 


\section{BE L A NATURE. 25}

comme le refte de la révélation, fur l'uni- La Déformité des faits qui confpirent à un même Monstr. but. L'Evangile étant donc prouvé par ÉVANGEL. des faits de cette efpece, il devient la regle de ce qu'il eft permis d'avancer fur les pouvoirs que Dieu accorde, foit aux bons, foit aux mauvais Efprits : \& les bornes très-étroites que Dieu a mifes à fa révélation fur ce poine, font auffi celles dans lefquelles les Chrétiens fe renferment. Ils ne tirent point leurs preuves de ce qui eft obfcur; mais en hommes droits \& fenfés, ils voient dans ces merveilles uniformes, dont les trois continents font témoins, non des Puifances indépendantes qui brouillent librement tout I'Univers; mais le deffein unique du Maître de la nature, qui fait entendre par-tout la même voix, \& annonce le falut à fa créature. Au contraire, la doctrine des Paiens fur la nature des Efprits, \& fur leurs opérations, n'avoit ni certitude dans fon origine, ni mefure dans fon étendue, ni conformite dans fes principcs.

La magie, la théurgie, les fortileges, toures les fortes de divinations par les oifcaux, par les ferpents, par les feuillages, \& autres prétendus moyens avec tous les enchantements, ont eu la même crigine que l'idolâtrie, \& n'avoient pas Tome VIII. Part. II. 


\section{LE SPECTACLE}

LA Dó.plus de réalité. Dès que la cupidité ¿̊ MoNstr. l'ignorance eurent pris les figures de l'anÉrARGel. cienne inftruction pour des Etres puiffants, \& les formules de chant qui les accompagnoient, pour des moyens d'obtenir tout ce qu'on vouloit; l'efprit de l'homme n'ayant plus de regle, fa dévotion devint auffi terreftre que fes defirs, \& fe porta, pour les fatisfaire, à toutes les pratiques abfurdes qui découloient de la premiere méprife. Toutes les parties de IUnivers étant devenues autant de petites Divinités bien ou mal-faifantes, \& de Génies, dont le moindre talent étoit de prophétifer, on ne laiffa pas ces Puiffances oifives; \& en leur adreffant les offrandes, les victimes, \& l'encens, on y joignit les anciennes formules de chant \& de prieres qui n'étoient plus entendues : ce qui donna lieu aux vifions des enchantements, \& aux prétentions de la magie.

La feconde fource des progrès de ces folies, font les récits des merveilles opérées par les Prêtres les plus entendus, difoit-on, dans la connoiffance des Dieux \& des cérémonies religieufes. La cupidité aidoit à imaginer ces contes. Elle n'aidoit pas moins à les faire recevoir.

L.e dernier moyen quiles accrédita, font les fuffrages \& les explications dont les 
DE LA NATURE.

Philofophes les honorerent à leur propre $L_{1} D_{L}$ confufion. Ces hommes qui avoient beau- Monstr. coup médité, \& communément beau- ́́VANGEL. coup voyagé, avoient trouvé par-tout des reftes de vénération pour la chafteté, pour la fobriété, pour la priere, pour l'abfinence \& le recueillement, comme étant autant de moyens de perfectionner l'homme, \& de le préparer aux actes de religion. Telles étoient les traces ineffaçables des regles \& des leçons de l'ancien culte, que le genre-humain rendoit à Dieu dès le commencement. Mais les hommes, \& les Philolophes encore moins que le commun des hommes, n'ont jamais voulu s'en tenir à un favoir borné $\&$ réglé fur leur befoin. Il faut qu'ils s'affranchiffent; il faut qu'ils percent : \& après que les Peuples eurent par toute la terre changé les idées de la premiere révélation, en y en fubftituant de monftrueures, puifque c'étoient celles de leurimagination guidée par leurs convoitiles; ils voulurent encore mettre le tout en ordre. Les Philofophes, comme les plus fuffifants, fe chargerent de la commiffion. Pouvoit-il y avoir quelgue chofe d'inacceffible pour ceux qui entendoient l'égalité des trois angles d'un triangle à deux droits?

$B$ ij 


\section{8 \\ LE S P E C T A C LE}

Li Dí- La raifon qui les éclairoir fur les rapmoxste. ports \& fur les mefures de ce qui étoir skasivilo autour d'eux fur la terre, leur parut les autorifer à embraffer tout dans leurs connoiffances. Auffi parlerent-ils de ce qui étoit en haut, \& de ce qui étoit en bas: ils diftribuerent par claffes les Dieux \& les Déeffes, les demi-Dieux \& les Génies; ils étudierent le goût de chacun d'eux, \& enfeignerent très-f́rieufement par quels facrifices \& par quelles cérémonies on pourroit leur plaire, ce qu'on pouvoit leur demander, \& quel degré d'abftinence pouvoit conduire les ames privilégiées à s'unir à eux extatiquement.

Tels étoient, difoient-ils, les heureux fruits de leur expérience, \& de leurs voynges. Auroient-ils tant médité \& tant couru pour n'arriver à rien? Telle fut la profondeur du favoir d'A pollonius, d'Eunapius, de Porphyre, \& de Julien. C'étoient des efprits avides de nouveautés, \& qui couroient fans regle après le merveilleux. De pareils hommes n'étoicnt pas propres à captiver leur encendement fous le joug de la Foi, qui ne nous montre que le néceffaire. On fent combien la Religion Chrétienne devoit leur déplaire, $\&$ il n'eft pas plus étonnant de voir tant de beaux efprits qui fe font infatués des 
extravagances de la théurgie, (c) que L.1 Dúd'en voir d'autres qui, en grand nombre, Mionst?. \& depuis trois milleans, perdent leur re-biancs. pos \& leur bien, dans la penfée qu'on peut trouver le moyen de vivre pluficurs fiecles, \& de faire de l'or avec ce qui n'eft pas or.

Le crédit \& l'éloquence des Philofophes retarderent autant l'œuvre du falut, que le firent les perfécutions. Chacun fe tranquillifoit dans fon incrédulité, en difant:Il faut que le Chrift ait été un grand Philofophe, \& qu'il ait eu à fa difpofition des Génies fort puiffants pour obtenir tant de guérifons, \& peut-être fa réfurrection. Mais nous avons nos Dieur $\&$ nos Génies, dont nous fommes contents : il y a trop peu de profit à honorer les Génies du Chrift \& des Chrétiens.

Ce raifonnement, qui étoit très-commun parmi les Gentils infatués des promefles de la magie, nuifit beaucoup à l'Evangile : mais ce qu'il y avoit de nébuleux dans ce raifonnement, fe diffipa peu à peu. Ce qui en fubfinta fut l'aveu de la réalité des faits, \& le temps dévoila tout aux yeux même les moins attentifs. On s'apperçut que les fatras d'Apollonius, publiés fur la foi de l'aventurier Damis

(a) Les opcrations des Dieux \& dics Génies.

B iij 


\section{LE SPECTACLE}

Li DÉ-plus de cent ans après l'événement, n' $n$ Mosstr. voient aucunes fuites; qu'il en étoit de ávarger. même des Dieux \& des Génies, tant vantés par les Philofophes poftérieurs; que toutes ces dévotions bizarres étoient fans témoignages; \& que cette philofophie anti-Chrétienne fe réduifoit à beaucoup de fuffifance \& de bruit.

On comprit de plus en plus ce que les coeurs fimples avoient compris dès la premiere annonce de l'Evangile, qu'il n'y avoit aucune comparaifon à faire entre les miracles de la miffion évangélique, \&. les opérations, foit de la magie, foit de la théurgie, qui ne différoient que de nom.

Ici on ne trouvoit qu'un tas de fables bizarres, qui n'avoient ni aucun but raifonnable, ni aucun lieu; un tas de merveilles adoptées par la crainte, accréditées par la fuperftition, mifes à profit par l'avarice, débitées par la charlatancrie. Ce qu'on rapportoit de la force des enchantements, \& de l'opération des Génies, fe paffoit dans les ténebres. Rien n'étoit nine pouvoit être examiné, moins encore approfondi.

Faire defcendre la Lune du ciel en terIe; faire crever les ferpents par la prononciation d'une formule requife; dégraifer 


\section{DE L A NA T URE. 3I}

les campagnes voifines au profit de la LA Dé fienne; envoyer la pefte, ou détourner MONSTR. la grêle; en un mot, maîtrifer la nature ÉVANGEL, \& la changer d'un tour de main; c'étoient les pouvoirs ordinaires, les menus plaifirs des enchanteurs : c'eft-à-dire, qu'ils n'avoient pouvoir de rien.

Tout le réel de la magie fe réduifoit Dinémencommunément à des maléfices î à des vires de ia empoifonnements. Pour punir des ames magie des $_{\text {mira- }}$ pleines d'orgueil \& de paffions, Dieu cles del'Eparoit avoir quelquefois permis qu'elles vamilk.

fuflent frappées ou de la vue d'un fpectró, ou d'une apparence d'acconpliffement de quelque pródiction. Mais ce que les démons ont pu mettre du leur dans tout ce qui fe nomme fcience occulte, n'a jamais formé rien de fuivi. Tout y eft borné, plein d'équivoques, c'impuir= fance, \& de menfonge. Tout y eft plein de rufes, d'indécence, de petitefle, de cruauté : \& ce qu'on ne fauroic trop remarquer, c'eft que ces ceuvres n'érabliffent rien de confant, la puiffance magique invoquée en Afre ne fe mettant aucunement en peine de celle qui opere en Europe. Il ne faut pas une mer pour dérober à un Génie la connoifrance de ce qu'un autre affure. Une muraille fuffit pour metre dens démons en défoldre,

$\mathrm{B}$ iv 


\section{$32 \quad$ LE STECTACLE}

LA D - ou deux fourbes en contradiction. (a) Monstr. Les cuvres du Chrift \& celles de fes KYANGEL. Difciples difperfés par-tout, avoient une même fin, \&s montroient un Auteur qui ne fe démentoit point, toujours également puiffant \& bienfaifant. Ce qui fe diloit, ce gqui s'opéroit de miraculcux en Afie \& en Europe, tendoit également à la fanctification des cours, \& à la gloire de Dieu par les mêmes vérités. L.es maladies des corps n'étoient guéries que pour convaincre les efprits des intentions de celui qui étojt annoncé comme le deftructeur du péché \& de la morr.

Tout fe paffoità découvert : fi les Chrétiens cherchoient quelquefois les ténebres, céroit ou pour prier en filence, ou pour fe fouftraire à la perfécution. iráís lés miracles de l'Evangile s'opéroient fous le foleil \& dans les Places publiques. Chacun en éroit juge: \& comme les Chrétiens, fans concert, \& en une infinité de lieux tout à la fois, rapportoient ce qu'ils avoient appris par leurs yeux,

\& touché de leurs mains; leur témoignage ne pouvoit raifonnablement fe réculer.

Ainfi ces guérifons étant fi diftinguées

(a) Voyez-cn les preuves fans nombre lans le fe cond Livre de Cicéron, de Divinitat. 
DE L A NA T URE. 33

des preftiges de la magie par leur dé- LA Décence, par leur publicité, \& par leur Mioxstr. réalité palpable, elles ont toujours eu le ÉvinGÉs. double avantage d'incliner les cœurs à la vertu, \& de prouver puiffamment la même vérité. Faut-il s'étonner après cela, fi les petits ont vu clair, tandis qu'une faufle fcience aveugloit les grands $\&$ les favants?

Il n'eft pas inutile d'obferver que ce pouvoir de maîtrifer la nature a quelquefois été accompagné dans les premiers Apôtres, de celui de frapper par des punitions fubites ceux en qui ils voyoient un profond déguifement. Mais l'ufage de ce pouvoir terriblea été fort rare. Nous ne le voyons que dans les mains de $S$. Pierre, $A \approx .5$. qui frappa de mort Ananie \& Saphyre; 1 . puis de S. Paul, qui frappa Barjefus d'a- 4.5 . 5 . veuglement, \& l'inceftueux de Corinthe éII.Cor. 2. d'une maladie qui lui fut falutaire.

Au don des guérifons Dieu joignircelui Le dnn des langues, pour réparer ce qui man- des Lanquoit aux Envoyés du côté des talents. Ils étoient la plupart Pêcheurs \& Artifans. A peine étoient-ils capables de parler leur propre langue. Ils paroiffoient conféquemment hors d'état de faire entendre la nouvelle du falut, \& la doctrine du Sauveur aux Nations étrangeres. Ces Pré- 


\section{LE SPECT A CLE}

LA Dé- dicatcurs furent cependant entendus parMONSTR. tout. Ils introduifirent la Foi, \& formerent ÉVANGEL. promptement des Eglifes nombreufes dans des Villes où les Philofophes les plus éloquents avoient à peine réuni quelques difciples défouvrés, ou amis de la difpute, \& dans des Provinces où l'ambition Romaine n'avoit pu pénétrer.

Le don des langues dans les Miniftres de l'Evangile, quoique néceffaire pour ouvrir la porte à la prédication, femble d'une autre part contredire la premiere intention qui les avoit choifi fimples, groffiers, \& fans lettres. L'intention de ce choix étoit que la conquête des ames ne parût point l'ouvrage de l'éloquence \& du favoir; mais qu'elle parût ce qu'elle étoit en effet, l'œuvre manifefte du ToutPuiffant. Aufli voyons-nous que le don des langues n'a été donné qu'avec réferve. Ceux que l'Efprit mettoit en état de parler une Langue étrangere pouvoient être entendus : mais ce don ne faifoit d'eux ni des Ecrivains polis, ni de grands Orateurs. Il leur laiffoit le tour de leur Langue Hébraïque ou Syriaque, \& la fimplicité de leur éducation. La merveille fe réduifoit à annoncer intelligiblement la miffion du Sauveur, \& la leur, à des Peuples dont ils n'avoient pas appris la Langue. 


\section{DE LA NATURE. 35}

Ils entendoient les Etrangers, \& ils en LA DÉétolent entendus. Mais la force étoit dans Monstr. leurs œuvres, plutôt que les graces \& la ÉVANGEL. beauté dans leurs difcours.

L'extrême modicité de leurs talents, jointe à un extérieur qui n'annonçoit ni rafinement, ni culture, faifoient tout attribuer à Dieu, rien à l'homme.

Souvent celui qui pouvoit, fous l'impreffion de l'Efprit, parler à des Etrangers un langage qu'ils entendiffent, ne comprenoit pas lui-même les paroles que Dieu mettoit dans fa bouche, ou ne les pouvoit pas faire entendre à ceux des affiftants qui parloient un autre langage. Souvent il avoit befoin d'un autre interprete, pour inftruire \& édifier fa propre Eglife de ce qu'il avoit dit d'intelligible à des Etrangers préfents. Souvent le don d'interprétation étoit fubitement donné à un autre Difciple, non-feulement afin que tout pût être entendu; mais pour mieux marquer l'action de l'Efprit, qui exerçoit fon pouvoir par des inftruments pleins de foibleffe \& d'incapacité. Le Prédicateur n'attiroit point l'admiration : l'on n'étoit occupé ni de fa perfonne, ni de fon efprit; mais du grand objet de fa miffion, \& de la force des preuves qu'il en produiloit. 
36 LE SPECTACLE

LA Dé- Les Epitres de S. Paul, \& fur-tout les - nuxstr. Actes des Apôtres, font un récit perpéaraicit. tuei des cflets de ce don des langues, par lequel des hommes fans fcience introduifirent par-tout la Foi, \& réunirent en très-peu de temps des Nations inconnues les unes aux autres, dans la perfuafion des mêmes vérités, \& dans un même éfprit.

Saint Paul qui écrivit fes deux Lettres aux Corinthiens, tant pour répondre aux divers éclairciffements qu'ils lui avoient demandés, que pour réformer des défordires qui s'introduifoient parmi eux, leur donne des regles pour ufer avec difcernement \& avec édification des dons miraculeux. Il recommande en particulier, 2. Cor. 14. \& établit pour regle, que celui qui a le don des langues étrangeres, fans celui de l'interprétation, garde le filence dans leur Afremblée; à moins que le don de l'interprétation n'ait été donné à quelqu'un des affiftants, a fin qu'on ne cherche pas à montrer fans fruit fes avantages perfonnels; mais uniquement à édifier J'Eglife de Dieu, par la communication de quelque lumiere, en facilitant à tous l'intelligence de ce qui a été dit.

Au furplus, quelque profitables que puffent être à l'Eglife naiffante ces dons 


\section{DE I A NA T URE. 3?}

miraculeux des langues inconnues \& des LA DŔ guérifons fubites, l'Apôtre fait bien voir Moss'tr. j'efprit qui le mene, en inculquant forte- ÉHANGLi。 ment qu'il eft des dons plus précieux pour le bien des Eglifes, tels que le difcernement des vrais \& des faux Prédicateurs; la connoifance des chofes cachées dans le fond des cœurs, \& l'intelligence des Ecritures. Il leur releve enfuite des dons encore plus defirables pour l'Eglife \& pour eux; la Foi, l'Efpérance, l'amour de Dieu \& du prochain. C'eft ce qui lui donne lieu de développer l'excellence \& les caracteres de la Charité, l'unique don durable, \& qui fubfiftera à jamais après la ceffation de tous les autres.

Ces Lettres de S. Paul aux Corinthiens portent donc les preuves de leur vérité, par la naïveté même des circonftances fur lefquelles ces Fideles avoient demandé les inftructions de leur Maître.

Eft-il naturel ou poffible de faire recevoir deux Lettres à une grande Société, pour lui reprocher différents défordres qui ne feroient pas réels, ou pour lui donner des regles fur le bon ufage du don des Langues, \& de l'interprétation, fi elle n'en avoit aucune connoiffance? Cette preuve eft fimple : elle démontre tout enfemble l'exiftence \& l'économie des 


\section{$3^{\text {S }}$ LE SPECTACLE}

LA Dá- dons miraculeux, qui laiffoient les MinifMONSTR. tres dans un état d'imperfection, pour ne \$YANGLia montrer dans leurs progrès que la puif, fance de la main invifible qui les dirigeoit tous.

On ne peut pas d'ailleurs douter tant foit peu de la réalité de ces Lettres, qui furent citées peu d'années après par faint Clément le Romain, écrivant aux Corinthiens mêmes. Sur la fin de la premiere, S. Paul informe les Fideles de cette Eglife de ce qui fe paffe en Macédoine, en Judée, à Ephefe, à Ancyre, \& dans toutes les Eglifes d'Afie. Toutes ces circonftances fe trouvent juftes. C'eft dans les mêmes lieux que fe font formées tout d'abord les Eglifes les plus célebres : elles ont tout d'abord montré les Lettres qu'elles avoient pareillement reçues de faint Paul : elles fe les communiquoient réciproquement, \& n'ont jamais difcontinué d'en faire la lecture dans leurs Afremblées. Ces Lettres ne peuvent être fauffes qu'en un cas; qui feroit que ces Eglifes fe fuffent expofées à la perfécution, pour avoir le plaifir de publier que faint Paul avoit été leur Maìtre, quoiqu'elles ne l'euffent ni vu, ni entendu. Mais ne prévenons point les témoignages poftérieurs, qui ont garanti \& perpétué les témoignages 
de l'Efprit. Si ces dons ont été réels; le $\mathrm{LA}$ D: miniftere eft divin. Cette conféquence eft noxsm. claire, \& elle nous fuffit pour le préfent. ÉYanget. Ce qui n'elt ici que conditionnel, fera démontré par la fuite.

Le don de la prophétie a achevé d'il- Le don de lufter la miffion du Sauveur \& des Apô- tie.. tres, foit en révélant par eux la jufte application qu'il falloit faire des anciennes prophéties aux événements; foit en mettant dans leur bouche $\&$ dans leurs écrits des prophéties nouvelles, dont l'accompliffement fe perpétue fous nos yeux. $\mathrm{Ce}$ dernier don elt vraiment le fceau attaché à la Lettre de créance. Il a rendu les Envoyés parfaitement reconnoiffables dès l'ouverture de leur miffion, \& il fe montre encore en entier dans les derniers fiecles. Le temps même y ajoute une force nouvelle, en mettant fucceflivement fous les yeux du genre-humain des révolutions \& des traits manifeftement prédits $\&$ écrits, dès avant l'empire de Titus. Là eft la marque de l'Efprit de Dieu.

"Il eft néceffaire, dit Jefus-Chrift, La6. 24 ; " que tout ce qui a été écrit de moi dans 4 .

"le Livre de Moife, dans les Prophetes,

, \& dans les Pleaumes, s'accompliffe.

Plufieurs des prophéties de l'ancienne Ecriture, à quelques-unes defquelles 


\section{L E S PEC T ACLE}

IA DÉ-Jefus-Chrift a fait une attention diftincte, MIONSTR. font moins des difcours que des actions \&́VANGEL. repréfentatives, ou des crayons de l'avenir. Tel eft le facrifice auquel Ifaac a furvécu; telle eft la vie de Jofeph vendu par fes freres, livré aux Etrangers, \& élevé en gloire, Diftributeur des graces \& de la vie, Sauveur des Etrangers, \& enfin de fon Peuple. Tel eft le figne de vie élevé par Moïle au défert : tels font les traits du nouveau Prophete qui doit fuccéder à Moïle, être Légiflateur comme lui, prendre la qualité de Sauveur, \& mettre le Peuple de Dieu en poffefíion des biens promis. Telles font tant d'autres images des myfteres de Jefus. Chrift, tracées par avance dans la foibleffe \& dans la victoire des Soldats Gédéonites; dans les fouffrances de David calomnié, rejetté, puis couronné; dans la gloire de Salomon, le Roi de paix \& le Fondateur d'un Tabernacle permanent; dans la prédication de Jonas, qui évite de parler aux Gentils, \& qui ne leur porte la parole qu'après une forte de séfurrection.

Plufieurs de ces prophéties font verbales \& expreffes. Nous ne rappellerons plus celles qui ont été faites à Abraham, à Ifmaël, à Ifaac, à Jacob, à Juda, à David, \& bien d'autres dont il eft vifible 


\section{DE L A NA T URE. $\quad 4$ I}

que l'accomplinement n'a été connu qu'a- LA DÉprès la publicatinn du Livre qui les con- Monstr. tient.

Nous nous abftiendrons de toucher ici aux célebres prophéties d'liäie, fur l'homme de douleur; d'Aggée, fur la gloire que devoit recevoir le fecond Temple en recevant le Defiré des Nacions, qui leur apporteroir la paix; de Daniel, fur le temps où le Fils de l'homme recevroic l'empire fur tous les Peuples.

Au-lieu d'infifer davantage fur ces traits, \& fur d'autres qui ont été fi heureufement, \& très-récemment éclaircis par le travail de tant d'habiles interpretes, nous nous arrêterons à quelques-uns des Pfeaumes que Jefus-Chrift s'eft appliqués. La maniere même dont il fe les applique eft une preuve de vérité.

Il nous invite généralement à "le cher", cher dans les P feaumes, parce qu'il y eft ", parlé de lui., Jefus-Chrift aide notre "parlé de lui. , Jefus-Chrift aide notre Lue. st:
travail en citant un mot de l'un, un mot de l'autre : mais il ne fait rien valoir, comme feroit un Savant qui femble fe défier de fon Lecteur ou de fa preuve, en développant laborieufement la conformité des menues circonftances prédites avec les événements réels. Le Sauveur cite ce qui le regarde dans les $P$ feaumes avec la fécu- 


\section{LE S P E T T C L E}

I.A Dé-rité \& la dignicé d'un Seigneur qui connoit Movstr. Sestitres, \& qui fe cor: nte d'indiquer le Évavgel. dépôt public où ils ont été mis long-temps avant fa naifrance. L'accès en eft libre aux Gentils comme aux Juifs : \& il fait que la fimple lecture en eft fuffifante pour mettre fes droits au plus girand jour.

Jefus-Chrift excite la curiofité des Juifs \&ìa nôtre, en leur demandant quelle eft la génération du Chrift, \& de qui il dois Mati. $22:$ defcendre. Les Juifs répondent : Il eft fils

P. 10 . Heb. 1: 10, de David : "Pourquoi done, dit Jefus,Chrift, Davidl'appelle-t-il fon Seigneur? Nous ouvrons le Pfeaume I09, auquel il nous renvoie, \& qui commence par. ces paroles: "Le Seigneur a dit à mon , Seigneur, \&c. Voici ce que nous y trouvons.

Analyre du I $I^{\circ}$. Dieu partage fa puiffance avec ce-
Irenuma

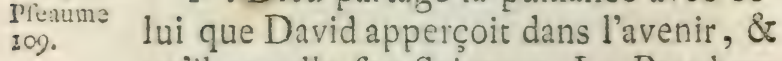
qu'il appelle fon Seigneur. Le Prophete le voit affis dans la gloire au mêne rang que le Tout-Puiffant, \& regnant malgré des ennemis fans nombre qui lui font foumis tour-à-tour, \& renverfés à fes pieds par des défaites fuccellives.

$2^{\circ}$. C'eft à Jérulalem que l'on verra commencer fon empire, \& il l'exercera au milieu même de ceux qu sui s'étoient li: gués pour le perdre. 
$3^{\circ}$. Sa fuprême puifrance fera mani- LA Difeftée aux yeux de tout l'univers par la monstr. multitude des Juftes quil lui obéiront, non- ÉVANGEI, feulement comme à un homme admirable, mais comme à un Dieu. En honoranten lui le Defcendant de David, on lui reconnoìtra une autre nature, une autre naillance, qui a devancé \& fa mere, \& l'aurore, \& les fiecles. (a)

$4^{\circ}$. C'eft ici l'œurre durable. Dieu fait ferment de ne la jamais rétracter ni changer. Celui qu'il a mis à fa droite, avecla qualité de Roi, portera auffi celle de Prêtre, non felon l'ordre d'Aaron, dans lequel on verfe le fang des animaux, dans lequel les Prêtres meurent \& fe fuccedent; mais felon un ordre différent, dans lequel une feule offrande remplace toutes les autres; dans lequel on ne connoît ni devanciers ni fuccelleurs : en forte que déformais c'eft par lui feul \& pour toujours que les hommes auront accès auprès du Pere.

$5^{\circ}$. Celui qui eft Roi \& Pontife éternel, eft auffi devenu Jugre de tous les hommes. Il n'a paru fur la terre que comme Sauveur : il n'a jugé perfonne, $\&$ a été condamné lui-même. Nais re-

(a) Hebr. Pre ulero \& preastora tibi eff geritura tha. Ce tour Hebraïque revicnt à ceci : erasprinflumm ofet mater rua, E anie conditam ?tacem. 


\section{LE S P E C T A E L E}

La Dé- vêtu de la puifance du Pere, il exercers MonsTR. un jugement terrible fur les Rois \& fur áVANGEL. les Nations. Tout fera foumis ou brifé devant lui.

$6^{\circ}$. Il aura ainfi paru dans deux états d'une extrême différence; l'un dans lequel fes fonctions lui auront coûté des facigues \& une altération femblable à celle d'un voyageur qui boit dans fon paffage l'eau bourbeufe du torrent; l'autre dans lequel il fera grand \& élevé en gloire.

La Synagogue a chanté ce Pfeaume \& l'Eglife le chante : mais au-lieu que les Juifs en refpectoient le fens \& les promeffes fans les comprendre, il eft dans la bouche des Chrétiens un vrai chant triomphal, que l'événement rend intelligible, \& qui eft l'expreffion de leur bonheur.

Parmi les différentes paroles forties de la bouche de Jefus. Chrift, arrêtons-nous Luc. 23: à celles qu'il proféra fur la Croix : Mon 45. Pere, s'écria-t-il, prêt à rendre les derniers foupirs, je remets mon efprit entre vos mains. Le Pfeaume trentieme, d'où ces mots font tirés, eft d'un bout à l'autre la priere la plus conforme à fon état actuel. On'y trouve une vive peinture de fes fouffrances, \& celle de l'attente où il eft d'une délivrance prompte. Il propofe même la vie nouvelle qui lui eft accordée, 
comme le puiffant motif de la confiance LA Dí. de tous les juftes qui fouffrent.

Ce fentiment peut faire trouver ces pa- ÉVANGEI. roles citées par Jefus-Chrift fur la Croix, peu compatibles avec celles qu'il avoic proférées peu auparavant : Mon Dieu, Matt. 27: mon Dieu, pourquoi m'avez-vous aban-47. donné?

Celfe \&r les autres ennemis du nom Chrétien, loin de difconvenir que ces paroles foient forties de la bouche du Chrift atuché au bois, les ont relevées comme la honte de notre Religion. "Voi" là, difent-ils, des paroles de défefpoir. "Il n'y a ni grandeur, ni patience dans " celui que les Chrétiens honorent : \& , bien loin d'avoir l'efprit de Dieu, il ne ", montre pas même la tranquillité d'un " homme conftant.

Nous ne répondrons pas à Celfe, que celui qui a éré fait victime pour nous tous, portoit en ce moment tout le poids de la Juftice divine. Celfe n'entendroit pas d'abord ce langage : mais nous lui ferons remarquer que ces paroles étoient for connues des Juifs qui les entendirent, \& qu'elles fervirent à toucher les uns, \& à convaincre les autres de l'opiniâtreté la plus criminelle. Depuis mille ans leurs Peres chantoient ces paroles 


\section{LE SPECTACLE}

LA DÉ- dans leurs affemblées. Les Ifraélites en les moNstr. récitant avec tout le Cantique dont elles EYANGLl. font le commencement, s'occupoient des deux états d'un homme extraordinaire Anatyfe du qui devoit être traité comme un impof-
Yy feaume Yreaume teui a teur, \& réduit au plus horrible accablebeaucung ment, puis être élevé en gloire pour anplus d'é- noncer avec les fiens le vrai Dieuà toures je Texte les Nations, \& pour établir la Juftice giehraique dans dans un Peuple que Dieu devoit faire la Vulgate. naître.

Quel eftl'homme, quel eft l'événement où l'on puiffe trouver la réunion des deux traits qui partagent tout le Pfeaume : je veux dire l'état d'un homme pouriuivi jufqu’à avoir les pieds \& les mains percés comme un malfaiteur, \& le paffage du même homme à une vie nouvelle, où il fera mis à la tête des adorateurs qui reviendront à Dieu de toutes les Nations?

Ces deux caracteres ne concourent qu'cn Jefus-Chrift. Ses Difciples ne tarderent pas à voir \& à faire fentir aux autres l'accord fingulier de tout ce Cantique avec les circonftances qui accompagnerent \& fuivirent la mort de leur Maître. Mais fes ennemis, que la citation conduifoit à l'intelligence du refte, loin d'en faire l'application à ce qui étoir fous leurs yeux, enchérirent par mille infultes 


\section{DE LA NA TURE.}

exprimées dans le Pfeaume, fur les trai- LA Détements des foldats Romains qui avoient MoxsTR. exécuté les ordres du miniftere public, ÉYANGEL. $\&$ fait entr'eux le partage de fes habits. Les foldats du Gouverneur \& les Juifs accompliffoient ainfi, fans le favoir, toutes les particularités qui font détaillées dans la premiere partie de la Prophétie aufil nettement que dans l'hiftoire évangélique.

La propagation de la doctrine de cet homme pourfuivi à mort, \& l'adoration du vrai Dieu, que les Envoyés du Chrift ont fait connoître à tous les Peuples, font les événements auffi clairement marqués dans la feconde Partie. Il eft diftinctement parlé dans celle-ci du repas qui fe donne dans l'affemblée de Religion, auquel les petits \& les grands viendront prendre part, où les pauvres trouveront l'excellente nourriture, \& où les Puiffants du fiecle s'abaifferont profondément devane l'Auteur de tous leurs biens.

Celui qui au commencement de cette priere éprouve l'excès de trifteffe convenable à la nature humaine, dans l'obligation de mourir fous l'effort de fes ennemis victorieux, \& à l'état de victime qui le charge de la malédiction due à nos péchés, glorifie enfuite fon Pere de la 


\section{L E S P E C T A C L E}

La Dí-nombreufe poftérité qu'il lui accorde; MONSTR. enfin de la communication qui fe va faire śangel. des vrais biens par fes Prédicateurs difperfés d'un bout de la terre à l'autre.

Quel autre efprit que celui de Dieu a pu par avance arranger dans ce détail, $i^{\circ}$. les circonftances précifes de la mort du Chrift; $2^{\circ}$. le cri le plus conforme à fon impuiffance apparente qui fait le triomphe de fes ennemis; $3^{\circ}$. fa délivrance \& fon retour à la vie; $4^{\circ}$. les articles les plus diftingués de fa doctrine; $5^{\circ}$. le culte da vrai Dieu, qui alloit être étendu par fes Envoyés dans toutes les parties de la terre; $6^{\circ}$. la naiffance d'un Peuple auquel Dieu va donner l'être, avec un nom auparavant inconnu? Tout cela eft arrivé.

Quel autre efprit que celui de Dieu a pu dans le temps conduire la langue d'un homme rafiafié d'opprobres \& d'angoiffes, à la jufte citation des premiers mots d'un Pleaume dont tout le refte eft l'abrégé fidele de fon Hiftoire, \& le tableau de tout l'avenir? Il falloit pour cela que JefusChrift cût la vraie intelligence des Ecritures. Difons mieux : il en eft lui-même la clef; c'eft pour lui que tout eft dit.

N'omettons pas qu'on voit en tolite rencontre combien les Evangéliftes font véridiques, par le foin gu'ils ont pris de - rapporter 


\section{DE I A NA TURE.}

rapporter des circonftances qui font au LA D:premier afpect ou indifférentes ou nuifi- novatr. bles à l'intention de préconifer l'cuuve du ÉvaNGëLo Chrift. Il s'en faut bien qu'elles y foient ni nuifibles ni indifférentes dans la réalité.

Quand elles n'apprendroient rien d'important aus Lecteurs, elles caractérifent les Hiftoriens, elles atreftent leur candeur \& leur affurance. Leur candeur paroìt en ce qu'ils ne s'étudient pasà plaire par le choix des faits : ils les rapportent comme ils font. Leur affurance paroit en ce qua'aulieu d'inventer ou de fupprimer des circonftances par intérêt, ils s'engagent dans des récits qui ne leur font pas avantegeux, \&r dans des détails fur lefquels une foule de témoins pouvoient les convaincre de faux. De ce nombre eft la méprife de quelques affiftants qui n'entendoient pas l'Hébreu des Pfeaumes, \&rquife figurerent que Jefus en proférant ces premiers mors du Preaume 2 I, Eli, Eli, mon Dieu, mon Dieu, appelloir Elie à fon fecours.

Mais ce trait ingénu, \& d'un fi petit profic pour l'Evangile, même défavantageux, felon les idées humaines, prouve également \& que l'Hiftorien n'a pas imaginécetie expreflion de décourngement, \& que Jeíus fur la Croix fic ufage de ces premicrs mots du Plonume 21, qui donTome VIII. Part. II. 


\section{L E S P E T A C L E}

I, Dí-nerent lieu à la méprife des Etrangers. Or, rmin. employer ces mots dans fon accablethakab. ment, c'étoir nous expliquer tout le refte de la prophétie \&r toute l'économie de l'œuvre du falut.

Le même efprit qui avoit révélé à David les différents états du Meffie, a montré aux Apôtres, quoique fans culture \& fans fcience, à diftinguer dans les Pleaumes tous ces traits prophétiques. Avant l'effufion de l'Efprit-Saint, ils comprenoient à peine les difcours les plus clairs. Après cet événement, ce ne font plus ces Matelots du Lac de Tibériade, qui ne connoiffoient que leurs filets, leurs barques, \& le Décalogue. Avant cette effufion Jefus leur avoit tout dit: mais ils n'en comprirent le fens quà la réception de l'Efprit, aujour de la Pentecôte. Le voile eft ôté de deflus leurs yeux en ce moment. Ils confulteat, ils citent avec intelligcnce le Recueil des Pfeaumes \& toutes les Ecritures. Ils y diftinguent comme dans un dépôt public, \&: produifent enfuite les titres du Sauveur qu'ils annoncent. Leur prédication eft fortifiée en toute rencontre pai les traits qu'ils ea tirent, \& qui n'ont jamais eu un fens jufte \& parfait qu'étant appliqués aux divers états de leur Maître: de forte qu'cn 
DE I A NATURE. 5 I lui feul fe trouve l'accomplifement de La D:tour.

Ils voient dans le deuxieme Pleaume ivarust. l'inutilité desefforts de ceux quil'ont op - $14 .+4: 25$. primé; la manifeltacion de la vie nouvelle

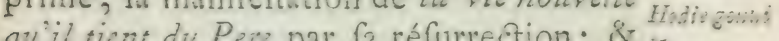
qu'il ticnt du Pere par fa réfurrection; \& ie. In toute-puiflance de Dieu qui exécute fes promefles \& fes volontés, par les complots des plus méchants hommes.

40. $4: 23$.

Ils voient dans le quinzieme la priere de Jefus-Chrift mis au tombeau, \& $1 \mathrm{a}$ Â. $2: 25$. prédiction la plus diftincte de fa réfurrection. "Le fépulchre de David, difent, ils aux Juifs, cft au milieu de vous. Son ", corps y eft en pouffiere. , C'eft à un autre que la fortie du tombeau, \& la préfervation de la pourriture eft promife.

Ils reconnoiffent dans le trente-neuvie. me l'infuffiance des facrifices de la Loi, Itobr.io: dont ils avoient eu dès l'enfance une idée ${ }^{5}$. fi avantageufe. Et ceux d'entr'eux qui ont montréle plus de zele pour la Loi, jufqu'a perfécuter le Chriftianifme avec fureur, font à préfent ceux qui publient le plus hautement, que la Loi cérémonielle n'étoit qu'une économie proportionnée à la grofliéreté de leurs Peres, \& préparatoire à une Loi plus parfaite.

Ils citent le quarantieme comme une peinture admirable de la charité de Jefus- Ae. I.

$\mathrm{C}$ ij 


\section{LE SPET ACL}

1. Di. Chrift, \& de la noirceur, tant de cclui monstr. qui l'a livré à fes perfécuteurs, que de fon knarcel. Peuple qui l’a méconnu \& condamné.

Le Nicfie, qu'ils voient communément, repréfenté comme un homme de douleur, cht le même qu'ils voient plein de beauté, \&r revêtu de gloire dans le quarante-quatrieme Pfeaume. Mais l'Empire dont il eft mis en poffeffion, n'eft point ce regne terreftre que le Juif charnel attendoir. C'ent'Empire de la vérité, de la concorde, \& de la juftice. La durée en fera éternelle : \& celui que Dieu a facré pour faire regner la vérité dans les cocurs, cft lui-même au-déffus de tout. Toutes les Intelligences céleftes lui font foumifes, \&r l'adorent. Il cft Dieu comme celui de qui il a tout reçu.

Hobr. 1:8. Les mêmes Difciples nous ont faitreconnoître dans le Pfeaume 68 le zele du Meflic pour l'ćtabliffement de la vraie juftice; le refus que fon Peuple feroit de l'entendirc; les traitements affreux que les fiens lui feroient fouflrir comme à un ćtranger \& à un impofteur; l'amertume yean. : : \& le fiel qu'ils lui feroient avaler, \& la 17. ${ }_{14 a t .27}$ : longue difperfion qui feroit le châtiment 4.8. de leur infidélité.

Rom. II :9. Cesapplications des Pfeaumes, \& beaucoup d'autres faites par Jefus-Chrift, ou 


\section{DE L A NATUR. $5 \hat{3}$}

par fes Envoyés, tirent une nouvelle force LA Dádes circonftances du temps où ils les firent, Movistr. \& des événements qui y ont répondu d’âge ÍVARGEL. en âge. Il s'y trouvoit des traits fans nom. bre actuellement reconnoiffables pour le temps des Apôtres. Mais cependant le Temple, l'ancien Sacerdoce, \& la Nation fubfiftoient en un corps de République. Quoique le nom du Dieu d'Abraham, les bénédictions promiles, la Religion du cœur commençafent à être prêchées partour; quoiqu'avec les fociétés Chrétiennes les exemples d'une chnrité toujours bienfaifante \& d'une pureté parfaite fe multipliaftent de toute part, on pouvoir douter fi cette cuvre fe foutiendroit, \& laccompliffement des prédictions pouvois devenir plus entier.

Ce puiffant témoignage de l'cfprit prophérique acquit donc un éclat nouveau quand les Juifs furent difperfés, comme le Preaume 68 l'annonçoit; \& que fuivant le même Pfeaume, Dieu eut fubfticué aux anciens facrifices un culte plus parfait; qu'il eut remplacé l'ancien Penple par des fociérés qui confeffoient le nom de Dieu; (a) qu'il eut enfin établi une nouvelle Sion, où tout homme in.

(6) Pfenume $63: 32$. Juda fignifie la confefion, is lotiange, le culte rendu a Dieu.

C iij 


\section{L $x$ S PE C T A C L E}

La D\& diffinctement devenoit citoyen \& poffefmowis? feur paifible, en joignant l'amour du nom - ANGEro de Dieu à la profefión extérieure.

Jurques-là les Irraélices avoient récité le quatre-vingt-fixieme $\mathrm{P}$ feaume fans le pouvoir entendre. Ils connoiffoient it la vérité la gloire qui avoit été accordée à la Ville fainte par préférence aux autres établiffements de Jacob. Mais ils ne comprenoient pas comment les Egyptiens, les Perfes, les Africains, \& les Afiatiques deviendroient chers à Dieu; comment ils feroient mis au nombre de ceux qui l'honorent. Noins encore comprenoient-ils comment les Philiftins, les Tyriens, \& tous les Etrangers, pourroient être enfants de la Ville de Dieu; ni comment le Seigneur, en parcourant Ia lifte de tous les Peuples, y reconnoittroit tels \& tels devenus habitants de fa Cité.

La prédication Apoftolique a dévoilé l'énigme, \& la chûte de la Jérufalem terreftre l'a éclaircic pour les Juifs mêmes, s'ils vouloient l'entendre. Tous les Peuples peuvent recevoir la nouvelle vie; être incorporés au Peuple adorateur du vrai Dieu, \& avoir part aux avantages incftimables de la Ciré fainte, que le Très-Haut a lui-même fondée. 


\section{DE LA NATURE. 55}

On n'eft pas étonné après cela, de voir L.1 Dél'Eglife perpétuellement occupée de la moxitu. récitation des Pfeaumes : elle connoit lo ívancris. perfonne qui parle dans la plupart de ces Canciques: \& au lieu de nouséorere de this: Cantiques; \& ati-lieu de nous égarer avec perputuel certains Interpretes qui nous y font voir yue l'kgiiuniquement on Duvid, ou Salomon, oute fatt des Ezéchins, ou Zorobabel, elle éloigne de notre efprit des événements bornés, \& peu dignes d'occuper tous les adornteurs dans la durée des fiecles. Elle chante l'homme de fouffrances, cclui qui a pris fur lui nos péchés, \& qui s'elt fait vietime pour nous. Elle chante le Roi de pair \&r de juittice, le Libérateur. Elle nous le montre, \&r veut que nous le voyions dans les diverfes circonftances qui répondent exatement aux expreflions des Pleaumes, \& qui en rempliffent le fens. Iis n'en ont plus en effet la plupurt, \& dégénerent en une emphafe outrée, lorfqu'ils n'ont plus de rapport aux myfteres du Sauveur. L'application communément n'en eft heureufe qu'à lui.

Ces Cantiques font évilemment los prieres du Chrift dans les différentes circonftances de fon ceuvre, \& fos fentiments, qui deviennent ceux des Fideles. font de la forte la nourriture \& le foutien de leur piété. 


\section{LE SPECTACLE}

La Dé- Mais comme tous les Pfeaumes non 3:oNstr. pas un rapport immédiat à fa Perfonne; - WANGLo quelques-uns étant feulement des leçons de morale, d'autres n'étant que l'expreffion des gémiffements d'une ame pénitente, \& vivement touchée de fes chûtes; enfin, d’autres étant la peinture des divers érats que la Providence rélervoir au Pelsple Juif, les Pfeaumes fe diverfifient felon tous les befoins. Ils font le vrai langage de la piété, \& le précis des preuves de la Religion.

Elle n'en a point de plus touchante que la promeffe faire par le Sauveur, de conferver les reftes d'Ifraël difperfés aux guatre vents, \& de les rappeller un jour à lui. Mais il a donné un relief admirable à cette preuve, en nous montrant dans les Pleaumes la prédietion des mêmes ćvénements. La vérité ne fe feroit trouvée ni dans les Pfeaumes, ni dans la bouche de Jefus-Chrift, fi le Temple \& la Nation fe fuffent confervés en place. Même preuve de faux, fi les foibles reftes de cette $\mathrm{Na}$ tion euffent fuccombé à la haine univerfelle qui les pourfuit par-tout. Mais nous allons voir que c'eft le Verbe incarné qui a infpiré David, \& qui conferve aujourd'hui Ifraë! contre toute vraifemblance. 
Jefus-Chrift après avoir verfé des lar- LA DS. mes fur l'endurciffement de fon Peuple aronstr. obftiné à le rejetter, déclare à plufieurs śvaxger. reprifes aux habitants de Jérufalem, qu'ils Lac. Is: vont perdre leur Ville \& leur Temple, 35. qu'il ne reftera jas pierre fur pierre de HIthar: celui-ci; qu'ils vont être contraints d'a- 4 ir.ron. Iz: bandonner la terre qui leur a éé accordée to. par un don fpécial; \& qu'il n’a plus de Lac. 20 : vifite ni de bien à leur faire en commun, jufqu'au temps oì ils le reconnotitront pour la pierre angulaire \& fondamentals qui avoit été mife au rebut par les Architectes: E qu'ils diront en revenant à lui : Béni foit l'Envoyé du Signeur.

Jefus-Chrift fuit encore ici fo coutume fort remarquable de citer l'Ecriture par un trait comme échappé, quilaiffe les indifférents dans l'ignorance, mais qui irrite les defirs de ceux qui cherchent la vérité. Il leur indique où eft la preuve, mais il In leur laiffe développer : il en fait la récompenfe de leur recherche. On n'ignore pas que c'eft dans le Pfeaume i I7 qu'i? cit parlé de la pierre de rebur qui fera l'appui des deux murs. Nous recourons à ce cantique; \& après ces paroles, nous y trouvons de fuite l'acclamation avec la. quelle l'Envoyé du Seigneur fera $r$ çu de soute la Nation. Mais en mettant cerre 


\section{L E S PECTACLE}

LA Dé- bénédietion publique dans la bouche des moxistr. Juifs revenus à celui qu'ils ont rejetté, EVANGEE. Jefus-Chrift nous apprend la circonftance précife où tout ce difcours aura lieu. Ceux qui parlent dans l'acclamation ne font poine dilférents de ceux qui reconnoiffent la pierre rejettée. Ce font les mêmes qui parlent dans le refte du $\mathrm{P}$ fenume. Ils nous y spprennent les chaitiments affreux que Dieu leur a fait éprouver parmi toutes les Nations, \& l'heureux rappel qui amenera leur acclamation \& l'effufion de leur joie.

Lorfque Jefus-Chrift citoit ce Pfeaume, \& y joignoit une prédiction expreffe de la longue féparation qu'il devoir mettre entre lui \& le Peuple Juif, il faifoit rouler fa prophétie \& celle de David fur quatre grands événements, dont aucun n’étoit accompli, favoir:

I. La réprobation de l'Envoyé de Dieu par les Doeteurs de fon Peuple;

2. La difperfion de ce Peuple, avec la chûte de fon Temple;

3. Sa longue perívérance dans le même aveuglement;

4. Eolin, fa fucure converfion.

- Il y a plus de feize cents ans que les trois premiers événements one commencé \& continuent de s'accomplir. Ils nous répondont du quatrieme, qui eft la vifire de mi- 
féricorde que Jelus-Chrift leur réferve. La D: Plaçons-nous dans ce moment où les If- moxra. mélites convertis chanteront le Preaume ivanuzi. de leur reconnoifance. Lc fens d'un bout à l'autie en eft alors fimple \& fuivi.

Les Irraélites rappellés, commencent par y rendre graces de la miféricorde qui me me nu-

vient d'éclater fur eux. Après avoir été haïs, pourfuivis, \& écrafés par des enne. mis fans nombre; après avoir éprouvé les mauvais traitements de toutes ces $\mathrm{Na-}$ tions, irritées contre eux comme des abcilles en furie, ou comme des epines on feu, ils remercient le Seigneur qui los déliure enfin de l'oppreflion. 1ls reconnoiflent que leur longue milerc eft un chieiment jufte, quoique févere; \& ils le glorifient de ne les avoir pas livrés à une entiere deftruction.

Mais quelle eft leur fuute? quel eft lo crime quils onc à fe reprocher, \& auquel ils ont tous pris part? Depuis la captivite de Babylone ìs n’ont montré aucun efpric de retour vers lidolatrie. Ils ont toujours fait profeffion d'honorer le Dieu d'Ábrahnm, le Créaceur \& le Confervateur de tout, le vrai Dieu. Quel eft donc cclui qu'ils confellent, \& qu’ils reconnoiflene enlin prur leur Seigneur \& leur Dieu? La grunde méprile, le grand srime C vj. 


\section{O LESPECTACLE}

LA DÉ- dont ils s'avouent coupables, eft d'avoir NiONsTr. méconnu celui qui étoit la porte par laÉVANGel. quelle on parvient à la juftice. Ils avouente que certe porte eft unique, \& qu'en s'éloignant de celui qui eft la porre, ils étuient bien loin de la juftice, qu'ils ne cherchoient qu'en euix. Its s'adreffent à celui qui les a prévenus, \& qui eft enfin Ini-même leur falut; à celui qui après avoir été rejecté par leurs Peres comme une pierre de rebut \& inutile à l'édifice de l'Eglife de Dieu, eft devenu la principale pierre de l'angle, pour donner la fermeté à tout l'ouvrage.

Cette grande vérité à laquelle ils on été fi long-tempis \& fi opiniâtrément oppofés, devient pour eux ce qu'elle eft en effer, l'ouvre du Scigneur la plus admiraBle, \& le fujet de leur furprife. Cetre œuvre ne leur étoit point conmue, \& c'éroit leur malheur. Elle leur eft enfin révélée; $\&$ cette connoifance les remplit tour àtour de repentir \& de raviffement. Ils fe livrent aux acclamations \&z à la joie la plus vive, en demandant leur falut à celui qu'ils ont rejecté. Ils ne peuvent contenir leurs tranfports. Ils annoncent le même falut à toutes les Nations, \& publient que celui qu'ils ont méconnu, eft l'Envoyé de Dieu : ils les invitent à connoître l'objet 


\section{DE I A N A T URE: 6 I}

de leurs bénédictions. Les ombres font $\mathrm{LA}_{\mathrm{A}} \mathrm{D}$ enfin difippées pour eux, \& le Seigneur a MONSTR. faic luire fur eux fa lumiere. Ils prennent śranged. part aux folemnités \& au feftin de l'Eglife. Ils ne fe peuvent laffer de dire \& de re. dire avec admiration, que celui qu'ils ont riéconnu eft leur Dieu \& leur Sauveur. Jefus-Chrift nous montrant dans la prédiction de David ce qui n'a ceflé de s'accomplir depuis fon avertiffement, met au grand jour certe vérıté, quele paffé \& l'avenir lui obéiffent. C'eft à l'école du Docteur de toure vérité que l'Eglife a pu apprendre ainfi à s'occuper d'un avenir éloigné comme s'il étoit déja. Elle en jouit par avance, \& elle ne doute non plus de la future converfion d'Ifraël, que de l'endurciffement où il perfévere. Elle prévient le noment de l'heureux retour de cette Nation défolée, comme elle l'y invite en d'autres temps en la provoquant par la peinture de fa milere, \& par la prédiction de fon changenient. Jerujalem, Jerufalem convertere.

Le Sauveur nes'eft pas contenté de produire les preuves de la mifion, en indiquant les traits prophétiques des anciennes Ecritures qui ia prometroient au Peuple Juif. Jefus-Chrift reconnoiflable par laccompliffement des anciennes prophé- 


\section{LE SPECT ACL}

L. Dśtics, l'eft encore par l'accompliffement Mtonstr. des fiennes. Il y a joint fur la formation ínacier. de fon Eglife, \& fur la perpéenité du miprophétics niftere de fes Envoyés, d'autres prédic-

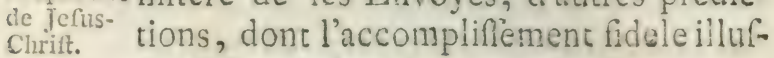
tre à jamais leurs pouvoirs.

Ceux qui ont des doutes fur la rćalité des prophéries de Jefus-Chrift, conviennent qu'on ne gagne rien à dire que les Livres de l'Evangile ont été fabriqués après coup ; parce qu'ils font indubitablement antérieurs à la ruine de Jérufalem, \& qu'en quelque temps qu'ils aient été écrits, ils ne peuvent être q̨ue divins s'ils annoncent des événements qui foient arrivés poltérieurement à la publication des Livres; \& qui aient été de nature à ne pouvoir être prédits fans une exceffive témérité. Mais ils prétendent qu'un peu de connoiffance des affaires du monde fuffifoit à Jefus-Chrift pour fentir fans être Prophete, que l'inquiétude des Juifs les conduiroit bientût à la perte de leur Ville; \& que fes Envoyés, après quelque réfiftance, établiroient enfin fon fyftême de religion, parce qu'il étoit d'un caractere à ĉtre bien reçu. Voyons fi la chofe étoit fi facile à faire, \& à prédire.

Après avoir lu l'Evangile, ou feulement les trois chapirtes ga'on nomme, 


\section{DE LA NATURE.}

Je Sermon fur la montagne, où Jefus- LA DÉ Chrift a rapproché les plus beaux traits moxstr. de fa doetrine; efliyons d'en faire, pour írangel. ainfi dire, l'horofcope; fervons-nous de notre expérience \& $x$ de la connoiflance que nous avons des difpofitions du cour humain, pour prévoir comment cette Religion fera reçue dans le monde. Nous comparerons enfuite notre prédiction arec celle de Jefus-Chrif, ar toutes les deux avec l'événement.

La Religion Chrétienne peut être an- Prophétie noncée la force en main, ou être aban- Chrift fur donnée à elle-même, \& laiffée fans fup- les perléport. Qu'arrivera-t-il dans le premier cas?

Si un Prince qui a un grand nom \& des armées à fon commandement, prenoit foin d'introduire cette Religion chans le monde, peut-être y prendroit-elle pied en quelques lieux à proportion des fuccès du Conquérant. Encore peut-on penfer que ce ne feroit pas lans de grands obltacles ni d'une façon durable, parce qu'elle condamne les idées reçues \& les préjugésde l'enfance, la Religion publique \& l'intérêt des Villes les plus floriffantes. Qu'on porte cette Religion, par exemple, à Ephefe. Cetre Ville eft pleine d'Orfevres, qui font un atiez grand trafic des 


\section{LE SPECT ACLE}

IA D- repréfentations qu'ils débitent en argent moxstr. \& en cuivre, du magnifique Temple de źaget. leur grande Déeffe. Ruiner le culte de la Déeffe, c'eft ruiner leur fortune. On peut prévoir que la même Religion préfentée à Eleufis, à Epidaure, ou dans Cythere, \& à Paphos, allarmera les Prêrres de Cerès, d'Efculape, \& de Vénus. Même incompatibilité par-tout ailleurs. On peut juger des obfacles qu'un Prince auroit trouvés en établiffant de force le Chriftianifine, par les réfiftances opiniâtres, \& par les fureurs auxquelles fe porterent les Normands, ou les Peuples voifins de la Mer Baltique, aigris par la févérité des Loix que Charlemagne, Louis fon fils, \& d'autres, avoient établies pour les rendre Chrétiens. Même conduite au douzieme fiesle de la part des Pruffiens envers Boleflas le Crípu, Roi de Pologne, qui leur portoit l'Evangile les armes à la main.

Que fi fuivant la prédiction \& l'intention de Jefus-Chrift, fa Religion eft laiflée à elle-même; fi elle eft annoncée par des Miniftes qui ne fe mettent en peine ni de fuire provifion d'argent, ni de préparer leurs difcours \& leurs réponfes, ni de fe ménager des protections, ni d'employer l'épée contre ceux qui leur réfifrent ( \& c'eft le cas où le Chriftianifme 


\section{DE LA NATURE. 65}

s'eft trouvé.) effayons de prédire quclle IA DÉfera fo deftinée. Il en fera de cetre Reli- monstr. gion comme des idées de Diogene, de ÉVANGEL. Zènon, d'Ariftote, ou de Platon. Elle fera fortune dans quelques écoles; ou peut-être tout au plus dans la tête d'un petic nombre de contemplatifs. Le Peuple qui eft grofler \& changeane, ou fera peu touché d'une Religion fi fage, ou n'y perfévérera pas, \& le tout s'en ira en fumée.

Si cependantla nouvelle Religion, malgré la force des préiugés \& des paflions, peut acquérir quelques partifnns; comme ils font profeffion d'aimer les hommes, \& de prier pour leurs propres perfécu. teurs; comme ils imitent celui qui fait lever fon foleil fur les bons \& fur les méchants, fans jamais maltraiter ceus qui ne penfent pas comme eux; une telle douceur ne peut que les rendre aimables. On leur paffera fans peine quelques idées fingulieres fur la réfurrection \&r fur les récompenfes qu'ils attendent. Ces fpéculations n'incommodent perfonne : \& l'on fera même fort aife dans la fociété d'avoir des voifins fi peu diflicultueux, fi juftes, \& fi bienfaifants.

Ainfi notre prudence nous conduit à faire deux prédictions; l'une, que cetre 


\section{LE S P E CTACL E}

La Dó-religion étant fans fupport, loin de fe Movstr. répandie, s'en ira promptement à rien; smanul. l'autre, que fi elle trouve quelques fectrteurs, on les verra de bon ceil, ou du moins on les laiffera en paix, en confidération de leur petit nombre, \& de ce caractere bienfaifant qui eft le grand lien de la fociété. Telles font nos deux prophéties, entiérement conformes à la façon de penfer \& d’agir qu'on éprouve par-tout. Jefus-Chrift en fait deux coustes contraires; l'une, que le Royaume des Cieux, ou la prédication de la bonne nouvelle, après des cominencements foibles, prendra de grands accroiffements, \& durera autant que le monde; l'antre, que fes Difciples feront par-tout hail, pourfuivis, \& traités cruellement. Comment pouvoit-il efpérer d'Âre cru, en prédifant que fon Evangile, qui eft la condamnation des ufages univerfels, profpéreroit par-tout, quoique fans fupport; \& comment s'eft-il flatté de trouver des Difciples \& des Prédicateurs, en débutan par ne leur annoncerà tous que des perfécutions $\& x$ des fupplices? Voila certes l'entier renverfement de nos idées. Par l'événement on pcut voir de l'ESprit de Jefus-Chrift ou du nûtre, qutel eft le prophétique. 


\section{DE I A NATURE. 67}

Voici un autre trait du mêtme Eiprit, LA D :. qui démontre que Jefus-Chrift a vu l'a-monstr. venir, parce quuel'avenirlui étoit foumis, ávangio \& que c'eft lui-même qui en difpole les événements.

Au temps où l'Evangile a été prêché, puis écrit, lidolatrie étoit fi univerfelle che Jefus\&r fi dominante, par les différents rapports la vocaquelle avoit avec toutes les convoitifes tion des de l'bomme, que la philorophie la plus éclairćen'avoit ofé la contredire. Socrate, Platon \& Cicéron penfoient bien autrement que le Peuple : cependant, ils avertifoient leurs Difciples de s'en tenir sux réglements publics; d'honorer Bacchus, Vénus, Cupidon, Flore, \& des Dieux encore plus infames; d'agir en un mot comme le Peuple. Ils fentoient l'inconvénient terrible qu'il y avoit à le contredire : \&e aucun d'eux ne rifqua l'entreprile. Leur complaifance alla jufqu'à prendre en main la défenfe du Polythéifune en le déguifant comme le firent Ariftote, Plutarque \& Pline. Ils crurent l'avoir merveilleufement fpiritualié, en attachant l'idée du feu à une Divinité, de l'enù ù une autre, de la végétation à une troifieme, de la génération \& de coutes les productions de la nature, à quelques-uns des noms révérés par la coutume: comme fi 


\section{LE SPECTACLE}

Li $D \leqslant$ - la fubftitution d'une phyfique triviale auris moxstr. idées populaires, pouvoit ou racheterles śuNGEL. défordres que ces idées toujours fubfiftantes autorifolent également; ou difculper les adornteurs d'avoir transféré à des êtres inanimés la gloire qui n’eft due qu’à Dieu. Les Génies dont les Platoniciens peuploient toure la nature, fans avoir la moindre connoifance de ce qu'ils affuroient, laifferent fubfitter toutes les folies précédentes, \&t y en ajouterent de nouvelles. Ils remplirent la fociété de mifanthropes, toujours pleins de l'efpérance de pouvoir converfer face à face avec les démons, toujours occupés de facrifices magiques, de fpectres, \& d'apparitions. Telle fut l'imbécillité de l'ancienne philofophie.

L'idolâtrie, le matérialifme, \&r la magie, ces trois fyftêmes également pernicieux, que les plus beaux efprits, quoique protégés \& admirés, n’oferent feulement attaquer, \& dont plufieurs firent l'apologie tour-à-tour, Jefus-Chrift entreprit de les ruiner par la prédication de douze Matelots. Il en prophétifa la réuffite, \& l'événement a fuivi.

Dans fa prédiction il égala l'étendue de fon œuvre à celle de la terre $\&$ des fiecles. Depuis le départ des Pêcheurs de Galilée, 


\section{DE IA NATURE.}

devenus, felon fa parole fi furprenante, la $D$ s. autant de Picheurs d'hommes, l'Evangile monstr. a acquis des coeurs fideles dans toutes les évanget. Niations. Il a percé jufques dans le Nou- Matt. 4: veau Monde, \& il porte les derniers coups ${ }^{19 .}$ à l'idolâtrie.

Si le choix des Euvoyés rend fa prédiction peu vrailemblable, les moyens qu'il leur recommande achevent de la rendre incompréhenfible. 11 leur recharge d'être comme des agneaux au milieu des loups; de n'employer ni l'argent, ni la protection, ni les difcours; je ne dis pas étudiés, mais feulement réfléchis; ni la moindre réfitance. Autant ces moyens font peu propres ì ébranler une opinion univerfellement fondée fur les cupidités du cœui humain, autant la trifte annonce que Jefus-Chrift fait à fes Difciples de contradictions \& de perfécutions violentes, femble peu propre à lui attirer des partifans. Il fait exactement tout ce qu'il faut pour ne trouver ni qui veuille entendre l'Evangile, ni qui le veuille annoncer.

Entreprendre par de parcils moyens de renverfer une Religion, qu'on ne féparoit nulle part de l'intćrêt de l'Eat \& du bonheur des particulicrs, c'ctt être Dieu, ou extravagant: l'altermative ett iné- 


\section{To LE SPECTACE}

LA Dí vitable. C'elt être extravagant d'annoncer monstr. la deftruction, de l'idolatrie, fi on n'elt ŕaNGel. pas le maitre de l'opérer, n'y ayant rien eu ni de fi fort que l'idolâtrie, ni de fi dénué de tour fupport humain que JefusChrift \&: fes Envoyés : c'eft êrre Dieu, fi l'événement répond à la promeflè.

Muis depuis cette prédication, que font devenus l'Oliris \& l'lfis des Egypriens, le Michras des Perfes, la Mylitta des Arabes, la grande Déefle de Syrie \& d'Ephefe, la Vénus de Paphos, la Cybele \& l'Athys de Phrygie, les puifrants Dieux protecteurs des Grecs \& des Romains, le Theutatès des Gaulois, l'Herminful des Saxons, \& tant d'autres? Ces idoles n'ètoient rien, je l'avoue; mais elles oppofoient aux attaques du Chriftinnifme les préjugés, le brillant des fềtes, l'entêtement, la féduetion, l'éloquence, la philofophie, la magie, la barbarie. Rien n'a tenu contre l'Evangile. Et qu'eft-ce donc dans la réalité que l'Evangile? Une parole, un fouffle : mais un foufle forti de la bouche de Jefus-Chrift.

Il y a ici quelque chofe de plus touchant. Le Sauveur a ćcé mis à mort fous l'Empereur Tibere, fans avoir quitté la Judée, ni adreffé la parole aux Gentils: ¿ aufli tôt après la mort du Chrift, fon 


\section{DE L A N A TURE. $\quad$ T}

Evangile fut reçu parmi eux. Mais c'eft LA DSprécifément la prédiction que l'Evangé- Monsir. litte $S$. Jean met dans la bouche de fon ĹVANGLu Maîre. Il lui fait dire fans la plus petice ombre de vraifemblance, que l'empire de l'Efprit de ténebres qui fe failoit tadorer à la place du vrai Dieu, alloit tomber, \& que la mort du Chrift feroit fuivie d'un ébranlement univerfel parmi les Nations, qui alloient renoncer à l'idolâtrie pour s'attacher à lui.

„C C'eft maintenant, dit Jefus-Chrift, $y^{\prime} s$, is : „, que le monde va êure jugé. C’eft main„, tenant que le Prince de ce monde va " être chaflé dehors; \&x pour moi, quand " j'aura été élevé de la terre, jatrirerai " tout à moi. "Ces paroles qu'on fuppoferoit inutilement avvir éré inventées par l'Evangélilte, ont été reconnues dès le premier fiecle; \& cela nous fuffit, puifque lidolâtrie étoit encore dominante au troifieme. Mais le coup mortel lui étcir porté. Ses pertes le peuvent compter comme les annces: \& la prédiction fi defticuée de vraifemblance, avoit levancé fa premiere chûte.

Laifions à part l'infuffilance de fes Envoyés, \& la folie de la croix, qui naturellement devoit leur ôcer toute créance. Quel privilege peur avoii, je vous 


\section{LE SPECTACLE}

LA Dé-prie, le moment de fon fupplice ou de ATONSTR. fa retraice, pour engager les hommes, ÉVANGEI. qui jufqu'à préfent n'ont cru ni en fa fageffe ni en fes œuvres, à venir à lui tour-à-tour, \& à écouter fes Envoyés plutôt que luii? Ou iln'y a pasl'ombre de fens, ou il y a une prefcience toute divine à attacher à un moment précis la libre converfion des cours, au milieu des circonftances les plus propres à l'empêcher. Cette prophétie eft fans contredit le plus fort témoignage que l'Efprit de Dieu ait rendu à l'œuvre évangélique. Elle àtcachoit à la miffion de fun Fils un fi puiffant motif de crédibilité, que JefusChrift l'a inculqquée en cent façons, \& fous une multitude de paraboles également propres à la rendre préfente à cous les efprits. Toute la Judcé a entendu de fa bouche, \&z tous les Pcuples ont appris de fes Envoyés, avant que les Evangéliftes euffent ćcrit, que le Fils de l'Homme, le Chrift, alloit donner fa vie; \& qu'enfuite à la prédication des fiens, il alloit venir de l'Orient \& de l'Occident, du Septentrion \& du Midi, une foule d'adorateurs qui aurolent place au feftin ntet. 8 : du Royaume des Cieux, \& honoreroient 11. C Luc. le vrai Dicu en la compagnie d'Abraham, d'ilaac \& de Jacob; au-licu que les enfants 


\section{DE LA NATURE. . . T3}

ingrats qui le rejettoient, feroient mis de- LA D:hors. Cette prophétie eft proprement le mossr?. fond \& l'économie de l'Evangile, qui n'a Lvaiciz. jamais exifté fi cette prophétie n'eft pas réelle. Il porte ainfi avec lui une preuve immortelle de vérité.

Si la prédiction du renverfement de l'idolàtrie infpire à tous les ficcles fuivants un jufte refpect pour le Livre quil'a láns contredit annoncé bien avant l'accompliffement; rien n'étoit plus capable de faire refpecter dès le commencement la prédication des Apôtres, que la prophétie des circonftances qui devoient fuivre immédiatement la mort du Sauveur, \& commencer le renverfement de l'idolatrie.

Jefus-Chrift annonce en toute rencon- protititi at tre à Ces Difciples, que fon cuvre étoit: $i^{\circ}$. d'amener les hommes à la pénitence, des crenements [1:dont Jean-Baptilte avoit fait l'ouverure; 2 , d'établir le Royaume des Cieux, ou (c) imnituintomitie la vraie fainteté daus les coeurs; $3^{\circ}$. de ruiner l'empire de l'idolitrie, que l'cforit de ténebres avoit étendu par-tout où il y avoit des hommes. En un mot, convaincre l'homme de fir milere, former des juftes, \& ruiner l'ceuvre de l'ancicn féducteur, voila la million de Jeius Chritt. Mais dans le moment le plus propre ì rendre fes Difciples atcentifs, il leur faic Tome VIII. Part, II. 


\section{LE.SPECT A C L E}

LA DÉ- obferver qu'aucune de ces trois opéraMONSTR. tions ne devoit s'accomplir de fon vivant, ÉVANGEL. que l'exécution en étoit réfervée toute entiere à l'Efprit qu'il alloit faire defcendre fur eux pour les dédommager de fa perte. Il va julçu'à leur déclarer que ces trois changements infignzes, qui étoient l'objet de fa venue, \& dont aucun n'avoit encore paru, alloient éclater incontinent; qu'ils commenceroient à s'opérer tous trois dans très-peu de jours, \& aufji-tót après fa retraite.

Goum.16:6. "Parce que je vous ai, leur dit-il, an"noncé le moment de mon départ vers " mon Pere, la trifteffe s'eft emparée de 3, votre cœur : cependant, je vous dis la "vérité; il vous eft avantageux que je "m'en aille. Car fi je ne m'en vais pas, "l'Elprit confolateur ne viendra pas à "vous: mais fi je m'en vais, je vous l'en"verrai. C'eft lui qui après fa venue ma"nifeftera parmi les hommesle péché, la " juftice, \& le jugement. C'eft à l'Efprit " confolateur qu'il eft réfervé de manifef"ter le péché ( $\&$ de convaincre les hom"mes de leur corruption:) car vous voyez "qu'ilsn'ont point cru en moi.(Le monde " eft encore dans fon impénitence,) c’eft "l'Efprit confolateur qui (en ma place) " manifeftera la juftice, (\& formera la 


\section{DE LA NATURE. $\quad 75$}

", fociété des Saints :) car pour moi je La Dé-

", m'en retourne vers mon Pere, \& vous Monstr.

" ne me verrez plus. C'eft lui enfin qui "VANGEL.

", manifeftera le Jugement; car la fen-

", tence eft portée contre le Prince de ce

, monde.

Perfuader aux hommes que le péché eft en eux; former au milieu de cette corruption un Peuple de Juftes; ruiner enfin le culce des Dieux pour faire adorer le feul Etre adorable, voilà autant d'entreprifes peu vraifemblables pour un hommeaufi foible en apparence qu'eft JefusChrift. Mais affurer comme il fait que ces trois chofes pour lefquelles il eft venu, $\&$ dont aucune n'eft exécutée, commen- . ceront à saccomplir précifément aufî-tôt qu'il ne fera plus fur la terre, eft une hardieffe encore plus inconcevable. Or dès les premiers jours de fa retraite l'effet parut, \& il dure encore.

Celui qui ne proféroir que des paroles de fageffe, ne fut point reçu des fiens. Il eut des auditeurs \& des témoins en foule; mais il eut peu de difciples. La crainte les retint, \& rendit fon ceuvre jufques-là inutile. Il difparut fans avoir ni introduic nulle part le repentir \& le changement de conduite; ni rendu la fainteté plus commune parmi les Peuples; ni livré

$$
\text { D ij }
$$




\section{LE SPECTACL}

LA Dé la moindre attaque à la tyrannie de l'erMonstr. reur qui faifoit adorer tout, excepté Dieu. E VANGel. Si Jefus-Chrift n'en a pas tenté l'entreprife daus une feule Ville idolâtre, par exemple, à Tyr \& à Sidon, des hommes auffi dépourvus de talents que le font les Apôtres, feront-ils plus heureux que lui? Il ne leur refte qu'à fe cacher: \& fa mort, comme l'abfurdité de la prédiction, doir fuffire pour les détromper. Mais loin de fuir comme ils avoient fait lorfque leur Maître vivoit encore, ils fe montrent publiquement, \&r l'annoncent dans le Temple. L'Efprit qui leur a été promis en fait fubitement des hommes nouveaux. Aux deux premieres prédications d'un Matelot groflier, qui fe dit le Difciple du Chrift, huit mille hommes embraffent la pénitence, \& font pénétrés de douleur d'avoir demandé fa condamnation au Gouverneur. Nalgré le dépic \& les menaces de l'ordre facerdotal, les exemples d'une foi conftante, \& d'une fublime piéré, fe multiplient à Jérufalem \& dans toute la Judée. L'Eglife \&̊̀ les mêmes vertus s'étendent à Damas, à Antioche, à Paphos \& à Corinthe : c'eft-à-dire, dans les Villes les plus débordées. L'Evangile donne la premiere fecoufe à l'idolâtrie, jufques dans Rome, jufques dans la Cour de Néron, 


\section{E L A NA T URE. T?}

\& daus la famille de Narciffe, c'eft-à-dire, L: DLdans le centre de tous les excès. * nosstr.

Il n'eft point de jour dans les fix fie- timouer. cles fuivants, où l'Aurel de quelque Dieu, "R $R$, if: difons plutôr de quelque monftre, ne foic renverfé. Par-tout l'idolâtrie perd fes partifans. Elle fe fauve dans les campagnes, \&z dégénere en rufticité. Enfin la barbarie en rougit elle-même : \& dans les quatre continents le vrai Dieu a des adorateurs.

Jefus-Chrift n’a donc exécuté par luimême aucune des trois parties de fon cuvre : \& en les accompliftant toutes trois fuivant fa promeffe, auffi-tôt après fa retraite, par des hommes incapables de tout, il n'a laiflé voir que l'E $\int p$ rit tout-puifant qui étoit en lui, \& qu'il avoit mis dans fes Envoyés.

On ne peut oppofer à cette preuve que des ténebres. Peut-être Jefus-Chrift n'a-t-il pas fait cette prophétie. On a bien de la peine à croire qu'il ait dit ces paroles. On eft perfuadé qu'il ne les a jamais dites. On trouve dans fa raifon la regle infaillible de la conduite que Dieu a dù tenir.

En attendant que nous produifions les témoignages que les Apôtres ont rendus aux prédictions de Jefus.Chrift, \& les

D iij 


\section{L L SPECT A C L}

Is D - témoignages fans nombre qui ont été renMonstr. dustant à la prédication qu'aux écrits des Evangel. faints Apôtres; arrêtons-nous un inftant fur le caractere de l'Evangélifte de qui nous apprenons la derniere prophétic. Regardons l'Evangile qui la contient comme tout autre écrit, comme tout autre témoignage humain, qui devient croyable à proportion des marques de vérité qui le relevent. Il n'y a rien qui rende fon récit fulpect; \&r toutes les préfomptions lui font favorables.

On fait par les rapports du Martyr S. Polycarpe, de S. Irénée, \& d'Eufebe, que l'Evangélifte Jean faifoit fa réfidence ¿̀ Ephere, où il étoit connu \& honoré de routes les Eglifes d'Afie. Ce n'cft point fon Evangile qui a introduit le Chriftianifme dans ces quartiers, mais c'eft la comnoiffance de la Doctrine Apoftolique, \& l'eftime finguliere des vertus de S. Jean, qui ont fait recevoir avec vénération fon Evanggile, écrit le dernier des quatre. C'ćtoit toujours la même hiftoire (a) quion tenoit de la bouche des térnoins oculaires qui en avoient été les Prédicateurs; mais mieux circonfanciée en plufieurs points.

(a) Sicut tradidornyt qui ab initio ips viderunt $\hat{C}$ minillri fuermat-fermonis. Luc. I : 2. 
Il n'y avoit point de témoignage qui LA DĹfut humainement plus croyable que le novstr. fien. Dans la difperfion des A pôtres conf- ÉrAnget. ternés par la crainte, il étoit refté feul aux pieds de fon Maitre jufquaprès fa mort : ce qui nous a procuré le récit plus détaillé de l'infcription mife fur la Croix; du fort jetté fur la robe de Jesus; \& du vinaigre qu'on lui fic boire. C'eft lui qui nous rapporte les dernieres volontés du Sauveur, \& le foin qu'il prit de fa Mere, en lui affurant l'entretien néceffaire fur le - bien \& fur l'amitié de Jean, donc ce teftament fait la gloire. Il nous rapporte aufii la circonftance de l'ouverture du côté de Jesus après fa mort; \& il y fait l'appli- Zacim. I: cation de la prophétie, qui prédit quele Chrift fera percé de coups par les fiens, \& qu'un jour ils reconnoîtron celui qu'ils ont-percé.

L'Evangélifte Jean eft le feul Apôtre qui ait été exactement témoin de tout. Mais il n'étoit point feul. Il s'y trouvoit avec une multitude d'affiftants, ou curieux de nouveauté, ou ennemis zélés de JefusChrift, \& plus ardents à lui ôter l’honneur que la vie. Toutes ces circontances dont ils avoient été inftruits par leurs yeux, les metroient en état de confondre

$D$ iv 
LA DE-le récit de l'Evangélifte s'il s'écartoit de MONSTR. la vérité.

SWAGel. Il y avoit pour lui des hommes plus à craindre encore que les ennemis de l'Evangile. Dans la recherche que nous faifons ici des moyens humains qui pouvoient naturellement faire recevoir fon zécit, nous devons pareillement faire état de ce qui pouvoit le décréditer dans la fuppofition d'impolture. Son hiftoire devoit offenfer la délicateffe ou la jaloufie des autres Difciples, ens'attribuant, comme il fait par-tout, la qualité de Difciple lien-aimé; en fe glorifiant d'avoir reçu chez lui cette Mere vénérable dont JEsus lui avoit fait le leg fpécial; enfin en couvrant tous les Apôtres de la honte d'avoir fui, accufacion peu néceffaire au progrès de l'Evangile.

Mais vous voyez par-tout dans les récits de S. Jean, la confiance d'un homme qui ne craint ni les réfutations, ni les défeveus, ni les plaintes. Vous y trouvez l'exactitude d'un témoin parfaitement inftruit, qui rapporte fans apprêt \& fans choix, ce qui fait pour fa caufe, ce qui y paroit indifférent, même ce qui y femble contraire, par cette unique raifon qu'il y étoit; \& qu'il dit les chofes naive. 


\section{D) E I A NATURE. $\delta$ I}

ment, comme elles fe font paffees fous les LA D

yeux.

MONSTR.

Selon les regles de la plus faine criti- ĹFargzt. que, l'exacte conformité du récit des expédicions de Céfar avec les circonftances des lieux \& des affaires d'alors, en démontre la vérité, quoiquele témoin n'cùt, au rapport de Cicéron \& de Sallufte, ni droicure ni religion. A plus forte raifon, cetce exactitude à rapporter les plus petits détails, \& à fe foutenir fans méprife dans ces noms de lieux, de perfonnes, \& d'affaires publiques, eft-elle une démonftrtion dẹ vérité, quand le témoin eft d'une probité reconnue.

Si certe preuve pouvoit acquérir quelque nouveau degré de force, c'eft parce que l'Evangélifte ajoute à la vertu la plus éminente une fimplicité d'enfant. On en peut juger par la candeur de fes Lettres. Commentun homme auffi fimple auroitil été l'inventeur d'un récit dont il feroit impoffible au fourbe le plus confommé d'affembler les circonfances fans broncher dans fa marche à tout inftant, \& fans être fréquemment convaincu de faux? Il n'y a donc aucun témoignage qui raffemble plus de caracteres de vérité, que le récit de l'Evangélilte Jean.

D'où il fuit, qua fi l'on a réfolu de 


\section{LE SPECTACLE}

LA Dí- foupconner de la fourberie dans la fingu. MONSTR. liere prédiction des trois ceuvres réfervées ŚVANGEL. a l'Efprit dont les Apôtres feroient remplis aufli-tôt après le départ de leur Maître, !'Evangélifie en eft déchargé. Tout nu plus il peut avoir été trompé par un homme plus fin que lui, \& avoir rapporté fes paroles avec trop de crédulité : mais puifque le fait eft réel, \& que ces parolcs font forties de la bouche de celui à qui on les attribue, comment veut-on qu'un fourbe life jufte dans l'avenir le plus prochain, \& dans un avenir très-éloigné? Les trois points prédits, ou très-anciennement couchés dans l'Evangile de faint Jean, ont commencé à s'accomplir aufítôt après la retraice de Jefus. On vit aufitôt des fociétés de pénitents \&̊ de jultes à Jérufalem, à Samarie, \& chezles Païens cux-mêmes.

Le Dieu d'Abraham, c'eft-à-dire, le Créateur qui avoit promis à Abraham de bénir en fa poftérité toutes les Nations, leur eft annoncé au nom de fon Defeendant; \&r la décadence de lidolittrie commencée à cette prédication va toujours en augmentant de fiecle en fiecle. C'eft furtour la perfévérance de cet accompliffement dans un avenir éloigné, qui fait connoître de quel efprit l'Evangélifte \& fon 
.7.

DE L A NATURE.

Maître étoient animés. Il n’y a done ici La Dśaucune fourberie, ni dans celui qui ra-MoNstr. conte, ni dans celui ģui prophétife, \& úvavion. Ia Miffion Chrétienne eft divine.

Une derniere remarque met encore mieux cette prophétie au-deffus de tout foupçon. Saint Jean ne la publia d'abord que de bouche, comme le refte de la vie de fon Maître. Il n'ëcrivit que tard, \& Jorfque le premier fiecle étoit fort avancé. Les deux premieres parties de la prédiction, nous l'avons vu, s'accompliffent de toute part. Mais ces commencements de pénitence '\& de fainteté pouvoient n'être pas durables. Le troifieme point de la prédiction, qui étoit le plus important, \& le plus vifiblement réfervé au pouvoir de Dieu feul, n'avoit pas à beaucoup près fon accompliffement marqué. Du vivant de l'Evangélitte l'idolâtrie fubfiftoit, \& avoit écrafé les Apôtres mêmes. Les efforts de la philofophie \& de la puiffance temporelle durant les fiecles fuivants, fembloient devoir anéantir le Chriftianifme. Il fut réfolu plufieurs fois de convaincre de faux les prédictions du Mcffie : mais ces efforts rendent témoignage à la prophétie \& la conftatent. L'idolâtrie n'eft plus, \& la parole de Jefus-Chrift a for effet. 


\section{LE SPECTACLE}

LA DÉ- Ces obltacles qui ont rendu la proMnoxst:. phétie plus célebre en la contredifant de ÉVANGEt. deffein prémédité, ont éré prophétifés Ies obfra-eux-mêmes. Jefus-Chrilt a prédit à plutos a fucc- fieurs reprifes, \& d'une façon très-narcomplife- quée, que la doctrine du vrai Dieu \& les ment des bonnes mours alloient s'introduire dans ties, ont la fociété; que l'Evangile feroit porté phétifes. d'une Ville à l'autre, \& s'y foutiendroit malgré des combats perpétuels.

Quand un homme qui n'a point reçu l'efprit prophétique fe mêle d'innoncer l'avenir, il faut du moins qu'il ne fe mette pas en contradiction avec la plus conftante expérience. On pouvoit prévoir humainement que la doctrine de l'Evangile trouveroir des oppofitions. Mais il ne falloit pas fe flatter que les fuccès feroient conftants comme les perfécutions. La connoiffance du cœur humain montre bien le contraire : \& il eft d'une infigne témérité, de prédire qu'une doctrine fera toujours traverfée \& toujours floriffante. Il fuffit même que des opinions ceffent d'être protégées pour tomber dans un difcrédit général. Les Dieux des Grecs \& des Romains n'ont point d'abord fouffert de perfécutions. Jamais les Empereurs devenus Chrétiens ne firent mourir ni les Prêtres des Idoles ni les Idolâtres. Lorf- 


\section{DE LA NATURE., 85}

que la police ferma les Temples des Dieux LA DÉdans les Villes, le culte s'en maintint dans Monstr. les campagnes, in Pagis: d'où eft venu érangel. le nom de Paganifme. Peu après cependant le feul défaut de protection y fic enfin renoncer totalement. On plaida fans fruit pour la confervation de l'Autel de la paix \& du Temple de la victoire. Bacchus $\&$ Vénus, ces Divinités enjouées, pour qui tout l'univers devoit prendre parti, font tombées comme les autres; \& fans nos théitres elles n'auroient plus nulle. part ni Autel ni afyle.

Toutes les fois qu'on a voulu attaquer les Religions dominantes, renverfer l'ancienne police, ou changer les coutumes des Peuples, on a trouvé, il eft vrai, plus ou moins de réfiftance. Mais tout cede avec le temps. On fe laffe de lutter contre le torrent. L'amour du repos amene infenfiblement des idées nouvelles : \& il n'eft point de changements que la durée des perfécutions n’ait intioduits. Il n'a ćté donné qu’à la foi des promefles \& à la fainte té des mours chrétiennes d'éprouver des attaques perpétuelles, foit du dehor's, foit du dedans, \& de ne pas fuccomber. La prédiction en eft donc d'autant plus touchante, qu'elle étoit fans vraifemblance; \& que pour l'accomplir dans fa plénitude, 


\section{LE SPEC.T A C L E}

L. Dé- les hommes qui font naturellement dous moxsik. envers ceux qui ne leur font point de kisicl. mal, font fortis de leur caractere dans l'acharnement qu'ils ont montré à pourfuivre le Chriftianifme.

D'une autre part, il eft naturel à l"homme de fe détacher de ce qui ne lui attire que des difgraces, quand elles ve font compenfées par aucun dédommagement réel. Mais quoique la confervation de l'Eglife, au milieu des fecoufes que les Puifiances temporelles \& l'efprit humain lai ont toujours fufcitées, foit une preuve fenfible de la Providence qui veille fur elle, \& la foutient contre toute vraifemblance, cette preuve tire une illuftration prrfaite de la prédiction qui a été faite d'une chofe fi peu croyable. Jefus-Chrift ne fe montre pas actuellement lui-même; mais fa parole n'en paroît que plus puiffante : \& par l'accompliffement immortel defes promefles, univerfellement publices Itesr.ıง: 8. avant l'événement, on fent "qu'il ćtoit , hier, qu'il eft aujourd'hui, \& qu'il fera , dans tous les fiecles.

La confervation du Peuple Juif prédite par I. C. \& S’il fe trou*e après la Religion Chrétienne une fociété perpétuellement maltraitee, \&t cependant indeftructible, c'eft egalement la Religion \& la Nation Juive. Mais la fans vrai- confervation de celle-ci n'eft pas moins 


\section{DE La Nature. 8?}

louvrage de celui qui a immortalifé le LA DLChriftianifme; \& qui à côté de fon Eglife Mronstr. a confacré l'ancien dépôt des preuves qui ÉYANGEL.

la mnnifeftent, en confervant l'authenticité de l'ancienne écriture avec le Peuple à qui il l'a confiée. Enfin ce qui démontre pleinement la divinité de cette longue \& peu vraifemblable confervation dans l'adverfité, c'eft encore la prédiction célebre que Jefus-Chrift cn a faice.

Qu'on refufe tout établiffement aux Juifs; qu'on les contraigne_à fuir dans d'autres climats, ou à fe tenir cachés dans le nôtre; quion les admette à fe montrer parmi nous à des conditions à peine fupportables; qu'on les dépoffede enfuite, comme il eft arrivé prefque par-tout, du peu de terrein qu'on leur avoit accordé, comme une faveur finguliere; qu'on les haiffe; qu'on les écrafe : ils fubfifteront. David, Zacharie, \&.Jefus-Chrift, ont annoncé que les habicants de Jérufalem béniront un jour l'Envoyé du Seigneur, sprès l'avoir mis au rebut; \& qu'ils re. connoitront celui qu'ils ont crucifić.

Quoique ce foit un grand fujet de furprife, de voir tout un Peuple confentil perfévéramment pendant une très-longue fuite de fiecles à être malheureux, quand il pout coffer de l'être en renonçant à quel- 
S8 LE SPECTACLE

LA Dé-ques opinions; ce n'eft pas uniquement la monstr. durée de ce Peuple coupé par pelotons, ÉVANGEL. qui donne droit de recourir au miracle: $\&$ nous ne difons point que toute opinion perfécutée foit pour cela même une doctrine célefte. Par exemple, on a vu les Gaures, (a) qui ont eu pour maître Zoroaftre, qu'on croit avoir vécu fous $\mathrm{Da}$ rius, fils d'Hyftafpes, (b) fubfifter longtemps dans la Perfe, puis fe fauver dans l'Inde, plutôt que de renoncer à leurs pratiques nationales. On les trouve encore au Mogol; \& il femble conféquemment qu'on puiffe être dans l'humiliation \& fubfifter long-temps.

Nais quoiqu'on doive remarquer que les perfécutions fufcitées aux Gaures ont été pafilugeres, \& qu'ils jouiffent paifiblement dans l'Inde d'une liberté qui ne s'y refure à aucune Religion, il y a une autre raifon de difparité, qui ne fouffre point qu'on mette leur confervation en parallele avec celle des Chrétiens ou des Juifs perfécutés. Nous ne féparons pas les deux marques des deffeins de Dieu fur un Peuple, qui font de fe conferver malgré les attaques les plus perfévéramment réité-

(a) Ceux qui fedifent adorateurs d'un feul Dicu fous ro iymbole dufeu. C"eft le fentiment que leur attribu: M. Hyde, de Relig. Perfar.

(b) Humplarci Pricieaus, II:je of the fewrs 
DE I A NATURE. 89 rées, \& d'en produire la prédiction diftincte.

LA D\&́MONSTR.

Ce n'eft ni la profpérité ni l'adverfité ÉVANGEL. qui fait preuve des intentions fpéciales de Dieu : mais c'eft la profpérité ou l'adverfité prédice \& fidélement accomplie qui porte le caractere de l'Efprit divin. Il n'y a que Dieu qui puiffe favoir la deftinée future des Chrétiens, des Juifs \& des Gaures. Il n'y a que Dieu qui puiffe dire ce qu'ils deviendront deux mille ans après la prédiction. Mais Dieu ne nous a rien annoncé fur les Gaures; ni ne les a difperfés parmi le genre-humain pour y être témoins \& confervateur's de quelqu'infigne vérité : au-lieu qu'il a prédit par $\mathrm{D}_{2}$ niel \& par Jefus.Chrift la longue difperfion des Juif́s; \& par les Apôtres, comme par la bouche de leur Maître, la perpétuité fi peu vraifemblable de la doctrine évangélique, malgré des traverfes toujours nouvelles jufqu’à la fin des générations humaines. Ils ajoutent à cette prophétie la réunion d'Ifraël à l'Eglife Chrétienne dans les derniers temps : \& c'eft un événement qui n'eft pas encore fous nos yeux, parce qu'il eft le dernier.

Tous ces événements qui ont été dès le commencement de l'Eglife Chrétienne la preuve lumineufe de la miffion de Jefus- 


\section{LE SPEC T A C L E}

L.s Dé-Chrift \& de fes Prédicateurs, ont acquis mossra. un nouvel éclat avec la fucceffion des IVANGEs. temps; puifque l'érendue \& la force de la preuve augmentent comme la fidélité \& l'étendue de l'accompliffement. En effet, aux perfécutions des trois premiers fiecles ont fuccédé des combats intérieurs encore plus redoutables, les difputes, l'intrigue, lavarice, le fafte. Avec les Princes \& la mulcitude des Peuples, tous les vices font entrés dans l'Eglife. Elle eut une infinité de membres qui la déshonorerent. Elle en eut qui travaillerent à la ruiner, \& qui. cefferent d'être fes membres. La raifon humaine, toujours ennemie ou peu contente de la regle de foi quila tient en captivité, attaqua tour-à-tour la Divinité du Verbe, puis peu à peu tous les articles de la commune \& invariable créance. La philofophie furprife elle-même des maux qu'elle a caufés, a encore l'injuftice de les reprocher au Chriftianifme. L'Eglife cut à fouffrir de la barbarie des Peuples du Nord, qui fembloient fe relayer pour la tenir dans des allarmes perpétuelles. Elle n'eut pas moins à fouffrir de l'ignorance du moyen âge, des fcandales intérieurs \& des entreprifes illégitimes contre Jefquelles Jefus-Chrift l'avoit prẻcautionnée : en un mot, elle deyoit toujours fouffir \& toujours fubfilter. 


\section{DE LA NATURE. DI}

Cette démonftration eft principalement La D: pour nous. A cet égard, la condition des derniers temps de l'Eglife acquier un EFANGEL. avancage fur celle des premiers. Ou plutôt il fe trouve une jufte compenfation de lumiere, qui met tous les fiecles en état de fe convaincre de la révélation évangélique. Les premiers fiecles ont vu les cuvres de l'Efprit tout-puifant : les fuivants \& les derniers fentent de plus en plus que JefusChrift \& fes Envoyés font le centre où viennent fe rendre les prophéties précédentes, \& d'où il part d'autres prédictions qui fe juftifient d'îge cn âge. De cette forte, l'Efprit de vérité n’a ceflè \& a ue cefle de juftifier par fon témoignage inmédiat, la réalité de-la miflion chrétienne.

Nous avions promis de montrer qu'clle eft divine, î l'Efprit-Saint l'a juftifiéc par les preuvesque rapportent les Erangéliftes. Nais nous avons déja fait plus. La condition n'eft plus incertaine, \& les faits fe trouvent réels. Sans fairc aucun cffort pour prouver la divinité des Ecritures, il nous fuffit que oe foient d'anciens Livres publiés par-tout arant laccompliffenent d'une multitude d'événcments très-peu rraifemblables qui s'y trouvent prédits. Voilà le fceau de l'Efprit-Saint; Sila mif- 


\section{LE SPECTACLE}

Lx Dé fion dont ceș Livres annoncent la perpégroxstr. tuité, ne va point fans fes preuves. B́VANGel. Mĩas tous les hommes n'étant pas également à portée ou d'avoir vu les æurres miraculeufes, ou de faire la comparaifon des prophécies anciennes avec les événements; ces premieres Lettres de créance que les Envoyés produifoient, \& qui peuvent encore être examinées par des yeux attcntifs, ont été fortifiécs ou remplacées pour tous par d'autres témoignages très-nombreux, les plus dignes de foi que les hommes puiffent rendre à ce qu'ils ont vu; \& qui, de la forte, ne faifant qu'un avec les témoignages précédents,

"rendoient ceux qui avoient cru fans 9on. so: ", voir les cuvres, aufi heureux que ceux 29 .

$"$ qui les avoient vues.

\section{II.}

Le témoignage du Baptême.

Je paffe done du témoignage de l'EFprit à celui de l'eau, c'eft-à-dire, au changement de ceux qui reçurent d'abord le baptême; parce que ces deux témoignages reviennent au même, le fecond fuppofant le premier, \& devant en tenir lieu. 


\section{กE I A NATUR̃. $\quad 93$}

Quoiqu'on n'aic pas vu les Lettres pa- LA'Dérentes de l'érection d'un siege Préfidial, monstr. ou d'une Cour fouveraine, on en eft źvakger. écgalement fùr par les atreftations de ceux qui en ont pris connoiffance : on !'eft par la perfévérunce de la République à maintenir ces Tribunaux; \& par l'acquiefcement des Provinces qui y portent leurs affaires. Un témoignage peut done être remplacé par un autre, fanscrainte d'illufion. C'clt ainfi que le témoignage rendu par le Pere à fon Fils au jour de fa tranffiguration, \& les témoignages rendus par l'Éfprit-sant à la miflion des Ouvriers évangéliques, ont été fuppléés par les témoins de fes ceuvres en faveur de ceux qui crurent fans les avoir vues : \& bien loin que ceux-ci foient blâmables d'avoir cru, leur acquiefcement à la Prédication $\&$ aux Ecritures évangéliques fur le fondement du témoignage des premiers Fideles, étoit d'une conduite infiniment raifontable; puifqu'ils avoient pour y ajouter foi, des motifs incomparablement plus forts que ceux qui diterminent toutes les démarches de la fociété dáns les affaires les plus importantes. Nous faifons avec la plus parfaice tranquillicé un contrat de vente, dans la perfuafion qu'une Terre nous apparcien:; que l'uete d'acquj- 


\section{LE SPECT A C L E}

I. I):- fition en eft dans nos mains; que la miMonst:. nute en eft chez tel Notaire; que nous * halr. l'avons toujours affermée fans trouble; quoiqu'il fe pourroit faire, fi quelqu'un ¿voit entrepris de nous jouer par des apparences adroitement préparées, qu'il y eût de l'illufion dans le tout. Cette illufion devient impoflible dans les faits qu'on nous propofe à croire, à proportion du concours des trois ou quatre caracteres fuivants :

$\mathbf{1}^{\circ}$. Que les objets \& les faits qu'on nous rapporte n'aient pas été vus dans l'obfcurité par maniere de preftirges, mais au grand jour; ni une feule fois en paffant, mais en plufieurs lieux, \& d'une façon durable qui permette à l'œil de s'arfurer de ce qu'il voit.

2?. Que les faits rapportés foient liés entr'eux, en forte qu'ils fe confirment mutuellement, que les feconds fuppofent les premiers, \& qu'avoir vu les uns foit autant qu'avoir vu les autres.

$3^{\circ}$. Qu'il ne puiffe y avoir eu de concert entre les témoins qui rapportent ces chofes aux perfonnes qui ne les ont pas vues.

$4^{\circ}$. Que les témoins donnent toutes les affurances qu'on peut exiger de leur exactitude \& de leur défintéreffement. 
DE I A N A T URE. 95

Ces caracteres n'ont aucun befoin d'è- LA Détre développés. Il ne faut que les appli- Monstr. quer. Ce que l'Evangile préfente n'eftpas Évangit. une opinion imaginaire, créée dans une tête, \&z arrangée avec art. C'eft une fuite de faits bien atceftés. Les œuvres de l'Efprit de Dieu qui ont été produices en preuves de la miffion évangélique, \& publiées par les premiers Chrétiens, n'étoient nullement fujettes à illufion, foit qu'on les confidere en elles-mêmes, foit qu'on 'es confidere par les difpofitions de ceux qui les rapportent.

Pouvoit-on fe méprendre avec d'autres, avec douze autres, avec cinq cents autres, en encendant la voix de JEsus après fa réfurrection, en touchant fes cicatrices, en le voyant agir \& manger au milieu de fes Difciples?

Les Eglifes pouvoient-elles fe méprendre fur le fait de la réfurrection, lorfqu'on les avertiffoit trente ans après cet événement, que la plupart des cinq cents freres qui avoient vu le Sauveur reffufcité, étoient encore en vie?

- Ceux qui n'avoient pas vu le Chrift reffufcité, avoient pu être témoins de l'effufion de fon Efprit. Ceux qui n'avoient pas vu les miracles de Pierre, avoient vu ceux d'un aurre Difciple. Les 


\section{Le SPECTACLE}

LA Dé- derniers faits tenoient lieu des premiers: MONSTR. \& tous étoient preuve foit de la vérité de ÉVANGEL. la réfurrection, foit de la vérité de la miffion \& de l'Ecriture évangélique. Toutes ces chofes étoient inféparab!es : une feule prouvée, tout étoit prouvé.

Les témoins qui les avoient vues, touchées, ou entendues, fe préfentoient partout fans concert, fans foupçon, ni apparence, foit de crédulité, foit d'impofture.

Les Fideles du fecond fiecle étoient convaincus tant par les faits dont ils étoient témoins eux-mêmes, que par les faits qu'ils tenoient des premiers témoins les plus refpectables de tous. La Grece \& I'Italie, très-probablement la Gaule \& l'Efpagne, avoient vu \& entendu S. Paul, ou S. Marc, ou S. Clément. Les habitants de Lyon joignoient leurs connoiffances perfonnclles au récirqu’Irénée leur faifoit de ce qu'il avoíc va \& entendu du vénérable Polycarpe fon maîcre. Celui-ci rapportoit aux Eglifes d'Ionie les converfations qu'il avoit eues avec $S$. Jean l'Evan7nrar. inif. gélifte, \& avec d'autres Difciples, fur les Ecclef. actions \& fur les paroles du Seigneur. Ces feuls exemples nous en font concevoir dix mille, qui étoient les mêmes par-tout.

Ceux 


\section{DE I A NATURE. 9 ?}

Ceux qui rendoient aux Miniftes de LA D\&1'Evangile le témoignage d'avoir vu leurs MoNstr. cuvres, étoient parfaitement dignes d'ê- ĹVANGLi rre écoutés. C'étoient des hommes faits, qui étoient devenus Chrétiens par choix, $\&$ avec comnoiflance de caufe. Les Juifs convertis avoient, conformément aux avis des Apôtres, comparé les promeffes \& les prophéties avec les événements. Les II. P Gentils avoient vu un concours étonnant ${ }^{19 .}$ d'œuvres merveilleufes qui établiffoient la même miffion.

Perfonne n'ignore combien il y avoir p̧eu à gânner pour les témoins de ces merveilles: \& cette preuve de leur probité a été maniée trop de fois pour avoir befoin d'ètre retouchée. Au-lieu de montrer de nouveau toutes les paffions, \& tous les intérêts humains réunis, pour écrafer les premiers Fideles; arrêtons-nous à ce qu'ils eurent à éprouver de la part de leur propre cœur : nous comprendrons par leurs combatsintéricurs, que la feule force de la vérité en a fait des témoins.

Si vous exceptez une efpece de gens Force di qu'on a de bonne heure accoutumés aux entreprifes hazardeufes par l'attrait du ge rendu pillage, \& en qui le grand ufage des cri. premiers mes a ruiné la confcience, ou éteint le refpect des Loix, tous les hommes font Tome VIII. Part. II. 


\section{L E S P E T T L E}

LA Dé- fortement attachés à la Religion dans lanoxstr. quelle ils ont été élevés. Ils ne tiennent * Vangel. pas moins fortement à leur Patrie \& aux intérêts de leur famille. Il n'eft pas aifé mon plus de rompre les liens qui les attachent à une demeure, à des poffeffions, à des plaifirs, ou à des pratiques dont ils ont contracté une longue habitude. Ce font tous ces liens enfemble qui arrêtent ceuxà qui l'Evangile eft annoncé, \& qui les retiennent d'autant plus fortement que ce font des liens agréables. Comment réfifter à une femme éplorée, qui remontre à fon mari le défaftre inévitable que fa créance va faire tomber fur tout ce qu'il a de cher. On conçoit ici mille obftacles également terribles, qui doivent naturellement rendre l'Evangile infructueux. Je ne vois point d'hommes fur la terre qui ne doivent y apporter une oppofition invincible, s'ils écoutent leurs intérêts, ou feulement leurs préjugés.

T.es pré- Annonce-t-on l'Evangile aux Juifs?

juges des

Juils, elltiérement contraires ^l'Evangiis.
Ils font pleins de vénération pour leurs pratiques extérieures, pour la Loi qui les dittingue des autres Peuples, pour la famille qui exerce le Sacerdoce, pour le Pays que Dieu leur a accordé en propre. Leur Temple eft le lieu que le Seigneur a choifi pour y faire fa demeure. Ils 


\section{E LA NATURE.}

feront à jamais le Peuple de Dieu. Ils font LA DḰles enfants d'Abraham \& d'Ifaac; la pof- Morstr. térité chérie. L'avenir le plus brillant źVAXYeLo leur eft réfervé. Ils attendent un Meflie qui les mettra en honneur, en leur foumettant les Nations. Comparent-ils ces idées avec la docirine évangélique? On leur déclare que la Loi, le Temple, le $\mathrm{Sa}$ cerdoce, \& la conceffion du Pays de Chanaan, ne font que des préparatifs, divins à la vérité, mais paffagers; qui fervoient à régler \& à contenir la Nation dépofitaire des promeffes jufqu’à la manifétation du Meffie; qu'il doit être mis à mort; que fon facrifice fera déformais le feul que Dieu agrée; qu'on n'en célébrera plus d'autre; qu'après cette ocuvre accomplie le Temple va êrre fupprimé, \& le Sacerdoce anéanti; que le Meffie au-lieu d'être le Conquérant des Nations, en va ĉtre le Docteur \& le Sauveur; qu'il va leur communiquer par fes Envoyés le culte du vrai Dieu, \& en faire des enfants d'Abraham par la Foi; que les Juifs, qui fe croyoient le Petiple de Dieu par exclufion, ne feron plus fon Peuple; \& que la Nation qui a abreuvé de fiel \& crucifié fon propre Roi, felon la parole des Proa phetes, va être, felon les mêmes prophéties, arrachée de fa terre natale, pour 
LA DÉ-demeurer clclave \& vagabonde parmi onstr. toutes les Nations.

i'Mnger. Quelles impreffions une telle annonce doit-elle naturellement faire fur les Juifs? Leur premier mouvement cít de ne vouloir ni rien examiner, ni rien voir, ou entendre de ce qu'on leur dit, ou qu'on lcur montre au doigt. Leur zele, qui eft déréglé par l’amour-propre, \& qui n'eft plus qu'une paffion brutale, fe convertic en fureur : \&au-lieu d'écouter les faits, ou de voir le rapport des événements avec les prophéties, ils fe bouchent les yeux \& les oreilles; ils commencent par pourfuivre, même par lapider les Prédicateurs.

On fent ici quelles révolutions ont dû fe faire dans le cour d'un Juif, pour le cétacher de fes premieres penfées, \& pour lui en faire prendre de fi différentes. Qu'un rémoignage a de force quand il eft rendu à une vérité de fait par des cœursqu'elle gagne au milieu de ces préventions! Un Paul, un Silas, un Barnabé, convertis de la forte, ne font ni des fanatiques échauffés dès l'enfance par les difcours de leur famille, ni des indépendants qui fe révoltent contre la Loi de leurs Peres. Ce font des hommes prudents \& de fens raffis, qui comparent les promeffes qu'on leura faites avec les effets qu'ils voient, \& qui, 


\section{DE L A NATURE. IOI}

bien loin de méprifer la Loi de leurs Pe- La Drres, commencent à en fentir la vraie ex- mosstr. cellence, en recevant les biens réels don Évavgeis elle étoic la préparation \& l’annonce.

De là le foin extrême que prend fain Paul dans toutes fes Letres adreflées aus Eglifes où il y avoit berucoup de Juifs convertis, comme dans celles aux Ro= mains \& aux Galates, à plus forte raifon dans l'Epître aux Hébreux, de leur faire obferver dans la Loi done ils avoienc connoiffance, une économie \& des defleins que ni lui, ni eux n'y avoient vus; mais que les événements leur metroient nettement fous les yeux.

Porte-t-on l'Evangile chez les Schifma- Onpontion tiques de Samarie? Ils refpectenc Moile, ritnins at $\&$ ont la Nation Juive en horreur. Ils ne ${ }^{12 E x a n}$.tes, pourront donc ni entendre dire que la Loi de Moile n'a plus d'exercice; ni foutenir la penfée de recevoir des Juifs l'accomplifiement des promefles, \& liannonce du falur.

L'Evangile efr-il porté aux Gentils ? Trtvon. Ils boivent l'iniquité comme l'cau. Poinc Gende de regle qui les gène. Leurs plaitirs au emmer. contraive lont autorifés par la Religion publique, \&z confacrés comme des actions agréables à autant de Divinités fjóciales, qui prenuent foin de les ricom- 


\section{IO2 LE SPECTACLE}

LA Dr-penfer. Les Nations les plus puiffantes fe munstr. Cont toutes préoccupées très-fortement ávariger, de cette penfée, qu'il falloit être fcrupuleufement fideles aux Dieux auteurs de leur profperité, \& fermer févérement la porte à toute Religion etrangère.

Difpon- Porte-t-on l'Evangile datis les écoles timn iles des Puiens? Les Philofophes, thalgré leurs pies. divifons, fe réunthent tous en un poine, qui oft didolatter leur raifon, \& deftimer peu le rapport des fens. Comment recevront-ils une Doctrine dont le premier but eft dhumilier la raifon? comment recevront-i!s une Doctrine qui gît En faits, \& qui n'eft point l'ouvrage de leur intelligence? A coup fur ils rejetteront l'Evangile, \& préferreront leur jugement aux atteflations les plus claires, dont ils fe débarrafferont en traitant les rapporis les plus uniformes de tolis nos fens, de moyens illufoires, \& peu propres à inftruire un Philofophe. Prenez les hommes dans telle Nation \& dans telle façon de virre, ou de penfer qu'il vous plaira : il faut en leur adreffant l'Evangile, les réfoudre à refondre toutes les idées qu'ils ont prifes, pour s'en former de neuves; à renoncer à tout ce qu'une longue habitude \& l'app'audiffement de la coutume paroiffoit rendre auffi eftimable 


\section{DE LA NA T URE, IO3}

que néceffaire. Il falloit tout enfemble les LA Direloudre à embraffer une Religion pleine sionstr. de gravité, une regle impitoyable, qui ÉVAarci, pour remédier au libertinage des fens, \& à la fierté de la raifon, réduifoic la raifon $\&$ les fens en captivicé. Par un nouvenu furcroit d'obftacles, il falloit recevoir des leçons de créance \& de conduite, d'une Nation qu'on favoir deftituée de philofophie, \& à laquelle fon extrême fingularité avoit attiré un mépris univerfel.

Mais de quoi les Emiffaires de cette Nation font-ils porteurs? Ils annoncent au genre-humain qu'il faur reconnoître pour Sauveur \& pour Maîre, un homme qui s'eft dit plus grand que les Prophetes; antérieur à Abraham; mis fous les yeux d'Abraham comme paffant par avance de la mort à la vie; né avant tous les temps dans le fein du Pere; le Fils de l'Homme tour enfemble, \& le Fils de Dieu; l'héritier de toutes chofes; qui s'eft dit la $\mathrm{S}_{2}$ gefle venue d'en hast; qui en un mot s'eft dit Dieu; mais qui a cependant habité parmi nous dans un corps mortel, \& a fouffert la mort. Il eft vrai qu'on l'annonce revenu à la vie: mais il ne paroit pas; \& les biens qu'on proner de 6 part font éloignés \& invifibles.

Veut-on çu’a propes d'un événemene 
104 LE SPECTACLE

la DE- incroyable dans la difpofition où font tous nionstr. les efprits, \& fur la parole de quelques frangel. difcoureurs fans talent, les hommes renoncent à leur façon de vivre, à leurs plaifirs, à tous les agréments d'une Religion brillante \& fenfuelle? Les hommes ne fe mettent pas à l'étroit de gaieté de cœur; il $1{ }^{\prime} \mathrm{y}$ a rien fur-tout dont ils foient plus jaloux que de l'indépendance de leur raifon : \& fi peu, fi peu qu'elle leur ais produit par leurs recherches perfonnel ?es, ils on peine à foufrir ce qu'ils ne peuvent concevoir.

Tels font cependant les facrifices qu'on fait par-tout en devenant Chrétien. Préjugés, habitudes, polfeffions, raifonnements, liberté de fentiments, voilà ce que les hommes mettent par-tout fous leurs pieds. Il faut qu'il y ait eu des événements bien finguliers, pour produire de tous côtés cette révolution : \& l'on peut jugerde la force des motifs qui ont touché les Juifs, les Gentils, les Barbares, les PhiJofophes mêmes, par le renouvellement univerfel qui s'elt fait en cux. Nouvelles idées, nouvelles efpérances manifeftées au dehors par une vie toute nouvelle.

Jefus-Chrift fait entendre à un Docteur de la Loi qui le confultoit, quelle eft la nature de ce renouvellement intérieur qูue 
I) L L N T T R E, 105 l'Evangile doit opérer dans les cœurs: \& ' LA DE-" il compare cette opération fpirituelle au MoNstr. foufle de l'air dont on entend la voix, strixgab. $\&$ dont on reffent les fecouffes, quoi qu'on ne fache nì d'où il part, ni où il fe porte. "Ce n'eft pas affez, dit-il, que joan. 3 : s.

, l'homme renaifie d'eau, (en faifanc par une purification extéricure la déclaration publique de vouloir changer de vie,) 2, mais il faut qu'il renaifle de l'Efprit; , qu'il change d'idées \& d inclinations: que l'Efprit en faffe un homme nouvenu. On ne voit ni d'où provient en lui ce changement, nile terme \& les efpérances où il le conciuit. Mais la force de l'Efpric qui le touche, \& la conviction des biens que le Fidele attend, fe montrent au dehors par une réforme qui embraffe toures fes actions \& fa vie entiere.

Cetre vie admirable qui après les liber. tés \& les énormités précédentes fuivoic perfévéramment le Baptème, étoir done l'expreffion la moins équiroque du changement que la vue des miracles \& la grace veroit d'opérer en cux. Alinfi, quoique la railon fut confondue dans les objets de la révélation, \& que les biens promis furfent invifibles, Dieu honoroit l'intelligence de l'homme, \& vouloit qu'il fit Chrécien par une déternination hige, ers

$$
\text { Li } 7
$$




\section{LE SPECTACLE}

L. Di. le frappant au dehors par des motifs auxMinsire quels la prévention ou les paffions feules EMAGLe pouvoient réfifter.

\section{I I.}

\section{Le ténoignage du Sang.}

Je m'apperçois que j'ai fait fentir par avance tout le mérite du troifieme témoignage, qui eft celui du fang. Car Thomme n'ayant rien de plus à coeur que fa vie, s'il la facrific plutôt que de défavouer ce qu'il a vu, entendu, \& touché, c'eit le plus fort témoignage qui fe puifie produire d'une chofe fenfible. Cette atteftation fe nomme fimplement LE MArsTyne, le tímoignage. Le martyre eft $\mathrm{cn}$ wher la prenve par excelience; parce que fi colle-la n'eft pas reçue en maticre de fait, ou de chofes palpables \& foumires au commun rapport des fens, il ne faut plus recevoir ni dépofitions, ni atteftations. Il $\in f$ impoffible de rien conftater. Lettres de nobleffe, chartres, titres d'acquifitions, prife de poffeffion, lettrespatentes, fceaux, promulgation de Loi, notoriété, tous ces moyens d'être inftruits de ce qui a été vu, de ce qui a été dit ou réglé, deviennent frivoles \& fans validité. Ce font toutes chofes fenfibles : il 


\section{DE I A NATURE. IOT}

n'y faut plus faire fonds. Il n'y a donc La Dáplus de certitude, ni de jufte fécurité en Moxsta. rien. Car fur quoi comprera-t-on done, EYAKGELo fil lon ne reçoit pas le témoignage que plufieurs hommes figes \& de fens rafin , que des hommes de tout îge, de tout éiat, de tout caractere, \& de tout Pays, rendent fans fe connoître, en différents temps, en tous lieux, à des chofes qu'ils. ont vues, on entendues; fans être ébranlis ni par l'infamie, ni par les rigueurs, ni par la perte de la vie. Nous n'avons rien de comparable ì ce témoignage. I! peut y avoir des fous: mais la folie ne fut jamais un mal épidémique.

Rier n'eft fi peu a fa place que le dif- Ce quil Rour g'ent ripou a fa place que le dir- fiut percours qu'on a coutume de rebattre à l'oc-ferdeceus: cafion des Martyrs "du Chriltianifme. yula vul? "Les fauffes Religions, dit-on, , fe vantent une on:" d'avoir eu leurs Martyrs. 110 U1?

Je fais qu'on peut mourir pour le Mahomérifne, \& pour toute opinion dont on s'eft laillé prévenir. Mais mourir pour une chole quion n'a ni vue, ni apprife par des rapports cerrains, c'elt attefler fa perfunfion, non la chole même.

Celui qui meure plutô que de défavouer le voyage de Mahomet au Cicl, dont qui que ce loit n'a ćté témoin, n’attelle que in propre préventión en faveur 


\section{IOS I E S P E C T ACLE}

L.1 Dí- de ce célebre Arabe. Il n'y a point de moxstr. Mahométan qui fe foit jamais donné pour 4yaciala témoin oculaire d'aucune partie de la million du prétendu Prophere. Quelqu'un l'a-t-il accompagné fur l'efcalier de lumiere? Quelqu'un a-t-il vu le grand coq, \& exactement pris fes dimenfions? quelqu'un au défaut du mefurage des cieux fait par lui-même, a-t-il entendu des Lxperts qui lui aient certifié cct arpentage, \& ces curioficés fi peu importantes à la fanctificarion des ames? C'cft trop infifter fur des chofes ridicules. Le Mahométifme, \& toutes les révélations qui fe font paffées dans le fecret, peuvent bien. avoir des Confeffeurs : mais elles n'on: point de Martyrs.

Au contraire quelqu'incroyable que paroiffe un événement, il y a lieu à le démontrer par un témoignage vraiment juridique \& convainquant, lorfque les tćmoins ont pu faire ufage de leurs yeux, de leurs oreilles, \& du concours de tous leurs fens, fur-tout s'ils l'ont fait fans concert, fi d'autres qui ne les connoiffent pas y joignent de femblables témoignagres, même au péril de leur vie.

L'homme ne peut donner une plus grande preuve de fa fincérité, ou de fa perfuafion. Mais comme cette perfuafion 
n'eft rien quand on n'a ni vu, ni appris TA $n$ les faits par le témoignage de ceux qui wonstr. les ont vus; cette perfuafion d'avoir vu LARGLL: \& fuivi les faits, quand elle eft atteftés par la perte de la vie même, eft la plus forte preuve de la réalicé des faits qui fe font paffés fous le foleil. C'cft de la forte que le martyre eft la grande preuve dus Chriftianifme, \& l'équivalent de tous les autres témoignages.

Ceux qui par des motifs que nous nous difpenferons d'approfondir, ont efiayé de réduire les témoins de la vérité de l'Evangile à un très-petit nombre, ont été parfaitement réfutés par les fairs infiuis, \& par les autoricés refpectables que Dom Thierry Ruinard a rapprochés dans la célebre Préface qu'on lit à la tête des Vrais Acies des Martyrs. Ces paradoxes ne font pas moins réfutés par un nombre infinis d'Ecrivains contemporains, \& par une foule de monuments réels, qui pour n'être pas des pieces par écrit, ou des faits détaillés, ne laiffent pas d'être des preuves ingénues des exécutions barbares que le Chriftianifme occifiouna par-tout。 On mettoit les Chrétiens aux prifesavec les bêtes dans toutes les arenes que chaque grande Ville ambitionnoit d'avoir à l'imication de Rome. Les prifons, les ga- 


\section{IIO LE SPECT ACLE}

I. Dé.leres, les carrieres \& les mines étoiene Musitr. remplies de Chrétions. Il y a même pluśvanger. fieurs faits qui démontrent que la haine du Chriftinnime, malgré la douceur \& les précnutions de plufieurs Empereurs modérés, avoit dégénéré par-tout en fureur, it occafionné le maffacre de plufieurs familles à la fois. Je n'en produirai qu'un trait. On retrouve dans les cimetieres qui étoient autrefois hors des portes de nos anciennes Villes, des lieux que la piété des Fideles a toujours difingués par le nom de Cimeticre des Martyis. En y creufant pour faire des fondations, on a fouvent trouvé des tombeaux de tuf, de pierre, ou de craię, dans lefquels fone couchés des fquelettes, avec des cloux enfoncés dans les coudes \&̊ fur la tête, ou avec des broches de fer quil les traverfent par les épaules en fe croifant fous la poitrine. Qualques-uns de ces tombeaux fe font trouvés affez fpacieus pour contenir à la fois plufieurs grands corps, \& plufieurs petits d'une caille inégale. (a) Prefque tous portent des marques d'une femblable cruauté. On voir ce que cela fignifie. On n'a jamais faic foufirir aux enfants des malfaiteurs, la peine due aux crimes

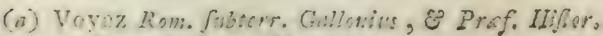
Bdoropol. Rewenf. Downi DIWWlut. 


\section{DE LA NATURE. IIT}

de leurs peres: \& la fépulture honorable $L A$ D'́qui fe refufe aux fcélérats, a vifiblement moxsta. été procurée à ces familles, par le même LVaxGEL Efprit qui eut la force de demander à $\mathrm{Pi}$ late le corps de Jesus, \& de le dépoler avec diftinction dans un caveau qui n'avoit pas encore fervi.

Les Auteurs des trois premiers fiecles, \& les trois anciens Continents, font pleins non de veftiges équivoques, mais de monuments très-expreflffs de la contance $\&$ du nombre de ceux qui on donné leur fang plutôt que de délavouer les faits done ils étoient parfaitement inftruits. Dhabiles Critiques (a) en ont recucilli \& fait valoir les preures, en écartant non-feulement le faux, mais même l'incertain.

Cetie preuve qui eft proprement le cémoignage des témoignages, s'eft accrue comme le nombre des Chrériens, \& s'ent: fortifiée trois cents ans de fuite. L'œuvre du falut avoit déja ceffé d'être locale, par l'univerfalité de la prédication : mais comme toute la terre a encendu les Prćdicateurs, \& vérifié leurs écrits; toute la terre a vu couler le fang des tómoins: \& Jefus-Chrift avoic donné par avance it ce témoignage une force invincible, en prophétifant contre toutc vraifemblance,

(a) Aurien Baillet, Claude Pleury, stes Hodnandires. 
II LE SPECTACLE

La Dé- qu'il lui feroit rendu devant les Tribumoxitr. naux des Juifs \& des Gentils.

Binfiel. Par tout ce qui précede, il eft fenfible qu'on ne peut raifonnablement douter de la coexiftence des Livres du Nouvenu Teftament, \& des Eglifes qui nous les ont uniformément attcités \& tranfmis, Les témoignages rendus par le Pereà fon Fils \& à les Envoyés, font également fùrs, puifquiils font rapportés par ces Livies, \& en même tcmps remplacés aux yeux de toute la terre, tant par le changement des Nations converties, que par la mort conftante d'une foule de témoins.

\section{O B J E C T I O N.}

Voici ce que j’ai oui avancer de plus fpécieux pour infirmer cette preuve, par des perfonnes qui avec beaucoup de jufteffe \& de conféquence dans l'efprit, ne laiffoient pas d'héfiter fur la certicude de la révélation, par un effei de l'habitude où nous fommes tous de perdre de vue Ies preuves claires quand notre raifon $y$ oppole une derni-lueur, ou feulement quelques obfcurités.

Nous ne difconvenons nullement, difoient-ils, que l'Evangile n'ait une parfaite proportion avec les befoins de l"hommes 


\section{DE LA NATURE. II}

foit pour humilier fa raifon préfomptueufe LA $D$ :en l'affujetriffant à la regle de la révéla- nosistr. tion; foit pour inclincr fon cœur à la Ĺvingeto pratique de toutes les vertus nécellaires à la fociété, en lui en préfentant les exemples les plus forts, \& les motifs les plus touchants. En ce fens nous applaudirons toujours au Chriftianifme. Nous n'avons point d'amis plus folides que les vrais Chrétiens. Nous avouons encore, à la gloire de l'Evangile, qu'en le mettant en parallele avec la doctrine des hommes les plus judicieux, tels qu'ont été Socrate \& Confucius; celle-ci elt froide \& deftitúe d'encouragement, n'ayant rien de plus pout animer nos efpérances que quelques raifonnements conformes au goute d'un petit nombre de perfones qui rélléchifo fent, mais fupérieurs à la porrée du commun des hommes. Or qu'eft-ce qu'une morale qui n'elt que pour les Philofo. phes; pour des gens qui fe croient tous capables d'en faire une autre encore plus belle? Au-lieu que la morale de JefusChrift eft intelligible aux plus petits. II ne fe pouvoit rien concevoir de plus popuInire, que de nous montrer l'un d'entre nous déja placé dans la gloire qui eft réfervée aux autres. Mais ce n'clt pas affiz que l'annonce de cerce auvre foit belle 


\section{LE SPECTACLI}

LA Dé- \& touchante, il faut pouvoir en admi. Monstr. niftrer les preuves dans tousles temps; \& SVLNGEL. c'eft ce qui ne paroît pas facile aujourd'hui.

Si l'Evangile s'annonçoit comme une fimple Hiftoire, ou comme un Traité de Philofophie, nous ne ferions pas étonnés d'en voir paroître des interprétations différentes, ou des preuves plus ou moins vraifemblables. Mais on nous préfente I'Evangile comme une alliance que Dieu fait avec l'homme. Et dans la vérité il le faut pour le befoin de la multitude qui fe perd dans une opinion difputable, mais qui entend très-bien les promeffes faites à Abraham, \& l'alliance prélentée par fon defcendant à tout le genre-humain. Or il n'y a point d'alliance fans ambaffade; \&: cette ambaffade doit néceffairement être une comme l'intention de celui qui l'envoie. Comment done accorderons-nous l'indilpenfable unité de la miffion avec la multiplicité des minifteres qui changent la doctrine, qui s'entre-condamnent, \& qui cependant nous difent tous avec une égale confiance : Vinzz à nous, nous fommes les Envoyés?

Quand enfin il refteroit dans la fociété un miniftere qui s'y montrît avec des margues plus avantageufes que n'en ont 


\section{DE I A NATURE. II}

les Auteurs des nouvelles fectes, il fau- La DÉdioit que ce miniftere pût prouver fon MrossTR. envoi comme le Parlement de Paris prouve śVANGR. fa royale inftitution; ou par fes Lettres-patentes, ou en remplaçant la lecture de celles-ci par fon Greffe, par fes privileges, \&r par les atteftations perpécuelles de cour ce qui l'environne. En cela le Parlement ne fe rend pas témoignage à luimême; il n'eft que porteur des témoignages qu'il a d'abord reçus, \& continuể de recevoir. Whais en eft-il de même du miniftere évangélique? peut-il aujourd'hui faire reviure les témoignages des œuvres de l'Efprit; \& les témoignages humains qui ont été rendus à l'oeuvre évangélique? Quand il feroit réel qu'ils ont été rendus: ce n'eft plus qu'une trèsancienne renommée: il n'eft plus poffible de les dilcuter, ni de les compareravec ce qui en pouvoit fürement montrer la force, ou l'invalidité. Le tout eft fi loin de nous, que c'eft comme s'il n'éroit plus.

Mais fi l'éloignement \& la difficulté d'échaircir les preuves de la miffion en one miné la certicude, les Porteurs de l'allian$c c$, quels qu'ils foient, n'ont plus que des oul-dire, pour alléguer les droits qu'ils s'attribuent. Ils fe rendent témoignage à cux-mêmes, au-lieu de fe préfen- 
I16 LES PECTACLE

LA Dé- ter à la fuite d'un témoignage quiles pré. moxsta. vicnne: \& l'Evangile n'étant plusqu'une syangel. affaire de raifonnement, nous ne lui voyons plus d'autre nérite que la fingularité des hazards. Il en fera comme de la métemplycole de Pythagore, qui a trouvé grace chez les Bramines; ou de cette beauté intelleçuelle de la vertu, qui toucha Socrate, \& après lui quelques fectateurs capables de penier.

Il ne liffic donc pas, ajoute-t-on, de produire, comme l'ont fait tant d'Ecrivains, les preuves de la Religion Chrétienne. Le commun des hommes ni ne lit, ni ne peut entendre ces difcufions: \& ceux qui y trouvent le plus de vraifemblance, ne font pas beaucoup plus avancés. Le principal point leur manque.

La Religion Chrétienne fe donnant en effer pour être eflentiellement l'alliance de Dieu avec les hommes, c'eft de cette alliance qu'il faut adminifter la preuve toujours vivante, toujours intelligible aux moins inftruits, comme aux plus Savants. Il faut lcur montrer une commiffion donnée \& clairement perpéruée : car on ne peut ĉtre fùr ni des vrais articles de l'alliance que par ceux qui ont la commiffion de l'annoncer; ni fur-tout de la réalité de leurs pouvoirs, que par des 


\section{DE L A NA T URE. II?}

témoignages qui fe puiffent toujoursvéri- LA Dŕfier. Mais fi les Lettres de créance, ou Mosstr. les témoignnages équivalents ne fubfiftent śvavgeL.'. plus, comment nous les produira-t-on? Nous n'avons point vu les œuvres de l'Efprit qui pouvoient prouver la miflion: nous n'avons point vu couler le fang des témoins qui en éroit comme le remplacement. Les actes de leur martyre font perdus, \& des légendes communément fabuleufes en ont pris la place. Le miniftere reftant fans preuve, l'Evangile peutil paffer pour une alliance réelle; \& n'avons-nous pas un jufte fujet de craindre que le cout ne dégénere en illufion?

Pour répondre à cette difficulté qui eft très-preflunte, \& qui fuppofe notre propre divifion de matieres, c'eft une néceffité indifpenfable de montrer la perpétuité du miniftere qui eft porteur de l'alliance, \& la perpétuité des témoignages qui garantiffent l'un \& l'autre à toutesles générations.

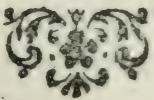


II LE SPECTACLE

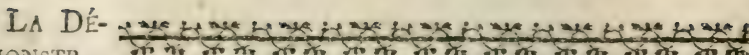
MONSTR. ÉVANGEL.

\section{HAP I T RE III.}

La perpétuité des Témoignages rendus au Miniftere évangélique.

Ette multiplicité de fectes détachées du corps de l'Eglife, qui indifpofe tant de perfonnes, ne déshonore que l'efprit particulier qui en eft l'auteur, \& n'affoiblit en rien la certitude du Chriftianifine. Le gouvernement d'un Etat ceffe-t-il d'être unique \& reconnoiffable, parce qu'il fe montre dans quelques Provinces des troupes de mécontents, qui fans avoir entre elles aucuns liens, ont chacune à part leur banniere, leur nom, \& leur méthode?

On peut divifer le nom Chrétien:Marcion, Manès, \& Arius fe peuvent dire Chrétiens : mais on ne peut non plus divifer le Chriftianifme, qu'on ne peut divifer l'Apoftolat. Il n'y a qu'un Dieu, qu'un Médiateur, qu'une alliance, une foi, \& un corps très-connu d'Ambaffadeurs qui fera le même pour tous les fiecles. Où fera l'Apoftolar, là fera le Chriftianifme.

Les auteurs \& les fauteurs des fchifmes font voir qu'ils ne connoiffent pas, ou 


\section{D $\approx$ I A NA TURE.}

n'exécutent pas la volonté de leur Mầ- La Dítre, qui n'a pas mis dans la bouche de monstr. fes Envoyés des paroles de contradiction, ÉYNGEL. ni faic partir plufieurs Ambaffades au-lieu d'une. Il faut donc que les Miniftres fchifmatiques ou n'aient point reçu de pouvoirs, ce qui rend leurs plus beaux talents inutiles pour le falut de ceux quiles écoutent; ou qu'ils aient perdu à notre égnrd le droit d'être écoutés, en exerçant à l'écart \& dans l'indépendance, une mifion qui devoit s'adreffer en tout temps à l'Univers entier, \& s'exercer folidairement.

Les deux grands objets qui ont occupé le Sauvenr fur la terre, font la rédemption du genre-humain parfon fang; \& le foin d'établir un miniftere capable par les leçons \& par la forme qu'il lui donna de Pricistions de T. C. pour rerdre fa milion toujours porter à tous les Peuples les mêmes do- fable. gmes avec les preuves de cetenvoi. C'eft pour prévenir toutes les démarches arbitraires de la raifon humaine; c'eft pour fixer à jamais les Fideles par le moyen le plus familier \& le plus fùr, que JefusChrift a adreffé à toutes les Nations \& à tous les fiecles fon A poftolat, c'eft-à-dire, un corps d'Ambafindeurs indiffoluble \& immortel.

Dans le deffein de former fon Eglife de Juifs \& de Samaritains, de Grecs \& 


\section{I20 LE SPECT A C L E}

LA Dś-de Barbares, il ne commença point par moNSTR. leur préfenter un Livre, parce qu'un Livre r VANGEL peut être fufpect aux uns, irintelligible pour d'autres, \& différemment entendu. Il ne jugea pas à propos de leur préfenter un Prídicateur unique, parce que cet Envoyé n'auroit puêtre préfent par-tout, $\&$ qu'il auroit pu abufer de fon pouvoir fe voyant feul chargé de l'œuvre. Mais il leur adreffa un corps de Députés, auxquels il avoit commandé d'annoncer conjointement, \& jufqu’à la fin des fiecles, ce qu'il leur avoit prefcrit; foit en le publiant de vive voix, foit en le mettant par écrit.

Ce miniftere auquel Jefus-Chrift luimême a donné le titre d'Ambaffade, quos zne.6:13. É Apoftolos nominavit, coupe pied à toutes les entreprifes de l'efprit de l'homme, puifqu'il eft comme les autres minifteres inftitués par mariere de compagnie; inftitution dont l'effet, comme l'intention nozoire, eft de prévenir, ou de fupprimer les nouveautés Es les vules perfonnelles. Il faut en même temps, puifque ce miniftere doit être perpétuel, que fes preuvesl'accompagnent \& le rendent toujours reconnoiffable. Le moyen de juftifier la perpétuicé du miniftere de fes preuves eft fous nos yeux. Il eft dans toure la fociéré. 
DE LA NATURE. I2T

Les exemples s'en trouvent dans chaque LA DENacion, dans chaque Province, \& dans mossra. chaqueVille.Quand nous lifons dans l'Hif- Ívanciet. toire de France, quel Roi a rendu le Parlement de laris fédentaire, qu'on ajoute à quelle intention il fit cet établiffement, à la décharge de qui, avec quelles obligations \& quelles attributions; nous devenons certains de la vérité de cette Hiftoire, en voyanc le même corps fe foutenirjufqu'aujourd'hui avec toutes les marques publiques de fa royale infticution. Certe Hiftoire par elle-même ne fait point preuve; mais elle eft prouvée par les rémoignages fublëquents \& permanents. Demême, nous trouvons la miflion évangélique dans une Hiftoire auffi ancienne que l'Eglife, \&r avouée de toutes les Socićrés qui fe font dic Chrétiennes dès le premier fiecle. Nous ne produifons point cetre Hittoire pour preuve de l'établiffement du Miniftere Apoftolique: moins encore avons-nous recours à l'infpiration des Livres qui la contiennenc. Indépendamment de l'efprit qui en a dirigé les Ecrivains, leur Hiftoire ne peut manquer d'accufer jufte à l'égard du Niniftere unique \& immortel, fi cet établiffement qu'elle rapporte fe perpétue dans tous les fiecles: soujoufrs dans fa premiere forme, toujouls

Tonk Flli. Part. H. F' 
122 LE S P E T A L E

L. Dé-accompagné des témoignages qui le renmonstr. dent reconnoiffable, \& qui n’autorifent trangel. que lui. Commençons par les traits qui caractérifent la miffion dans le récit de tous les Evangéliftes. Nous en verrons enfuite les effets juftificatifs \& perpétuels dans la fociété.

$I^{\circ}$. Jefus-Chrift en quittant la terre, n'adreffa rien aux hommes par écrit : mais il leur adreffa l'Apoftolat. Auffi l'Eglife fut-elle formée avant que la parole de la prédication fût écrite; \& jamais aucune Eglife n'a été formée par la lecture d'un Livre, mais par la prédication nom. 10: des Envoyés. La Foi vient de l'ouie $\xi_{0}$ de 37.

la parole qui a été prếchée.

Quand bien même les Prédicateurs auroient préfenté d'abord un Traité écrit, encore auroit-il fallu préalablement faire connoitre leur perfonne, \& certifier le 'Traité par la juftification de leur envoi. Cela fe pratique chez les Peuples policés, $\&$ chez les Peuples barbares : parce que tous veulent être fûr's des perfonnes avec qui ils traitent. L'Apoftolat devance donc l'Ecriture.

$2^{\circ}$. Jefus-Chrift en établiffant le Miniftere n'a point parlé à un feul Miniftre, mais à plufieurs enfemble. Ite. Docete. C'eft donc un corps d'Ambaffade qu'il 


\section{DE L A NATURE. 123}

envoie, \& qu'il nous faudra retrouver. LA DE-

$3^{\circ}$. La commifion de ce corps em- Monstr. brafle toute la terre. Docete omnes gentes. ÉrANGLi. Le Miniftere n'ert donc point local dans fa totalité. Il n'eft point comme le Sacerdoce Lévitique, attaché à une Ville \& à un Temple unique. Il eft univerfel.

$4^{\circ}$. Quoique difperfé par-tout, ce Miniftere eft étroitement aftreint à une doctrine unique, \& porteur précifément des mêmes intentions, comme doivent l'être tous ceux qui compofent une Ambaffade, ou une Magiftrature. On ne les met en corps, on ne les affujettit à la loi des correfpondances $\&$ de la fubordination, que pour empêcher le partage $\&$ les caprices de l'efprit particulier. Docentes eos fervare omnia qucecumque mandavi vobis.

Il y aura donc concert \& folidité dans le Miniftere : fans quoi nulle uniformité dans la commiffion, nulle certitude dans le T'raité; chacun le pouvant interpréter à fa façon, s'il fait fon ceuvre à part, \& fans en être comptable envers fa compagnie.

$5^{\circ}$. Jefus-Chrift en écablifrant des Parteurs \& des Docteurs, leur promit fon affiftance pour tous les jours jufqu'à la confommation des temps: Ecce ego vobifcum fum omnibus diebus ufque ad confummationem freculi. C'eft donc une légation 


\section{I24 LE SPECTACLE}

Li Di-permanente \& une ouvre immortelle. Mokstr. Si la légation ne fubfifte plus, toute cette ÉYANGLL. ceuvre elt fans réalité : \& fi cette cuvre dure jufqu'à la fin destemps, elle fe perpécue par une ambaffade qui ne peut être qu'une d'un bout du monde à l'autre. En fuivant littéralement les paroles de l'Inftituteur, voilà une compagnie mife en regle, qui a pour objet le falut des hommes par la participation de la doctrine \& des mérices du Chrift ; pour département, toute la terre; pour durée, tous les fiecles; pour premier devoir, de ne dire quue ce que la premiere légation a reçu de fon Inftituteur. Mais on appercoir qu'il funt ici quelque chofe de plus. Proifque le Niniftere Chrétien eft une compagnie établie à demeure \& pour toujours, elle doit, comme toutes les autres, avoir les moyens de créance qui autorifent \& font connoître, même long-temps après l'infticution, toutes les Compagnies pormanentes. Ces moyens fon deux. 1. Ln publicité du Miniftere \& de fes pretives. $2^{\circ}$. L'unité des Miniftres, ou leur fubordination qui n'en fait qu'un corps.

La publicité met au grand jour les témoignages qui font rendus à la mifion : 8. l'unité ou la fubordination réguliere des membres qui agiffent chacun à leur 


\section{DE LA NATURE, 125}

maniere au nom d'une compagnie \& de LA Díla part du Légiflateur qui l'a autorifée, MoxsTr. manifefte le légitime ufage d'un même ĹVANGEL. pouvoir, quoiqu'exercé par différentes perfonnes, en difrérents temps \& en diffé. rents lieux. Ceux cui font hors de cette unité, ou n'ont rien reçu, ou abufent de tout. Ici rien n'eft arbitraire : ces regles font faites avant nous; elles font avant l'Eglife Chrétienne, \& font les mêmes par-tout. Ce fontles Loix de l'humanité; c'eft par elles que les hommes font fùrs de leur état : \& le Verbe en fe faifant homme, a conformé l'établiffement de fon Eglife aux moyens qui notifient tous les établiflements. Il s'eft bien. gardé de foumettre fon alliance \& fes volontés à l'examen des Philofophes, ou à la décifion des beaux efprits, qui font à cet égard auffi ignorants que le refte des hommes, \& plus dangereux, parce qu'ils font plus fuffifants \& plus fufceptibles de vues paffionnées : mais il a préfenté fon alliance \& les vrais biens à tous les hommes par la voie qui fait leur fùreté, par un miniftere public \& autorifé.

Qu'un hommes'érige en Ambaffideur. ou entreprenne d'établir une chambre de Judicature, en s'affociant des Collegues \& des Subalternes; on n'y a point d'égard. 


\section{LE SPECTACLE}

$L_{A}$ DÉ-parce qu'on fait d'où il vient, ou qqu'on Monstr. Lait même très-certainement par le fimÉVANGEL ple défaut de témoignage, qu'il s'eft alrogé ce pouvoir, \& qu'il n'en a point de réel qu'il puiffe communiquer à qui que ce foit.

D'une autre part, qu'un membre légitime du Sénat de Genes, ou de quelqu'autre Confeil public, entreprenne de former un Tribunal à part, pour régler d'une façon nouvelle les affaires d'une Vallée ou d'un Bourg, \& qu'il veuille pour cela fe rendre indépendant du corps dont il s'eft détaché; fon entreprife eft vaine. L'homme le plus ignorant peut en fentir l'infuffifance. Chacun fait la nouveauté de ce démembrement. Il porte un nom différent du Sénat de Genes, \& il n'eft ni avoué ni fouffert: ou s'il fe prévaut de quelques fupports pour fe maintenir, il ne peut ni anéantir l'autorité de l'ancien Sénat, ni tranfmettre à d'autres un pouYoir légitime.

L'auteurde la premiere entreprife s'arroge ce qu'il n'a point reçu : l'auteur de la feconde abufe vifiblement de ce qu'il a. Le premier ne pouvoit devenir juge qu'étant incorporé à la compagnie qui a les pouvoirs; \& l'autre, quoiqu'Envoyé, perd le fruit de fa miffion, parce qu'il ne 
l'exerce pas conjointement avec les autres LA DEEnvoyés, \& conformément à l'inftitution sionstr. du Miniftere commun. On fait le lieu \& ÉVANGer. le jour oì il a commencé à faire bande à part. Depuis ce jour-là fon cuvre a ceffé d'être celle du corps dont il s'eft retiré.

- Par une fuice néceffaire de ces regles univerfellement reçues, il nous eft à tous auffi aifé de favoir s'il y a un Traité d'alliance qui nous réconcilie avec Dieu, que de favoir s'il y a un Traité de paix entre la France \& la Hollande. Ce n'eft point pour nous une recherche pénible de favoir où eft le miniftere qui met l'homme en fociété avec Dieu par Jelus-Chrift. Il eft public : il fe préfente avec tous les témoignages dans l'Eglife, qui a notoirement étendu fa foi à tous les temps \& à tous les lieux.

Nous n'avons pas befoin de montrer en détail que telle \& telle fociété, comme celle des Ebionites, celle des Manichéens, celle des Ariens, ne font point l'Eglife de Jefus-Chrift; puifque le Miniftere qui les a aftemblées eft de nouvelle introduction, \& qu'il a prétendu, contre toute regle, dégrader le Miniftere ancien qui étoit immortel, pour fe mettre en fa place. Nous n'avons pas befoin de montrer qua Ia fociété des Coptes, ou celle des 


\section{LE SPECTACLZ}

L. Dé-Arméniens, n'eft pas l'Eglife de Dieu; MONSTR. puifque le Miniftere qui les gouverne, sangel. quoique provenu de la vraie Eglife, a rompu avec le corps de l'ambaffade univerfelle, \& condamne comme anéanti un Miniftere qui continue jufqu’à la fin des fiecles à fruetifier d'un bour du monde à l'autre. L'Eglife Catholique eft celle qui fait porter la parole de vie à toute créa-

Marc. 16: ture; celle qui montre l'ancienne \& im35. mortelle ambaffade; toujours reconnoiffable par ce qui a toujours caractérifé tonte ambaffade; je veux dire par la publicité des témoignages q̨ui l'accompa. gnent, \& par l'unité qui éleve les actions de plufieurs Miniftres à la gloire de devenir les actions du corps entier.

\section{I.}

La publicité du Miniftere Catholique, E de l'Eglife Catholique.

C'eft un langage fynonyme de dire que l'Eglife Catholique, ou que le Minifrere Catholique fe montre en tout temps \& à toute la terre, avec des témoignages parfaitement clairs \& certains. En effer, quoique l'E glife foit fort différente du Miniftere; quoique les Fideles qui compofens 


\section{B E L A NATURE. IIS}

l'Eglife n'aient reçu ni conféquemment LA Dé. pu donner de pouvoirs à perfonne, \& Moxistr. que le miniftere lui vienne néceffairement warick de Dieu, qui a daigné traiter avec elle, c'eft pour elle qu'eft le Miniftere, c'eft pour elle que font les Envoyés \& le Chef de la miflion : Ominia veftra funt, five I. Cor. 3 * Apollo, five Cephas. C'elt par ce Minif- ${ }^{22 .}$ tere qu'clle jouit de tous ces tirres. Elle n'eft fùre des biens qui s'acquierent chez clle, \& ne les promet avec confiance, que par la certitude où elle eft de la fainteté de fon Miniftere. Elle confefle que c'eft Tefus-Chrift qui eft l'auteur \& le confommateur de fa foi; qu'il eft le IVar̂tre unique de qui elle tient fa Doctrine; qu'il eft le modele de fes mœurs \& le principe de fa juftice : c'eft par lui qu'elle eft fainte, $\&$ que la fainteté eft en tout temps communiquée au moins à un nombre de fes membres. Mais comme il n'y auroit point d'slliance pour elle ni pour perfonne s'il n'y avoit point d'Envoyés, elle eft autorifée à fe dire l'Eglife faince, unique, \& Catholique, s'il eft notoire qu'elle a reçus l'unique ambaflade qui apporte aux hommes la bonne nouvelle \&r les biens de l'allince. De cette forte, elle a la fainteté intéricure que l'Efprit-Sain: communique sux juftes, \& qui ne fe voit pas. Elle a en 


\section{LE SPECTACLE}

LA DÉ- même temps la fainteté extérieure \& fenMonstr. fible, qui eft l'avantage de tout le corps, \& śVANGEL. à laquelle tous les particuliers, même les maurais Chrétiens, ont part; étant notoirement unis au Miniftere qui a les pouvoirs. Elle connoît \& annonce les titres qui la diftinguent, parce que c'eft chez elle, \& uniquement chez elle que fe retrouve la forme conftance de la premiere \& irrévocable miffion. Perfonne ne peut ignorer que la forme réguliere \& conftante des établiffements publics eft ce qui en maintient le fond \& qui en montre les pouvoirs, tant qu'ils ne font point révoqués. Cette forme ôtée, la fociété ne fair plus à quoi s'en tenir. Si donc il y a un Apoftolar immortel, nous devons par la forme excérieure du Minifo tere qui perpétue le premier envoi, retrouver fans équivoque la vraie Eglife que ce Miniftere eil venu former \& fervir. A côté du Miniftere nous devons retrouver la perpétuité très-fenfible des preuves qui ont d'abord maniftété la mifion, \& établi le Chriftianifme. Ajoutons que les progrès de cette perpétuité qui fe retrouve uniquement dans l'Eglife Catholique, font les mêmes que dans une compagnie de Judicature, \& dans une Chambre Souveraine gu'on recounoit long-temps 
DE LA NA T URE. 13 I

après fon établiffement fans ambiguité \& LA Dŕ-

fans crainte de méprife. Cette efpece de monstr. tradition, ou de tranfmiflion, qui ne de- Évangel. mande ni Livres ni lectures pour être entendue, n'eft pas feulement publique, mais infaillible. Elle tient à des élections, à des réceptions, à des actes publics, à des bâtiments dont chacun fait l'ufage; à tant de moyens confpirants \& permanents, qu'il ne fe peut rien trouver de plus certain dans la Société.

La lecture des Lettres d'établiffement ne fe réitere pas tous les jours: elle n'a même été faice qu'au commencement, \& ne fe demande plus. Cing cents, ou cinq mille témoins, la chofe eft indifférence, ont d'abord entendu faire cette lecture, Leur témoignage eft enfuite remplacé par l'atteftation de ceux qu'ils en ont inftruits: par l'exercice même des Miniftres qui commencent l'établiffement; par l'incorporation publique de ceux quileur fuccedent, \& qui rempliffent les places vacantes; par l'acquiefcement des Peuples qui portent leurs affaires à ce Tribunal; par la diftinction des Chambres, \& des affaires dont elles connoiffent; par la diverfité des fonctions aflignées aux dirrérents membres qui les compolent; par la perpétuité des lieux, desufages, des habirs, \& 


\section{IJ LE SPECTHCLE}

- La D's-des privilegges qui leur font affectés. Is MoNsTr. concours de ces circonftances eft équivaÉVANGEL. lent à la réitération journaliere des témoignages de l'établiffement : il y fupplée.

Les pouvoirs accordés par la Puifance légiflative dans les affaires temporelles, ne font pas plus vifibles que les droits \& l'envoï du Miniftere Catholique : \& comme ces pouvoirs temporels font atteftés extérieurement par des marques durables, les droits de l'Eglife Catholique fe produifent avec la mểme évidence par la confervation de fon extérieur, \& par la publicité des témoignages rendus d'un jour à l'autre à fon miniftere. Suivons. cetre comparaifon dans quelque détail.

Fernctuiré Les cinq cents Difciples qui eurent le

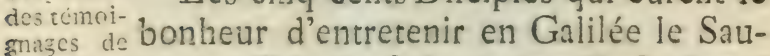
j'icipritqui veur reffúcité, \& les huit mille Juifs qqui a forné 1'eglifeca- fe convertirent aux premieres prédicathuligue, tions de S. Pierre, appuyées des merveilles de l'Efprit-Saint, voilà avec les Apôtres les premiers garants de la miffion de Jefus-Chrift. Les autres Fideles. qui grofilirent bientôt l'Eglife de Jérufalem, conjointement avec ceux qui dans. zoute la Judée dépofoient ce qu'ils avoient vu \& entendu; voila les nouveaux témoins de l'œuvre du Meffie, \& des: pouvoirs $\Lambda$ poftoliques. C'eft par eux que: 
commencela publicité. Cinq centsoucing La Domille témoins de la réfurrection, huic MuNstr. mille ou quatre-vingt mille témoins de Evangabs la defcente du Saint-Efprit, c'eft la même chofe pour les fiecles fuivants; parce que les uns \& les autres étant morts, leur témoignage a dî̀ être remplacé par ceux qui les ont ouis : or, nous fommes auffi furs d'une atteftation univerfellement rendue au rapport uniforme de cinq cents témoins, que de celle qui auroit été rendue à cinq mille.

Si cependant on veut qu'il y ait, même pour nous, plus de certicude dansles atteftarions rendues par les Fideles du premier âge au récit de cinq mille témoins de la réfurrection, qu'à celui de cinq cents; \& à quatre-vingt mille témoins des merveilles de l'Efprit-Saint qu'à huit mille; je disque l'E glife jouit de cet avantage, \& d'un avantage fort fupérieur. Elle a publié \& tranfmis par des moyens fûrs à tous les âges fuivants, les dépofitions non de quelques centaines, ou de quelques milliers de témoins de la premiere miffion; mais d'une vraie nuée de témoing non fufpects.

Ils ne font point fufpects, parce qu'il ne peut y avoir ni illufion dans ce qu'ils ont vu publiquement, ni collufion dans 


\section{LE S P E C T A C L E}

LA DS- le rapport de gens qui ne fe connoiffoient MoxsTr. pas. Ce n'eft pas un événement unique, Evaxcer.. attefté par les habitants d'une feule Ville, mais divers événements que des témoins fans nombre affurent avoir vus en différents Pays, dans des Villes célebres, dans une longue fuite d'années; \& tous événements qui fuppofent le même pouvoir, qui tendent à la même fin. Il eft égal d'avoir vu Lazare forti du tombeau après quatre jours de fépulture, ou d'avoir vu le Sauveur reffufcité. Plufieurs ont vu les merveilles \& les premiers dons de l'Efprit: d'autres ont vu les réfurrections opérées à - Joppé \& à Troade; d’autres des miracles auffi peu équivoques: plufieurs les ont vus la plupart. Or attefter par troupes les faits poftérieurs, c'eft attefter la réfurrection \& l'effulion des dons de l'ECprit-Saint, dont ils font les effers \& les preuves. De cette forte, les premiers témoins non-feulement ne font point fufpects, mais fe trouvent réellement innombrables. La réfurrection du Sauveur, \& la miffion Evangélique, acquierent par ce moyen une illuftration qui s'étend \& fe perpétue de toute part.

L'Eglife formée à Jćrufalem ne ceffe de communiquer fes témoignages \& les prouves aux autres Eglifes naiffantes, qui 


\section{E I A NA TUR E. I35}

lui en rendent d'auffi touchants. Tout s'op- $L_{A} D$ pofe à cette correfpondance : \& elle s'é- Micisir. tablit avec une facilité qui $\in$ ft elle-mêrne ÉvAnGEL un prodige. La haine n'empêche pas les Samaritains de recevoir des Juifs le faluc que ceux ci annoncent. La jaloufie n'empêche pas l'Eglife de Jérufalem de fe réjouir à la nouvelle que l'Éprit-Saint, qui avoit manifefté parmi cux fa préfence, s'étoit communiqué de même aux nouvenux Fideles de Samarie. Quand on connoît les préjugés \& les dédains des Ifraélites à l'égard des Nations idolâtres, on fent que la feule force de la vérité a pu porter les Juifs \& les Samaritains convertis, à glorifier Dieu de ce qu'il avoit fait part aux Gentils du don de la péni-Aò.rx: 1s. tence pour les conduire à la vie; au-lieu qu'auparavant ils s'attendoient que leur Meffie n'auroit affaire aux autres Nations que pour les écrafer, ou pour les metre en fervitude.

Les Grecs d'Antioche, quoiqu'accoutumés à un langage poli, \& à des difcours favants, ne s'offenfent point de la fimplicité de ceux quileur apportent l'heureufe nouvelle. La vérité leur fuffir, avec ce qui en eft la marque. L'évidence des fairs l'emporte donc par-tout fur les haines nationales, fur le mépris qu'on faifoit 


\section{I30 LE SPEC T ACLE}

LA DE- des Juifs, \& fur la doetrine de la Croix, MIONSTR. qui, féparće de fes preuves, paroiffoit une anncel. extravagance. Tous ne font plus qu'un Peuple, une même ame, un même nom. Leur gloire n'eft plus d'être habitants de Jérufalem ou d'Antioche. L'Eglife eft formée. En quelque licu qu'on foit, on peut prendre naiffance dans cette Ville, \& en PGăkis. 86. être Citoyen.

Une telle publicité eft incomparablement plus grande que n'auroit été celle d'une apparition du Sauveur, vu après fa réfurrection dans le Temple de Jérufalem en préfence de vingt mille habitants. $\mathrm{Ce}$ n'eût été qu'un fair : \& pour éluder une rencontre unique on allégueroic les illufions des fens, la magie, la fafcination. Nous ne ferions pas, à beaucoup près, auffi touchés aujourd'hui du témoignage rendu dans le fiecle fuivant au récit de cette apparition par les enfants des premiers témoins, que nous le fommes des témoignages rendus fans concertà la prédication Apoftolique par ces Eglifes nombreufes, contre leurs inclinations, malgré leurs préjugés, malgré leurs querelles, malgré l'intérêt le plus capital. Er de peur que vous ne vous teniez fur la défiance à l'égard du Livre qui raconte quaelques-uns de ces faits arrivés à Lydda, 
DE LA NA T URE. I3?.

'̇ Joppé, à Damas, à Salamine, à Ico- LA Désnium, à Troade, à Philippes, à Thefla- nonstr. lonique, à Corinthe, à Malthe, ou à Ro-Évanger. me; c'eft précifément dans ces lieux que fe forment fubitement des Eglifes que les profanes y ont connues \& atteftées, qui fubfiftent encore, \& qui ont garanti tant Jes faits, que l'hiftoire qui les rapporte. C'eft ainfi que les Duché \& Comté de Bourgogne font encore la preuve juftificative de l'Hiftoire qui établit les Bourguignons dans ces quartiers. C'eft ainf que le changement du nom de Gaule en celui de France, juftifie l'hiftoire qui incorpore les Rois Francs aux armées Romaines, \& qui nous en montre l'agrandiffement dans la décadence de l'Empire.

Quand on parle devant certains efprits de l'établifrement de l'Eglife, il femble qu'on leur conte une aventure d'invention, dont on a mis la fcene où l'on 3 voulu, par exemple à Theffalonique, ì Corinthe, \& à Rome, plutôt qu’à Torneo de Laponie; \& que pour la rejetter il fuffife de dire: Nous n'y étions pas. L'Eglife écoit formée en Italie, conformément au récit de S. Luc, fous les premiers Succeffeurs de Tibere; puifqu'au rapport des Païens mêmes, on brûloit guvens. fes enfants enduits de poix pour fervir de 


\section{I33 Le SPECTACLE}

I. D - fanaux; illumination digne des jardins \& movsta. des fêtes d'un Néron. L'Eglife étoit trèsÍAGEr. nombreufe dès-lors dans toute l'Afie-Mi-

Plise ie neure, puifqu'un Magiftrat Romain, enśmbe. voyé par Trajan en Bithynie, fut bleffé de voir conduire une telle multitude d'habitants au fupplice, \& d'être contraint luimême par l'ufage à les y envoyer, fans leur connoitre dautre crime que le nom de Chrérien.

L'Eglife qui va fe perpétuer comme le Miniltere de qui elle a tout reçu, ne ceffera plus d'en attefter les cuvres \& les pouvoirs. Tous les nouveaux actes, tous les érabliffements que nous allons voir paroitre dans ce Corps difperfé par-tout, vont devenir non de fimples monuments hiftoriques, propres à exercer les Savants, mais des témoignages populaires univerfellement rendus au Miniftere, aufli vifibles à tous, \& aufi immortels que lui.

La premiere boucle de cette chaîne de témoignagesqui tientaux premiers Fideles \& s'alonge jufquà nous, eft l'OrdiIa furcer-nation publique. Ce fut en effer la prepublique miere démarche des Apôtres, à leurretour des Ainif- de la montagne des Oliviers, lorfqu'ils tres. étoient encore tout pleins des regles que le Seigneur venoit de leur donner avant fon départ, \& des promefles d'un Mi- 


\section{DE L A NATURE, I39}

niftere qui dureroit comme la fucceffion LA DÉ des fiecles.

MONSTR.

Le premier des Apôtres * fe leve au LVAnget. milieu de l'Eglife, qui corfiftoit alors en *Aeे. I: I fix vingts perfonnes. Il y propofe l'élection d'un homme parfaitement inftruit de la vie publique du Sauveur, depuis le baptême de Jcan jufqu’à la réfurrection, \& capable de remplir la place qui étoit vacance dans le College Apoftolique. Toute l'Eglife fe met en priere, \& Mathias reçoit les pouvairs de l'Apoftolat. Telle fut la premiere fuccefion dans le Miniftere. La notoriété n'en pouvoit être plus grande, puifque toute l'Egllie y étoit : \& c'eft avec la même füreté que I'Eglife a toujours reçu depuis \& conuu les nouveaux Miniftres à qui les Anciens communiquoient les pouvoirs \& les fonctions pour la perpéruer elle-même.

Nous voyons par plufieurs autres traits du Livre des Actes, par les regles que S. Paul donne à Tite \& à Timothée, par l'ancien Recueil des Conftitutions qui venoient la plupart des temps Apoftoliques, \& par la pratique de tous les temps qui on fuivi, que l'Eglife a toujours employé l'impoficion des mains de fon Clergé, avec le jeûne folemnel \& les prieres de tout le Peuple, afin de rendre la fuccero 


\section{40 L. E S E C T A C L E}

L. Df́-fion dans le Miniftere très-publique \& monstr. très-tefpectuble. Le Peuple y a toujours draxgel. pris part; non pour donner aux nouveaux Envoyés des pouvoirs qu'il n'a point reçus, mais pour obienir la bénédiction du Ciel fur l'œuvre évangélique; pour rendre témoignage à la probité de ceux qui y font appellés; \& pour montrer à tous la ligne de ceux qui font chargés de l'alliance \& de la communication des vrais biens.

La publicité de la réception des nouveaux Magiftrats n'eft pas une vaine cérémonie, mais une nouvelle atteftation des pouvoirs de la compagnie dans laquelle ils prennent place. On ne peut s'y méprendre: \& dans l'Eglife Chrétienne, comme dans l'érat civil, cette forme d'inftitution n'a été mife en ufage que pour prévenir les entreprifes illégitimes, en notifiant le vrai Miniftere fans en renouveller davantage les premieres preuves. Mais puifque ces preuves font remplacées, elles font perpétuécs.

1. 3inir- Nous voyons l'adminiftration des pretorec connu mieres Eglifes entre les mains des Apôpar les mis tres, des Prêtres, \& des Diacres. Tous cires de la enfemble, felon le degré de leurs pouvoirs chie. $\&$ de leurs fonctions, ils veilloient au bien Aar.20:20. commun. L'Esprit-Saint vous a établi inf- 
DE L A NA T URE. I 4 T

pecteurs pour gouvernar l'Eglife de Dieu, La D.eft-il dit aux Prêtres de l'Eglife de Milet. Monstr. Mais cet mot d'Irepccteurs n'exprime vifi- xangeL. blement ici que les devoirs généraux du Clergé, \& la vigilance néceffaire à tous les ordres; il n'eft ni un titre, ni un nom diftinctif : il le devint enfuice par la réferve fpéciale qui en fut maturellemenc faire en faveur du premier ordre.

Les Apôtres, \& ceux qui leur furent aflociés, comme MIachias, Barnabé, Paul \& Silas, fe tranfportoient par-tout où ils étoient appellés par l'occafion, ou par le befoin. Ils étoient néceflaires pour fonder les Egliles, pour ordonner le Clergé, pour confirmer les Néophytes, pour juger défnitivement les queftions fur la Foi. Mais bientôt après, lorfque ceux qui compoloicne le premier ordre furent attachés à demeure au gouvernement fpécial d'un troupeau, ils prirent uniformément, \& s'approprisrent le nom modefte de Survillant, (a) qui en les diftinguanc les avertifloit de la follicitude paftorale dont ils avoient la principale part. Ainfi tous les premiers affociés \& fuccefleurs des Apôtres, fur-tout à mefure qu'ils devinrent fédentaires, furent diftingués dans le Clergé par ce nom d'Epêjue, comme (a) Ėrivoter, Eycque. 


\section{I42 LE SPECT A C LE}

LA DE. Timothée \& Onéfime à Ephefe, Tite en Monstr. Crete, Marc à Alexandrie, Evodius à EVANGEL. Antioche, Polycarpe à Simyrne, Lin \& Clément à Rome. Cette diftinction des trois ordres, chargés des différents fervices néceffaires aux Eglifes, n'a jamais difcontinué nulle part, \& nous montre en fe retrouvant encore la primitive Hiérarchie.

Le nom de Pape ou de Pere, qui a été commun à tous les Evêques, fut par la fuice réfervé à celui qui remplit la premiere Chaire, \& qui continue la primauté de Céphas, centre néceffaire de l'Apoftolat difperfé. Ce titre exprime la jufte vénération des Fideles pour celui qui étant. le premier dans l'Epifcopat, le Chef du Miniftere \& de l'Eglife univerfelle, n'a pas feulement l'infpection particuliere du Diocefe de Rome, mais embraffe le maintien du Chriftianifine univerfel dans l'étendue de fes devoirs \& dans la généralité de fa jurifdiction.

Le Miniftere s'étoit moñtré au premier fiecle avec toutes les opérations extraordinaires de l'efprit quil'autorifoit : il en montra de nouvelles au fuivant : mais par la notoriétéqu'ellesavoient acquifes les uncs $\&$ les autres, il commença à n'avoir plus befoin de les réitérer. La publicité des 


\section{DE L A NATURE. I T 3}

preuves précédentes fe tranfmit comme LA $D \div$ le Miniftere, \& ne s'en fépara en aucun Mox:Ti. remps. Comme il fe montroit fuffiam- ŕvaxiet. ment par l'ordination \& par la diftinction invariable des trois ordres d'ouvriers, il n'attiroit pas moins les yeux par les actes avoués \& continuellement réitérés de fes différents pouvoirs.

Il n'en eit pas des actes d'une compa- Le Minisgnie comme d'un monument à demi-ron- tere cumn les acgé, ou d'une médaille qu'on peut foup-tus. çonner de fauffeté, \& dont l'explication peut être conteftée. Les actes d'une compagnie font aufi vivants qu'elle, \& n'ont pas befoin d'explication. Ils produifent en tout temps deux effets; l'un, de remplir l'objet dont la compagnie a les pouvoirs; l'autre, de la montrer elle-même tous les jours, \& d'en entretenir la notoriété. La longue inaction la feroit perdre de vue: au-lieu que la réalité de fes titres fe faic toujours fentir par la perpétuité de fes fonctions. De même les différents actes du miniftere évangélique, \& toutes les pratiques ou les établiffements émanés de ce pouvoir, ont le double effet de fanctifier les ames, \& de nous tranfmetre les témoignages d'un Apoftolat immortel. C'eft aux Pafteurs \& aux Théologiens à nous apprendre l'excellence \& l'appli- 


\section{LE SPE C T A CEL E}

La DÉ-carion réguliere des moyens par lefquel monstr. le miniltere communique aux Fideles Ies brangli. effets de l'alliance. Ce que nous confidérerons ici dans ces pratiques auffi anciennnes que l'Eglife même, c'eft l'avantage qu'elles ont par leur vifibilité, d'être les monuments auffi indeftructibles que publics de la Doctrine apoftolique \& de In légitime autorité. Car il eft aifé de voir que ces pratiques étant fignificatives \& permanentes comme le Miniftere qui les emploie fans interruption, elles font une vraie pérpétuité de témoignages toujours rendus tant aux dogmes qu'elles expriment, qu'à la miffion de Jefus-Chrift \& aux pouvoirs de fes Envoyés, dont elles font l'exercice. C'eft de cette forte que les actes, les réglements, \&le cérémonial même d'une compagnie de Députés ou de Sénateurs atteftent la réalité de fes pouvoirs \& la nature de fon département.

Nusvelle Après l'ordination qui devoit perpéla perpe- tuer le miniftere \& fes fonctions, le premite de la mier établiffement apoftolique fut celui vie de tri- d'une fête hebdomadaire, qu'on nomina tablifiement des tereschreส่อnการ.

le jour du Seigneur; \& d'une fète annuelle, qu'on nomma la Páfue ou la Réfurrection. La célébration de ces fêtes étoit une profeffion claire de la créarion de tout par un feul Dieu, de l'incarnation du Verbe éternel 


\section{DE $E^{4}$ A A N T URE. $\quad 145$}

étcrnel, de la mort du Meffie pour notre I,A Défalue, \&r de fa réfurrection pour garantie moketr. de nos efpérances. Ces fềtes par leur ávangelo nom, par l'inftruction des Pafteurs, \&s par Ie fens de in priere publique, ont toujours étéle Catéchifme vulgaire de la Doctrine Evangélique, \& un exercice toujours nouveau de tous les fentiments de la piété. Mais les mêmes fêttes perpétuées, portoicntavec clles, d'une femaine à l'autre, $\&$ d'un fiecle à l'autre, les preuves de $1 \mathrm{a}$ Mifion falucaire. Elles en continuoient fans interruption les témoignages, parce que la cercitude de la Mifition eft inféparable de l'atreftation des faits dont on glorifie Dieu dans chaque folemnité, \&r de la fonction de préfider aux Afremblées.

$I^{\circ}$. Nous ne pouvons effectirement re. fufer aux fêtes Chrétiennes les témoignages qui réfultent chez les aurres Peuples de leurs fêtes annuelles, fur-tout quand elles font lices d'ailleurs à des monuments connus. Il en réfulte d'abord l'atcoftation Ia moins ambiguë, \& la plus grande célébrité d'un fait.

Le College des Prêtres d'Augufte, \& 8 les facrifices qu'ils lui faifoient en certains jours, étant liés avec les actes \& les divers monuments de ce Prince, attcfTome VIII. Part. II. 
I46 LE SP E C TACLE

IA Dé. toient d'une façon très-marquée qu'il avoit Monstr. vécu, \& qu'on l'avoit déclaré Dieu après AWANGeL. ia mort. Voilà les deux faits qui réfultene de l'établiffement du College Auguftal, \&. de fes fêtes: mais rien de plus. Niles Pontifes du premier âge, ni leurs Succeffeurs, n’atteftoient qu'Augufte eût été vu parmi les Dieux.

Les Ifmaélites d'Arabie, d'Afrique, de Perfe, \& de divers autres Pays, n'ont pu confpirer dès le commencement \& malgré leurs divifions, à célébrer l'Hégire, ou la fuite de Mahomet hors de la MIecque, fa Parrie, pour fe rendre à Médine, fans garantir d'une façon inconteftable la réalité de ce fait.

Or, nous ne demandons autre chofe pour le Chrifianifme. Les faits font réels de part \& d'autre, parce qu'ils ont été vus \& atteftés par-tout fans concert : ou que fi un Peuple en a célébré la mémoire ì l'exemple d'un autre Peuple, c'eft par un effet de la conviction où ils éroient également de la vérité du fait, touchant les uns comme les autres à la fource de cette connoiffance.

Mais attefter qu'on a vu fuir un homme hors de fa Patrie, \& qu'on l'a fu arrivé, puis ćtabli ailleurs, oil il s'eft effectivement montré en bien des rencontres les 
nE L A N A T U R E.

armes àla main; ce n'eft pas atcefter qu'on LA Dél'ait vu revenir du Ciel avec les marques nonstr. de fa mifíion. Ce n'eft pas attefter qu'on źVANGLL。 ait oui la voix de Dieu qui le déclaroit fon Prophete. Mahomet a voulu être cru fur fa parole; \& s'il n'a point prouvé fon ambaffade, il n'a pu la perpétuer. Ceux qui viendront après lui pourront dire qu'il a tout vu dans le Ciel: mais comme les premiers n'ont éré témoins de rien, ceux qui leur fuccedent n'atceftentrien de plus que l'exiftence, la fuite, \& les guerres de Mahomet d'une part, \& de l'autre leur vaine confiance en fon Apoftolat: au-lieu qu'attefter qu'on a vil le Sauveur reflufcité, ou qu'on a ćté témoin de l'effufion de fon Efprit, \& des merveilles par le concours defquelles les Envoyés ont établi la foi de la réfurrection \& l'Eglife, c'eft divinifer l'Evangile, \& c'eft le faire avec droit. Attefter enfuice, comme ont faic les Fideles qui célébroient les mêmes fètes au fecond fiecle, qu'ils avoient entretenu les Inftituteurs de cesfètes, entendulcurs témoignages, connu leurs intentions, vis leurs oeuvres admirables; c'étoit tranfmettre au troifieme ficcle $\&$ aux fuivants les affurances de la véricé des fâits, \& le croit de la publier. Les témoignages rencus d'abord aux faits évangéliques, \& à

$\mathrm{G}$ ij 


\section{I48 LE SPECTACLE}

LA DE- lo divinité de la miffion qui en eft infépamans. ruble, fone done tris-publiquement perzrakt-L. pétués par la célébration annuelle \& hebdomadaire des fètes Chrétiennes. Elles font dans leur durée l'exncte répétition des mêmes témoignagges. C’eft la même certicude \& la meme valeur.

S'il y avoir en Orient \& en Europe des fêtes annuelles ou hebdomadaires de la Dictature de Cúfar, infituées par Auguíte, \&̂ toujours célébrécs depuis, au moins dans les deux mois qui portent leurs noms; ou fi les Allemands, les Italiens, \& les Francois avoient conframment renouvellé d’année en année des rournois \& une fète générale en mémoire du couronnement de l'Empereur Chariemagne, en l'an 800 ; ce feroit alors apparcmment que l'efprit humain trouveroit quil cil beau de nojouter foi ni à In Dietature de Jules-Céfar, ni à l'origine de la dénomination des mois de Juillet \& d'Aout, ni au couronnencnt de Charlemagne.

20. Ces fètes \& lc miniftere font inféparables. On n'a jamais livré ni le minittere, ni la préfidence des fètes au pre. nier Bourgeois, ou au premier Aitifan qui voudra ouvrir fa porte, \& attrouper le monde pour les cúlébrer. Le Pafteur 


\section{DE I A NA T URE. If9}

qui les annonce \& qui y préfide, a tou- LA D? jours été pris dans la ligne très-connne Monsts. qqui perpécue les pouvoirs. Ainfi ces fêtes, ĹRAigs. cn nous confervant la conferfion des faits, \&zen montrantle Pafteur, perpétuent les preuves de fon miniftere, comme l'excrcice réglé de la Judicature perpétue la notoriété du pouvoir des Juges.

LEglife a fair plus que d'entrecenir lo premiere confeffion des faits effentials à fh Foi par les mots de Noël, ou Dien avec nous, de Réfurredion, de defcente du Paraclet, d'Epiplanice, \& antres noms très-fignificatifs qu'elle donne à fes fêcee. Avec les objets de fa joie \&: de fa crénence, que ces noms expriment fommairemone, l'Eglife a tranfmis à cous les âges fuivants les mocifs de fa perfuafion \& la réalicé de l'envol de fes Miniftres, par des moyens qui ajoutent une force inlinie aux témoignages précédents. Elle n'a pas infticué les Sacrements; mais elle en a réglé l'adminiftration felon l'intention de Jefus-Chrift, de maniere à en faire une nouvelle école, où les mêmes vérités fe répetent, \&̊s ne vont point fans leurs preuves.

On faic par tous les monuments biforiques, \&r par la Lettre de Pline a Trajan, que l'Eglife Chrétienne tenoit fes affemblées au jour du Soleil, "pour chanter 


\section{T. E SPECTACLE}

I. Di-, des Hymmes au Chrift comme à un maxt., "Dicu, puis pour s'entiexhorter à la 2.Axut. , vertu \&́ à la haine de toute infidélité

", dans le commerce de la vie., On fait par les premiers Apolngiftes du nom Chrétien, que l'Eglile allembloit fes enfants lo jour du Seigneur, qui eft celui qu'on nommoit du Scleil, pour leur lire les écrits de fes preniers Miniltres, pour les encourager à la pracique de ce quils venoient d'entendre, \& pour leur diftribuer les préfents q̧u'elle avoit reçus pout eux de fon Inftituteur. Tamais ni ce Miniflere, ni ces lectures, ni cette diftribution, ni le choix de ce jour n'ont difcontinué. C'eft la raifon naturelle qui nous prouve que ces Livres, qui fe retrouven par-tour les mêmes, comme le Miniftere, les Afremblées, \& les communes pratiques, font indubitablement auffi anciens que l'Eglie, ez qu'ils contiennent la véritable hiltoire des témoignages univerfellement rendus par les premiers Chrétiens à la Miffion évangélique. Mais à côté de ces Livres, dont nous tâcherons dans peu de faire connoitre l'excellence, l'Eglife en préfente d'autres plus courts, aufi intclligibles, \& en un fens très-véritable, encore plus précieux pour les Fideles; puifure fi les Livres faints contiennent la 


\section{DE I A NA TURE. I5I}

Doctrine falucaire, les Sacrements quifont LA $D$ : les Livres dont je parle, avec la doctrine niosstr. qu'ils expriment, contiennent la grace \& úvirivı. la réalité des biens promis.

Parmi tant de pratiques \& de fêtes commémoratives, arrêtons-nous à celle de Pîque. D'abord l'antiquité en eft la même que celle de l'Eglife, puifqu'il y avoit partage pour le choix du jour entre les Gentils convertis \& les premiers Fideles Juifs qui fuivoient encore les ufages de la Synagogue. La Pâque Chrétienne étoit accompagnée de la célébration du Baptême, de l'impofition des mains de l'Evêque fur les nouveaux baprifés, pour leur communiquer les dons du Saint-E[prit; \& enfin de leur premiere participation au repas du Seigneur.

Quoique les Sacrements inftitués par Jefus-Chrift tirent leur force \& leur validité de fon infticution, remarquons que l'Eglife en demande cependant l'effet par Foi. des prieres folemnelles, qui de la forte fe trouvent être une excellente expofition de fa Foi : comme la priere que JefusChrift nous a enfeignée, ou la demande que font tous les jours les Fideles du pain qui eft actuellement fous leurs mains, eft une excellente confefion de leur difette Les prie res de l'E. glife font l'exponi-

$$
\mathrm{G} \text { iv }
$$




\section{LE S P E T A C L E}

LA D:- naturelle, \& de la gratuité des préfents wonstr. que leur fait la Providence.

Erangei. C'elt ainfi que l'Eglife confeffoit \& confeffe encore l'état malheureux qui pré-

Prieres cede le Baptême Chrétien, en demanCaréchu- dantpour les Catéchumenes la délivrance de la tyrannie jufques-là exercée fur eux par les efprits de ténebres.

-córemo- La Foi qui fe trouvoit nettement dénies inf- veloppée daus les formules de fes prieres,
cucuives. ne l'étoit pas moins dans fes faintes cérémonies. Elle publioit ainfi l'égale puiffunce des trois Perfonnes divines, en conférant le pardon des péchés \& la jultice, par l"égale invocation de tous les trois, \& en joignant en bien des lieux la triple immerfion a la triple invocation.

Les nouveaux Chrétiens étoient mis dans in état de mort fous les eaux du Bapcû̉me. Ils en fortoient comme des hommes régénérés, ou rendus participants d'une vie nouvelle. L'action même extérieure écoic donc une profeflion claire de 6n. 3:r. mourir au péché, pour ne plus vivre que de Rom. $6: 3$ la vie de celui qui écant mort \&reflufcité $\theta^{3}+1$.

hibo. 6 : néprouve plus la mort. Cette peinture $1,3,62$ extérieure qui retraçoit vivement en eux la mort \& la réfurrection du Sauveur, n'étoir donc pas moins une déclararion 
publique de la commune croyance de la LA Déréfurrection, quin engagement à vivre MONstr. dans l'éloignement du péché.

ÉVANGEL.

La réception du Baptême étoit par fa forme le précis de toutes les inftuctions quiavoient précédé; \& toures ces inftructions n'étant que les fimples conféquences d'autant de faits très-publics, le Baptême étoit un témoignage rendu, non à des opinions fyitématiques \& fuggérées, mais à des événements faciles à juftifier.

L'Eglife ne recevoit dans fes aftemblées nides vifionnaires, ni des enthoufiaftes, ni des Philofophes prévénus d'une doctrina par des raifonnements. Elle favoit que toutes ces voies conduifent par l'incerittude à la confurion \& à l'égarement. Elle ramenoit avec foin la raifon à l'excellent moyen qui la fixe en tout temps, \& dont Dieu a fait choix pour fe manifelter fans équiroque au genre-humain. Ce moyen c'eft la preuve teftimoniale, ¿̇la parfaite notoriété des faits. Tous les jonis l'/iomme fage fe rend, malgré fos préventions, à ce qui a été vu \&r attefté par des témoins oculaires \& défutéreflés. L'Eglife n'admetroit fes Catéchumenes au Baptême quaprès de longs préparatifs, dont le moindre degré, ou le préalable nécefluire éroit que les Catéchumenes priffent foin 


\section{$154 \quad$ LE S P E C T A L E}

LA Dé-de s’informer des fairs évangéliques, \& aronstr. puffent fe répondre à eux-mêmes comme EVAXGEL. aux autres, qu'ils avoient vu les premiers Miracles, ou qu'ils en avoient vu d'équivalents, ou que les premiers \& les fuivants leur avoient ćté affurés par des témoins non récufables. L'Eglife ne craignoic rien tant qu'une crédulité légere \& une confeffion chancelante. Elle aimoit mieux compter un moindre nombre d'enfants, que d'avoir à déplorer leurs chûtes.

Les Néophytes eux-mêmes favoient que la réception du Baptême devenoit la condamnation du Judailme, \& de la vie des Paiens. Cette démarche les conduifoit aux avanies, aux infultes, à la perte de leurs biens, au martyre. Le danger du témoin le mettoit dans la néceffité d'aller exactement aux enquêtes, \& ajoutoit à Ta con- fon témoignage le mérite de la prudence. firmation,

La Confirmation qui fuivoit le Baptêtémoinga- me, atceftoit tout enfemble la premicre aux Dons du SaintEfprit.

L'Euchariftie, pueffufion des Dons du Saint-Efprit, \& la continuation fenfible de ces Dons, qui venoient de former tant d'Egliles où le fouvenir en étoit encore récent.

blication immortelle de la Mifín evangéliรูue,

Le Néophyte étoit enfin admis au repas du Seigneur ; \& par cette action, qui étoir le grand objet de fes defirs, comme le grand motif des épreuves préparatoires, 


\section{DE L A NA T UR E. I5J̃}

il atteftoit nettement tous les faits évan- L.1 DÉgéliques. Il devenoit vraiment le Prédi- mosstr. cateur de l'œuvre du falut; \& en perpé- Évaxigi. tuoit la prédication d'un fiecle à l'autre, jufquà l'avénement du Fils de Dieu.

Le Baptême étoit la peinture la plus vive de la nouvelle vie de Jefus-Chriftreffufcité, \& du renouvellement intérieur du Catéchumene. C'étoit l'abjuration de fa vie précédente pour paffer à une conduite oppofée. Mais ce Sacrement ne fe réitéroit pas. Au-lieu que le repas euchariftique étant la participation à la Vićtime fainte, \& devenant la nourriture ordinaire du Chrétien, il y trouvoit fans ceffe l'avertiffement de fa vocation, \& les motifs les plus touchants, ou même les plus terribles, de fe maintenir dans une extrême pureté. L'Euchariftie de la forte devoit à jamais, \& tous les jours, montrer le Miniftere qui a le droit de la difpenfer; répéter la doctrine dont elle eft la prédication, \& animer les mœurs dont elle eft le plus fort encouragement. C'étoit perpécuer le Chriftianifme en entier \& fans variation. En effet, les variations n'ont point d'accès dans les compagnies qui ont leurs formules réglées, \& leurs fonctions connues de tout un Royaume. A plus forte raifon les diverfes parties de l'Eglife

$$
\text { G vj }
$$




\section{$156-\mathrm{LE} S$ P E C T A C L}

L.1 Dé-Catholiq̣ue, fi défunies d'intérêt, \& fi difMonstr. perfées fur la terre habitable, nous ontGiakielo elles fidélement tranfmis les témoignages \& la confeffion des premiers Fideles, en continuant à saffembler fous la préfidence du même Miniftere, \& en attachant toujours à fes fonctions des idées uniformes. On les retrouve les mêmes jufques dans ces focićtés dont la Providence a trèsanciennement permis la féparation d'avec le corps de l'Eglife Cacholique. L'Inftitureur a vifiblement artaché la certitude au moyen de tranfmiffion dont il a fait choir dans l'établiffement de l'Euchariftie.

Voyons de quoi toutes ces anciennes fociétés glorifient unanimement le Sauveur dans cette importante action. Voyons le préfent qu'il nous y fait, \& les vérités que confeffent de tout temps tous ceux qui le reçoivent.

Le repas euchariftique ne confiftoit pas feulement dans l'ancienne offrande de quelques fruits de la terre, pour remercier Dieu de la création des êtres, \& des moyens qui les confervent. Telle étoit l'Euchariftie de l'homme innocent. Cer hommage prefcrit avec tant de juftice au premier homme, fur continué après fa chute, \& fe continue encore, comme les préfents que la Providence continue 
d'année en année à lui départir. Tousles LA Dá. Peuples y ont anciennement ajouté ce sunstr. qu'ils avoient appris d'Adam \& d'Abel Érauger. par Noé; je veux dire, l'efiufion du fang des bêtes qu'ils mettoient en la place du leur, \& qui étoic non l'expiation, mais la confeflion de leur's péchés.

Le repas eucharifique des Chrétiens étant enfin la participarion à la Victime de l'alliance éternelle, à l'Agneau de Dicu qui ôte les péchés du monde, c'étoit toujours l'Holtie d'Abel \& l'Euchariftie du pécheur, mais du pécheur enfin réconcilié : c'étoit tout enfemble le plus grand de tous les préfents, \& l'action de graces du Fidele intimement uni au facrifice propitiatoire.

Ce repas étant ce que la Religion aroit de plus grand, \& ce qui intéreffoic le plus les Fideles, n'en prenons pas les idées dans nos raifonnements, mais dans İs rapports des premiers témoins.

Recevoir ce que l'Eglife diltribuoir dans ce repas, ce n'étoit plus fe nourric d'un pain \& d'un breuvage communs. L'Apologifte du Chriftianifme, S. Juftin, qui nous le dit, auffi-bien que S. Ignace d'Ancioche, \&r S. Irénée de Lyon, fes contemporains, ajoute comme cux, que c'ćtoit recevoir le Corps \& le Sang mème de 


\section{I5 L E S PECTACLE}

L. Dé-Jefus-Chrift. " L'Eglife étoit très-certaiMonstr. "ne, felon l'énergique expreffion du faint ávangel." Martyr, que la toute-puiffance duVerbe ", divin, qui avoit éclaté dans l'Incarna" tion, en fe revêtant d'un corps humain, " étoit la même qui agiffoit dans l'Eucha-

"riftie, en nous nourriffant de fa chair. Cette confeffion, qui eft du commencement du fecond fiecle, eft parfaitement d'accord avec les épreuves exigées des Fideles : \& c'eft la nature de la doctrine qui étoit le fondement de la rigueur des regles eccléfiaftiques.

Otons pour un moment cette conferfion du premier âge : réduifons le pain \& le vin euchariftiques à un fimple figne, à un fymbole inftitué felon des idées modernes, pour nous avertir de penfer à celui qui a été brifé, \& qui a verfé fon fang pour nous. Ce figne fera un mémorial d'inftitution. Nous pourrons, en le voyant \& en le recevant, exciter en nous un fentiment de reconnoiffance. Mais cette action ne demande ni de grandes épreuves, ni n'occafionne des regles féveres, ni n'attire aucunes conféquences effrayantes. On peut voir un fymbole, \& même un beau tableau de la mort de Jefus-Chrift fans courir le rifque de devenir plus criminel, faute d'une épreuve 


\section{DE LA NATURE. 159}

précédente. Onferoit encore plus touché LA Dém de la lecture détaillée de la mort du Sau- Mos'str. veur, ou d'un difcours pathétique fur fes ÉVANGes, fouffrances. Le figne, la lecture, \& la prédication peuvent être confeillés aux plus grands pécheurs. Cette action peut bien leur être inutile : mais loin de leur nuire, elle peut les rappeller au milieu de leurs défordres, \& il n'y a perfonne à qui il ne faille l'accorder. Il n'en eft pas de même de l'Euchariftie, \& elle n'eft pas fimplement un tableau. Les termes dont S. Paul s'eft fervi pour en régler les approches \& la participation, jettent l'épouvante dans tous les cœurs.

Si cependant il a plu à l'Inftituteur d'exiger l'épreuve \& l'affurance raifonnable d'une bonne conduice pour recevoir ce figne; alors la néceflité de ces faintes difpofitions découlera de la volonté exprefre \&x de l'ordre marqué du Lćgiflateur, non de la nature même du préfent qu'il nous fait. Or c'efl de la nature même du don que recevoient les Fideles, \& $\mathrm{du}$ changement opéré dans l'Eucharifie par la toute-puifance de la Parole de Dieu, que provenoient leurs frayeurs, \& les alarmes où l'Eglife étoit pour eux.

Pour nous en convaincre, il ne faue cue reprendre la confefion que nous 


\section{LE SPECTACL}

La Dé-tenons des premiers Chrétiens, felon lamons'rr. quelle la toute puiffance du Verbe agit EVANGel. autant en nous donnent fon corps qu'elle a agi en s'en revêtant. Voici les contéquences naturelles que nous en tirons néceffairement.

1. Cor.10: „, D’abord, puifque ce pain eft unique, 37.

"étant plufieurs, nous ne fommes plus

$"$ qu'un feul corps; car nous participons

" tous au même pain.

De là la tendre charité qui doit nous unir tous : de là l'égalité qui nouss place comme les enfants d'un même Pereàune même table : de là l'ineompatibilité des I. Cor: II: dittinctions dans l'affemblée eucharifti^o \& 2 I. que avec la charité \&r l'égalité inféparables du repas du Seigneur.

I. Cor. 10: "Jettons les yeux fur les Ifraélites, \& I.

" même fur les facrifices de la Gentilité.

"Ceux qui mangeoient de la victime ne " participoient-ils pasau facrifice? „C'eft ainfi que nous avons partà celui de JefusChrift; ce qui ne feroit pas, fi ce que nous recevons n'écoit pas ce qui a été offert en expiation.

De cette forte l'Euchariftie eft l'affociation à l'alliance nouvelle \& éternelle. C'eft le don du Ciel : c'eft le don par excellence. Mais quoique la réceptionen doive pénétrer le Fidale de joie \& de re- 


\section{กE I A NATURE. I I I}

conmoiffunce, il y a une jufte craince infé- LA Dŕparablementattachée à l'excellence même moxsrs. du don qu'il recoit. Cetce action infpire Évascus. la frayeur a l'Eglife entiere aufi-bien qu't chaque Pardiculier. La follicitude de l'Eglife pour fes enfants a dù conféquemmenc produire des regles, prefrrire des épreuves, des délais, desrefus. L'cfiet de la froyeur des Fideles a dù être de s'éprouver, de fe juger eux-mêmes avant de recevoir leur Juge; parce que fe préfonrer indignoment, \& lans apporter ì une action ti fainte les dilpoficions que l'Eglife demande, "6 c'elt fe rendre coupable dẹ $T$. Cr. as:

"L profunation de fon Corps \& de fon

, Sang.

Cedófaut d'épreuve \& de changemene de conduite eft une difpoficion fomblable à l'indiflerence de celui qui diy connoitwoit quin pain commun, \& qui " n'y „2 difcemeroir pas le Corps duSeigneur: Ium.

$\because$ mais ne l'y pas difcerner lorfque le "Touc-Puilian l'y mee, comme dans "I'Incamation, cerces c'eft mnger fon ", propre jugement, \& boire in propre " condamnation.

L'Euchariltie elt de cette fordo \& par une fuice neceffaire de ce qu'clle contient, la plus gronde auvre du Minintere Chrétien, le grand objer de la diloipline de 


\section{I62 LE SPECTACLE}

LA Dé- l'Eglife, le fujet de l'effroi des pécheurs, monetr. aufi-bien que de la reconnoiffance des suavel. juftes, le motif d'une vigilance perpétuelle, l'ame des bonnes mœurs, l'action de graces de tous les bienfaits, la confeffion de tous les myfteres; difons tout en un mot: C'eft la perpétuité de la Prédication Chréticnne. (a) Tous les Chrétions I. Cor. II : en ce fens deviennent à jamais par la ré$=6$.

ception de l'Euchariftie, les Prédicateurs du Chrift, puifque toutes les fois qu'ils la reçoivent, "ils annoncent par leur action ") l'cuvre du Seigneur \& l'attente de fon ") dernier avénement.

Pfalm. 44. Ces paroles, memores erant nominis tui, ne fignifient pas un fimple fouvenir, mais la confeffion publique du Nom de Dieu, \& l'emploi honorable de le faire connoître à toute la terre : de même ces paroles, in meî memoriam faciecis, ne fignifient pas feulement: Vous vous fouviendrez de moi; mais en recevant mon Corps rompu pour vous, autant de fois vous publierez mon facrificc. Votre action fera la prédication de ma mort, de ma réfurrection, \& de vos efpérances. (b) Toutes ces conféquences qui fe tirent de la doctrine de l'Euchariftie, même par les

(a) $I_{12}$ memoriam mế fucietis.

(b) IItortcm Domini annuntiabitis donsc veniat. 


\section{DE: L A NA T U R E. I63}

plus fimples, en font néceffairement la LA Déplus exprefinve confeffion desvérités évan- Monsrr. géliques, Er la plus puifinte exhortation Ívanger. à la vercu. Quelle différence entre un fymbole froid ou un fouvenir paffager de la more du Sauveur, qui laiffe l'homme à toute fon indifférence, \& un mémorial qui nous donne le bien quil annonce, \& tient tous ceux qui s'cn approchent falutairement, émus des retours qu'ils font fur eux-mêmes, fans pouvoir être raffurés que par l'accord de leur vie avec leur confeffion!

Mais ce commentaire de la doetrine des faints Martyrs Juftin, Ignace \&: Irénée, n'eft pas le mien. C'cft une explication qui les a précédés; c'eft une explication auffi ancienne \& auffi étendue que l'Eglife même, puifque c'eft celle de faint Paul. Elle n'étoit point particuliere à l'E. glife de Corinthe, qui atteftoit l'avoir reçue de lui, comme il l'avoit lui-même reçue du Seigneur. Les autres Eglifes ont trouvé cette doctrine \& la foi des Corinthiens conforme à celle qu'on leur avoir annoncée. Ni S. Juftin, ni S. Ambroife, ni S. Cyrille, * nil'Eglife Catholiquen'auroient eu recours dans ce myftere à l'opé* Tierorol. Coneciest. ration de la toute-puifance pour y trouver une repréfentation, un avis. Il ne faut 


\section{I64 L E S E E C T ACL E}

LA DÉ-point de toutc-puifance pour établir un Moxtr. figne aud: \& jamais la raifon des Fideles Exangel. dans fon obéifance à la Foi, n'a écé bleffée d'entendre demander, commele font toutes les anciennes Liturgies grecque \& latine; que le pain \&o le vin devienume le Corps \& le Sang de Jeflus-Chrift: jamais la raifon des Fideles n’a reproché à l'Eglie Carholique de lui faire illufion, ni de ruiner dans fon dogme la vérité du rapport de nos fens qui voient un figne \& rsçoivent une réalité differente, parce qu'il n'eft point fric d'lllufion à nos fens quand nous fommes avertis. Or JefusChrift nous avoit avertis qu'il nous donneroit os propre chair à manger, \& nous affocicroit à fon facrilice. II le répere dans ies parnles de l'intitution. S. Paul le redit après lui. Tous les Doeteurs, toute l'Eglife nous en ont avertis. L'Euchariftia Catholique nous pénetre done de refped, de reconnoiflance, \& d'une falutaire frayeur, fins nous tromper en rien. C'eft au contraire une économie vifiblement proportionnée à notre dur; \& les mêmes témoins de la Foi primitive gui nous ont strefté l'action de la toute-puiffance dans l'Eucharittie, n'ont pas moins relevé la chariré tendre qui nous communiquoit la chair \& !e fang de la Victime excellente, 


\section{D) E A N A T URE. I $\delta_{5}$}

fous le voile invariable d'une nourricure LA DÉordinaire.

MONSTR.

Ces fublimes vérités ne font point une WVAXGEL. tradition de quelques bruits populaires "qui fe diverfifiene de bouche en bouche, ou d'opinions fcholaltiques abandonnées sus jugements des Particuliers. C'eft une Foi générale à laquelle une Eglife ne peut toucher que les autres ne la réclament; whe Foi notoire, \&xqui ne peutêtre ignorée de perfonne, parce qu'elle tienc aux fonctionsles plus diftinguées du Miniltere; à des fères folemnelles dont le retour eft invariable; a des devoirs \& à des regles qui embraflant tous les états, ne laiffent perfonne dans l'ignorance à cet bzard. Ce ne fera pas une differtation philofophique du neuvieme fiecle, abandonnée dans le fond d'unc Bibliotheque poudreufe, qui viendra informer l'Eglife qu'elle rrompe fes enfants encxagérant les préfents qu'elle leur fait. Ce ne fera pas l'onzieme ou le feizieme fiecle qui nous apprendra ce qu’il en faut croire. Nous répétons aujourd'hui la même œuvre \& ln même confefion que nos Peres ont reçue avec les Livres faints des Succefleurs des Apôtres, \& qui leur a été certifiée comme ces Livres par les témoignages unauimes de toures les Eglifes. Nous célébrons cette 
166 LESPECTACLE

LA DÉ-Pâque folemnelle, \& nous réitérons ce Monstr. repas falutaire dans des Temples de fept ÉVANGEL cents ans, de mille ans, de douze cents ans; dans des fociétés de quinze \& feize fiecles. Ce font toujours les mêmes Aurels, les mêmes inftruments, la même Licurgुie, la même préfidence, une œuvre $\&$ un fens qui ne peuvent changer. Er comme il n'y a point fur la terre de pratiques plus univerfelles ni plus folemnelles gue celles qui ont tranfmis jufqu’à nous ces trois parties effentielles à nos affemblées, favoir le banquet Euchariftique, Ia publication des faintes Ecritures, \& le Miniftere qui préfide à l'un \& à l'autre; il n'y a point non plus de certitude qui puiffe être portée à un plus haut degré que celle de la perpétuité indivifible de l'Eucharifie, de l'Ecriture fainte, \& du Miniftere.

Dans tout l'extérieur du Chriftianifme nous n’avons jufqu'ici fait ufage que de la fête de Pâque; \& dans cette fête nous avons choifi uniquement la réception que l'Eglife faifoir à fes nouveaux enfants. Si une feule partie du Rituel des fêtes Chrétiennes, même avant que le Pafteur cût commencé à inftruire par lui-même, contenoit déja tant de lumieres \& de fentiments, que fera-ce de la totalité des autres 
DE LA NATURE. I 6 ? fêtes, des cérémonies, \& des leçons qui LA DÉleur étoient propres; des prieresauxquel-Monstr. les tous les Fideles s'uniffoient au moins ÉVANGEL. pour l'acclamation d'Amen; en un mot des fecours fans nombre qui étoient dans le Miniftere \& dans toute la Liturgie?

Je ne dirai plus: Quelle publicité! mais je dirai: Quelle intaillibilité, \& quelle étendue d'inftructions! Je vois des milliers d'affemblées Chrétiennes: mais je ne vois qu'une école : c'eft par-tout le même Catéchifme. Voilà le Livre de tous les états \& de tous les âges. On y lifoit, $\&$ on l'entendoit au dixieme fiecle comme au quartieme \& dans le rôrre.

Les Savants accourumés à recueillir les lumieres que les Livres fourniffent, connoiffent le mérite des Livres, \&r y atcachent avec raifon leur eftime. Mais cette eftime peut quelquefois être accompagnée d'injuftice $\&$ d'inattencion, quand ils ne fentent pas affez le mérite fouvent fupérieur des autres fecours par lefquels Dieu nous tranfmet la vérité. Nous cherchons les témoignages de la Foi dans Tertullien, dans Origene, dans Eufebe, dans Théodoret, \& dans ceux qui ont fuivi; c'eft une méthode qu'il n'eft pas permis de négliger, \& qui eft finguliérement en recommandacion dans l'Eglife Cacholique: 
I68 LE SPECTACLE

I.A D. mais quelquefois à côté de l'expofition monsm. de la Foi Catholique, il fe trouvera dons 2yanazl. les Livres de ces Docteurs une explication qui fe reflent de la philofophie \& des recherches de la raifon; parce qu'il arrive affez fouvent que plus elle eft cultivée, moins renonce-t-clle à fes penfées propres; moins veut-elle s'en tenir modeftement à la fimplicité de la révélation. Il faut alors des dilcuflions : c'eft une néceffité de difcerner ce qui eft la Foi commune de l'Eglife, d'avec les penfées des Philofophes, \&r d'avec les méthodes humaines. L'Eglife profite des fecours qui fe tirent de la conformité des témoignages de cous les fiecles. Mais elle diftingue toujours le Docteur d’avec le témoin, \& ne fouffe en rien de fes imperfections, puifqu'elle a d'autres moyens d'une certitude enticre \& d'une précifion parfaite pour commoitre la docirine révélée, \& pour l'échaircir quand il faudra. Ces moyens Surs \& toujours préfents, fonc les objets très-diftincts de fes fêtes, de fes pratiques, $\&$ de fes prieres univerfelles. Elle trouve la regle \& la preuve de fa doctrine dans ia conformité tiès-publique de la croyance de tant d'Eglifes particulieres, toujours en état d'attefter les dogmes \&̈les Ecritures qualelles ont reçus dès le commencement.

Ceux 
DE LA NATURE. 169

Ceus qui veulent favoir à fond les IA $I:$. droits \& les ufages du Parlement de Lon-Monstr. dres, ou de l'Eglife Catholique, ont re- Évarigr.. cours aux Livres qui en ont parlé dans la durée des différents îges. Ils peuvent euxmêmes en faire de nouveaux. Mais ces grands établiffements n'ont eu befoin de Livres, ni pour fe former, ni pour exercer leurs droits, ni pour les faire connoîcre. Ils devancent les Livres; ils font difparoître par l'éclat de leur notoriété les petites objections qu'on peut tirer de tel ou tel Ecrivain, contre des maximes univerfellement reconnues. Ni le Parlement, ni l'Eglife ne dépend des hiftoires ou des differtations qu'on en faic. Les Livres ne peuvent ni leur rien acquérir par leur juiteffe, ni leur faire rien perdre par des expofés faux ou imparfaits. Les Fideles peuvent devoir des lumieres ou des fecours aux bons Livres: mais jes bons Livres \& la faine Théologie doivent tout à l'Eglife, \& à fon immortelle prédication.

Suivons les effets qui ont naturellement découlé de la premiere conflitution de l'Eglife. Un feul \& même Mliniftere l'a d'abord formée par tout, \& lui a donné par-tout la même Doctrine, la même Hiérarchie, lés mêmes Fêtes, \& les mê. Tome VIII. Part. II. H 


\section{I70 LE S PEC TA C L E}

I. A tu-mes pratiques. D'où il fuir que le culte masir. extérieurn'eft pas ieulement une inftrucfrangret tion perpétuelle, mais un dépòt de té-

i'exti- moignarges immortels, \& un chartrier de rieur n'eft pieces incorruptibles qui fixent la foi de ment une tous les fiecles. Les moyens de connoître cicole, mis is clerrerier. toute vérité dans l'Eglife Catholique, à qui toute vérité a d’abord été confiée, font inalićrables. Les Pafteurs pour inftruire les Fideles, n'attendent ni n'ofent annoncer aucune nouvelle révélation. On ne les écouteroit pas. La révélation de toute vérité a été faite par la premiere prédication. Les Succeffeurs des Apôtres n’ont fait que répéter ce qu'ils tenoienc słes Apôtres, qui le tenoient de JefusChrift. Les actes des uns \& des autres fe font diverfifiés fans fin: mais ce font les mêmes intentions, \& les mêmes vérités. Ceux qui viennent après eux font dans la néceffité de conformer leurs enfeignements aux pieces du dépôt, \& au langage univerfel. Quand les Pafteurs fe laifferent furprendre au temps de l'Arianifme par des formules équivoques, \& qui n'exprimoient rien diftinctement, la prédication commune, \& la leur propre, ramenerent au grand jour le dogme qu'on avoit en guelques lieux laiflé obfcurcir.

Siles Pafteursvenoientale taire, comme 


\section{DE LA NATURE. ITI}

dansles fiecles d'ignorance, les pierres \& LA DÉtous les inftruments du fervice public le fe- Monstr. roient encendre en leur place. Si quelqu'un ÉVANGEL. d'entr'eux avoit dit: Jefus-Chrift n'elt pas Dieu comme fon Pere, on lui auroit montré la forme du Baptème, où il eft invoqué comme le Pere. Si un Pafteur oloic dire : Unillez-vous par la penfée à celui qui a été immolé; mais le pain que vous avez offert fur certe table eft toujours le même pain; l'Euchariftie n'eft point la victime. On lui diroit, \& on eùt dit dans les premiers fiecles comme aujourd'hui: Nous avons un facrifice, nous avons un Autel, \& l'Autel eft fait pour la victime.

Ceci feroir la mariere d'un article vraiment utile, mais d'une trop grande étendue pour avoir place ici. On y verroit, \& chacun voic fans que j'en entreprenne le détail, que tout clt lié dans la formation \& dans la propagation de l'Eglife; que le corps des pratiques extérieures, en perpétuan les témoignages des intentions Apoftoliques, a rendu la Foi de l'Eglife fenfible à cous les efprits, \& nécelfairement invariable : parce que comme le Miniftere \& les pratiques s'entr'aident \&r revicunent aux mêmes vérités, quand on fuit ce qui a été cru d'abord \& par̈tour, l'inftuction \&i les pratiques s'entre- 
IT: LESPETTALE

LA DĹ-condamneroient au contraire à la moina wonstr. dre innovation, à la moindre altération. śrangel. Le Miniltre peut héfiter; mais le dépô: eft fans paffion \& fans héfitation.

Perpetuité Les établiffements Apoftoliques ne ciu témoi- font pas feulement la répétition journaliere peau. des Lettres de créance qui ont d'abord autorifé le Miniftere; ils ne font pas feulement la confeffion publique \& immortelle de l'Incarnation, de la Réfurrection, des dons du Paraclet, accordés, felon la promefle du Sauveur, à fon Eglife, \& de toutes les œuvres par lefquelles l'Efprit-Saint a prouvé au genre-humain la réalité de la bonne nouvalle, \& la réalité de fon Ambafrade. On y retrouve auffi le témoignage de l'eau, ou la preuve qui réfulte de in converfion furprenante des Juifs, des Idolâtres, \& des Barbares. La perpétuité même de l'Eglire, eft la perpécuité de ce témoignage.

On ne nous débite point des hiftoires brillantes, ou devenues incertaines par la diftance des temps, quand on nous dit que les Juifs, les Samaritains \& les Gentils, malgré les préventions les plus fortes, malgré la féduction de la coutume, malgré la perte de leur repos \& de leur vie, fe foumirent à l'Evangile par le fimple efiet de la conviction des événements dont 


\section{DE I A NATURE. 173}

ils furent les témoins. Trois cents ans de LA $D E$. perfévérance dans la profeflion de cette monst?. Foi, concourant avec trois cents ans d'une ÚVANGé. haine dénaturće contre ceux qui s'y rangeoient, il en forti un témoignage plus touchant fous Dioclétien, qu'il ne l'avoit été fous Néron. Et ce témoignage fi fort fe faic encore entendre; puifqu'il tít bien plus notoire que c'eft ce témoignage qui a rendu la Grece, l'Italie, la Gaule, \& l'Efpagne Chrétiennes; qu'il ne l'eft que les Grecs, les Italiens, les Gaulois, \&xles Efpagnols ont acquis avec plus ou moins de réferve le droit de Bourgeoifie Romaine. On n'héfite pas fur la vérité de ca droit de nos Peres, quoiqu'il ne foir plus rien. Bien moins peut-on héfiter fur la réalité de certe étonnante converfion dontnotre Chriftianifme eft la fuite \& la preuve encore fubfiftante.

On ne nous débite point des faits douteux, quand on nous dit qu'il y a deux Religions qui ont fait par-tout des profélytes, la Mahométane \& la Chrétienne; mais que la Mahométane n'a profuéré que parmiles nombreufes Tribus d'Ifmaël, \& parmi quelques autres Peuples qui leur étoient unis par de grands intérêts; que le Mahométifme n'a rien changé aux pratiques des Irmaélites, \& n'y a introủui 


\section{LE SPECTACLE}

I. D.. d'autre nouveauté que de leur affurer Menstr. l'indépendance \& la protection; ou de 1VANGR. les écrafer en cas de refus : au-lieu que les autres Barbares tour-à-tour ont volontairement abjuré les leçons de leurs Peres pour embraffer le Chriftianifme, \& conféquemment les Loix de l'humanité.

Je conviens que les converfions des temps poftérieursn'ont pas dans le même degré le mérite du témoignage rendu par jes Chrétiens des premiers fiecles, qui avoient tout contre eux. Mais il n'y a poine de Pays où le Baptême \& le Miniftere Chrétien ne fe foient introduits. Le témoignage eft donc rendu à la vérité par toute terre $\&_{x}$ en tout temps, foit parce que les demieres converfions font traverfées comme les premieres par toutes les oppofitions de la nature $\&$ de la coutume; foit parceque Jefus-Chrift \& les Apôtres ont prédit la propagation du Chriftianif́me jufqu'aux derniers climats, \& jufqu'aux derniers âges.

Nometrons pas ici que la réalité des faits évangéliques, fi finguliérement atreftés de toute part, étant le fondement de toute converfion folide, la perpétuité de la Foi eft la continuation d'une obéiffance éclairée.

Mlais quoique tous les premiers témoi- 


\section{DE L A N A T UR.E. 175}

guages tiennent à des fères immortelles, LA DL. à des monuments durables, \& à des eflets wonstr. permanents, il eft jufte de faire valoir un F....üi.. nouveau moyon dilluttration que la Providence a cncore accordé à fon Eslife, Nous allons voir fortir du quarrieme fiecle une nouvelle lumiere qui éclairc tous les fiocles Chrétiens, \& qui répand juiques fur les demiers jours tont l'éclat des preuves dontespremiers Fideles ont ćté touchés.

On a quelquefois ellayé, non pas d'a- Rence 1 néantir, car il eft impolfible, mais d'obf- l'objection curcir les preuves précédentes, en alléguane la liberté rendue aux Chréciens en venr acce fiecle par la politique de Conftantin. Conthetin Voila, dit-on, ce qui a ruiné l'Idolâtrie, an Chrif-

\& étendu le Chriftinifme de façon ì nous ôter le droit de trouver du furnaturel dans ces deux événements.

C'eft un peu dommage pour l'honneur de cetre objection, qu'elle vienne trop tard. Il y a trois cents ans que le Chriftianifme dure, malgré les oppofitions de tout ce que le monde a de fort, \& que lidolàtrie s'ébranle de tous côtés, par les attaques de ce que le monde a de plus foible; cet événement eft incroyable, \& il a été prédit. Le Chriltianime a donc fait fes preuves avant Confancin; \& l'cu- . 


\section{LE SPECTACLE}

LA Dé- tiere décadence de l'idolâtrie, loin d'y déITONSTR. roger, y ajoute une force nouvelle, puifŚYNGEL. qu'entre tant d'événements prophétifés \&: accomplis, celui-là manquoit encore.

Quand on croit pouvoir donner quelque couleur à cette objection, il faut fe réfoudre à avoir deux poids \& deux mefures. Tout eft politique dans Confantin. Il ne perfécuta point les idolâtres; \& en favorifant le Chriftianifme, il fe contenta de rendre l'idolâtrie ridicule. C'écoit ì vraie façon de s'y prendre. On vout que ç'en foit allez pour devoir très-naturellement anéantir l'idolâtrie, \& mettre le Chriftianifme en vogue. Si on ne change point de regle $\&$ de méthode de raifonnement, que doit-il arriver fous Julien? Il eft tout-puifiant comme Conftantin: mais à fa qualité d'Empercur viennent fe joindre le favoir \& la dextérité. Son goût pour les connoiffances extraordinaires l'a détaché du Chriftianifme, qui ramene l'homme au fentiment de fes bornes, \& le réduit à croire non ce qu'il conçoit, mais ce qui lui eft attefté. Julien s'eft mis en tête que les fublimes conceptions 2 les auftérités extraordinaires d'Eunapius, de Porphyre, de Maxime, \& d'une troupe de Philofophes quil'obfedent, le conduiront à toutes les f́iences occultes, \&r l'uni- 


\section{DE LA NATURE. 177}

ront intimement avec les Dieux. Il eft de- $L A D E$ venu fyftématiquement idolâtre, \& n'en noxsm. eft que plus ardent à établir ce qu'il croit ÉYAivel. entendre : même il attaque la Religion Chrétienne avec les armes qu'elle lui a fournies, confervant toujours les grands fentiments \& l'eftime de la vertu que fon éducation lui avoit infpirée. Il fe garde bien d'employer la violence ouverte : mais apiès avoir ôté aux Chrétiens leurs Temples, leurs Livres, \&i leurs Ecoles, il emploie fon éloquence \& celle des plus grands Maîtres, pour fpiritualifer le plus qu'il fe pourra le culte des Dieux, en attaquant en toute rencontre la Religion Chrétienne par le côté qui y paroit délavantageux. La folie de la Croix devient, en un mot, la matiere d'une fatyre univerfelle. Pour le coup c'en eft fait du Chriftianifme : qui pourra le maintenir contre ce nouveau genre de perfécution?

La main de Dieu, qui a promis de le maintenir jufqu'aux derniers jours, malgré toutes les Puiffances réunies pour le perdre, fait tourner ces attaques à fon avantage. Les efforts de l'Empereur demeureront impuiffants. Sa faveur, qui enhardit les exces des Philofophes, achevera, en les produifantau grand jour, de les accabler d'un ridicule done ils ne fe

$$
\mathrm{H} \mathrm{V}
$$




\section{LE S P E C T A C L E}

I. A J)-releveront jamais. Lcur grand malheur M axs?: eft d'avoir écrit \& conftaté leurs vifions. trange. Pauvre philofophic! que ne demeuriezvous dans votre ancienne obfcurité! Les ténebres de vos Mylteres faifoient révérer de loin ce qu'on n'entendoit pas. Mais vos partifans vous ont trahie, \& ont défabufé le Public en lui préfentant par écrit vos prétentions \& vos preuves.

Ces hommes avides de merveilleux aroient, en courant le monde, affemblé queiques reftes des vérités révélées dès le commencement à tout le genrehumain, \& outré les plus anciennes pratiques de fobriécé. ills y avoient ajouté les imaginations de tous les Prêtres idolâtres, \& leurs propres égarements. C'eft ainfi qu'on vit un $\Lambda$ pollonius \& bien d'autres Philofophes errants, chercher, depuis Cadix jufqu'à Babylone, les difputes les plus animées, les Interpretes les plus fuffifants de la pofition des aftres \& de la route des influences planétaires, les plus favantes leçons de magie; mais fur-tout Ies plus beaux faits de Théurgie $\&$ de Nécromance. Ils couroient par-tout de cave en cave, \& d'antre en antre. Ils parvenoient cnfin à voir quelque fpectre, quelque illufion nocturne préparée par un impofteur, ou par le pere du menfonge. 
A la vue de ces prétendues merveilles LA Dstouce la doctrine de Placon fur les Dieux moxstr. \& fur les Génies, devenoit indubitable. ÉVANGEL. Hé ! qui pouvoit raifonnablement héfiter fur leur exiftence \& fur leurs facultés? Socraie même, le fage Socrate, cn avoit un qui étoit à fon commandement. Il ne falloit qu'un certain régime, certaines abtinences, cercains facrifices pour plaire à l'un, pour fe délivrer de l'autre. On comptoit parvenir aux extafes, \& aller de plein pied dans toute vérité.

Tout ce favoir emphatique tomba en pouffiere avec Julien : \& le Chriftianifme fublifta. Ce Prince avoit prêté l'oreille à la philofophie, \& il fir honneur à celle-ci des lumieres $\&$ des fentiments qu'il ne devoir qu’à fon éducation Chrétienne. Cecte ingratitude n'eft pointrare. Onlui fit des promefles comme on en fait aujourd'hui à ceux qui fe laiment infacuer de la profondeur des connoiffances de l'homme. Voyez, lui difoit-on, jufqu'où Ia raifon feule peut parvenir. La rôtre eft faite pour atteindre à tout ce qu'il y a de plus fublime. Il fecoua le joug de la Foi, qui le renfermoit dans des vérités de pratique, fans rien offrir à fa ranite : \& cherchant en lui-même fa fagefle, il alla de délire en délire, parce que qui ne fuit pas 
I 30 LE SPECTACIE

IA Dé- l'unique Mấtre que Dieu nous a donné, . niONSTR. marche dans les ténebres.

f́angers La chûte des vifions de Julien \& de

Le qua- toute cette extravagante érudition, eft trieme fic-
cles lumieire de I'E-Chriftinifine remporta dans ce fiecle. gife. Avec la liberté l'Eglife acquit toutes les facilités de faire valoir fes preuves aux yeux de tout l'Univers, \& de les rendre plus durables que le marbre \& le bronze. Durant trois cents ans l'Eglife avoit eu peine à conferver quelques bâtiments en propre. Ils étoient communément faifis pour d'autres ufages, ou abattus prefqu'auffi- tôt qque conftruits. Si on pénétroit dans fes affemblées, on y trouvoit plus l'apparence d'un Sénat que d'un Temple. Son Autel étoit une table : fon facrifice ne montroit aucune trace de la moindre effufion de fang: on ne connoiffoit point fes Miniftres, on ne comprenoit rien à fes fềtes; \& on ne connoiffoit guères l' $E$ glife que par fes fouffiances.

Elle fortit enfin des cimetieres \& des diverfes retraites où elle cachoit fes foJemnités, \& où elle encourageoit fes enfants à la perfévérance, en leur montrant les urnes qui contenoient le fang \& les cendres de fes témoins. Elle n'oublioit rien de ce qui lui étoit cher. Ses fon- 


\section{DE LA NATURE. 18 I}

dateurs, fes maîtres, fes martyrs, leurs IA Dóleçons, leurs lettres, leurs fouffrances, les monstr. actes de leur miniftere \& de leur confef- ÉVANGEL. fion, tout lui étoit préfent : tout étoit recueilli \& écric. La mémoire qui s'en renouvelloit d'annéc en année dans fés fêtes, fe renouvelloit d'un jour à l'autre dans les converfations de fes enfants. Quand il lui fut libre, non-feulement de célébrer fes Solemnités, mais de publier \& de prêcher par-tout fa Foi; au-lieu de s'occuper à rćfuter l'idolâtrie \& la philofophie, comme il étoit raifonnable \& d'un ufago trèsordinaire auparavant, (a) l'Eglife produift route la doctrine au grand jour. L'Eglife montra par-tout fon ancienne hiérarchie, la fucceffion de fes Evêques, fes anciennes inftitutions, \& la confeffion des vérités qui étoient inféparablement unies à fes pratiques. Ainfi s'ouvrit au quatrieme fiecle le Chartrier du Chriftianifme. Les actes qui le compofoient écoient la plupart auffi familiers aux Chrétiens du commun, quà ceux quỉ inftruifoient les autres. Les inftruments \&: les établiffements Apoftoliques, quoique multipliés comme les Eglifes, fe retrouverent par-tout les mêmes. La croyance

(a) Toyez Lactance, Arnobe, Clément d'Aleasndric, Skc. 


\section{I82 LE SPECT AC L E}

LA Dá- des Eglifes d'Afie, mife auprès de celle Munerr. des Eglifes d'Afrique \& d'Europe, ne fe Eravela trouva en rien différente. Quand on la fentit incompatible avec la métaphyfique d'Origene ou d'Eufebe de Céfarée, ou de quelqu'autre nom célebre, on profica de ce qu'ils avoient de bon. Mais toutes leurs penfées fur les Anges, fur la Réfurrection, fur la génération du Verbe, \& fur d'autres points qui ne fe trouverent pas d'accord avec la Foi commune des Eglifes, furent profcrites comme des doctrines étrangeres \& pernicieufes. Cette regle fi fimple de ne dire que ce qui avoit toujours été dit, fidélement obfervée à Nicée par les témoins de cette Foi qui s'y étoient raffemblés de toute part, tranfnit aux fiecles fuivants le Chriftianifme des premiers avec la preuve de fa pureté. Il eft vrai que chaque fiecle Chrérien annonce au fuivant ce que le précédent lui a appris : mais c'eft d'une façon très-fpéciale que le quatrieme fiecle devint la publication \& la répétition du Chriftianifme des trois premiers.

Il y eut en celui-ci des difputes trèsvives : mais par leur nature elles font la gloire de l'Ëglife, \& notre fùreté. Les uns plaidoient pour leurs penfées, ou pour la doctrine d'un Muirre célebre: 
DE LA NATURE. I8 3

ce qui a toujours été \& fera toujours la la Démaladie de l'efprit humain. Les autres Monstr. plaidoient pour ce qui avoit été prêché ÉVANGEL. \& reçu; pour ce qui étoit cru par-tout, $\&$ atcefté, foit par les prieres publiques \& par la commune prédication, foit par les pratiques conftantes, foit par les autres inftruments de la foi des Apôtres. Ce qui a toujoursété, \& fera à jamais le falut de l'Eglife.

Cecte extrême fermeté des Peres de ce fiecle à énoncer nettement \& uniformément non ce qu'avoient penfé Origene, Philon, ou Platon; mais ce que confefloient les Pafteurs \& les Fideles de l'âge précédent, qui touchoient à la fource de toute vérité, fe trouve accompagné d'un autre carnctere de droicure qui appartient en propre à leur fiecle, \& qui en fait pour nous, après le temps du Sauveur, le fiecle le plus refpectable, \& le plus lumineux.

On venoit de paffer fubitement d'une longue \& cruelle oppreffion, à la liberté la plus entiere. Ce moment n'étoit pas fort propre à donner naiflance à aucune innovation. La plupart des Prélats \& des Prêtres menoient depuis long-temps une vie errante \& $x$ pleine de dangers. Un grand nombre de ceux qui furvivoient à la per- 
I84 L E S P E C T A C L E

LA DĹ-fécution portoient les cicatrices \& les moNiTR. marques d'une confeffion généreufe, ou sVANGEL. étoient exténués par les rudes travaux des mines \& des carrieres. De tels hommes connoiffoient le prix de leur Foi, \& n'étoient pas de caractere à annoncer, ou à fouffrir des fables, ni des fyftêmes frivoles, quand la liberté fut rendue. On les trouve fimples \& entiers. Ils font fur le langage de la Foi d'une délicateffe extrême : ils fe déclarent hautement contre ceux qui veulent allier les penfées de l'Ecole avec la philofophie du Sauveur : \& la même uniformité qu'ils veulent dans la Foi, ils la demandent dans la conduite: ils veulent en tout la même droiture.

Epiphan. "Qu'il vous fied mal, difoit Potamon,

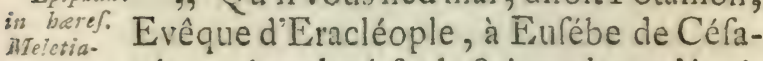
mor. rée, qui malgré fa doctrine plusqu'équivoque fur la divinité du Verbe, fiégeoit à Tyr dans le Concile affemblé contre le grand Athanafe; "qu'il vous fied mal de "vous affeoir ici en qualite de Juge! \& $"$ peut-on fouffrir qu'un Athanafe foit " accufé, paroiffe ici debout, \& attende " fonjugement d'un homme tel que vous? "Je vous connois parfaitement : nous "nous fommes trouvés enfemble dans les " fers au temps de la perfécution. Jai ") perdu cet œil pour la vérité : mais, 


\section{DE L A NATURE. 185}

9) vous, quelle perte avez - vous faite? LA DÉ-

"Quel eft le martyre qu'on vous ait fait MoNstr.

, endurer? Il ne vous refte aucune mar- P.VAarchi.

, que de votre confeffion : parlez, quel

, aurre moyen trouvates-rous pour vous

"faire ouvrir les prifons, que celui de

", promettre à nos perfécuteursque vous

"Cacrifieriez? \& peut-être n'eft-il que

, trop vrai que vous avez cenu parole. "s

Eufebe ne put tenir contre ce reproche, \& quitta le Concile, fous prétexte d'aller affitter à la Dédicace de la nouvelle Eglife de Jérufalem.

Qu'on a droic de fe faire écouter avec de pareilles preuves de conftance $\&$ de fincérité! La pluparr de ceux qui illuftrerent pour lors la Foi de l'Eglife, ou par leurs écrits ou par leurs atteftations portécs au Concile géneral, ou par d'autres fervices, étoient autant de Confefreurs. Quelques-uns étoient favants. Plufieurs s'en tenoient à la fimplicité de la doctrine Chrétienne : ils redifoient avec candeur ce que leurs Prédéceffeurs leur avoicnt appris. L'Eglife éroit leur école; fes écritures \& fa liturgie leur Bibliotheque. Voila les hommes qui perpétuerent le Chriftianifme, \& qui en attacherent les témoignages à des folemnités publiques, ¿ des bầtimonts, \& à des inftruments aufil 


\section{I86 LE S PECT ACLE}

LA Dé-durables que tout l'avenir. Voila les mấMonstr. tres qui en ont formé d'autres, tels qu'lliśvanger. laire, Jćrôme, Ambroife, Auguftin, Chryfoftôme, Léon, \& tous les Doeteurs du premier ordre. L'Eglife s'étoit montrice jufques-là, par fesmiracles, par la fainteté vaiment prodigieufe des hommes les plus pervers devenus fes enfants, \& par les foufrances de fes témoins. Mais fa beauté étoit défigurée aux ycux du genre- humain par les opprobres; \& une vaine philofophie prévaloit. C'eft lo quatrieme fiecle qui plaça l'E gilife dans une fituation avantageufe pour être vue. La Croix fut exaltée par-cout, \& c'eft principslement de ce fiecle fi éclairé, puis du fuivant, que nous vicment les premiers Recueils de l'Hiftoire Eccléfaftique, les Liturgies célebres, les Collectes de nos Fêtes, lcs inftructions de toute efpece, le rétabliffement des Bafiliques, les dédicaces \& la forme de tout le culte cxtérieur; en un mot, le parfair modele de tout ce qu'il falloit croire \& pratiquer d'après l'inftitu. tion des Hommes Apoftoliques.

ra perpes- Ils couronnerent cet ouvrage fi imtuité du té- portant pour nous, par la perpécuité du moign ie sang. témoignage qui renfermoit généralemenc tous les autres, \& qui en tenoit lieu. Ils renouvcllerent par-tout les bâtiments $\&$ 


\section{DE LA NATURE. I87}

les Átrels confacrés à Dieu, fous le nom La Dé. des Témoins, ou fous le nom de Mémoires monstis. de tel ou tel Martyr. On y indiqua les af- Évanget. femblées des Fideles; \& ces folemnités qu'on ne fréquentoit auparavant qu'arec inquiétude \& quavec beaucoup de précaution, fe célébrerent par-tout en grand concours. Ce témoignage qui intéreffoit le ccur des Fideles par les impreffions les plus touchantes, cŏmmença per toute terre, comme toutes les vérités précédentes, à tenir à des fêtes qui le vont rendre préfent à tous les fiecles. Alu-licu done de nous faire aujourd laui d nous-nemes des inftitusions \& des idées du Chrifianifme qui nous autorifent d̀ condamner, méme dans ies premiers ficcles, ce qui ne s'ajuftera pas arec ces idées; notre fagefle efe uniquenuent d'objerver les témoignages des trois premiers ficcles, E de prendre nos idées dans la lumicre du quatrieme, pour $y$ conformer foigneufement notre cráance. Ce n'étoit pas une coutume qui fût particuliere aux Chrétiens, d'enfevelir les morts avec honneur, de célébrer des fètes anniverfaires aux tombenux des perfonnes d'une grande confidération; d'y chanter des hymnes, ou d'y faire l'éloge du défunt, \& de defcendre proceffionnellement daus les Cryptes foutcrraines avec 
isS LE S E C T A L E

LA Dé- un cierge ou une lampe à la main. On MoNstr. voit par les Iliftoriens, par les Poëtes, źangel. \& par les infcriptions qui nous reftent, que les anniverfaires \& tous les honneurs rendus aux morts font aufii anciens que le monde. On peut lire dans la Thébrïde de Stace les fêtes cálébrées fur la fépulture d'Archémore; dansle cinquieme Livre de l'Enćide, l'anniverfaire d'Anchife; $\&$ dans l'ancien Teftament, les homeurs annuels qui ont été rendus à la fille de Jephté, aux Patriarches, \& aux Prophetes auifi-tôt après leur mort, \& long-temps après leur mort. L'Ecriture ne blâme ni les monuments, niles fêtes funebres, niles éloges des morts, mais la déteftable coutume de leur facrifier, äèoquici les efprits, \& de prétendre les interroger fur l'avenir, en safleyant familiérement avec eux autour du fang des victimes mortuaires, dont on les croyoit fort avides.

L'Ecriture parle de cette pratique dans le Livre du Lévitique, (a) dans Ezéchiel, (b) \& bien ailleurs. L'O dyffée nous en fournit le détail le plus conforme à celui d'Ezéchicl, dans le facrifice que fait Ulyffe à l'ombre de Tiréfias. C'eft un abus infigne d'une ancienne pratique très-

(a) Levit. 16:27, \& Hebr. 13:11.

(b) Ezech. $43: 25$. 
innocente, \& c'éroit en même temps une LA Dépreuve parlance de l'ancienne \& univer- monsti. felle perfuafion où l'on éroit de l'immor- Evasigr. talité de l'ame. Les Poëtes font preuve en ce point; parce que leurs fictions fuppofent \& imitent ce qui étoit d'ufage.

Ce qui étoit particulier aux Chrétiens les Mic. à cet égard, \& qui ne pouvoit être d'u- moiresits fage ailleurs, c'étoit de pofer au jour de moven in:l'anniverfaire d'un Marcyr, la table Eucha- failible ce riftique \& le Corps du Seigneur fur les té. reftes qu'on avoit fauvés du corps de fon témoin; ou de pofer ces reftes fous un Autel à demeure. L'Eglife mettoit ainfi auprès de l'Euchariftie, non un fecond objet d'adoration, mais la preuve la plus touchante, foir de la réalité des biens que les Fideles y venoient recevoir, foit de la fainteté du Mliniftere qui les leur difpenfoit.

Le mot de Reliques déja introduit par l'ufage où on éroir en bien des lieux de mettre les corps fur le bucher, \& d'en conferver les cendres dans la famille, devine encore plus commun dans les fêtes Chrétiennes, où l'on ne plaçoit fous l'Autel que les reftes informes d'un corps à demi-brûlé, d'un corps mis en pieces par la violence des bourreaux ou des bêtes.

Gardons-nous toujours de prendre 


\section{I90. LE SPECT ACLE}

LA Dé-quoi que ce foit dans nos propres penfées Monstr. pour l'attribuer à l'Lglife; \& connoiffons Évanuel. les intentions des premiets Chrétiens dans cet ufage, par le rapport des Docteurs les plus refpectables que le quarrieme fiecle ait produits, puifque le premier fruit de la liberté que l'Eglife y obtint, fut de célébrer à découvert les fêtes du Seigneur \& les anniverfaires de fes Témoins. Mais on y trouve en même temps la preuve de leur délicateffe fur l'uniformité. Ils avertiffent de ne faire que ce qui fe faifoit dans les temps de contrainte, \& fe plaignent amérement de la nouveauté des grands repas, qui depuis la liberté de l'Eglife devenoient communs auprès de ces tombeaux. Ce défordre \& leurs plaintes fervent à conftater la très-ancienne célébrité de ces fêtes, la perfévérance des témoignages, l'uniformité de la doctrine, \& l'oppolition du Miniftere à toute nouveauté.

Saint Ambroife, dans le difcours qu'il adrefle à l'Eglife de Milan, pour la féliciter d'avoir recouvré les corps de fes deux martyrs Gervais \& Protais, nous inftruit tout à la fois de l'ancien ufage où étoit l'Eglife d'ériger fes Autels fur les cendres des Martyrs, \& de la différence infinie qu'elle mettoit entre le cuite rendu 


\section{DE L A NatURE, I9I}

a) Jefus-Chrift \& le fouvenir honorable LA Déde fes Saints. "Honorons, dit-il, le Monst? ", triomphe de Jefus-Chrift, en lui ame- Évactis

" nant ces victimes dans le lieu où il

"eft victime lui-même. Mais il appar-

" cient à celui qui eft mort pour tous " d'êcre fur l'Aurel : au-lieu que ceux " qui ont été rachetés par fa mort font " fous l'Aurel.

Saint Auguftin parle de cet ufage avec la même jufteffe \& avec le même feus: "Le Peuple Chrérien, dit-il, (a) fré"quente les Mémoires (b) des Martyrs, "\& les honore par de faintes folemnités, " pour sanimer à fuivre leur perfévéran" ce; pour être affocié à leurs mérites: "pour être aidé par leurs prieres : avec ", cette réferve cependant que nous n'éle", vons point d'Autels aux Martyrs, mais " au Ceul Dieu des Martyrs, même dans "les Temples qui portent leurs noms. "Car quel eft lé Prềrre qui en célébrant " à l'Autel fur le lieu où repofent les corps " faints, ait jamais dit: C'eft à vous, Pier"re, ou Paul; c'eft à vous, Cyprien, que "nous faifons l'oblation. Mais ce qui eft " offert, eft offert ì Dieu, qui a couronné

(a) Libr. 20. conn. Fanf. cap. 21 .

(b) On donnoit ce no:m aild bitiments aufli-bien ภูแ'ลแx fêtes. 


\section{I) LE SPECTACLE}

LA Dú- , fes témoins, \&lui eft offert dans les MéMONSIR. ZVANGEL.

„, moires de ceux qu'il a couronnés.....

"Nous honorons donc les Marcyrs de

, ce culte de dilection \& daffociation

", par lequel nous honorons même les

"faints hommes de Dieuqui font encore

", en vie, avec cette différence que nos

", fentiments pour ceux qui ont confeflé

"la Foi, fontplus animés, parce que les

, Martyrs n'ont plus de cluâte à craindre

", après les combats dont ils fonc fortis

"victorieux. Mais nous n'honorons ni

" n'enfeignons à honorer que Dieu fcul

, de ce culte, que les Grecs appellent de

" Latrie. C'eft à fon culce feul qu'appar-

, tientl'oblation du facrifice. De là vient

, qu'on donne le nom d'idolâtres à ceux

"qui offrent le facrifice aux idoles. Nous

"fommes fort éloignés de le faire : nous

" n'en offrons pas même ni n'enfeignons

" à en offrir à aucun Martyr, ou à aucune

2, Ame fainte, ou à aucun Ange.

Aprèsavoir nettement expliqué ce que l'Eglife fe propofe dans les anciennes folemnités de fes Martyrs, S. Auguftin fe plaint des défordres qu'une joie peu mefurée y introduifoit, \& que l'Eglife ne - fouffroir qu'avec un dép!aifir extrême, en attendant qu'il lui fût poffible de les arrêcer. Cetre expofition de la créance des 


\section{DE I A NATURE. IS3}

Peres du quatrieme fiecle, eft celle de la La Dú.

Foi Catholique actuelle; en forte que fi Monarr. quelqu'un ofe rejetter celle-ci, c'clt une nécefficé qu'il rejette auffi la doctrine des Peres du quatrieme fiecle. Maisleur doctrine n'eft que la propagation de celle des trois premiers ficcles précédents : \& elle eft d'autant moins fufpecte, que tenant à des ufages \& à des fèrès d'une notoriété univerfelle, elle n’a pu être inventée par aucun Docteur du quarrieme fiecle. C'eft une atceftation trìs-folemnellement rendue aux pratiques de l'Eglife, qui avoient éé par-tout pour les premiers Chrétiens de puiffantes leçons \&r de grandes confolations dans leurs foufrances.

On conçoit avec quelle allection les Chréciens qui avoient perdu ce quils avoient de plus cher fous les quacre Prédécelleurs de Conftantin, fe porterent à inmortalifer les derniers tómoignages, ex à les afrocicr aux précédents. C"eft ainfi que le quatrieme fiecle cit le lien de 10 Foi des premiers Chrériens \& de la nutre. Car comme la noure fe retrouve ì chaque page dans les Lcrivains de ce fiecle, qui ne firent que publier fur les toits ce qu'on étoit contraint auparavant de fo dire is l'oreille; il s'enfuit que l'Eglile Catholique a dans tous les temps la même Tome VIII. Part. II. 


\section{I94 LE S PECTACLE}

I.A Dé- Foi, les mêmes fêtes, \& les mêmes téMonsth. moignages.

6incre. Après quoi il devient peu néceffaire d'accumuler ici les atceftations rendues à l'antiquité des Mémoires par S. Cyprien, par Tertullien, par les actes du martyre de S. Ignace, \& d'autres auffi anciens; par la Lettre de l'Eglife de Smyrne à celle du Pont; \& par tant d'autres monuments qui fe trouvent dans l'Hiftoire d'Eufebe \& ailleurs.

I.s for- Il étoit naturel que les monuments de me dic nos cette pratique fe trouvaffent par-tout. Elle Im.jen de étoir en effet des temps Apoftoliques, \& nerpétuer faifoit une partie de la forme qui fut donnage. née dès le commencement aux affemblées des Chrétiens. Cette forme confiftoit dès le premier fiecle en quatre ou cinq parties principales, toujours réunies : une Chaire diftinguée \& placée derriere l'Autel, mais à quelque diftance $8 x$ au fond du bâtiment où la vue fe terminoit ; c'étoit le fiegre de l'Evêque : à côté de lui, à droite \& à gauche, d'autres fieges pour les Prêtres : au milieu de l'affemblée un Autel, fur lequel on célébroir l'Euchariftie: fous l'Aurel, une ou plufieurs urnes où l'on conlervoit ce qu'on avoit pu recueillir ou fauver, foit dufang, foit des cendres, ou les aurres dépouilles des Martyrs: 


\section{DE LA NATURE. 195}

enfin un ou plufieurs candélabres pour LA Défourenir les cierges ou les lampesqui éclai- MoNstr. roient les Minittres \& les Fideles. Cetre árangel. forme fe trouve encore dans l'Eglife de S. Pierre de Rome, dans plufieurs anciennes Cathédrales, dans quelques Eglifes Abbatiales, \& autres; fur-tout felon que les Décorateurs ont pris l'antiquité pour leur regle. S. Jean, dans fa révélation voir la gloire célefte, felon des idées conformes à l'ordre des affemblées Chré. tiennes; un Trône dans le fond; des fieges de part \& d'autre pour les vingtquatre Prêtres rangés à côté de celui qui eft affis fur le Trône : un Autel fur lequel eft l'Agneau comme une victinue égorgúe; fous l'Aurel les Martyrs revêtus d'habits c..the. blancs; enfiu plufieurs candélabres pour éclairer l'Autel \& l'Affemblée.

Le fruit comme l'intention de cetétabliffement Apoftolique, a été de rendre la mémoire des Martyrs toujours préfente \& chere à la poftérité, \& de cerrifier leur confeffion à tous les âges par $\mathrm{la}$ plus grande publicité qui fe puiffe concevoir. De la forte les Fideles ne participerent jamais au mémorial de la mort, de la refurrection, \& de l'afcenfion du Sauveur, fans en avoir devant eux le témoignage le plus fort que des lommes

$$
\text { I ij }
$$




\section{L E S P E C T A C L E}

L. Di-aient pu rendre; qui cft de mourir pour mositr. ce quils ont vu eux-mêmes, \& appris ivmull. de toute part par d'aurres témoins oculaires.

Ces monuments, très-touchants par cux-mêmes, devintent avec cela très-célebres par le concours. Dans une infinité de lieux ils fe convertirent en de grandes Baflliques, ou même en des Villes trèspeuplées, qui en prirent leur nom. Et c'eft parce que le fang des Martyrs a coulé par-tout, que ce témoignage eft devenu univerfel. On ne folemnife nulle part ni les ravages d'Alexandre en Afie, ni ceux des Scipions en Afrique. Quelle part en cfet le genre-humain y prendroit-il? mais oì ne cólebre-t.on pas depuis frizo cents ans les expédicions entreprifes par Pierre \& par Paui, pour gagner des coeursà JefusChrift? connoit-on des Conquérants plus aimables? en eft-il de plus utiles? avec cola connoît-on des conquêtes mieux avérées? eft-il un Continent, un Royaume, une Ifle, où l'on ne montre les monuments du paffage de quelqu'un de ces Miniftres de paix, \&r où l'on ne dife que par eux nos Peres ont connula vérité, \& font entrés dans la voie du vrai bonheur?

Nous ne l'atachons pas ce bonheur à la pompe des céremonies, ou à la magni- 


\section{DE LA NATURE. IO?}

ficence des bitiments. Mais Dieu a permis LA DLqu'en vifitant le plus beau Temple qui lui moxar: foic élevé fur la terre, on puiffe dire: śvaci. Voilà où eft la chaire \&t le tombeau du premier des Envoyés Evangéliques. Le Vatican, oì il elt venu terminer fa carriere, eft cout enfemble le mémorial d'un autre Héros qui a fait la conquête des Gentils. Quel témoiguage que le maufolée commun de ces deur Vainqueurs placé fur les débris de l'idolâtrie?

Les autres Cachédrales montrent partout fous leur Autel, ou ì côté, les monuments de leurs premiers Evangéliftes. II a écé dic à ces illuitres Témoins, d'ateendre le rétabliffement du corps cu'ils on généreufement quitté : mais femblables aux os de Jofeph, ils ont continuellement annoncé à l'Eglife de Dieu fa vocation, \& fes efpérances. La mort n'a pas mis fin à leur prédication. Ces urnes confervées par-tout, ces phioles de lang, ces débris échappés à la dent des bêtes, ces ns noircis par le feu, les bailers des Fideles, lcurs magnifiques préfents qui ont couverti les Mémoires des Témoins en autant de monuments immortels, \&r les on en pluficurs lieux accompagnées d"une Chaire Epilcopale; ici tout eft parlant. Après tant de fiecles nous recrouvons les 


\section{LE SPECTACLE}

IA Dé-fêtes des premiers Ambaffadeurs, leurs Mozstr. tombeaux, leur œuvre, \& leurs Succefbavg.t. feurs. Cet affemblage de monuments publics \& confpirants, eft particulier à l'Eglife Catholique. Les pierres, le bronze, $\&$ les Livres, fur le concours defquels on fait tant de fonds pour s'affurer des événements de l'Hiftoire profane, font, quoiqu'ils fe trouvent ici par mille, les moindres inftruments de la gloire des Martyrs. L'Eglife par fes fêtes leur a acquis une célébrité infiniment fupérieure. Il y a donc perpécuité, \& les preuves du Miniftere Catholique font en tout temps à côté de lui.

Comme nous avons vu les monuments des promeffes difperfés fur toute la terre, nous vojons les témoignages de l'accompliffement, \& les preuves de l'alliance également répandues. Mais quoique le concours de tant de voix foit d'une force invincible, chacun de ces monuments pris à part, porte encore avec lui la célébrité d'un témoignage aufi durable que les fiecles.

J.es aetcs ¿i les mo.

Comme le premier effet de la liberté duments moyen du quatrieme fiecle avoit été de rétablit agc repe- avec fplendeur les Mérnoires des Marconftatent tyrs que la perfécution avoit abattues ou ceux du premier. profanées; les mêmes bâtiments venant 
par la fuice à périr de récufté, le moyen LA Déâge les renouvella, \&r nous communiqua noNstr. tous les nêmes témoignages par des Dí- Évaxgíl. dicaces nouvelles, \& par des Tranfiations qui atteftent d’annce cn année, non les inventions du neuvieme ou du onzieme fiecle; mais le rétabliffement des fètes \&: desbâtiments qui avoient précédé. Quelle précaution falloit-il prendre qui n'ait pas été prife, pour certifier les faits, \& pour continuer la chaine des témoignages?

La certitude fortavec naïveté des défor- Les défordres mêmes. On la retrouve dans les excès $\&$ dans les tumultes inféparables du grand abord des Peuples. On la retrouve dans l'indifcrétion même des Légendaires du moyen âge. N'ayant point par-tout les Actes des Martyrs recueillis felon la praticue de bicn des lieux, \& commu- de fonmi. pratiçue de bicn des lieux, \& commu- niftere. niqués par les Notaires (a) mêmes, plufieurs enchérirent par des traits d'invention fur l'ancienne renommée pour fournir dans ces fêtes les éloges qui étoient d'urage, \& donnerent licu tant aux füntes regles de l'Eglife, quau difcernement d'une faine critique. La faufle monnoie

dires reprochés à I'Eglife

Catholi-

que prou= vent la vérité de fes monuments, \& 


\section{LE SPECTACLE}

İ Dífe difcerne \& fe rejerte fans prójudice ce noxstr. Ia vraie : clle la fuppofe. Anovero La certitude de la vérité fe retrouve dans les débats des Peuples pour ces monuments de leurs premiers Prédicateurs, \& jufques dans l'indécence avec laquelie ils fe les font quelquefois arrachés.

C'ctue vénération pour les tornbeaux des Martyrs, devenus les Aurels du Seigneur, fit accorder de très-bonne heure ou la même fépulture, ou une place honorable à côté de l'Autel, à ceuxqui, fans verfer leur fang, avoient édifié l'E ylife par une éminente piété, \& par des fervices perfévérants. Le même refpect pour tous ces vafes d'élection, fit ceffer l'horreut quon avoit auparavant pour les corps morts: \& l'habitude de réferver cette diftinction à la vertu, fit fouhniter, puis sccorder peut-être trop aifément la fépulture dans les Eglifes au commun des Fideles. Mais ni cet abus, fi c'en eft un, ni les autres, même les plus réels, n’infirment en rien la fuite de la perpétuité; \& le Miniftere Catholique fe tiouve Apoftolique, par la confervation de tous fes émoignages : ils font inféparables de fa fuccefíon, de fes fétes, de les érablifiements, de fes bîtiments, de fon cxercice public \& uniforme, de res aflembléc 
DE L A NA T URE. 20 I annuelles, \& des monuments de toutes LA Deles infignes verus que le Chriftianilme a moxisr. enfantées de fiecle en fiecle. C'eft un tout waigi. indivifible.

Mais il y a une forte d'Actes qui faic la plus grande publicité dos Compagnies de Judicacure, ou d'autres, \& quil eft bien néceffaire d'obierver féparément. C'eft le perpétuel \& principal exercice de leurs fonctions. Leurs anciens Actes fe confervent par écrit. L'esercice actucl en oft la concinuation. Il en réfulce un tout qui annonce nettement les mêmes pouvoirs, \& Is premiere intention. Rien ne montre mieux un Purlement à tout fon reffort, que cette fuite de Réglements \&̊ d'Arrêts qui décident les cas furvenus, qui préjugent les femblables, \& que les Peuple alleguent pour la regle de leur police, $\&$ de leurs profeffions.

Jamais on ne s'eft avifé de troubler les Peuples dans la cercitude oì ils font d'avoir des Traicé: de conmerce \& des Compagnies de Judicacure, qui les reglent, Jamais on ne s'est avilé de trouver dang leur perfunfion un cercle vicieux, qui feroit de moncrer l'ćtabliffement \& le départoment d'une Compagnie par les actes qu'elle a coujours exercés; puis de prouves l'untoricé de fes actes par fon éra.

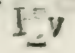




\section{LE SIECTACLE}

La Dé- bliffement \& par les pouvoirs qu'elle a reMoNsTR. çus de la puiffance légiflative. Ce qui fait ĹVANGEL. que ces deux procédés font bons fans fe nuire l'un à l'autre, c'eft qu'à côté de l'établiffement de la Compagnie, \& à côté de l'exercice de fes pouvoirs, fe trouve la fociété enticre qui a pris connoiffance de l'un \& de l'autre; \& par qui fon acquiefcement nous garantit que l'un eft la fuite de l'autre. Alors pour prouver les pouvoirs \& la nature du département d'une Compagnie, il devient indifférent, ou de recourir aux Lettres de fon établiffement, ou de juger de la teneur des Lettres par les Actes qui font émanés \& émanent de fon pouvoir; parce que le Public a une autorité fuffifante, difons même, une infaillibilité naturelle pour nous répondre de la réalité de l'établiffement, \& du droit conféquent de l'exercice.

Il en eft de même de la poffeffion où eit le Miniftere Catholique d'enfeigner toute vérité, de l'éclaircir, \& de la définir. La Dialectique nous accufe d'attribuer à ce Miniftere un pouvoir qu'il nous eft impoffible de juftifier; parce que tantôt nous prouvons l'autorité de l'A poftolat \& du Miniftere immortel par les paroles des Ecritures qui en font émanées, \& par la poffeffion ou il a été d'âge en 


\section{DE L A NATURE. 203}

âge de prêcher \& de définir la vérité; LA Détantôt nous prouvons l'autorité des Ecri- zionstr. tures, \& des Actespoftérieurement éma- ĹVANGel. nés du Miniftere Catholique, par la certitude de la miffion Aportolique.

Ce procédé pourroit paroitre défectueux, fi l'excellence de l'Apoftolat, \&: l'excellence de fes Actes, ne nous étoienc également démontrées par un moyen infailible. C'eft l'atteftation \& l'acquiefcement d'une fociécé vraiment immenfe, répandue par-tout, incapable de collufion, incrpable de méprife fur l'objer de fon atceftation. Telle eft l'Eglife Catholique : elle a vu, touché \& atterté par toure terre les œuvres de l'Apoftolat; elle a femblablement attefté \& garanti la réalité des Ecrits provenus des hommes Aportoliques. Elle nous a inftruits des droits du Miniftere qui a fuccédé aux Apôtres en recevant fa prédication, fes regles, les décifions de fes Conciles, fes profefions de Foi, les prieres de fa Licurgie, enfin les écrits mêmedes Docteurs particuliers, à proportion de l'analogie que le Niniftere $\mathrm{y}$ a reconnue avec la prédication précédente. Tous ces Actes recueillis, attcftés, \& employés tous les jours par une Société qui ne meurt point, forment us

$$
\text { I vj }
$$


20\%. LE SPECTACLA

LA Dú- dépôt aufri public \&̊s aufỉ indéfectble que monstr. la Société même.

ḱvangel. Nous honoions ayec une jufle recennoiflance la faine critigue \& l'érntition qui éclaircir les doutes, \& qui redrefleles méprifes. Mais il y a une notorićté fort fupéricure à l'érudition. La plus favanta hiftoire de notre Magiftrature, \& de nos Traités de paix, n'elt pas ce qui nous affure nos poffeffions, nos limites, \& nos privileges. Nous en fonmes redevables à la réalité du Miniftere qui les a réglés; \&̊ cette réalité nous eft garantie, non par la plume des Hiftoriens, mais par le témoignage très-public \& très perférérant de la Société qui en a pris connoiffance.

Nous n'avons pas befoin de montrc: ici en détail combien la fimplicité de ces moyens, \& la concorde de tous ces Actes fucceflifs du Miniftere, joints au langage uniforme des pratiques univerfellement les mêmes, donnent de facilité aux Pafteurs pour former leur prédication; ni combien les Fideles y trouvent d'abondanies reffources pour être invariablement inftruits de la Foi des fiecles précédunts, même daus les temps d’héréSes, de fchifmes, de perfécutions, de 


\section{ENILA NA T URE. 205}

nunges, de fandales. Ce que nous avons la DĹnéceffairement à faire voir, c'cft la cer- mon:sn?. ticude parfaice où nous fommes dans l'E- t́vingen. glife Catholique d'avoir le vrai Minittere \& la confervation réguliere du dépôt de la Foi.

Or on ne peut non plus contefter ni l'un, ni l'autre à l'Eglife Catholique, qu'on ne peut contefter à la France la rćalité de les Parlements, ou à Venife la connoiffunce de fon Sénat \& de fes Actes.

Ce qui fait qu'une grande Société ne peut fe méprendre fur l'établiffement d'une Cour fouveraine, c'eft que le fait êt très public, \& que la Société y a applaudi comme ì un établiffement trèsavantageux. Cette connoiffance une fois prife fe perpérue dans la même Société: on ne réitere plus les premieres preuves des pouvoirs accordés aux Juges. Leur fuccellion, leurs jugements, leurs réglements, \& l'exercice actuel, montrent ce qu'ils iont. Seulement fil l'un d'cux excédoit fespouvoirs, ou fi tous enfemble ils entreprenoient de réglor ce qui n'eft pas de leur département, par exemple, les opérations militaires; la Société, fans rompre avec eux, les renfermeroit dans leurs boines. 


\section{LE SPEC T A C L E}

I.A Dé- Comme il n'y a jamais eu de publicité MoxsTr. comparable à celle de l'Ambaffade EvanEvinicer. gélique, puifque la voix des Ambaffadeurs, \& les preuves de leur miffion ont été portées par.tout; il n'y a point eu non plus de confentement ni plus touchant, ni plus foutenu, que celui qui a été donné au Miniftere Chrétien par l'Eglife univerfelle; puifque c'eft dans le fort de la durée des preuves qui ont mis au jour la vérité de l'Apoftolat, que cette Eglife s'eft formée de Juifs, de Samaritains, de Grecs, de Romains, d'Africains, d'Afiatiques, \& d'Européens, malgré le favoir \& la policeffe des uns, malgré la barbaric des autres, malgré les dédains \& les préventions réciproques, malgré des oppofitions terribles, malgré des intérêts très-vifs qui tendoient \& tendent plus à les féparer qu’à les unir. Cette conviction dans une multitude d'hommes fi divirés, fi innombrables, fi inébranlables dans une même Foi, ne pouvant être en maticre de faits publics \& foumis au rapport des fens, que l'effet des preuves les plus palpables \& les plus victoricures, la fimple perfévérance de cette grande Société dans fon attachement au Miniftere évangélique le difpenfe de réitérer fes preuves. La Société perpérue elle-même 


\section{DE L A. NA T URE. $20 \%$}

les rémoignages de l'établifiement, \& la la D:notoriété des droits du Miniftere.

De là vient d'abord, que comme le ÉVMNGés Magiftrat rend la juftice fans avoir befoin de prouver fes pouvoirs, le Pafteur $\mathrm{Ca}$ tholique adminiftre la parole \& les Sacre. ments fans fe mettre on peine de montrer le droit qu'il a de le faire. Sa Société, les bâtumentغ, les monuments, l'œuvre qu'il perpérue, tour parle pour lui. L'inquićtude \& les efforts ne conviennent qu"à ceux à qui touc l'univers reproche leur nouveauté, \& la témérité de leur féparation.

Il eft vrai que divers accidents ont détruit plufieurs Eglifes célebres, \& que le fchifme a détaché plufieurs Sociétés d’avec l'ancien Corps de l'Eglife Cacholique. Mais leur témoignage n'eft pas détruit pour cela. Celui que l'Eglife d'Egypte a rendu au Difciple Marc, d’avoir ćté le premier Evêque de ra Capitale, \& d'avoir écrit une Hiftoire Evangélique, fubfifte toujours. Toutes les Hittoires nous ont confervé ce témoignage; \& il eft auffi certain que celui qui a été rendu par les Eglifes d'Afie à l'Apòtre S. Jean, d'avoir réfidé à Ephefe, d'avoir été exilé à Patmos, d'avoir écrit l'Evangile \& l'Apocalyple qui portent fon nom. Le témoi- 
.08 LE SPECTACLE

LA Dé-chage rendu à S. Paul par les habitants de sanstr. Theffalonique \& de Corinthe, de leur inanuzl. avoir adreffé les quatre Lettres qui por. tent fon nom \& le leur, n’a jamais été obfcurci par le moindre nuage, non plus que celui par lequel les Romains nous ont conftaté la Lettre qui les regarde. Toutes ces Eglifes s'entre-communiquoient ainfi leurs richefles : elles ont revu leurs Fondateurs \& leurs Maîtres depuis la réception des Réglements \& des Ecrits qu'ils leur avoient adreffés. Ills font morts au milieu d'elles, en leur donnant tout leur fang pour derniere preuve de la vérité de leur miffion.

Sous la garantie de tant d'Eglifes, témoins de la réalité des miracles, de la réalité des Ecritures, \& des établiffements Apoftoliques, le Miniftere n'a plus els befoin dans les fiecles poftérieurs que de fe montrer avec le dépôt de fes Actes, \& avec le corps de fes pratiques univerfelles, double moyen de rendre à jamais fa prédication invariable.

Sous la garantic de tant d'Eglifes qui n'en font qu'une, il eft également für ou d'écouter le Miniftere pour connoìtre le fens des Ecritures \& des inftitutions primicives, ou de prendre dans les écritures \&. daus le dépôtdes autres Acies du Minif- 


\section{1) E, I A NATURE. 20 ?}

tere, la connoiflance des légitimes pou- La D:voirs des Pafteurs, \& de leur jufte étendue.

Tel eft l'avantage de celui qui fait par- ívasums. tie d'une grande fociété, par exemple, de la Nation Françoife; qu'il eft fü de fon propre état, fans être obligé de faire de longues recherches; \& que s'il les veut faire, il importe peu qu'il commence par examiner fes propres titres, ou qu'il débute par s'affurer de la réalité du Notariat qui les garde, ou du Parlement qui les a réglés. Ses démarches le menent toujours à la certitude, \& la Nation abrege tout en $\mathrm{fa}$ foveur. De là vient encore que fi un efprit féditieux attaquoit les Droits du Parlement, cette Compagnie le condamneroit \& le puniroit, fans craindre le reproche d'avoir jugé dans fa propre caufe.

La République applaudit à cette conL'merepitie dattaques: ita droits du Tlinilate nelesinitme pint: 1. bon.tete les maintient. duite, \& attefte les pouvoirs que cette Cour fouveraine a reçus pour tenir tout dans l'ordre. Tel eft le repos dont jouit le Citoyen dans un Etat policé; telle eft la fécurité du Catholique : elle eft même fort fupérieure.

Pour le faire voir d'une autre forte, analyfons l'Eglife \& la Foi : ne royons dans l'Eglife que ce qu'clle a d'extérieur. Nenvilageons dans la foi du Particulier 


\section{IO LE SPECTACLE}

I.A T) - que le procédé de l'efprit de l'homme. mowstr. Laiffons à part l'opération de l'EfpritEMriol. Saint, qui eft avec fon Eglife, qui forme un coeur fidele, \& qui perfectionne la condition de l'un \& de l'autre.

La foi àu Catholique prife humainement, eft la perfuafion d'avoir partà l'alliance éternelle par le Niniftere qui n'a cefle, lui dit-on, d'en faire l'annonce de la part de Dieu par-tout où il eft poffible. de pénétrer.

Cette foi ne feroit qu'une crédulité légere, fi le Miniftere n'étoir garanti : mais la prédication du Clergé Catholique inclinant l'efprit par la plus grande autorité qui foit fur la terre, \& par la plus grande fûreté que l'homme puiffe defirer, notre acquiefcement ne peut être pour lors qu'une conduite très-fage, \& notre refus ne peut être qu'inexcufable.

Les Miniftres des Rois obtiennent des pouvoirs pour former un établiffement : mais le Particulier qui veut y prendre part n'eft für de rien que par le témoignage public \& foutenu que la Société rend à cette commiffion. L'A poftolat qui s'eft dit immortel \& univerfel, eft digne de notre foumiffion, s'il eft divin; mais comment ferons-nous certains que cette condition eft remplie? Pournous en con. 


\section{กE I A NATURE. 211}

vaincre pleinement, il eft jufte que ce Mi- LA $D$. niftere ait d'abord fait fes preuves, \& Mosstr. qu'une Société digne d'être crue ne ceffe ÉYanger. point de nous les perpétuer. C'eft le cas où nous fommes, $\&$ il ne fe montre nulle part plus avantageufement. Nous recevons le Miniftere Cacholique fous la caution d'une Société immenfe, \& difperfée par-tout; Société originairement témoin des mêmes faits \& des mêmes preuves dans la difperfion; incapable à cet égard d'illufion \& de collufion; rendant témo:gnage aux mêmes vérités de fait contre fon intérêt capital, \& donnant pour toujours à fon témoignage la plus extraordinaire notoriété; d'abord par trois cents ans de fouffrances, puis par une foule de monuments indeftructibles, \& placés de toures parts fous nos yeur.

Tous ces articles ont été prouvés précédemment. Le concours \& l'éclat de ces preuves nefe trouvent nulle part dans un degré comparable à ce que nous voyons dans l'Eglife Catholique. Elle a toujours porté ce nom, parce que ceux quila com. pofent n'ont par toute terre, \& dans tous les fiecles, qu'une même prédication, \& qu'un même culte extérieur. Ils ne fe font point d'abord affemblés ou unis pour rendre témoignage à ce qqu'ils avoient vis 


\section{$2 I 2$ LE SPECTACE}

LA Dé- \&appris: mais l'uniformité du témoignage MoNstr. qu'ils ont rendu dans leur difperfion au ÉVANGer. Miniltere Apoltolique, eft ce qui a le plus contribué à les mettre en un corps de fociété. Nil'hiftoire du genre-humain, ni les communs moyens de garantie ne nous offrent rien qui approche de l'autorité de ce magnifique témoignage rendu par les premiers Fideles; \& c'eft parce qu'ils ont compris l'avantage qui en revenoit à leurs enfants, aux autres Peuples encore égarés, $\&$ à toutes les générations à venir, qu'ils ont pris foin d'attacher leur témoignage, leur crénnce, \& tous les Actes fucceliffs du Miniftere, à des moyens de publicité $\&$ de confervation que rien ne pû́ détruire, ni même obfcurcir.

Rien de plus lumineux ni de plus fü: que la regle de la Foi Catholique : "Ne $\because$ pratiquer, ne dire que ce qui fe prêche "par-tout, que ce qui fe trouve dans "les Actes de la prédication univerfelle: Quod smper, quod ubique.

Rien de plus fenfible, ni de plus efficice que les moyens d'uniformité parmi les Catholiques. Leurs fètes, leur liturgie, les Mémoires des Témoins, tout l'extérieur, voilà l'ancienne \& immortelle expoficion de la Foi Catholique, avec fes preuves toujours vifibles. Que fera-ce 


\section{DE I A NATURE. 2ij}

quand on y joindra les témoignages LA D:écrits?

Vienne fe préfenter, qui l'ofera, pour úranute. livrer l'attaque à un point de la créance, ou des pratiques univerfelles. Arius ofet-il ouvrin la bouche contre la divinité du Verbe qui s'elt incarné, \& qui eft notre Emmanuel, Dieu avec nous? Vigilantius ofe-t-il blâmer l'Liglife de placer honorablement fous la table de fon facrifice les cendres de fes Témoins? 'Tout eft réfuté par avance. La feule diffonance, la nouveauté fuffit pour confondre toures les rectes. L'Eglie Catholique les voit nairre à gauche, à droite, Ex rentrer l'une après l'autre dans leur néant. Seule elle fubfitte \& enfeigne avec autorité, parce qu'elle ne fe montre qu'avec un Miniftere immortel \& divin, done elle a perpétué les preuves \& tous les actes.

Ce n'eft pas ici une traition du caractere de l'hiltoire Chinoile ou Egypdienne; ce n'ell pas une ronomméc comme celle gui faic homeur à Fuby \& à Mercure daroir invencé \& communiqué a) leurs Pcuples des fecrets trís-importants apris lequels on court encore; ce ne funt point de vieux oul-dire, qui prennent dez formes diffirentes d'un Pays l'autre, 


\section{It LES SECTACLE}

LA Dé-d'un jour à l'autre, d'une bouche à l'autre. worstr. Tout eft prédication dans l'Eglife CachoEvacke. lique, \& elle eft hors d'état de rien changer à la créance qui tient à des moyens de notoriété auffi ftables que ceux qui caractérifenc les établiffements humains; avec cette différence, que les bâtiments $\&$ les actes qui montrent le Parlement d'Angletcrre font uniquement dans cette Ille, su-licu que les diverfes pratiques, rout l'extérieur de la Religion Catholique fe perpécuent fans fin, \& font les mêmes par-tout.

La condition de l'Eglife Catholique eft donc bien éloignće de fe trouver inféricure à celle des Républiques qui certificnt \& même s'approprient les Actes de leur Magiftrature, en forte que le Public y puiffe déferer avec fécurité. Dans l'Eglife Cacholique c'eft exactement parlant le Miniltere feul qui prêche, qui offre le lacrifice, qui s'affemble en Concile, qui faffe des réglements \& des définicions, qui inftruile \&r qui engendre des enfants à Jefus-Chrift. Mais l'Eglife Catholique, gui fair que le Miniftere eft infticué pour fon avancage \& pour l'édification die tout le corps, s'en approprie les actes funs injuftice, en s'y foumetant \& en s'y conformant. La doctrine qu'elle reçoir, cile l'appelle fa doc- 
DE LA NATURE. 215

trine. Le facrifice qui s'offre en elle \& La Dśpour elle, elle l'appelle fon facrifice. Elle Monstr. renouvelle dans fes fêres la publication de ÉVANGeL. fes écricures, de lesfymboles, \& de toute fa créance : elle met le tout à l'ufage de tous fes enfants, \& ne craint rien tant que de voir fes richeffes demeurer inutiles faute d'être connues. Où trouveroit-on une plus parfaite notoriéré \& une plus conftante publicité. De même donc que les pouvoirs \& les opéracions de la MIagiftrature, toujours atceftés pas le même cxtérieur, \& toujours maintenus par la République pour qui le tout ctit familier \& $\$$ uluel, ne font ni une tradition obfcure, ni un établiffement incertain; le Catholique trouve un repos auffi parfait dans la garantic de l'Eglife univerfelle, qui ne peut s'approprier \& perpétuer les Actes de l'ancien Niniftere fans être vraiment pour nous la colonnze de la vérité.

Cherchons un aurre moyen de vérité $\&$ de fùreté, s'il s'en peut trouver un. Voyons cclui auquel ont eu recours en divers remps des hommes décififs, qui offenfés d'appercevoir des céfauts dans les Miniftres de l'Eglife, ou blefrés de fe voir affujertis à croire des myfteres audeffus de leur incelligence, crurent devoir fe rendre indépendants. Pluficurs ef- 
216 LE S PECTACLE

I.a Dé-fayerent dans cette vue de détruire le $\mathrm{Mi}$ moxsTr. niftere, qu'ils regardoienc comme un poiárangel. fon dans la fociété; c'ult ce qu'ont fait les Donatiftes: d'autres d'extirper la doctrine commune, qui leur paroiffoit une ganSrene; c'eft ce qu'ont fait les Ariens. Les uns \& les autres ont eu des imitateurs. Suppofons qu'il ait été donné aux derniers venus d'abatre par-tout les Chaires Epifcopales, d'exterminer le Clergé, de dimper toutes les affemblées Chrétiennes, \&r de mettre à néant cous les Actes du Miniftere, à l'exception des Livres Saints. Comme la chofe a été tentée, on peut demander, en cas d'une réufite cnticre, s'il n'eût pas été poffible d'introduire dans la Sociéré un Chriftianifine plus pur.

Laiffons à part l'excoffive abfurdicé d'une fuppoficion où le Miniftere fe trouve abandonné de Jefus-Chrilt contre fa promefie, \& où les hommies entreprennent de faire quelque chofe de plus beau que ce qu'a fait Jefus-Chrift lui-même. Je réponds directement à la fuppofition de l'entier anéantiffement du Miniftere Chrćrien; qu'en ce cas, il n'y a plus de Chriftinnifme fur la terre, \& quon ne pourta l'y faire revive. La preuve en elt fimple.

Quoique 
Quoique l'Eglife univerfelle aic perpé- LA DŚqué fon Miniftere \& fon Dépôt par des Monstr. moyens de confervation auffi fenfibles ávanger. que ceux des Sociétés humaines, il s'y trouve une différence effentielle. Le témoignage rendu publiquement \& perpétuellement par des hommes qui fe fuccedent, eft le même dans l'Eglife \& dans lEtat. Voilà l'exacte reflemblance extérieure. Mais les pouvoirs auxquels le témoignage eft rendu, font fort différents. Les pouroirs des Minifteres civils viennent des hommes: la million Apoftolique vient de Dieu. Des mécontents peuvent entreprendre de ruiner los Bâtiments \&̊: les Actes du Sénat de Venile ou de la Comprgnie des Indes. Mais la République \& la Couronne font invulnérables. La République peut fe rendre un autre Sénat, fi on avoit tué fes Sémateurs; ơ fi des féditicux avoient fait main-bafle fur la Compagnie des Indes, le Roi peuten former une autre. Mais fi le Miniftere péric daus l'Eglife, tout eft perdu pour elle. On difoit d'elle qu'clle baptifoit, qu'elle offroit, qu'elle ordonnoit, qu'elle enfeignois; parce que le Miniltere qui a reçu la propriété des pouvoirs les exerce pour elle. Mais fil'homme qui voit, parce qu'il a des yeux, vient à les perdre, il fer Tome VIII. Part. II. İ 


\section{LE SBECTACLE}

L.a D.- pour toujours dans les ténebres. Qui lui yonsm. rendri des yeux? Dieu feul peut confímoch. truire l'ceil : Dieu reul peut faire revivre l'œil pour le fervice de l'homme. Dieu eft aufil le feul qui puiffe donner des pouvoirs à fes Envoyés, \& par eux vivifier le Corps de l'Eglile. Mais dans l'anéantiffement du Miniftere de falut, la fource des dons falutaires eft tarie pourl'Eglife : elle ne peut plus donner d'enfants à Jefus-Chrift: elle n'eft plusque le fquelerte d'un corps qui a vécu.

On a, dites-vous, fauvé les Livres faints de la déroute univerfelle. Le Texte évangélique nous demeure en entier. Inais qu'en penfez-vous faire? Approchez ce Livre de vorre fouclette d'Eglife, \& cfisyez de lui rendre la vie. Vos efforts feront vains. L'Ecriture évangélique eft un des premiers Actes du Miniftere: mais cet $A$ cte eft fans utilité, depuis que le Miniftere qui le faifoit valoir n'eft plus. C'eft la plus belle partie de la prédicarion : mais il n'y a plus de prédication, puifque tous les Envoyés font cxterminés.

C"eft encore dans les idées univerfellement reçues que nous allons prendre la vraie notion de l'eftime qui eft due à l'Ecriture-Sainte, au plus ancien 
DE LA NATULE. 2IS

Acte que le Miniftere nous ait laifle par LA DE écrit.

MONSTR.

Ei général toutes les Ecritures, foit EANGel. facrées, foit civiles, font par elles-mêmes fonserétifans activité \& fans authenticité. Elles ture. font fans activité. Un Lirre ne vient pas à nous; il faut que quelqu'un nous le mette en mains. Le Traité de Munfter, ni aucun autre, ne s'eft mis en marche vers nous : \& ce qui paffe pour un Traicé de paix, de limites, ou de commerce, ne le feroit pas, ou demeureroit fans effer, fi quelqu'un n'étoit chargé de le produire.

L'activité d'un inftrument devient enfuice la même que celle du Dépofitaire. Si celui-ci n'eft que garde-note \& confervateur, l'Acte demeure chez lui, \& eft fédentaire comme lui. Il faut aller trouver le Notaire pour avoir l'Aete. Mais it le dépolitaire eft Ambafladeur; \& encore plus, fi c'eft une Compagnie, un Corps permanent qui fe montre à cout le Public, \& qui foit chargé d'inttruire les autres de ceque ces Actes contienuent, denrenouveller la publication, de faciliter à tous le moyen d'en prendre connoiflunce, fans jamais refler dans l'inaclion; alors quoiqu'on puiffe \& qu'on doive s'adreller a ce corps pour cue inftruirs, to grand mérite 


\section{$220 \quad$ L E S P E C TA C L E}

LA DĹ- des Actes de cette efpece, leur vraie actiMonstr. vité, n'eft pas feulement d'inftruire quiEYaiger. conque cherche la lumiere; c'eft fur-tout de nous prévenir, \& de ne laiffer perfonne dans l'indifférence. Telle eftl'immortelle activité des Ecritures dans l'Eglife Catholique. Son Miniftere les porte partout, les publie par-tout, \& il eft le feul qui le fafle. Par-tout de fête en fête, \& de jour cn jour, il annonce par un fignal clair, le moment où il renouvelle par partie la même publication. Par-tout dans nos Eglifes, le premier objet qui s'offre aux yeux des affitants, eft la Tribune qui fépare le Peuple d'avec le Clergé, ôx d'où fe fait l'annonce del'Ecriture Apoftolique aux Fideles; \& les Infideles n'en font pas exclus.

Cette lecture, l'exhortation du Pafteur, \& l'offrande du facrifice, voilà le fond de toutes les Liturgies, \& de ce qui fe prariquoit dans les affemblées des Chrétiens du premier âge. (a) L'affemblage de ces trois parties fe retrouve dans les folemnités Catholiques des quatre Continents. C'eft done chez les Cathoilques que l'Ecriture eft vivance; c'eft par eus qu'elle eft annoncée univerfellemen $t$

Z'authen. ticited de TEerizure हvangeliकृue.

Comme une Ecriture eft d'elle-même un inftrument mort, ou fans activité ? (a) Voyez l' $\triangle$ pologic de S. Juftin, 


\section{E LA NATURE. 22I}

elle eft encore par elle-même fans authen- T $T_{A} D_{s}^{\prime}$ ticité. Il ne fuffic donc pas qu'une main Mossin. en nous l'apportane, ou une bouche en wravcet. nous la lifant, lui donne une forte de vie. On ne fait pas pour cela d'où clle vient ni par quelles mains elle a paffé. Il faut pour être reçue \& reconnue comme vraie, que l'Ecriture \& le Porteur aient une garantie.

Il n'y a perfonne qui ne fache qu'une Lettre, un Teftament, une Sentence, une Patente, un Traité, ont befoin pour être reçus, qu'on en connoiffe la main, le Notaire, le Tribunal, le Sceau, l'Ambarfadeur. Mais enfuite quand ces pieces ont été vérifiées, qu'elles ont été avouées par le Public, \& fur-tout par une Société trèsnombreufe qui en devient le témoin \& le répondant, l'Acte ne fe montre plus fans la parfaite notoriété de fa valeur, \& l'on $\mathrm{y}$ trouve à jamais des lumieres fùres.

La Société conferve en même temps les autres inftruments écrits ou non écrits, les monuments, les pratiques, \& toutes les circonftances relatives, foit à la réalité, foit à l'éclairciffement de l'objet de cette Ecriture.

Mais ce qui acheve de faire la fûreté des Actes confervés par écrit, cequi forme en leur faveur une évidence d'expérience

$\mathrm{K}$ iij 


\section{LE S IECTACL}

IA Dí à laquelle on ne réfifte que par entête. Bronstr. ment; c'elt que le Corps ou le Miniftere Avanger. de qui ces $A$ cetes font émanés, foit fubfiftant, \& les maintienne. On fent la différence qui fe trouve entre le Recueil, tant des communes Loix Françoifes, que des Réglements de nos Cours Souveraines, dont la manutention demeure confice à des Compagnies permanentes; \& les Loix d'Athenes ou de Lacédémone, qu'on ne rrouve plus que dans les Livres. On peut bien douter que celles-ci foicnt de Lycurgue ou de Solon, parce qu'aucun Sénat n'a plus la commifion d'en conferver le texte : aucune Compagnie de Judicature n'eft avouée \& $\&$ autorifée à les interpréter, ou à les appliquer. Elles n'ont plus d'effer.

Ainfiles Loix, les Traités, les Actes, \& routes les Ecritures civiles \& faintes, tombent parterre fans validité, quand on les fépare des Dépofitaires qui en ont reçu la garde, \& qui font autorifés à en maintenir l'exécution.

Mais de même que les Loix humaines méritent cout le refpect qui eft dû̀ ì la Puiflance légiflative, quand elles font préfentées \& maintenues par le Miniftere public chargé d'en faire l'application; à plus forte raifon recevrons-nous comme 


\section{DE L A N A T URE. 223}

dirines les Ecritures que nous appellons La D:faintes, quand nous en entendons faire monstr. la publication \& l'interprétation par le śvaAget, Miniltere notoirement chargé de cctre double commiffion.

Si un Quaker, ou quelqu'un qui faic profefion de l'Arianifime, fe préfente pour nous expliquer l'Ecriture-Sainte, cette parole, lui dirons-irous, eft fans autoricé dans votre bouchc. Il eft vrai que le Texce en vient des Apôtres, \& que la fucceflion Apoftolique continue à la publier. Mais du moment que vous avez rompu avec ce Sénat, on ne vous connoît plus de fonction. Vous n'ètes plus Miniftre de la parole : \& écrice ou non écrite, ellen'eft dans votre bouche que la parole d'un homme qui la tourne comme il veve. C'eft le fens de ce Texte, St non la Letre qui en fait le mérite. Mais le Miniftere ancien \& univeriel, notoirement chargé de publier ce Texte $\&$ de nous en tranlmettre le fins, eft cout enfemble aidé \& gouverné dans fon interprétation par les lumieres du dépòt public, \& de la prédication univerfelle.

Ce Texte peut avoir été copié avec des variantes. Il peut avoir été bien \& mal traduit. Mais ces imperfections n'allarment point l'Eglife Cacholique : elles y 


\section{LE SPECTACIE}

ia Dé font compenfées par des inftruments cogonstR. rélatifs, qui fe trouvent fans nombre dans ŚVANGel. le dépôt. Elles y font pleinement réparées par le Miniftere qui a prêché toute vérité avant lo publication des Ecritures évangéliques, \& qui depuis cette publication n'? percu ni fes droits, ni fes connoiffances.

Mettez les Loix Françoifes auprès d'un homme qui fache lire; vous ne formerez pas un Tribunal. Mais qu'un Roi ou une République autorife un Miniftere permanent à publier, à interpréter, à appliquer fes Loix : pourlors on connoit la validité des Loix \& de tous les Actes conféquents, parce qu'on connoît le Miniftere que l'Etat autorife.

L'Ecriture-Sainte n'a donc pas l'unique avantage de nous prérenir par l'activité du Miniftere qui nous l'annonce : elle a de plusle double mérite d'une authenticité qui lui eft affurée par l'Ambaffade que l'Eglife Catholique honore, \& d'un fens que tour concourt à fircr. Correfpondance des Actes de toute efpece, correlpondance du Miniftere qui tient par-tout le même langage, aveu de la Société qui connoit de tout temps les pouvoirs de fon Miniftere; voila les fecours publics \& confjinuts qui alurent l'état du Citogen. 
- ej i i a TuRE. 225

Les mêmes fecours affurent l'état du Ca- La Détholique. Tel eft de part \& d'autre le pro- MIONSTR. grès de notre certitude. Nous fommes fûrs ÉVAżiger. des Actes par le Miniftere : \& nous avons la notoriécé du Miniltere par l'aveu de la fociété.

Quoique les promefles de Jefus-Chrift, fi perfévéramment accomplies jufqu’à nos jours, forment un témoignage fupérieur à tous les autres, concinuons à voir combien il y a de certicude dans les moyens humains que l'Eglife Carholique nous prélente comme toute autre fociété.

Cet aveu d'un feul Miniftere, auquel il faut s'adreller, eft aufli clair \& auffi conlo tant dans l'état civil, que les établiffements publics \& les revenus qui y font atrachés. Cet aveu eft auffi ancien \& auffi perfévéant dans l'Eglife Catholique que les Chaires Epifcopales, que les Temples où nous nous affemblons, que les revenus qu'on y a très-anciennement attachés pour le maincien du même Miniftere, \& de la même œuvre.

L'extérieur eft le même, dit la Méta。 phyfique : mais qui empêche que l'efprit \& la Doctrine ne changent? Il faut alors revenir à l'Ecriture.

Ce changement peut arriver dans les Cociétés qui ont ruiué le Miniftere : elles

I $y$ 


\section{LE S PECTACLE}

L. DÉ-ont en même temps ruiné l'extéricur, ç monstr. les Actes qui les incommodoient, mais ÉVANGEL, qui nous fixent. Chez elles tout eft pure intellection, pure métaphyfique, \& l'E. cricure y tourne comme l'efprit qui is mene : en vain y revient-on. Mais dans l'Eglife Catholique la Foi \& le fens des Ecritures font invariables. La réalité de cette perfévérance du Miniftere dans la faine prédication, eft le fruit de la céle- Bre promefle : \& l'un des plus parfaits moyens de crédibilité qui nous puiffent faire fentir notre avantage, fe trouve dans la ftabilité du dépôt public. Il y a de la forte deux prédications immortelles: l'une muetre, l'aurre très-fonore. Elles fe maintiennent; elles s'entre-éclairent, elles s'entre-juftifient.

On comprend après cela, combien il y a de jufteffe dans ce mot que nous répétons d'après un grand homme. "Je n'a", jouterois point foi à l'Ecriture évan"gélique, fi je n'y étois déterminé par "l'autorité de l'Eglife.

Comme nous avons diftingué dans la Foi ce qui vient de Dieu lorfqu'il touche in cœur, d'avec la conviction de l'hom. me qui croit fur de bons témoignagesce qu'il n'a point vu; nous laiffons ici à part l'autorité fpirituelle que l'Eglife reçoit du 


\section{DE I A NA TURE. 27}

Chef qui la fanctifie, \& qui remplit le LA Dúcœur de fes enfants d'une fécurité inefiz- Moxstr. ble. Nous n'envifageons pour le préfent śvaxgez. que cette infaillibilité naturellement inféparable d'une grande fociété, lorfqu'elle atiefte des faits très-publics. Les Egुliles, comme les Erats, en fe perpétuant perpétuent les témoignages. Cette voie, aufii fùre qu'abrégée, \& à laquelle l'homme étoit fait, eft celle don: Dieu a fait choir pour itui montrer clairement l'Ambafiade de la grande Alliance. La Société la plus croyable en matiere de fait, nous a tranemis, fans incerticude, certe Ambaftade \& fes Actes, dont l'Ecriture du Nouveaus Teftament eft le plus ancien.

Ce Livre ne nous procure pas feule- i'Ear. ment le bonheur d'entendre ceux qui ont Nure da été immédiatement éclairés de l'efprit de Tefum nt Dieu : il nous eft encore finguliérement nous finkavantageux, en nous avertifint de ce qu'il nifter. ne nous livre pas, \& en réglant la mefure du refpect qui lui eft dù.

Quoi donc fe peut-il faire qu'on excede dans le refpect qu'on porte à l'Ecriture de la nouvelle Alliance? Ce mot a befoin d'une prompte explication, \&: elle fe préfente.

L'Ecriture fans le Miniftere eft une lettre morte : \& quoigu'en elle-même elle

$$
\text { K vj }
$$


220 LE SPECTA E

LA DE. foit une philofophie admirable, une phiMoNstr. Lofophie vraiment divine, on ne peut pas transiel. cependant la regarder comme un inftrument qui fuffie pour livrer les effets de l'alliance. On ne peut pas même montrer qu'elle contienne toute la doctrine néceffaire au falue.

La preuve s'en trouve dans la nature $\AA^{2}$ dans le caractere de chacune des pieces qui compofent le Recueil de cette Ecriture. Ce font diverfes parties de la prédication apoftolique mires par écrit. Mais la prédication \& le Miniftere fructifioient précédemment L'Eglife étoit formée. Ce n'eft donc pas l'Ecriture qui forme l'Eglife. Pour la former dans tous les fiecles, il faut que l'Ecriture évangélique, \& tout le dépôt fubréquent foient accompagnés \& appuyés du Miniftere qui les a devancés. Trois ou quatre faits peuvent le faire voir : \& ils fe trouvent dans les événements qui donnerent lieu aux différentes parties du Nouveau Teftament.

La connoiffance exacte que S. Luc prit de toute la vie publique de Jefus-Chrift, en fréquentant affidument les Apôtres, lui donna lieu d'écrire un Evangile plus déraillé que les Hiftoires qui en avoient été recueillies par plufieurs Particuliers. Les blafphêtmes de ceux qui nioient, lợ 
BE LA NATURE. 220

was ia réalité du Corps de Jefus.Chrift, L a DLles aurres la divinité du Verbe, donnerent monstr, lieu à S. Jean d'écrire une Hiftoire évangé- úvancuz. lique, où il infite beaucoup fur ces deux points \& tur les derniers difcours du Sauveur pour recommander à fes Difciples la perfévérance dans l'unicé.

Les Actes des Apôtres font la feconde partie de l'Evangile de S. Luc, \& conticnnent non les actions ou les difcours de Jefus-Chrift, mais l'établiflement de fon Eglife.

La difpute furvenue à Rome entre les Juifs \& les Gentils convertis, fur la préfërence que les uns croyoient avoir à bon titre fur les aurres dans la nouvelle allian. ce, fut l'occafion \& le fujer de l'Épitre aux Romains, qui les réduit tous à un égal befoin de la grace du Sauveur.

Les queftions propofées par les Corinthiens, \& les défordres qui s'étoient gliffés dans leur Eglife, donnerent lieu aux deux Epirres que S. Paul leur adrefte.

L'entreprife faite par plufieurs Docteurs Juifs de foumetre les Gentils, quoique baptifés comme eux, à la réception des ufages de la Loi de Moife, fut l'occafion de l'Epitre aux Eglifes de Galatie.

La vénération bien fondée, mais peu éclairée, que les Hébreux de la difperfion 


\section{LE SPECTACL E}

LA Dé-confervoient pour les facrifices \& pour les woxs rR. autres obfervances de la Loi, eft ce qui enavangelo gagea S. Paul à les inftruire, fans fe nommerlui-même, fur l'excellence du Sacerdoce éternel de Jefus Chrilt, \& fur l'unité de fon Sacrifice, qui fupprimoit les autres en accompliffant tout ce qui avoit été promis.

Par ce court expofé, il oft fenfible que les picces qui comporent le Recueil dut Nouveau Teftament font infpirées comme les Ecrivains qui les ont donnces. $\mathrm{Ce}$ font différents Actes de la premicre prédication. Les lire \& en entendre la publication, c'eft entendre les paroles des A pôtres, \& de celui qui les inftruifoir. Mais cette haute idée que nousavons des Ecritures, \& qui eft en connoifance de caufe, ne nous mene point à négliger les autres moyens de falut, pour nous renfermer dans celui-ci. Ce refpect fi néceffaire \& fi jufte, a donc fa mefure.

Il eft fenfible que ces différents $A$ ctes de la premiere prédication, ont d'abord été des inftructions locales, \& fur des fujets particulicrs : on n'en peut pas conclure que ces différents écrits foient, ni chacun à part, ni tous enfemble, toute la Prédication, tout le Traité qui a été lirré ats Miniftere. Les Apôtres avojent reçu leura 


\section{ก E L NATUKE. 231}

infructions précédemment, \& la parole La Dóa été féconde avant que d'être écrite. Mais MoNstr. quand il feroit réel que les Ecritures évan. ÉvaNGé. géliques renferment le germe de toute vérité, comme elles le renferment fans doute, elles n'ont pas également développé tout. L'interprétation n'en eft pas abandonnée à l'efprit particulier, mais confiée au Miniftere dépoficaire du Texte \& du fens. Elles nous avertiffent elles-mêmes dins lestermesles plus précis: "Que „ la foi vient de i'ouie, que l'ouie eft fon"dée fur la prédication, comme la prédi"cation vient des Envoyćs : " qu'il faut donc recevoir l'A mbaffade; que le Miniftere a reçu de l'E/prit toute vérité, \& l'a communiquée à l'Eglife; que l'Eglife qui nous montre à jamais le vrai Miniftere, eft ainfi le maintien de la vérité.

D'où il fuit que le refpect fi juftement ${ }^{15}$. dû̀ à la doctrine du Nouveau Teftament, n'autorifa jamais perionne à rejetter le Miniftere, ni r rejetter l'Eglife; mais, au contraire, mettra toujours à la tête de nos devoirs celui de recevoir tous les dogmes qu'elle enfeigne unanimement; parce que fachant toute vérité nécellaire, clle nous l'enfeigne à jamais; qu'au befoin elle peut la décider quand elle eft obfcurcie; \& que la confentement des Eglifes 


\section{LE SP E C TACL}

L. Dí-fur un dogme, ne peut être que l'expre?3.ONSTR. fion d'une vérité révélée aux Apôtres \&VANGEL. pour faire partic du dépôt.

Ainfi, quoique Jefus. Chrift n'ait pas voulu que la Foi fùt jamais pareffeufe, puifqu'il avertit fes Difciples de demander, de chercher, de frapper à la porte, de fe précautionner contre les danger's \& contre les mauvais Maîtres, de croître dans la fcience du falut, \& de favoir la vérité pour la pouvoir confeffer; on ne peut qu'admirer les moyens fi fimples, fi publics, fi indivifibles, qui forment \& affermiffent la Foi dans l'Eglife Catholique.

C'eft là que nous trouvons tout, de même que le Citoyen trouve tous les fupports dont il a befoin dans le concours des Loix \& de l'autorité, qui enfemble maintiennent tout le Corps de la République, \& l'état des Particuliers.

Ici figurez-vous un Particulier, puis un autre, \& à leur exemple un troifieme, qui difent chacun à part: "Ne me parlez "plus du Miniftere public. La Magiftra$"$ ture a perdu tous fes droits : elle ne "mérite que nos mépris, \& j’y renonce.

"Eft-ce ainfiqu'on rend la juftice? Je la "r rendrai, moi, \& je la rendrai bien. Il ") ne faut que me laiffer faire : j'ai une 


\section{DE I A NA T URE. 233}

, bonne copie des Loix. Je les applique-

" rai jufte, \& les interpréterai conforméLa DEs " ment à la droite raifon, qui en derniere Evangr. " amalyfe eft le fouverain Juge, \& qui " conféquemment doit juger de tout. Il ", eft vrai que d'autres pourront les inter"préter autrement que moi : mais il n'im$"$ porte ; les gens choifiront; on s'adref" fera à celui qu'on trouvera le méilleur "Juge, \& l'Etar fera réformé. Certes ce n'eft point là la réformation de l'Etat; c'en eft la confuifion \& la ruine: ou plutôt, foit dans l'Etat, foit dans l'Eg li$\mathrm{fe}$, le particulier ne regle rien. Les Lois el!es-mêmes, ni les Réglements écrits n'operent rien; c'eft le Miniftere qui conduic les particuliers, qui applique les Loix, qui enfin opere des effets folides \& durables.

Mais n'eft-ce pas mettre dans la Société un pouvoir qui peut y devenir exorbitant, \& y porter le trouble, parce qu'il paroît illimité?

Il n'y a au contraire rien de plus limité ou de moins arbirraire que le pouvoir Eccléfiaftique. Les Miniftres de l'Eglife Car. tholique font porteurs de la parole \& des Conduite nécefiaire dans l'abus des deux Puifiances. Sacrements; mais ils ne dominent pour cela ni fur les Nations, ce qui n'appartient qu'aux Souverains; ni fur la Foi, ce qui n'appartient qu’à celui quui en eft l'auteur. 


\section{LE SPECTAC IE}

LA Dí- Dis le commencement, le Médiateu: zrosstr. de la nouvelle \& éternelle Alliance inftruiZMANGLL. fit nettement les Envoyés de fesintentions, \& leur ordonna de les communiquer à tous les Peuples fans y rien retrancher,

Resle fans y mettre du leur: Docentes eos ferprecicrite Jetus- vare omnia quacumque mandavi vobis.

curit. La regle des premiers Envoyés fut de confulter fidélement leurs inftructions, avant que d’adreffer la parole à leurs AuRegle te diteurs: Omnia quacilmaque mandavi vobis. 5. Siul.

La regle de leurs Succeffeurs dans le Miniftere qui devoit durer comme le monde, fut de garder le dépôt qui leur avoit été confié : Depofitum cuftodi.

LeCorps Epifcopal n'avoit point d'autre regle dans les fiecles fuivants. "Qu'il ne Rog̣c নin " foit rien changé : Nihil innovetur. N'anPape S.EFtisine.

" a été tranfmis : Nifi quod traditum eft. Regle de "Ce que les faints Peres nous ont ap\$. Bifilc.

$"$ pris, difoit-on a quatrieme fiecle, nous "l'annonçons à ceux que nous avons à ", inftruire. "L'avertiffement de Vincent de Lérins n'eft qu'une application perpétuelle de cette maxime aux plus célebres queftions de Foi.

Tous les fiecles ont répété \& fuivi la même Loi : il eft même impoffible à qui qque ce foit de s'y fouftraire impunément, 


\section{ก E I NATURE. $\quad 235$}

parce que cette Loi n'eft pas feulement LA Dtdans des Livres : elle eft vivante; elle eft monstr. parlante \& intelligible ì tous, puifqu'elle Éraxiat, n'eft point différente de l'immanquable conformité qui fe trouve dans la prédication univerfelle. Si on l'altere en un lieu, elle crie \& réclame dans dix mille autres. Ajoutons qu'elle eft toujours devant nous, \& qu'elle eft auffi publique que l'cuvre la plus publique qui foit au monde. Les Offices de l'Eglife ne fe célebrent pas à huis clos. De quoi font compofées ces Homélies, ces Collestes, \&z ces Liturgies que nos Prélats font réimprimer \& traduire avec un zele fiédifiant? Que contiennent-elles avec l'Evangile, finon les écrits, les prieres, \& les exemples; en un mot, la foi des premiers Fideles? Quand le Clergé voudra changer ou déguifer la Foi des premiers fiecles, c'eft une néceffité qu'il commence par fupprimer la Priere publique, \& le fignal qui en annonce l'ouverture.

Si des Minifres de l'Eglife font quelquefois fortis de leurs bornes aufii connues que l'Evangile, \& fe font portés à des procédés qui excédoient ou leurs pouvoirs ou la prudence de leur Miniftere, quelle devoit être alors la conduite des Fideles? La conduite qu'on a dù cenir, \& qu'on 
236 LE SPECTACLE

LA Dí- a tenue en effer par-tout où l'on fuit les M. NsTr. regles de l'Evangile \& les exemples des waNgel. premiers Chrétiens, a été de fe comporter dans les entreprifes du Clergé fur le temporel, comme les vrais Fideles fe comportent à l'égard des Princes qui empietent fur la Religion. Ces deux maux ne le guériffent ni par la rebellion, ni parle fchifme. Le parfait Catholique demeure foumis à Conftance; mais fans abandonner la Foi de Nicée : \& il demeure uni à Sixte-Quint; mais fans méconnoître le droit inaliénable de la famille des Bourbons. Il remplit toute juftice, \& concilie

* tous les devoirs. Là uniquement eft la vraie patience \& la fage tolérance, où l'on ne bleffe ni l'intégrité du dépôt, ni l'autorite, foit temporelle, foit fpirituelle.

Quand on procede avec droiture, dira-t-on, l'on ne peut difconvenir que les fcandales ne foient compenfés dans l'Eglife Catholique par la prédiction que le Seigneur en a faite, \& par cette multitude de voix toujours parlantes qui y tiennent le même langage jufqu’à la fin destemps, \& ne ceffent d'y publier la même foi \& les mêmes regles. Mais fi les Actes que nous ont laiffés par écrit lesHommes $A$ portoliques, fi leurs établiffements, \& tousles Łémoignages des premiers fiecles fe fons 


\section{B E I A N A T UR E. $\quad 237$}

perpétués de compagnie avec le Niniftere $\mathrm{LA}_{\mathrm{A}} \mathrm{D}^{\prime-}$ fous les yeux d'un grand nombre de $\mathrm{Na}$ - Monstr. tions toujours fubfiftantes; ce Miniftere fi ranger. bien avéré ne fera-t-il pas auffi Apoftolique à Corinthe qu'à Rome? A la bonneheure qu'on fe détourne de toutes ces Eglifes de nouvelle infticution, dont les Architcetes s'entendent auffi peu que les ouvriers de Babel. Mais le Niniftere qui nous prévient fans interruption avec fa Foi, avec fes Autels \& fes monuments, avec l'immortel aveu de fes Eglifes, n'eftil pas auffi digne d'être écouté dans les Sociétés Orientales que dans l'Eglife Latine?

Cela étoit véritable tant que les Eglifes Orientales \& l'Eglife Latine ne furent qu'un corps. Mais le Niniftere de Corinthe \& celui d'Alexandrie ne font plus le Miniftere Catholique, depuis qu'ils ne fone plus partie de la Légation, qui de droit $\&$ de fait porte la parolelévangélique à tout l'Univers, en confervant encore la premicre forme qui a toujours fervi à montrer fes pouvoirs.

Ces Sociétés comme leurs Minifteres, fe Cont détachées les unes des autres, \& d'avec la premiere Chaire, qui en étant auparavant le lien commun, écoit auffi la marque de l'unité du tout. Ce n'eft pas 


\section{$23^{\text {B }}$ LE S P E T A L E}

L.1 Dé-aflez qu'elles confervent un Miniftere qui MoNstr. foit originairement Apoltolique. Il eft voEVANGEL. lontairement vitié \& foultrait à la regle de l'AmbafTade, puifqu'il eft exercé à l'écart \& fans liaifon avec le corps très-connu des Ambaffadeurs. Ces Sociétés font ainfi retombées dans l'incertitude de la philofophie, \& dans les défordres de l'efprit particulier. Cecinous conduit au principe de l'unité, qui cft la feconde qualité effenrielle à un Miniftere pour le rendre légicime \& reconnoiffable.

\section{I.}

I'unité du Minifere Catholique, E de I'Eglife Catholique.

La Sigefre éternelle, en afrujettiffane notre raifon a la croyance de fes Mytteres, lui laiffe tout le mérite d'un acquiefcement jufte, \& y joint le repos de la certitude : puifque pour nous mettre en état de difcerner fans méprife les Envoyés qu'elle a chargés de traiter de fa part avec nous, elle a fait connoître leurs pouvoirs parles deux moyens également fürs \& fimples qui montrent toutes les Compagnies autorifées, \& qui diftinguent fans dilcuflion les Légations per- 


\section{DE LA NATURE. 239}

ivanentes d'avec les pouvoirs irréguliers LA DL¿̂ ufurpés. L'uu de ces deux moyens eft mossta. la publicité de l'exercice actuel du Minif- inangru. tere \& la publicité des Actes de l'exercice précédent; c'eft ce que nous venons de voir : l'autre eft l'unité du Corps, quoique difperfé en différents lieux.

C'eft encore dans les procédés trèscommuns de la Société que fe trouve la jufte notion de l'unité. Un enfant en eft cupable: \& elle épargne toute recherche au Savant, que la multitude de fes vues expole fouvent à fe méprendre. Auffi le Chriftianifme qui eft pour tous, a-t-il ćté réglé fur le pied des établiffements fenfibles qui fe difcernene du premier afpect.

Dans le reffort d'une Cour fouveraine, qui eft une Légation perpétuelle, l'Appariteur a fon pouvoir particalier. Le Juge Notiois contriture de lunite. Commiffaire en exerce un autre. Le Procureur-Général \& fes Subftiturs ont leurs fonctions. Les Tribunaux fubordonnés \& les différentes Chambres ont leur département propre. Mais toutes ces actions, quoiqu'exercées par différentes perfonnes \&r en différents lieux, reviennent à l'unité. Chaque Tribunal fe montre par le concert de fes Membres fous la préfidence d'un Chef. Chaque Chambre a le fien. Le premier Préfident eft à la tête de la 
240 LE SPECTACL E

LA Ds-premiere Chambre, \& de toutes les arovstr. Chambres. Il eft le Chef de toutle Corps. śrANGEL. Tout y eft ainfi dans une correfpondance connue : en forte que les actions particulieres étant faites au nom \& de l'aveu de la Compagnie, portent le nom \& font les actions du Corps, comme les actions de l'oeil, du pied \& de la main font les actions de l'homme.

Telle eft l'unité que Jefus-Chrift a mife dans le Niniftere, qui conféquemment la communique à l'Eglife univerfelle, dont il eft extérieurcment le principe fanctificateur, l'agent néceffaire, \& le lien vifible.

La fin de la miffion du Sauveur, \& de l'œuvre évangélique, eft " non-feule"ment de procurer le falut promis à la , Nation Juive, mais aufi de raffembler "les autres enfants de Dieu malgré leur * Foan 11: ", difperfion* fur toute la terre; ", c'eft de 5.1. 52. former de ces différentes Eglifes une feule Eglife, dans laquelle les vrais adorateurs, unis à leur $\mathrm{Chef}$, rendront à jamais au Pere le culte qu'il demancle, qui eft de l'adorer du ccur \& en vérité. Le Verbe divin a daigné devenir l'un d'entr'eux, les appeller fes freres, \& ne faire qu'un corps avec eux. L'Incarnation \& l'Apoftolat ne tendent qu'à former ce Corps. In cedificatiosipkes. 4 : 22. nem corporis Chrifti.

Cew: 


\section{DE L A NATURE. 24I}

Ceux qui d’âge en âge font, malgré LA Déleurs imperfections, admis dans ce corps nonstr. d'adorateurs, font profeffion de n'être ÉvANigeL qu'un encr'eux, comme ils ne veulent être qu'un avec leur Chef \& avec le Pere, par la charité. Quoique difperfés par-tout, ils doivent s'unir par les fentiments intérieurs, croire les mêmes vérités, atcendre les mêmes biens, embraffer dans leurs prieres, dans leurs fervices, \& dans leur tendre dilection, toute la fraternité.

Cette communion des Fideles qui nous eft donnée * comme la marque à laquelle seom. is: on reconnoitra à jamais les Difciples du 35. Sauveur, a toujours été conféquemment caractérifée au dehors par des liens reconnoiffubles, toujours guidée, facilitée, \& foutenue par l'union extérieure de plufieurs familles avec un Pafteur du fecond ordre, de plufieurs Paroiffes avec un Evêque, de plufieurs Pafteurs du premier ordre, \& de plufieurs Eglifes nationales avec le premier Siege, avec le Chef du Miniftere Apoltolique.

L'amour de l'ordre \& de la paix ne fuffic pas dans la Société pour y établir la paix \&z l'ordre. Il faut des Loix, des Traités de partage, un Miniftere, une promulgation, une magiftrature, une police Tome VIII. Part. II. L 


\section{LE SPECT A C L E}

I.a Dí-réglée. L'amour de l'union ne fuffit pas monstr. non plus pour faire des Chrétiens : mais I I'AnGLL. c'eft pour opérer, régler, \& montrer cette union, que Jefus-Chrift a inftitué un Mi* E.p. 4 : niftere*, \& une affociation connue, com32. Luc. 2: me la réceprion de ce Miniftere. $\dagger$

16. Ceux qui s'en féparent, portent du jour de leur rupture, le caractere de l'efpric particulier qui fort de la regle, \& à qui il n’a rien été promis. " Ne fuffiez-vous, " dit le Sauveur, que deux ou trois Dif", ciples; affemblez-vous en mon nom, , \& je ferai au milieu de vous., , Livret-il enfuite toutes ces petites Sociétés de Chrétiens attroupés en différents lieux, à l'incertitude de leurs penfées, \& à l'indépendance inféparable d'une telle folitude? C'eft, au contraire, pour prévenir la diverfité de conduite, \& la diverfité de doctrines, qui eft le fruit de l'indépendance, qu'il a donné au genre-humain un Miniftere compofé des différents ordres de Pafteurs, d'Evangéliftes, \& d'Ouvriers fubordonnés, travaillant de concert $\&$ dans un même efprit, à former un feul Ephres. 4: corps \& un même cœur : Unzun corpus 4. E. unus Spiritus.

Réunir des hommes difperfés fur toute $I j .11, I=$, la rerre \& dans des fiecles différents, en 13. une même Foi \& en un même efprit, 


\section{D) $E$ L A $\quad N_{A}$ T U is $\mathbb{E} . \quad 243$}

voilà la fin de l'Incarnation. Rien de moins LA D'́compatible avec cette intention, que des MoN'Tr. Prédicateurs ifolés, \& fans fubordination. ÉVANGRL. Rien de plus efficace pour y parvenir, que la concorde des actions d'une Compagnie, dont les différents ordres travaillent conjointement à la même ceuvre : Per ont- Ibid. İ. nem juncturam fubminiftrationis.

Cette uniré d'un Miniftere répandu en diffèrents lieux, eft, felon les idées humaines, la marque la plus vifible de la Société dont il eft le mobile \& le lien.

Mais eft-il fûr que ce foit là réellement la conftitution de l'Eglie, \& qu'elle foit une par l'unité de fa foi, opérée par l'unité de fon Miniftere? N'attribuons point d'inrentions à Jefus-Chrift : mais apprenons celles qu'il a eues, par les difcours \& par les établiffements que toutes les Eglifes ont reçus des Apôtres, \& nous ont tranfmis. Le Sauveur eî̀ expliquant fes intentions à fes Envoyés, leur avoit expreffement recommandé " d'enfeigner \& " de faire obferver toutes les chofes qu'il ", leur avoit ordonnées. "Il y avoit ajouté la promeffe de leur envoyer l'Efprit qui leur donneroit l'intelligence de tout ce qu'il leur avoit précćdemment enfeigné, \& qui leur fuggérercit toute vérité. Ce que les Envoyés après cessatiurances von

$$
\text { L. ij }
$$

iht.its. $=3$ : 20.

Fo.71?. I!: 20. 
244 LE SPECTACLE

LA Dé dire, faire, \& ćtablir pour toujours, c'eft Monstr. Jefus-Chrift qui l'aura infpiré. CommenÉvangel. çons par leurs difcours.

Saint Paul eft fi plein de la communication de tous les fecours que Jefus-Chrift a mis dans l'uniré, qu'il n'elt point d'imagequ'il n'emplo:e pour inculquercette vérité importante. Il met en oppofition l'incerticude des Philofophes, livrés, chacun à part, à la vanité de leurs penfées, avec le bonheur des Fideles qui ne font plus emportés à tous les vents des opinions humaines, mais qui font guidés \& fixés *bes. 4. dans l'unité de la même Foi par différents Ninifteres fubordonnés entr'eux, pour Ibid. $8: 16$. travailler de concert à la même œuvre. EColos, : : iy.

Il va jufqu'à comparer l'Eglife entiere avec le corps de l'homme; jufqu'à comparer les fonctions du Miniftere, qui communiquent à l'Eglife entiere les lumieres $\&$ les graces, avec les liaifons des vaiffeaux miniftériels \& fubordonnés, qui malgré leur difperfion \& la multiplicité de leurs opérations, ne laiffent pas de diftribuer conjointement la vie \& la fanté au corps humain. Tout membre qui eft détaché du corps, ou des vaiffeaux nutritifs, n'a plus en lui l'influence, ni l'action qui vivifie.

C'eft de cette comparaifon, qui eft 


\section{DE L A NA TURE. $\$ 45$}

familiere au faint Apôtre, qu'il tire les LA D'savis les plus néceffaires aux Fideles pour les tenir dans une étroite union avec leurs ÉvaNgers. Pafteurs; \& les plus falutaires aux Pafteuris eux-mêmes, pour empêcher, par exemple, que l'cil trop fier de fa fonction ne dife au pied : Je n'ai pas befoin de vous.

Cette uniré n'ert pas un trait d'élo quence, ou une peinture ingénieufe des avantages de la concorde. C'eft la forme eflentielle que Jefus-Chrift avoit donnée à fon Eglife pour être perpétuée, \& facile à diftinguer julqu'aux derniers jours, Jugeons-en prélentement par les faits, par les établiffements Apoftoliques.

S'il fuffifoit à chaque Eglife, pourêtre L'Apoftoinftruite, \& guidée dans les voies du fa- lat n'un, \& lut, de fe donner à elle-même un $\mathrm{Mi}$ - parluitowniftre fans avoir rien reçu d'aucune autre tes les Eglife, alors ni les Miniftres ne feroient n'en font fubordonnés entr'eux, ni les Eglifes ne qu’ue. feroient un corps. Quelle unité pourroitil y avoir cntre différents Miniftres qui ne forment point une Compagnie? Il ne peut conféquemment y avoir til place vacante, ni aggrégation néceffaire dans une Compagnie qui n'eft point : \& n'ayant poine d'unité entr'eux, ces Miniftresn'en pourront mettre dans les fociérés qu'ils cors

$$
\downarrow \text { iij }
$$




\section{LE SPECTACLE}

LA D'- duifent. L'efprit, les principes, \& les noms movstr. en feront différents. Ce n'eft point làl'Ervavaet, giife de Jefus-Chrift. L'Eglife éternelle eft une par l'unité très-vifible de fon Miniftere, \&x par la profeffion qu'elle fait en le recevant d'être unie à tous ceux qui le reçoivent.

Ce Miniftere renfermé dans Jérufalem, ne fut d'abord qu'un : difperfé \& accru par la fuite, il ne fut toujours qu'un. C'eft parce que l'Apoftolar eft un corps, que la place qui y vaque eft remplie par un Difciple qui n'eft pas feulement choifi, mais aggrégé publiquement. (a)

Avec le College Apoltolique, nous voyons dès le commencement deux autres Colleges; celui des Prêtres, \& celui des Diacres fubordonnés au premier. Mais le même objet, le même efprit, les réunit tous : \& quoique l'excellence de leurs fervices ait différents degrés; quoique leurs actions ne foient pas les mêmes, aucun n'a fon action à part : tout fe fait conjointement, \& il n'y a qu'une Hiérarchie : d'où il fuit qu'il n'y a qu'une Eglife.

Concart Le tréfor commun des Fideles eit la tù Minif- même Foi. Il n'y fauroit être porté atteinte ve de l'u- dans une Eglife, que les Recteurs des nité.

(a) Alusungratas eft cmn amdecim. Act. I : 26. 


\section{E L A NA TURE. 24 ?}

autres Eglifes, que tout le Miniftere ne LA Dssallarme \& ne vienne au fecours. On monstr. héfite, on fe partage à Antioche fur une f́vanget. queftion importante. Les Apôtres, pour en connoitre \& pour rendre le caline à $A$ t. Is. cette Eglife, interrompent leurs différents travaux : ils fe rendent à une affemblée $v .2$. commune. Convenerint Apojtoli.

Le premier ordre honore \& confulte le fecond: Convenerunt Apofoli \& $\int e-$ niores videre de verbo hoc. Selon la letrre du Texte grec; "les Apôtres \& les Prêtres , s'affemblerent pour difcuter ce poinc. "Après qu'ils en eurent beaucoup con"féré enfemble \&i confronté ce que Dieu ", avoit révélé \& opéré à cet égard, Pierre "Te leva, \& prononça fon jugement. „. Barnabé \& Paul y joignirent le leur. Jacques, Evêque de Jérufalem, où fe tenoit: l'affemblée, termina la féance par le fien. Et ego judico.

La pluralité de tous ces jugements qui concourent à n'en faire qu'un pour fixer de l'unité l'Eglife entiere fur un dogme précis, ca- les Comractérife parfaitement l'unité du Miniftere qui la gouverne.

Cette Eglife étendue en très-peu de temps hors de la Judée, \& au-delà même des limites de l'Empire Romain, ne changea point de forme. La hiérarchies'y re- 


\section{LE STECT $\triangle$ CLE}

L.A Dś-trouve la même, \& les trois Minifteres sToNstr. fubordonnés reparoiffent par-tout. $\mathrm{Ce}$ 2 ANGEL. font en tout temps les mêmes fonctions: \&: quoique les Miniftres fe multiplient, tous leurs fervices ne font qu'une même nuvre. Ils s'entre-donnent avis de tout: ils blâment ce qu'ils trouvent de répréhenfible dans le travail de leurs collegues: ils confirment le bien par l'approbation qu'ils y donnent : \& le concert continue à manifefter l'unité.

Le College Apoftolique s’augmente comme les befoins de l'Eglife. Barnabé,

Tagrré- Silas, \& d'autres, y font cooptés. Mais gacion atu College Aportolic'elt l'affociation même qui continue à montrer l'effentielle \& indivifible unité de que, preu- l'A poftolat. Il ne faut point de cooptation,
ve de l'u. nité.

Lia conduioù il n'y a ni Corps, ni Compagnie.

Paul inftruit par l'Efprit de Dieu, ante de faint nonce l'Evangile en Arabie \& dans l'Afie, Paul fuppore la looi đe l'unité.

* Gal. I : II, $128^{\circ}$ 17. fans en avoir* conféré avec aucun homme. Quelque temps après, pour rendre fa doctrine, non pas plus certaine, puifqu'elle étoit autorifée des dons du Saint-Efprit, mais plus profitable à tous par la vifibilité de fon parfait accord avec tout le MiGas. r: İ, niftere; il alla vificer Pierre, puis par un Secunam ordre exprès de Dieu, le College Apofrevolatio- tolique, "de qui il reçut les témoignanow. "zes de l'unité de fon œuvre avec la 
" leur, , \& le département foécial de fa La Duprédication. * Dixtras dederunt mihi \& Moxirr. Barnabre focietatis.

La correfpondance entre les ouvriers s'écend comme l'Eglife, \& ne fauroit être ÉVANGEL. plus publique. Si donc celui d'entr'eux qui n'avoit rien reçu des $\dagger$ hommes, qui te- $t_{\text {s. }}$ Glat. $z$ : noit fa doetrine immédiatement de lefusChrift, évite par une révélation lpéciale de travailler à part, \& " craindroit, dit, il lui-même, de courir en vain,, ou d'avoir rendu fon travail infructueux, faute d'avoir, par un concert marqué, reconnu \& honoré la fraternité Apoftolique; eft-il après cela au pouvoir de quelqu'un de féparer fon œuvre propre de celle du Corps Sacerdotal? Il eft clair que le repos de l'Eglife eft le fruit de l'unanimité, comme l'unanimité eft le fruit de l'oblervation de la regle. Or la regle ef? connue dans toutes les Sociérés humaines, \& elle fe montre à découver dans les progrès du Miniftere évangélique. Ceux qui l'exercent fe multiplient de jour en jour, à proportion du nombre des Fideles. Mais comme il n'y a qu'une alliance, \&x qu'une même foi qui doit les fanctifier tous, il n'y a toujours qu'un Apoltolat. Deux Ambaffides indépendantes feroient un monftre, ou une fource de con- 


\section{LE S P E T A C L E}

IA DĹ fuiron: \& quoique la mifion prît de jour MoNitr. en jour des accroiffements nouveaux d'un ÉVANGEL. Continent à l'autre, l'unité y fubfifta : l'unité embraffa toute la terre.

Les Succeffeurs des Apôtres continuerent à cenir le premier rang; à ordonner les différents Miniftres, qui devoient perpétuer les trois Ordres; à confirmer les Níophytes; à s’aflembler au befoin; à juger définitivement de la Doctrine; \& à faire tous les réglements convenables dans. leurs Synodes; enfin à exercer conjointement la plénitude du pouvoir. Quoiqu“ils. eufrent chacun à part l'infpection d'une Eglife, ils travailloient en commun pour toutes les Eglifes, en leur communiquant les mêmes profeffions de Foi, en rendani générales les décifions formées dans les affemblées particulieres felon l'analogie de la commune prédication; enfin en s'affemblant en commun de toutes les parries de l'univers, quand la chofe devin p̧offible \& néceffaire.

L'Eglife devenue libre au quatrieme fiecle, avoit déja produit au grand jour fa Doctrine, fes Fètes, \& tous fes anciens ufagus. Les difpures fufcitées par la PhiloSophie fur le point fondamental de la Religion Chrétienne, acheverent de monmer la forme primitive \& effentielle de 


\section{DE LA NATURE. $25 \mathrm{I}$}

¡Eglife, en illuftrant par une Afremblée LA Dóécuménique, fon gouvernement \& fon MoNstr. unité. Certe unité, qui avoit toujours été, Ćr.LNGEr. \& qui devoit toujours être la regle vifible des efprits, \& le caractere précis de la vraie miffion, parut à Nicée dans le plus grand éclat. Le modele en avoit été dans le premier Concile de Jérufalem, tenu par les Apôtres mêmes : \& le premier fruit de la liberté de l'Eglife fut de confondre une erreur capitale, en oppo. fant à la Philofophie d'Arius la créance ancienne \& générale, les témoignages des Députés de toutes les Eglifes, les Ecritures Apoltoliques, les anciennes proferfions de Foi, les prieres communes; enfin la décifion infiniment réguliere du premier Ordre, prononçant avec une autorité divinement \& naturellement infaillible. Elle l'étoit divinement, puifque c'efit avec les Apôtres, \& conféquemment avec leurs Succeffeurs, répétant ce qu’ils ont reçu, que Jefus-Chrift a promis d'ètre jufqu'a la confommation des temps. Elle l'étoit naturellement, comme le font toutes les Compagnies qui ne peuvent ignorer leurs propres Loix, fur-tout en confultant juridiquement la poffefion \& lez. Actes publics, où ces Loix fort énoncśes.

$$
\text { L. vj }
$$




\section{LE SPECTACL}

L. J)- Mais l'Eglife Catholique, dont l'unitê Mcsstr. eft rendue vifible par la réunion des PréźVANGel. fidents des Eglifes particulieres avec leurs

Vurite Docteurs en un Concile général, ne perd toujours rifible, rien de fes droits, ni de fa vifibilité même dans dans fa difperfion. Elle n'a pas tous les la difperfi. in des jours befoin de faire des décifions : mais Eveques. elle a tous les jours befoin de faire voir fon unité, afin qu'on ne fe méprenne point dans le choix d'une Eglife. La marque de cette unité doit donc toujours fubfifter.

La pri- La place qui étoit la premiere dès le alauté du Siege de S. Pierre. remps des Apôtres, l'eft encore aujourd'hui : ceux qui l'occupent ont la préfdence \& la prérogative dans les Conciles; ils l'ont dans l'Eglife difperfée. De même que Pierre avoic eu la primauté parmi les Apôtres, étane nommé le premier, agiffant, parlant, \& jugeant le premier, à Jérufalem, à Antioche, \& à Rome, oì il termina fon $\Lambda$ poftolat par le martyre que Jefus-Chrift lui avoit prédit; fes Succeffeurs dans ce dernier Siege, eurent le même rang parmi les Evêques, \& dans toute l'Eglife. Le Siege de Pierre, de fon vivant, \& après fa mort, fut toujours regardé comme le centre commun de la prédication évangélique. Toujours on re- 


\section{DE IA NATURE, $\quad 253$}

garda comme travaillant hors de l'unicé, LA Das $\&$ fans regle, ceux qui étoient fans rap- noxsTr. port à ce centre.

GYANGEL.

Cetre primauté du Succeffeur de Pierre n'eft ni un honneur frivole, ni une domination arrogante, qui dégrade fes collegues, ou qui anéantiffe leurs pouvoirs; c'eft une préfidence qui les montre, c'eft un lien qui affocie leurs fonctions à l'œuvre univerfelle, \& qui en prouve la valeur. C'eft une forme non de bienféance, mais de néceffité. Cette forme étoit connue par-tout dans les fociérés humaines: \& de même que l'Apoftolat, elle eft de l'infticution de Jefus.Chrift. Celui qui a La primute d'inftitufait choix d'une Ambaffade pour inftruire tinn dive à jamais les Nations, a pris foin de la dif- ne. tinguer de toutes les miffions qu'il plairoit à des aventuriers de fe donner. Il n'a fait de tous les Envoyés qu'un corps unique. Tous les membres de ce corps ont un Chef. Par cette union le Corps entier, le Chef, \& les Membres, font à jamais reconnoiffables. Les Clergés, les Chaires, \& les Evêques, font difperfés partout. Mais l'Epifcoparn'cit qu'un. Toures les Chaires n'en font qu'une : \& comme nous n'avons qu'un maître, qui eft JefusChrift, il n'y a qu'une école fur la terre, gुui eft l'E.glife Catholique. 


\section{LE SPECTACLE}

IA Dé- Ricn de plus vifible, comme rien de mosetr. plus néceffaire, que l'unité des AmbaffaÉVANGEL. deurs : rien conféquemment de plus vifible, ni de moins fujet à méprife, que la fociété qui a reçu l'alliance avec la vraie Ambaffade infailliblement rcconnoiffable à fon unité. C'eft ainfi qu'ont parlé de l'Eglife rendue vraiment une parl'unité de l'Epifcopat, tous les Peres les plus refpectables, Irénée, Tertullien, Cyprien, Athanafe, les Peres de Nicée, Auguftin, Optat, \& tant d'autres, dont les témoignages expriment bien moins leurs penfées particulieres que la commune confefiion des Eglifes, \& la réalité de leur union indiffoluble avec le Siege Apoftolique.

C'eft cette invariable \& très fenfible unité du Miniftere, qui en rendant au dehors l'Eglife de Dieu auffi vifible qu'une Ville fituée fur une montagne, y opere intérieurement les plus heureux effets.

$1^{\circ}$. Cette unité affure l'état du particulier, que la néceffité de fon travail difpenfe d'une étude approfondie.

$2^{\circ}$. Cette unité éclaire \& dirige le choix du particulier qui veut s'inftruire \& fe mettre en éta: de défendre la caufe de l'Eglife.

$3^{\circ}$. Ello opere l'infaillibilité de la com- 
ก E L A NA TURE. $\quad 255$

mune prédication. Où fubfifte l'unicé de LA DéİAmbafirade, là eft le même langagge, Monstr. \& l'effet du 'Traité.

$4^{\circ}$. Cette unité en même tempsoblige de toute néceffité les Miniftres de la $\mathrm{Pa}$ role à faire une écude exacte de la doctrine Chrétienne, bien loin de les en difpenfer. Les trois premiers articles ont été éclaircis : le dernier n'eft pas moins évident. L'unité du Miniftere oblige les Miniftres à une érude affidue, parce que l'uL'unité du Minifnité de l'Ambaflade étant deftinée à in- la Foi une, croduire par troduire par-tout la même foi, \& les ble. mêmes efpérances, c'eft une nćceffité que tous les Ambafíadeurs aient reçu les mêmes inftructions, \& publient le même Traité. Or ils n'ont que deux moyens poue y parvenir : c'eft, ou d'apprendrele tout par une révélation nouvelle, que Dieu ni ne promet nulle part, ni n'accorde à perfonne; ou de prendre leurs inftructions dans !e dépôr, comme S. Paull'ordonne, \& comme il fe pratique dans toutes les l.égations permanentes. Ils font donc obligés, pour n'avoir quu'un langage, comme ils ne font qu'un corps, de former leurfavoir fur les Actes du dépôt que leurs devanciers dans la léegracion leur ont laiffé. Mais tel eft l'avantage des Miniftes $\mathrm{Ca}_{2}$ tholiques, que leurs fonctions mên!es 


\section{LE SPECTACL}

IA Dé-fón des leçons pour eux, que la Liturgie cuxstr. eft pour eux une Théologie excellente, trarget. \& qu'ils ne peuvent prier beaucoup fans commencer à favoir beaucoup.

La conformité de leurs inftructions, néceffairement puifées dans les archives de l'Ambaffacte, la folidité de l'œuvre qu'ils accompliffent en commun, \& l'infpection de cout le corps fur le travail de chaque ouvrier, affurent conféquemment à l'Eglife une Doctrine invariable.

Cette infaillibilité, naturellement digne de notre confiance, fe trouve relevée \& vraiment divine par la promefle que fait Jefus-Chrift à l'Ambaffade de la maintenir tous les jours jufqu’à la fin des temps. L'effet eft conforme à la promeffe : la miffion non-interrompue fe fait encore entendre jufqu'aux derniers climats, \& n'y annonce rien qu'elle ne le juftifie par les Actes de l'ancienne prédication.

Mais la condition du Fidele Catholique eft-elle auffi avantageufe qu'on le dit? fon Pafteur, \& tout autre Pafteur, ne peut-il pas abufer plus on moins de fon Miniftere? parmi les Pafteurs, même du premier ordre, S. Pierre ne fut-il pas ré. préhenfible? Victor ne fut-il pas blâmé par les Evêques d'Occident ou de dureté, ou d'imprudence? Ne compie-i-on pas Les 


\section{DE I A NATURE. 25?}

chûtes ou les égarements du Pape Libere, IA D d'Honorius, de Jean XXII? quelle con- Mtonstr. duite que celle d'Alexandre VI? Si les wavari. conducteurs font aveugles, ils conduiront d'autres aveugles dans le même précipice: ou s'il fautque les Peuples réforment leurs Pafteurs, de quoi leur fert-il d'être gouvernés?

Cetre objection qui a été tournée en cent façons, tombe à plomb fur les fociétés défunies; elle en découvre l'incertitude \& l'extrême mifere. Mais bien loin de déshonorer l'Eglife Carholique, elle en releve les avantages: elle en montre les richeffes, qui font faciles à acquérir; faciles à recouvrer quand on a eu le malheur de les perdre; communes à tous; toujours abondantes \& indeftructibles.

Les défauts des Pafteurs feroient déplorables dans l'Eglife Catholique, s'ils devenoient les défauts de l'Eglife mềme. Mais la perpétuité \& l'unité de fa prédication remédient fuffímment à tout. Dans les Sociétés qui le font donné de nouveaux maitres \& de nouveaux noms, l'erreur du maître devient celle de la Société. Trois Eglifes modernes en prélence, fe reprochent néceffairement l'incertitude de leurs voies, par leur proprevariécé: \& comme elles fe réfervent le droit de fe. 
$25^{8}$ LE SPECTACLE

LA DŚréformer, fouvent elles corrigent une MonsTR. doctrine fauffe par une autre aufí pets SYHANGEL. füre.

Hors de l'uniré, l'erreur de celui qu'on écoute eft néceffairement contagieufe, \& la vérité qu’il enfeigne eft dans fes mains un tréfor périffable. L'unité feule remćdie à toute erreur: \& non-feulement elle enfeigne, mais elle garantit toute véricé; parce que l'unité eft vifible, \& qu'elle rend les pouvoirs, l'alliance, \& toute vérité auffi vifibles qu'elle. Saint Cyprien fe trompa fur la rébaptifation: mais en fe gardant de rompre l'unité Sacerdotale, \& en fuppofant pour regle de Foi de s'en tenir à la décifion \& à l'unanimité du Corps des Succeffeurs des Apôtres, il nous montra lui-même le remede de fa méprife. Son attachement à l'unité empêcha les fuites de fa faute, qui fut ainfi couverte par une grande charité. La précipitation, les foibleffes inféparables des penfées humaines, l'erreur miême peuvent pasoître dans l'unité; mais ce font les défauts de tel \& de tel. Jamais ils ne deviendroni ceux de l'Eglife, parce quel'unitéredreffe ce qui eft déréglé; qu'elle réfute fufliiamment toute erreur; qu'elle conferve \& publie à jamais toute vérité.

Cette infaillibilité qui eft affurée à l'E. 


\section{DE I A NAT U R E. 259}

glife Catholique, \& qui l'elt à elle feule, LA D:eft le fruit de fon unité, \& l'unité de ce mosstr. Corps eft l'effer de l'unité de fon Miniftere. Amancers Plufieurs Provinces, qui auparavant n'avoient aucun autre lien que celui d'être limitrophes, viennent-elles à être foumifes à une même Magiftrature \& aux mêmes Loix? ces Provinces forment enfemble un reffort. L'unité de leur Magiftrature \& la perpétuelle application qui leur eft faite des mêmes Loix, lcur communiquent nonfeulement l'unité, mais la connoiffance certaine de leur état commun, \& des procédés qu'il faut fuivre pour s'y maintenir. Le temps fortifie les liens \& la cercitude. Il n'y a qu'égarement \& qu'affliction pour toute famille qui voudra fe fouftraire à l'unité de ce gouvernement.

Cette unité des Minifteres humains, fi propre à lever toute incertitude, eft vifiblement ce que le Sauveur a eu en vue dans les promefles qu'il fic à S. Pierre, Pour favoir tout ce qu'elles fignifient, voyons-en l'exécution.

Aufli-tôt après l'effufion de l'efprit qui Exćcution devoit montrer les effets de l'œuvre de des proJefus-Chrift, \& confoler les Difciples de tes à fuin: la retraite de leur Maitre; Pierre com. Pierre. mence à exercer publiquement la commifion d’inftruire au nom du Seigneur, 
260 LE SPECT A C L E

LA DÉ. \& de dire qui eft Jefus-Chrift. Il fait ufage wonstr. du pouvoir de lier \& de délier : il accorde kvanget. le baptême aux cœurs pénitents, \& refufe la rémiffion des péchés aux converfions fauffes ou équiroques. Il fait ufage des clefs que Jefus.Chrift lui avoit promifes, comme la future récompenfe de fon excellente confeffion: Tibi dabo claves regni. Au moment même de cette promeffe, le Sauveur lui avoit défendu, \& aux autres Difciples, de dire à perfonne qu'il étoit INatt. 16: Jefus le Meffie. Enfin la défenfe eft le30.

vée. Le moment d'exercer le Miniftere eft arrivé : \& par ce pouvoir, comme par la parole de vie, Pierre forme \& fonde l'Eglife, il lui communique les effets de l'infaillibilité \& de l'indéfectibilité promifes pour clle à l'Apoftolat: Porte inferi non pravaliobut adverfus eam.

Pierre eft relevé de fa chûte. Il eft affermi : \& par les prieres du fouverain Médiateur, il eft inébranlable dans fa foi: Rogavi ut non deficeret fides tua. C'eft alors que toutes fes fonctions \& toutes fes qualités fe déclarent. Il eft Pierre \& fondement de l'édifice où Dieu fera à jamais honoré par une foi pure \& par de faintes mours.

Mais cet Apoftolat qui fonde \& forme l'Eglife, lui eft commun avec d'autres En- 


\section{DE LA NATURE. 26 I}

voyés, puifquil eft le premier de tous. * LA D."Recevez l'ESprit-Saint, leur a-t-il été Monstr.

" dit en commun. Ceux dont vous re- évangel.

", mettrez les péchés, ils leur feront re-* Matt. io:

", mis. , + Par ces pouroirs communs, ${ }^{2}+\dagger$ Goan.

\& par leur Légation commune, ils for- $20: 2=2,2 \hat{\mathbf{z}}$. ment l'Eglife conjointement avec Pierre. Leur Apoltolat ne fe divife point. Pierre eft le fondement, \& ils font le fondement : Fundamentum Apoftolorum.

Dans la révélation faice à $S$. Jean, les 20 . noms des Apôtres font écrits fur autant de pierres qui font les fondements de la Cité fainte, \& qui ne forment qu'un édifice, dont Jefus-Chrilt eft l'appui commun: Ip fo Jummo angulari lapide Chrifto Jeju.

Voilà donc deux importantes vérités que l'Eglife n'a jamais defunies; l'une que le Miniftere qui la forme \& qui la gouverne fera jufquaux derniers jours fous la protection de celui qui en a fait l'envoi, en forte que le corps des Envoyés prêchera toujours la véricé: Allez, leur dit-il, enfeignen, \& affurevous que je fuis sratt. 2\&: avec vous tous les jours jufqu'à la con- ${ }^{10,}=9$. fommation des temps; lautre que cousles Envoyés enfemble ne feront qu'un avec le premier de tous, \& que le premier de tous étant par excellence la pierre, la 


\section{LE SPECTACLE}

LA DÉ-premiere pierre du fondement, tout édiMONsTR. fice qui ne tient pas à cette pierre eft hors svancel. du fondement, hors de l'unité, hors de la ftructure de l'Eglife : au.lieu que l'édifice bâti fur cet appui fera l'Eglife de Jefus-Chrift, \& en recevra l'immobilité, qui doit rendre toutes les attaques de l'enfer inutiles.

Si les promeffes du Sauveur fur l'immobilité \& fur la vifibilité que la vraie Eglife tirera de la forme même extérieure de fon Miniftere, avoient befoin d'être expliquées, où faudroit-il raifonnablement en prendre !'interprétation? Par quel privilege les derniers fiecles pouriont-ils mieux entendre les paroles du Sauveur que les âçes prócédents? Il eft prudent \& néceffaire de n'en chercher le fens que dans l'exécution même des promeffes. Le vrai, le grand éclairciffement des paroles du Sauveur fur fon Eglife, fe trouvera fans doute dans la forme de l'Eglife des premiers âges, dans le langage conftant des anciens Docteurs de tous les Continents, \& fur-tout des Docteurs duquatrieme fiecle, qui Tortant avec toute l'Eglife de l'oppreffion \& des ténebres où elle étoit forcée de fe tenir, commencerent à montrer aux Fideles, aux fchifmatiques, \& à tout l'uniFers, l'unité de leur Société, quoique ré- 


\section{E I A NA TURE. $=63$}

jandue par-tout, quoique foumife à divers Pafteurs qui n'étoient tous enfemble qu'un feul \& même Miniftere par leur comLA DÉMONSTR. munion entr'cux, \& avec le Succeffeur de Pierre. Tel eft leur principe \& leur ftyle.

L'effet naturel de cetce forme extérieure n'eft nullement obfcur. Le Sauveur, en protégeant invifiblement fa Légation, cache fon opération fous le voile des procédés ordinaires de la prudence humaine. Ces liens publics, cette communion marquée de tous les Pafteurs entr'eux \&: avec un Chef connu, voilà ce qui rend le corps Sacerdotal fenfiblement femblable à tous les corps infticués par des Légillateurs. Il en réfulce un double effet, qui eft de rendre le gouvernement vifible à tous, \& de perpécuer à jamais l'exécution des volontés du Légiflateur.

L'unité feule opere les mêmes pratiques, le même langage, le mêrne dépôt. Otez l'unité extérieure, il n'y a plus de perpétuité ni d'unanimité.

S'il furvient donc, comme il furviendra fans doute, quelque partage d'avis fur un point; tout alors fera éclairci fuivant les rémoignages de la Doctrine que chaque Eglife a reçue \& toujours profeffée. Tout fera au befoin réglé \& défini par le concours du Chef \& des premiers Paitturs 


\section{LE SPECTACLE}

LA DÉ-dans l'expofition des mêmes dogmes. MONSTR. Quelque autorifés que foient les Fideles ÉVANGLL à chérir \& à pratiquer les vérités qui fe Moctéra- trouvent énoncées dans le dépôr, ilsn'ont tion né- point d'autorité pour condamner ceux
ceffaire aux Fide- qui les conteftent : c'eft au Corps Paftoles. ral qu'il a été dit d'enfeigner, \& qu'il appartient de placer à temps fa définition.

Si le Sauveur n'a pas d'abord tout dit, ni développé ces regles à fes Apôtres dans le temps où ils lui faifoient fur la primauté \& fur la nécefice de leur être affociés, des queftions qui decéloient leur orgueil; c'eft parce qu'il réfervoit à l'Efprit-Saint qu'il devoit répandre fur eux, de les guérir de l'amour des diftinctions \& de la jaloufie des avantages perfonnels; de leur apprendre à temps la forme du gouvernement de fon Eglife; \& de leur révéler toute vérité néceffaire. Il la leur apprit de bouche dans tous les entretiens qu'il eut avec eux depuis fa réfurrection. Il leur en donna l'intelligence, \& leur en fit fentir la force \& l'etendue, par la communication de fon Efprit. Ce qu'ils ont pratiqué vient donc de Dieu: c'eft là, \& non dans les penfées d'aucun homme, que nous trouverons notre regle.

Le commentaire de tout l'Evangile \& le modele de tout l'avenir doivent conféquemment 


\section{DE I A NATURE. $2 \sigma_{5}$}

quemment fetrouver dans la conduite des I.A TSE-

Âpôtres. Deux traits que nous y pouvons monstr. choifir, embraffent tout.

WWANGEL.

Hymenée \& Philet, trop accoutumés Ia comaux difputes des écoles Grecques, \& ne duite de pouvant fe réloudre à admettre comme modele de révélé ce qu'ils ne pouvoient concevoir tout lavefe mêlerent de doymatifer dans l'Eglife de Corinthe fur la réfurrection des corps, \& d'en nier la poffibilité. Les Fideles indignés, enavertirent S. Paul, leur premier Prédicateur. Il réfuta les penfées de ces difcoureurs, \& raffermit la foi de ceux qu'ils avoient ébranlés. Bientôt le foulévement général des Fideles, très-bien inftruits mềme dès auparavant de cette vérité capitale, \& la très-explicite conferfion qu'en faifoient toutes les Eglifes en célébrant annuellement la réfurrection du Sauveur, fermerent la bouche dans Corinthe à ces Philofophes, \& décréditerent leur favoir par-tout où ils oferent oppofer leurs raifonnements à la révélation. Le fandale ceffa. Chacun apprit la néceflité de captiver fon intelligence fous l'obeirlance de la Foi; \& il ne fut point affemblè de Concile, parce qu'on avoir le conientement des efprits \& l'unanimité dans la doctrine. On avoit paravance ce qui auroit été le fruit du Concile. Tonze VIII. Part.II. MI 


\section{$266 \quad$ L E S P E C T A C L E}

L) Dé- Il n'en fur pas de même d'une autre MUNisTR. vérité très-importante \& très-connue, ÍVANGEL. mais obfcurcie dans quelques Eglifes par une grande diverfité de fentiments. Le jufte refpect qu'on ne manquoit pas de conferver pour la Loi de Moïre, \& le zele mal réglé avec lequel plufieurs Hébreux convertis entreprenoient d'afrujettir les Gentils aux pratiques de cette Loi, jetterent plufieurs Fideles \& des Eglifes entieres dans de grandes perplexités.

Saint Pierre, de retour de chez Corneille le Centurion, avoit déja informé l'Eglife tant de la defcente du Saint-Efprit fur les Gentils, comme fur les Juifs baptifés, que de la défenfe expreffe que Dieu lui avoit faite de regarder davantage comme impurs ceux que fa grace avoit fanctifiés.

Dès auparavant le faint Précurfeur, \& Etienne le premier Martyr, avoient nettement annoncé la fin de la Loi, \& la ceffation des Sacrifices pour faire place au feul Sacrifice de Jefus-Chrift.

La doctrine de faint Paul étoit trèspublique \& très-précife fur cette matiere. La vérité étoit connue; elle faifoit partie de la prédication univerfelle : mais elle étoic traverfée par les vues particulieres de plufieurs Miniftres de la parole, qui 


\section{DE LA NA T U RE. 267}

avoicnt destalents, du crédit, \& un defir LA D́́extrême de fe rendre importants. Comme nos'str. la jaloufie \& non l'amour de la vérité ÉFANGEL. étoit l'ane de leur conduite, ils s'appliquerent à exténuer les fervices de S. Paul \& des bons ouvriers; d'une autre part, à egaler par des fophiftiqueries étudićes, la Loi préparatoire à ln Loi évangélique : en forte que bien des Fideles du nombre des Gentils fe croyoient tenus à la profeflion de l'une \& de l'aurre.

II fut donc accordé au befoin des Eglifes, \&al'agitation que cette querelle y caufoit, d'aftembler le corps des Envoyés. Tout fut difcuté par les témoignages confpirants de ce que l'Efprit-Saint avoit opéré \& déclaré par-tout, tant fur l'adoption des Gentils, que fur la ceffation des effers de la Loi depuis les jours de Jean-Baprifte.

Le principal fruit de la difcuflion ne fut pas d'apprendre à l'Eglife un dogme nouveau, puifque l'Eglife décida la vérité qu'elle prêchoit dès auparavant; mais ce fut de réunir les jugements fur ce point, \& de rendre plus fenfible l'unanimité qui étoit déja très-réelle. Après quoile dogme fur lequel on avoit fupporté l'héfication de quelques-uns, érnnt mis dans un nouveau jour \& préciément déeni, ce

$$
\text { M ij }
$$




\section{LE S P E C T A L E}

LA Dé- point acquit le droit de foumettre tous les MONSTR. efprits.

s'ancel. Telle va être à jamais l'autorité de l'Eglife ou difperfée, ou repréfentée dans un Concile par fes. Députés. Toutes fes démarches découlent de l'unité, \& y reviennent. Ses procédés déformais font connus : fa forme eft confante, \& il n'y fera point fait de changement.

Cette forme, qui eft l'interprete des volontés de Jefus-Chrift, fera à jamais la fùreté de l'Eglife. La Primauté n'y anéantit pas les autres pouvoirs: au contraire, elle les fuppofe. L'Eglife eft fervie par le concours de tous les témoignages, par l'exercice de tous les droits, \& par l'ufage d'une jufte liberté: mais toutes ces actions n'en deviennent qu'une, parce que la Primauté en fait la liaifon, \& en montre l'unité.

1.T:Tilire Voici ccpendant auffi-tôt après la mort n'êt point des Apôtres, une nouveauté qui femble condition être un affoibliffement dans l'Liglife, \& funs les doun succef- domne lieu à de jultes définnces. Les Apôfeurs des tres pouvoient enfeigner fürement \& dé-

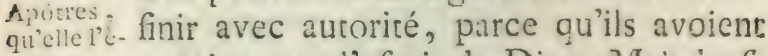
toit au notoirement l'efprit de Dieu. Mais lorfcomment- que les Succeffeurs de leurs places voudront de même faire des décifions, le pourront-ils avec la même cercitude? II 


\section{DE LA NA T URE. $26 \%$}

leur eft nettement commandé de garder LA Dí. le dépôt de la Foi : Depofutum cuftodi. Ils Monstr. font obligés de la forte, \& s'engagent à t́wivgr. confulter toujours le dépôt. C'eft là qu'ils prendront leur prédication : c'eft là qu'ils prendront au beloin la décifion d'un dogme connu, mais obfcurci par des difputes. Ne peut-on pas dire qu'il y a en ceci un grand affoibliffement dans le Miniftere, puifque les Miniftres précédents pouvoient prendre leurs connoiffnnces dans l'immédiace révélation de l'efprit de Dieu; au-lieu que ceux qui vont fuivre, ne s'attendent point à une pareille infpiration? Ils ne doivent dire que ce qui aura été cru, \& toujours, \&s par-tout: Quiod femper, quod ubique. Leur condition fe trouve donc fort inférieure à celle du premier Miniftere, \& la nôtre conféquemment moins avantageufe que celle des premiers Chrétiens.

Mais en cela il ne fe trouve ni défavantage, ni changement réel. C'eft aus contraire un moyen fûr, commun, \& efficace pour perpétuer fans équivoque les intentions du Légiflateur. Comme il n'y a qu'un feul Seigneur qui a une fois nocifié les volontés à fon Ambaffide, il n'y aura qu'un Traité \& une même Doctrine pour tout, \& par-tout. Ceux guj

$M$ iij 
270 LE SPECTACL 2

Ls DĹ-compofent l'Ambaffade enfeignent conMonstr. jointement, \& s'entre-éclairent folidaireíVANGEJ. ment. L'arbitraire ne s'y peut préfenter que les autres ne fe récrient; \& comme l'Ambaffade avec fes actes dure autane que les fiecles, la Foi eft une dans tous les temps.

Si la condition de l'Eglife Catholique eft heureufe, ce n'eft pas feulement parce que les mêmes dogmes ne peuvent être unanimement reçus par tant de Nations qui la compofent, qu'ils ne foient Apoftoliques \& uniformément tranfmis; mais parce que les Miniftres de l'Ambaffade Catholique ayant encore les mêmes fonctions, les mêmes places, le mêtme Chef, la même univerfalité, \& la même unité, en recevant cc Miniftere, nous fommes fürs de recevoir l'Apoftolat qui devoit toujours durer.

On peut bien, par des accufations affectées ou étrangeres au fujet, rendre l'Eglife Catholique odieufe, comme fi elle pouvoit, quand elle voudra, faire paffer des erreurs en dogmes. Mais cet inconvénient n'eft à craindre que dans les Sociétés où l'on fe donne un maître, où l'on écoute un homme. Pour nous, c'eft le Miniftere de tous les fiecles que nous écoutons. Ce quui vient uniquement 


\section{DE I A NATURE. 27I}

des écoles, non du dépôt public, nous La Dúen portons le jugement d'eftime, ou de sonstr. tolérance que l'Eglife en porte elle-mê- ÉVANGEL. me. Nous n'en failons point la regle de notre créance, \& le lailions pour ce qu'il peut valoir. Mais notre commune Foi, la Doctrine qui nous fauve tous, eft précife \& annoncée par-tout. Jamais il n'y fera retranché un iota.

Quand une vérité n'eft pas encore décidée par un jugement fpécial, elle eft cependant déja connue, puifqu'elle ne pourroit être définie, fi elle n'étoit déjz dans le dépôt public où l'Eglife prend tout ce qu'elle annonce. La publicacion d'aujourd'hui ne peut donc impunément être différence de celle d'hier; \& les décifions qui fe pourront faire dans cent ans, font des vérités publiées dans les Livres faints, î dans les monuments des premiersâges, quoiqu'elles n'aient pas été l'objer d'une ¿éfinition fpéciale. L'Evêque de Samofate, un Prêre d'Alesandrie, un Archidiacre d'Angers, peuvent annoncer de nouveaux dogmes: mais tout le Miniftere veille folidairement pour les réprimer. Ce qu'un Miniftre avance de faux, les autres le réfutent. S'ils fe taifoient durant un temps, le dépôt parleroit toujours en leur place. Au contraire, ce que l'un d'en. 


\section{LE SPE T A C L E}

LA Dú-tr'eux dit de bon, les autres en avouent, Monstr. en louent la conformité avec la prédicaatingel. tion univerfelle : \& en lifant l'expofition de la Foi par M. de Meaux, ce n'eft pas Bofluet qu'on écoute; on écoute tout le Miniftere qui y a reconnu la Doctrine de tous les temps. Par la forme même que le Sauveur a donnće à l'Apoftolat, la vérité eft inexterminable dans l'Eglife $\mathrm{Ca}$ tholique, \& jamais l'erreur n'y peut être érigée en article de Foi.

L'efprit particulier peut fans doute caufer de grands maux, même dans l'Eglife Cacholique : mais nous fommes munis contre fes entreprifes, \& il ne peut $\mathrm{em}$ pêcher ni l'indéfectibiliré de l'Eglife, ni l'indéfe cuibilité de la prédication qui fanctifie l'Eglife.

L'erreur. Quelqu'un ofe-t-il ajouter au dépôt, ou en retrancher? Voilà l'erreur. Mais cette erreur, quoique haiffable à proporcion fur-tout qu'on eft inftruit, ne reçoit pas d'abord les qualifications qu'elle peut mériter. C'elt même un devoir d'en fupporter les défenfeurs avec autant de patience que l'Eglife en montre, fi elle differe à condamner cette opinion erronée.

Lheréfie. On ne lui donne le nom d'héréfie qu'après la condamnation. De la forte, la rébaptifation étoir dans S. Cyprien, Firmilien, 


\section{$D E$ I A NA T UR E. $2 \geqslant 3$}

\& leurs adhérents, une erreur : mais de- I. D D puis la définition de Nicée, c'elt une Mon.rn. héréfie.

SVANGET.

Quelqu'un ofe-t-il toucherà l'unité du te anic. Miniftere, foit d'abord en fe fouftrayant à lancienne Hérarchie Catholique, comme tombée en ruine; foit, en fecondlieu, en s'arrogeant une mifion nouvelle \& extraordinaire, pour faire revivre l'Eglife; foit enfin en exerçanc dans l'indépendance $\&$ fans fubordination un Miniftere réguliérement acquis dans fon origine? Voilà le fchifme, pire encore que l'erreur. II ruine dans l'exacte vérité les effets de l'alliance, en rumant la charité, qui efl l'ame du Chriftanifme; \&s il eft tour à la fois la fuice de l'erreur qu'on s'obftine à défendre, \& l'occafion des nouveaux ég̨rements quamene l'indépendance.

On dic aux Partifans de la premiere o 8 de la feconde féparation: Oì eft la révocation de l'ancienne Ambaffade? où eft la vraifemblance de fon extinction après les promeffes précifes que Jefus-Chrift lui a faices, d'être avec elle jufqu'aux derniers jours? \& quand il feroit pollible que JefusChrilt, contre fa parole formelle, eut laifé fon ancienne Ambaffade à l'abandon \&s fans fupport, où font les marques de la vâtre? qui êtes-vous pour réprouver lo 


\section{$274 \quad$ L E S P E C T A L}

LA DÉ- Miniftere précédent, \& pour vous intro. MONSTR. duire en fa place? \& quand vos plaintes źvaNgel fervient juftes, lui ôtent-elles fa miffion, \& vous l'attribuent-elles? pourquoi voulez-vous qu'on vous écoute par préférence à Ebion, à Manès, à Arius, à Donat, \& à tant d'autres qui prennent, comme vous, la qualité d'Envoyés? Vous les réprouvez, \& ils vous réprouvent; vous vous rendez mutuellement juftice: \& fans délibérer, nous vous la rendons à tous, parce que vous êtes fans titres.

Tous tant que vous êtes, vous vous préfentezl'Ecriture-Sainte à la main. Vous ne voulez point d'autre regle : mais loin de vous donner quelque droit, elle vous couvre d'opprobre. Le Traité d'alliance, felon cette Ecriture, a érć confié à une Ambaffade immortelle qu'il faut écouter: \& l'on connoît les différentes dates de vos prétendues miffions. Certe Ecriture facilite la connoiffance \& la méditation des principaux articles du Traite : mais on ne peut pas dire qu'elle foit tout le Traité: le fupplément en $\in$ ft donc dans le Miniftere qui a publié les intentions du Légiflateur avant que d'écrire, \& qui coninue à faire l'annonce verbale du Traité entier, depuis la collection des Ecrics Apoftoliques comme auparavant. 


\section{DE L A NA TURE. $\quad 275$}

Mais quand il feroit vrai que l'écriture LA DÉ du Nouveau Teftament feroit tout le Trai- Inonstr. té, eft-ce affez que vous en ayez une copie évAigeL. pour vous dire Ambaffadeurs?

La confufion feule eft le fruit de cette multiplicité d'Ambaffades : \& comme vous n'avez chacun à part aucun titre qui attire la confiance, vous n'avez chacun à part aucune regle qui vous fixe. Vous prenez cous l'Ecriture pour regle; mais elle n'en eft plus une pour vous. Puifque le fens en eft fous le gouvernement de votre efprit, au-lieu d'être comme eft l'Ecriture dans l'unité Catholique fous l'interprétation du Miniftere qui en eft porteur, \& tout enfemble fous l'éclairciffement du dépôt univerfel. Dépôt infiniment public, dépôt qui fixel'interprétation, \& maîtrife autant les Ambaffadeurs qu'il les aide. Dans l'Eglife Catholique tout fe prête des fecours mutuels : chez vous tout s'entredétruit.

Loin de pouvoii juftement prétendre à la qualizé d'Envoyés quion ne fe donne point, vous ne pouvez pas même raifonnablement vous flatter de la qualité d'enfants de l'Eglife. Carficelle qui vous Virres. a enfantés étoit l'Egiile, vous n'avez pas ${ }_{N}^{B}$ Nutu, dûl la quitter. Si la vraie Eglile étoit quelque part ailleurs, par exemple en Abyfi-

$$
M v j
$$




\section{L E S P E T ACL $\mathbb{E}$}

I. DÉ-nie, ou en Grece; pourquoi ne vous y MronsTR. êtes-vous pas unis? \& fi l'Eglife n'éroit ÁYANGEL. plus, qui vous a engendrés à Jefus-Chrift? vous avez tout perdu pour vous-mêmes, \&: égaré vos Difciples en enfeignant hors de l'unité.

Quant à ceux qui croient avoir confervé le Miniftere Aportolique, mais qui l'ont démembré du total, qui ont réprouvé le refte, \& concentré l'Eglife dans leur fociété particuliere, on leur dit: Vous avez une apparence de fucceffion dans le Miniftere. Mais vous en avez perdu le fruit en l'exerçant à votre gré, \& en vous fouftrayant à la Loi de toutes les Légations permanentes, qui eft d'être uni au Chef, \& de travailler fous l'infpection du corps de l'Ambaffade entiere. Celle-ci n'étoit néceffairement qu'une, foit pour annoncer les mêmes vérités \& la même alliance à tout le genre-humain; foit pour rendre l'Eglife de Dieu reconnoiffable en la diftinguant des Sociétés irrégulieres par l'unité vilible du Sacerdoce univerfel. Il ne tienr pas à vous que la Foi ne foit devenue équivoque, \& le choix d'une Eglife incertain. Vous avez à jamais perpétué les haines \& le trouble, en multipliant les Eglifes. A quel titre avez-vous pu, chaque Cauton a part, vous approprier la Léga- 


\section{DE LA NAT URE. $27 \%$}

zion? une parcelle détachée du corps de LA D\& l'Ambaffade devient-elle toute l'Ambaffa- Monsar. de? après cette rupture, quelle certicude Evaron. aurons nous de l'intégrité de votre commiflion, \& de la confervacion du dépôt dans vos mains? en rompant avec le Corps Sacerdotal, vous n'avez plus de garants qui répondent de la bonté de votre œurre? fi l'erreur s'eft gliffée parmi vous, où avez-vous trouvé une lumiere fidelle? \& fi vous êtes tombés, qui a pris foin de vous relever?

Ne voyez-vous pas qu'aucune Eglife particuliere ne fe fuffic à elle-même, \& In $\cos$ muning qu'iln'y en a aucune qui ne publie qu'elle croic la Communion des Saints? mais en cas Saints vain le dites-vous comme les autres, fi tiques vous vous privez de cette Communion \& de fes effets, fi vous rompez le lien extérieur qui le communique. En vain ces faintes Sociétés, répandues par-tout, enverront-elles leurs témoignages ou leurs Députés, pour procurer aux Particulier \& au Corps entier des avercillements, des réglements, des décifions. Ces précieux effers de la Communion des Snints fone perdus pour vous. Toute Eglife qui s'arroge l'indépendance en ruinanc les liens de cetre Communion univerfellement honorée, introduit une forme d'Eglife que 


\section{LE SPECTACLE}

LA Dú les Hommes Apoftoliques n'ont pas étaMIONSTR. blie. Elle perd fa propre autorité, \& fe Ĺ LANGel. refure le profit de l'aucorité que les autres confervent, en demeurant inféparables.

Vous aviez, dites-vous, des griefs qui demandoient votre féparation d'avec le Siege de Rome \& d'avec les Occidentaux. Iis fe rendoient indignes d'être plus long-temps dans la Communion de vos Eglifes, en continuant, malgré vos plaintes, à inlërer dans le Symbole que l'EfpritSaint procede du Fils comme du Pere; à célebrer l'Euchariftie avec du pain azyme; \& à interrompre pendant le Carême le chant de l'alleiuia.

Quand vos reproches feroient plus fondés \& plus graves, votre féparation n'en feroit ni plus prudente, ni plus légitime. Vous rous qui, avec les Pafteurs d'Occident, partagiez le Miniftere Cacholique, \& ne faifiez qu'un avec nous, vous aviez dans vos mains, auffi-bien que nous, les Ecritures, la prédication univerfelle, les maximes des faints Docteurs, \& tout le dépôt qui contient, avec les principes de tout bien, la réforme réguliere des abus, l'avertifement des fcandales à venir, \& les moyens de vous en défendre. Parmi ces moyens vous n'avez point trouvé celui de la ruprure. Vous y 


\section{ก E I A NATURE. $\quad 279$}

avezappris, au contraire, que les Envoyés $L_{A} D_{k}$ même couroient en vain, s'ils préten-MONSTR. doient exercer leur Légation, indépen- Ívaligel, damment du Corps de l'Apoftolat.

Tout l'univers a condamné les Dona. * Gal. 2: tiftes qui concentroient chez eux l'Eglife. Tout l'univers a applaudi à la maxime d'Auguftin, qu'il ne peur y avoir de jufte caufe pour faire une Eglife à part en rompant avec les autres.

Si vous pouviez vous éloigner des $\mathrm{Oc}$ cidentaux, c'étoit au casque l'Eglife univerfelle les eût convaincus de quelques faux dogmes, \& les eût manifeltement retranchés fur le refus opiniâtre d'abandonner telle \&r celle erreur. Mais la chofe implique dans les termes, \& ne peut être arrivée. Cumment voulez-vous que la moirié de l'Eglife \& le Chef commun fe retranchent eux-mêmes, ou puiffent être reuranchés par l'autre moicié? Quand les fcandales \& les erreurs auroient été réels, c'étoic le cas de fe fupporter en paix. L'unique parti légitime éroit d'aider mode[tement la véricé à prendre par-tout le deflus, \& d'attendre fans amertume l'éclairciffement de vos prétendus griefs.

On ne remédie à rien par l'impatience; \& quand il feroit vrai que toutes nos Eglifes étoient pleines d'ivraie, nous 


\section{LE SPECTAC I}

LA Dé-érions avec vous la commune moifion Monstr. du Seigneur : nous érions dans le même áVANGLL champ. Or il avoit expreffément défenciu à fes ouvriers d'arracher tout d'un coup l'ivraie avant la moiffon, \& de la jetter dehors. Il falloit, dans la fuppoficion de fon mèlange général avec le bon grain, la foufrir avec le bon grain, de peur d'cmporter le bon grain, en voulant extirper l'ivraie par trop multipliée. Une telle réforme ne pourroit être qu'un vrai ravage.

Ce u'eft pas feulement par cette infigne défobćiflance que vous êtes convaincus d'etre de mauvais ouvriers. Vous nel'êtes pas moins par la petirefe avec laquelle vous exercez vorre Miniftere. L'Eglife Catholique feule fe fouvient à jamais que le fien n’a point de bornes, \& il fe montre pair-tout, parce qu'il eft pour tous. Sa prédication \& Con zele s'étendent comme fes obligations. Jufques dans les derniers jours il illuftre fa prédicacion par le martyre. (a)

On vous entend faire des plaintes ameres de fon activité. Nos Miffionnaires s'infinuent, dites-vous, dans tous vos

(a) Voyez le difcours de Jionoit XIV fur la mertyre de leverine de Niauricaltre, decopite a la Chinc lo s6 MIai $17 \div 2$. 


\section{DE LA NATURE. $28 \mathrm{I}$}

Etats, \& dans vos familles. C'eft une ar- LA Dosdeur, une inquiérude qui vous bleffe : MoNst?. \& vous la réprimez par des Loix féveres. "vaxøeis

Mais jugez mieux de la ferveur de leur prédicarion, \& de la froideur de la vôtre. Vous confeffez par vos plaintes que le Miniftere Catholique s'adreffe au genrehumain. Hé, n'eft-ce pas là fa vocation? Il ne ceffe ou de tirer les hommes de l'infidélité, ou de les ramener de l'égarement du fchifme dans l'unité. C'eft une œuvre à laquelle les Princes \& les Peuples Catholiques contribuent noblement. On cultive à Rome, à Lisbonne, \& à Paris des Pépinieres Eccléfinftiques pour introduire ou pour rétablir la Foi par-tout où il eft poffible : \& telle eft l'intention d'une grande partie desfecours vraiment édifiants, qui font envoyés de tous les Etats Catholiques au Clergé de Rome. An-lieu que vous autres, foit inftitureurs, foit fauteurs de Communions féparées, vous renfermez votre follicitude dans cette petite troupe qui condamne avec vous tout le refte de l'univers. Contents d'être écoutés en Abyfinie, en Grece, dans telle Inle, ou dans tel Canton, vous demeurez muets pour le refte de la terre, \& vous avouez votre infufifance par votre taciturnité. 


\section{$282 \quad \mathrm{~L} \approx \mathrm{SPECTACL}$}

LA Dí- Nous ne voulons pas dire, en adrefMoNiTR. fant ces paroles aux Sociétés Schifmatis Yaver. ques, que les Eglifes célebres d'Ephefe, de Corinthe, \& de Theffalonique, ou les Sociérés Arméniennes, Mofcovites, \& autres qui fe mettent fi peu en peine de la propagation de leur Foi, ni da falut des autres, foient abfolument fans juftice \& fans vie.

Plufieurs Sociétés Orientales réclament ouvertement contre cette défunion. Bien loin que le fchifme foit confommé dans tout l'Orient, plufieurs particuliers fe joignent à nous, tant qu'il leur eft poffible: des Monafteres, \& de plus grandes Sociétés font profeffion de nous être unies. On en trouve de plus ou moins nombreufes, en Macédoine au Mont Athos, en Syrie au Mont Liban, en Arménie dans un très-grand nombre de Paroiffes, \& ailleurs. Les Sociétés qui ont fait fchifme après avoir réguliérement reçu l'ancien Miniftere, ont l'Ordination Apoftolique, en forte que l'Eglife ne réordonne pas leurs Miniftres quand ils reviennent à l'unité. Elles ont la fucceffion, finon des légitimes pouvoirs, au moins des places Epifcopales. Elles ont la réalité des Sacrements, \& la perpétuicé du dépôt plus ou moins pur, parce qu'il n'a pas 


\section{DE LA NATURE. 283}

été aifé, même chez elles, de toucher à La D’á. ce qui fe tranfmet dans des Sociétés na- MoNstr. cionales, par la commune prédicacion des áyAxGeL. Pafteurs unis entr'eux, \& fubordonnés à un Patriarche, ce qui, avec la Liturgie, eft un moyen d'une grande publicité \& d'une grande fûreté.

C'eft en petit l'imitation des liens \& de la conftitution de l'Eglife univerfelle. Plufieurs Néophytes reçoivent dans ces Sociécés le baptême, la créance duSymbole, $\&$ plufieurs prieres qui nous font communes. Ils reçoivent les Sacrements, \& un commencement de vie fpirituelle. Nous ne connoiffons ni leurs defirs, ni les vœux qu'ils peuvent faire pour la réunion. Perfonne n'ignore qu'ils l'ont plus d'une fois demandée par des Députations que les Princes mal intentionnés ont rendu inutiles. Il ne m'appartient pas d'ofer dire ce qui fuffic ou ne fuffic pas, pour rendre leur ignorance excufable ou inexcufable, ni jufquà quel degré les Peuples fchifms. tiques participent à l'aigreur de la rupture, \& à la haine qui divife leurs Pafteurs d'avec nous. La premiere penfée qui nous vient, à propos des Eglifes féparées, eft de nous attendrir fur le fort de nos freres, \& de defirer qu'il y eût, s'il éroit polfible, en leur faveur des excep- 


\section{$284 \quad$ LE SPECTACL I}

LA DÉ-tions à la rigueur de la loi qui attache Monstr. la fainteté à l'unité de l'Eglife, \& au feul trangel. Miniftere qui forme le Corps des Saints.

Mais cette compaffion toute humaine doic céder aux vues adorables de la Sageffe fuprême, qui n'a établi la loi inviolable de l'unicé dans fon Eglife, feion la commune profeffion, credo unam... $E_{c-}$ slefiam; que pour rendre la vraie Eglife \& le vrai Miniftere à jamais reconnoiffables par des liens fenfibles, \& par un caractere qui fût à la portée de tous. Nous ne pouvons donc que plaindre ces Eglifes fchifmatiques, non-feulement des dangers, mais des malheurs inféparables de leurs démembrements.

La Providunce qui a permis les infinuations de la philofophie parmi les Pafteurs, \& les féparations que la jaloufie ou la manie des opinions a tant multiplićes, en a d'abord prévenu le fcandale * a Tim. 4: par la prédiction. * Elle en a tiré de plus $3, c_{c}$ un avantage très-réel, qui eft de ménager à fon Eglife des atteftations convainquantes, foit de l'antiquité de fes dogmes, foir de l'intégrité de fon áépôt. Ces atteftations, fans être néceffaires à fes enfants, ferment la bouche à fes contradicteurs.

Affurément la forme de fon inftitution empêchoit par des précautions efficaces 


\section{De la Nature. $=85$}

\& durables l'altération de fon Miniftere LA DE¿̊ de fa Foi; maisrien n'empêchoir qu'elle movstr. ne pût être calomniée ou accufée de ÉvañGus. changement : \& voici des Sociétés depuis huit, onze, \& douze cents ans féparées d'avec nous, \& défunies entr'elles, qui atteftent par leur commune créance la même en tout que la nôtre, hors le point qui les fépare, l'intégrité \& l'apoftolicité de celle-ci. (a)

Nous avons de plus contre toutes ces Eglifes, \& pour nous, l'aveu unanime qu'elles firent autrefois de l'Apoftolicité de notre Hiérarchie, comme de celle de notre Foi. Lorfque toutes enfemble elles n'étoient qu'un nêtme corps avec nous, elles confefferent par une Députation générale à Nicée, \& par les réglements de certe Affemblée, l'unité de l’Eglife, la primauté de S. Pierre, celle de fes Succeffeurs dans le Siege de Rome, en un mot la forme de gouvernement qui duroit depuis trois fiecles, \& à laqueile nous fommes encore fideles.

(a) Yoyez les temoignages de in commune creance des Socictes Oricitales, rapportes par . M. cie Nointel, Ambaffadeur à la Porte.

L'Auteur fe fouvient d'avoir vu, en I7]7, le Czar pierre s’abalfor profondement s arec génullexion, devant le stand Autei cinue Cathctra!e Cacholique: action parture, \& timoignage publis de lis perfuadon de so Rrince śclairé. 


\section{LE S P E C T A L E}

La Dé- Les Evêques des différentes parties du moNstr. monde Chrétien, affemblés dans le voifiÉVANGEL. nage de Byfance, qui alloit devenir la nouvolle Ville Impériale, auroient pu, remble$t$-il, faire une démarche très-agréable à l'Empereur \&̊. au Clergé de Conftantinople, s'ils avoient voulu y transférer la premiere Chaire Apoftolique, avec laquelle tout l'Epifcopar \& toutes les Eglifes entretenoient une communion confante. Les politiques s'entre-difoient alors à Nicée: Nous avons l'occafion la plus he ureufe d'illuftrer à jamais le Clergé de la nouvelle Rome parla Primauté. Nil'unité del'Eglife Catholique, ni la vifibilité, qui eft l'effet néceffaire de l'unité, ne fouffriront de ce tranfport. On peut faire par choix ce qui pourroit arriver par une néceflicé inévitable. Des Pcuples Barbares peuvent fe rendre maîtres de Rome, \&̊ y éteindre le Chriftianifme. L'idolâtrie, dont Rome eft encore pleine, peut reprendre le deflus, \& en interdire l'entrée aux Chrétiens. Un tremblement de terre peut ruiner Rome, comme il arriva à cette Ville de Nicée le jour de la mort du Sauveur; ou même engloutir Rome, comme il arriva à la célebre Herculane fous l'Empereur Titus. Ce n'cft ni a Jérufalem, ni au mont de Samarie, ni aux fept montagnes de Rome, que le 


\section{DE LA NATURE. $2 \delta$ ?}

Chriftianifme cft attaché. L'Eglife Catho- LA Dílique peut perdre une Ville ou une Pro- Moxsrr. vince; mais elle ne peut perdre ni la śmang. Chaire Apoftolique ni la Primauté qui montre à tout l'univers un feul Clergé, compofé de tous les Clergés, \& une feule Eglife compofée de toutes les Eglifes. Rome va s'obfcurcir : \& certe Chaire éminonte, tranfplantée dans la premiere Ville, n'en feroit, comme elle l'étoit ci-devant, que plus en place pour être vue, \& pour entretenir toutes les correfpondances. Les Peres du Concile n'en font-ils pas les maitres, \& une age politique ne le leur confeille. t-elle pas?

Les Evêques de cette augufte Afremblée penferent bien autrement: ils ne crurent la chole ni utile, ni jufte, ni abandonnée à leur pouvoir. Ils favoient que l'Ordre primitif de la Hiérarchie étoit l'œuvre de l'efprit qui avoit conftitué l'Eglife, \& que cetce prééminence deftinée à maintenir l'unité du Miniftere, ne pouvoit fans doute être anéantie, ni par la caducité des bâtiments, ni par linvafion d'aucune Puifance ennemie: cependant ils ne déplacerent point ce Siege principal; \& le laifrerent toujours uni à la même Ville qui avoit été illuftrée par la prédicntion \& 


\section{LE STECTACLE}

LA Dós-par le fang du premier Apûtre, puis par Mcostr. La longue fucceffion de tant de Docteurs ersicllo prefque tous Martyrs comme lui. Ils ne voulurent point féparer la premiere Chaire d'avec le plus grand témoignage qu'il y ê̂t fur la terre, \& ne connurent point d'illuftration préférable à celle-là. Les Peres de Nicée ne fe laifferent pas ébranler par l'obftination de la plus grande partie du Sénat \& du Peuple Romain, qui en perfiftant dans l'idolâtrie ou dans la haine du Chriftinnime, fe rendoient indignes d'avoir chez eux le Chef \& le centre du Miniftere Chrétien. Ils ne toucherent en rien à cette difpofition, qui remontoit à 1a naifance de l'Eglife. C'eût éré expoler à l'obicurciffement la fuccefiron des Chefs de l'ordre Saccriotal, dont la ligne it l'autorité avoit fervi depuis trois cents ans à réprouver toutes les Sociétés irrégulieres par la fimple connoiffance de ce centre d'unicé qu'elles rejettoient.

Le Concile de Nicée ne donna rien à Rome : il refpecta feulement, \& fit à jamais refpecter ce qu'elle aroit reçu. Ancioche \& Alexandrie avoient les feconds rangs : mais par la fuite Conftantinople l'emporta fur ces deux Siegses. Pourquoi donc n'en fut-il pas de même de celui de Rome? Le Concile fit 


\section{B E I A NATURE. $\quad 289$}

voir que la primauté du Siege de S. Pierre LA DSavoit un aucre fondement que la préémi- consss?. nence paffagcre de la Ville où il étoit pla- Évangei. c.́. Il comprit qu'on répandroic un nuage fur les droits de cetce Chaire, en l'introduifane dans la nouvelle Capicale de l'Lmpire, \& qu'il paroitroir à l'avenir qu'où il n'y auroit plus de premiere Ville, il n'y auroit plus de premier Siege.

On n"ignoroit pas dans lEglife, non plus que dans la Société civile, que l'inftiturion d'un Chef perpétucl étoit inféprrable d'une Compagnie perpéruelle: d'ou il fuivoit que comme le Sauveur avoit inltitué le College Apottolique, en l'inmortalifunt par une fueceffion réguliere, il en avoir de même inftitué le Cher; \&̀ qu cetre Primauté, coujours néceffitire au Corps, devoit, comme le corps del'Ambaffade, être perpéruée par la fucceflion. Les Peres de ce Concile \& des fuivants ne maininent que mieux cer ordre elfentiel par la précaution de ne pas déplacer la ligne de cente fucculion, \& d'cn conferver à Rome le privilege.

L'Eglife ne peut perdre ni fon gouvernement, ni la Primauté qui fait le lien de fon Apoftolut. Mais quoiqu'clle puille perdre Rome, elle ne regarde pas ave: inutiérence le lieu où réfide cenc Chays Tone VIII. Part.II. 


\section{LE SPECTACLE}

LA DÉ-refpectée de tous les fiecles. Ici, comme MONSTR. en tout, l'extérieur attefte \& maintient ÉNANGEL. la vérité, par fon invariable uniformicé. La confervation du privilege accordé à Rome, a toujours montré \& maintenu l'ordre primitif, l'ordre néceffaire, la premicre place, le centre du Miniftere \& de toutes les Eglifes.

Les Conciles OEcuméniques laifferent donc à tous les fiecles fuivants le modele de conduite, \& la regle quiles devoit fixer. Quelle main téméraire ofera déformais toucher à des bornes fi facrées ? qui pourra fe flatter en quittant Rome, de trouver silleurs cette Chaire principale, \& la Primauté néceffaire à l'unité? Quel fera le Clergé, quel le Particulier qu'on doive fuivre, quand il voudra bâtir en rejettant cette pierre fondamentale, à laquelle font jointes toutes les autres pierres du fondement?

On ne manquera pas de fe récricr, que ceux qui le font afis fur cette Chaire n'ont pas, en plus d'une rencontre, montré la modeftie \& la régularité de faint Pierre, ni du très-grand nombre de fes Succeffeurs.

Objection vaine, \& qu'on laiffera fans réponfe. A quelles illutions \& à quelles extrémités ne s'eit-on pas porté dans la 


\section{DE LA NATURE. 291}

fauffe méthode d’attribuer à l'Eglife, mal- IA J)igré les promeffes qui la rendoient indé- monstr. fectible, des defauts humains \& des pré- Ĺvanga tentions perfonnelles?

Si depuis l"ancienne idolatrie il eft monté dans l'efpric de l'homme une idée déraifonnable, \& pourtant féduifante par fes rapports fecrets arec l'amour-propre, c'elt la liberté que fe donna un parciculier, puis un fecond, \& enfuite plufieurs autres de réformer l'Eglile, tandis qu'clle avoit fon gouvernement; \& de régler les articles de la Foi, tandis que depuis quinze fiecles il y avoit dine part un Apoftolat immorcel qui ne ceffoit de la publier, \& d'une autre part un Chartrier indeftructible qui juftifioic la préuication.

Les Sociérćs humnines fe gardent bien d'abundonner la Légillation \& l'ordre public aux vues des particuliers. Jefus Chrifi avoit fait plus que d"écublir iordre commun dans fon Eglife par l'intiturion d"un Corps de Miniftres autorifés, mique, \& fuccelif. A ce moyen qui opere n turcliement l'indéfectibilite de l'ordre, \& la notification immanquable des intencions du Légiflnteur, il avoit ajouré la prom ffe de ne les abandonner jamais, \& d'ampècher l'erreur de prévaloir dans l'Eglife. 


\section{2) 2 LE SPECTACLE}

LA D:., Aflurez vous, leur dic-il, que je feral monstr. ,, avec vous tous les jours jufqu' la fin =vanuler., des temps. , Et voici des hommes qui viennent dire en face à Jefus-Chrift: Vous n'éres plus avec vos Envoyés; \& c'clt nous qui allons apprendre aux hommes vos intentions.

Le principe de la Réforme a été comnunément énoncé dans ces termes: Si on no reforme pas nus Eglijes, nous fommes on droit E duns l'obligution de les réformer nous-ménes. Or il ne faut pas de moindres pouvoirs pour riforner l'Eglife que pour l'áablir. Nons avons done le difinnemene des Dotrines, le pouvoir ales clejs, E. l'Apoftolat.

Pour juger de la valeur d'un pareil principe, il eft peu nécellaire de recourir a l'événement : fuivons cependant la regle que Jefus. Chrift nous a donnée pour faire le difcernement des mauvais mairres. On doit enfinles reconnoitre ì leurs fruits. S'il y a donc une réflexion capable de ramener à l'unité ceux qui ont pris part aux fuices énormes de cet énome principe, c'eft de remarquer qu'on ne s'eft fi diveriement égaré en quittant l'unicé, que parce qu'au fortir de l'unité on ne rrouve non plus de regle que d'autorité. Le Chrilianime slors cit d'une condicion 


\section{ก I. I $\wedge$ N T URE. 293}

fort inférieure à celle des fociétés humai- IA Dínes: il n'eft plus qu'une philofophie con-monstr. tentieufe:au-lieu que les fociétés humai- ÉvaNGEL. nes ont un ordre conftant \& un Miniftere immortel, qui arrête l'inquiécude des particuliers.

Les fcandales qui fe trouvent dans l'unité, ont été prédits. Il eft néceffaire qu'il y en ait pour l'exercice des Juftes : mais i) n'eft pas moins néceffaire de demeurer dans l'unicé malgré les fcandales. Ils font utiles pour rendre la vérité plus manifefte, \& les bonnes mceurs plus prćcicules : ils font donc compenfés par de grands profits, \& redreffés par les reffources, ou les fupports fans nombre qui font dans l'unité, \& qui ne font que là. Les fandales ne deviennent donc jamais un tiue pour la quitter. Les dépits \& la fatyre ne nous acquierent point de droit. Où cft l'unité é la patience, là eft l'efprit de Jefus Chrift. Au contraire lia eft l'efprit de l'homme \& le principe de toute confufion, où regne l'indépendance \& la réjection du Miniftere autorifé pour toujours.

Au-lieu de nous occuper plus longtemps de la bigarrure déplorable de ces réformes contradictoires, qui ne lont ni la mifion ni l'alliance Chrétienne, puifN iij 


\section{LE S P E T A L E}

iA Dé-qu'elles font fans fucceffiun \& fans unité ; anoNstr. arrêtons nos yeux fur la perfévérance de s vangel. tant de grands Royaumes dans la communion des Mircyrs, des Fondateurs de nos Eglifes, \& de la ligne de leurs Suzcefteurs. Rappellons-nousl'exemple d'une conftante \& infigne modération: jentends celle du Cleraé de France \& de nos Rois dans la difcufion des incérêts les plus vifs avec la Cour de Rome. Les a-t-on vu délibéree un inftunt sils renonceroientat faint Siege? I!s non jamais mis de différence entre renoncer à l'unité Catholique, \& renoncer à l'Eglife Chrétienne.

Qu'on dife tant qu'on voudra que nos Rois ont eu plus que bien d'autres des fujets de fe plaindre. Nais ils one faic connoicre mieux que les autres, qu'il n'y en a point de fe féparer.

Il y a des regles, \& ils les ont fuivies, en rejetrant des Décrétales nois autorifées \& d'autres notoirement fuppolées; en réclamanc au befoin la doetrine de l'Evan. gile, les Canons des faints Conciles, les exemples des premiers Fideles, \& des faints Ilommes de tous les fiecles, les ufages \& la pofleflion; ils ont adouci, fouvent terminé de grands maux. Ils ont ainfi avec leur Clergé maintenu l'intégrité dos droits de l'Epifcopat, l'indéper- 


\section{DE I A NATURE. 295}

dance de leur Couronne, \& l'ancienne Li Dúregle qui fait le repos des Eglifes, \& la monstr. furreté des Erats. Mais ils n'ont pas ac- StaxgLto quitté un devoir aux dépens d'un autre devoir : \& comme ils ont confervé une liberté réguliere, ils n’ont donné aucune atteinte ni à l'autorité de la premiere Chaire, ni aux liens des Eglifes.

Auffi le refpect que nous portons a nos Rois eft-il animé par la plus vive reconnoiflance. Ils nous ont appris la conduite cu'il faut tenir dans la défenfe d'un droit légitime, \& ils nous ont confervé la réalicé du Chriftianifme, en nous confervant l'unité.

'Toutes ces fectes qui ont mis la fo-Origine du ciéré Chrérienne en pieces pour la per- Toleranfectionner, fe font promptement apperçues que l'une renverfoit avec chaleur, ce que l'autre s'appliquoit à écablir. Elles fentoient qu'il ne falloit point de miffion pour une cuvre où tout s'entre-détruit: \& la conviction fecrete d'un égal défaut d'autorité les difpofa prefque toutes à n'oler s'attribuer à part ni une miffion fpéciale, ni le falut par exclufion. Elles n'étoient hardies que contre l'Eylife $\mathrm{Ca}$ tholique, parce qu'une même inipatience les avoit armées contre fa regle de Foi, qu’elles traitoient de Tyrannie. Mais elles 
206 LE SPECTACLE

LA Dé- fe trouvoient timides \& déconcertées les Honstr. unes vis-à-vis des autres. On fe voyoic Arabicis. fans conformité comme fans regle. Les confelfions étoient incompatibles, \&l'on s'entr'excomınunioit.

Nous nous y prenons mal, pour nous faire ćcouter, ont dit plufieurs d’entre les défenfeurs des PrétcnduesRéformes. Nous entr'excommunier, c'eft nous reprocher publiquement les uns nux autres de détruirc une partie eflentialle de la Foi. Mais pouvons-nous rout cnfemble être les réformateurs de l'Eglife \& les deftructeurs de fa Foi? Si nous fommes fi chancelants ou fi divifés dans la Doctrine, avec quelle vraifemblance nous dirons-nous Envoyés pour redreffor la créance du Genre-humain? Nos querelles nous démentent : \& ne pas favoir nos inftructions, c'eft n'en avoir pas reçu. Baiffons donc le ton : ne parlons plus de milfion extrnordinaire, \& tenonsnous-en à une mérhode plus prudente, à une façon plus modefte de tourmer le principe qui a domné naiffince à nos Eglifes. Cetre méchode contilte à laiffer à chacun la liberté d'examiner la Doctrine, afin qu'il puiffe fe réformer lui-même en fe déterminant en faveur de l'Eglile où il trouvera la Doctrine la plus pure \& la neilleure façon d'enfeigner. Du principe 


\section{DE I A NATURE. 29?}

do notre réforme, il n'y a plus qu'un pas is Dr. au Tolérantifme univerfel, fi ce n'eft la maxm. même chole. Car accorder à autrui lo ípanisas liberté de difcerner \& de choilîr une doctrine, c'eft lui laiffer la liberté de la fuivre, ou c'eft ne lui rien accorder. Peut-on l'excommunier enfuice fans décider qu'il ruine la Foi; \& décider n'eft-ce pas dominer? Notre conduite n'eft point d'accord avec notre principe; il nous incline à la modéracion, \& notre conduite eft pleine de hauteur \& d'aigreur. Nos divifions ue font réparées par aucun air de bienféance, ni par aucune regle qui nous rapproche.

Il regne plus de conféquence dans l'Eglife Cacholique. Elle a fes opinions, dunt on ne parle pas aux Fideles, \& qui n'exercent que fes écoles : mais elle a une regle qui prévient les divifions, \& qui fixe bi conduice comme la foi. L'objer de Is creance univerlelle le préfente par-touc svec dignicé \& avec conformité. Quand on Bonne l'annonce du Sermon \&e de la Priere publigue à Marfeille, à Québec, ous Ponticheri; dans tous les Continents les Fileles Cucholiquesfavent, comme le Paituur, de quel dogme \&s de quelle véricé on les occupera. C'elt par-tous le mème langage \& la mème million. II $y$ 
298 LE SPECTACL

La Di- a une forme de doctrine univerfellemene monstr. connue, qui met le Palteur en regle aufisvanger. bien que le Peuple.

Le Pafteur renouvelle \& perpétue la publication d'une partie de la Doctrine commune. Il en tire de quoi faire naître des fentiments \&raimer les bonnes mours. Ses talents peuvent éclairer \& toucher: mais c'eft d'abord la connoiffance de la réalicé de fa miffion qui perfuade. On eft convaincu que la parole de vérité eft fur les levres du Pafteur, parce qu'il ne fe préfente qu'avec les témoignages notoires de l'envoi Apoftolique : \& d'une autre part, In même regle qui prévient les égarements du Pafteur, en l'affujettiffant à l'étude dus đépôt, faic en même temps la fùreté des Fideles. Ceux-cine demandent non plus les preuves des dogmes, ou de l'Evangile, ou du Miniftere, qu'ils ne demandent les preures de l'acquifition de leur patrimoine ou de l'ćtabliffement de leur Magiftraturo. La preuve en feroit aifée: mais à quoi bon prouver ce qu'on ne contefte pas. A guoi bon faire par des paroles une démonftration qui eft, difent-ils, toujours fubfiftanre, \&z qui parle à tous les yeux? Il y a une poffellion publique. Il y a une perpétuicé d’actes \& de fucceflion. Il y a unfin une regle, qui eft d'être fù des in- 


\section{DE LA NATURE. 299}

rencions d'un Légiflateur \& de l'effer de LA Défes Loix, quand ceux à qui il en a donné Monstr. la difpenfation ne font point révoqués. Il ĹVAzGer. faut avouer que cette confiance fied bien au Miniftere qui montre une fucceffion de dix-fept cents ans, \& qui fait profeffion de ne rien dire de lui-même, mais de tranfmettre ce qu'il a reçu.

Quant à nous autres qui fuivons plus nos lumieres naturelles que l'autorité, \& qui fixons la révélation par la raifon, nous ne croyons avoir de droit d’être écoutés qu'autant que l'argumentation nous en donne : E cette autorité que nous fentons bien qui manque à notre Miniftere, nous tîchons de la retrouver dans la force de nos fyllogifmes. Nos Sermons de in forte deviennent des controverfes par léternelle difcullion du pour \& du conrre. Nos dogmes conféquemment fe diverffient comme nos penfíes.

Nous ne connoiftons aucun frein. $\mathrm{Ni}$ les Théologiens qui vivent, ni ccux qui ont vécu, niles Peresdespremiers fiecles, nilesaffemblées des Egliles, ni les formules univerfelies; rien ne nous fubjugue, parce qu'un feul efprit, difons-nous, peut quelquefois mieux voir que tous les efprits,

Cetre maxime, qui foumet tout à notre jugenent, nous conduit par elle-même.

N. vi: 


\section{L E S PECTACT}

LA Dú quand elle eft leule, à des divifions aum monstr. interminables qu'indécentes. Mais cette śrangel. liberté deviendra proficable quand elle fera accompagnée d'une regle qui mette la paix parmi nous. Il y a long-tempsqu'on en a fenti la néceffité.

Le défavantage que nous éprouvons dut côré des lumieres, nous pouvons le réparer par une condefcendance fans bornes pour ceuxqui penfentautrementquenous: cetre douceur déconle naturellement de 10. liberté que nous laiflons à chacun d'examiner \& de choifr. Faifons-nous-en un devoir, une maxime de conduite qui nous caractérife. Tolérons ce que nous n'avons pas le pouvoir de condamner; ô n'ayant que celui de nous réfomer nousmemes, felon nos lumieres, gardonsnous, foit de noter les fentiments d'autrui, Soit d'ixcommunier les perfonnes.

Nous ne ferons pas, il eft vrai, un même corps par l'uniformicé des doğmes confentis : mais nous montrerons la difpofirion la plus nécelfaire pour entrer en fociété, qui eft de ne pas époufer nos propres fentiments avec chalcur. Le nom de Tolérants que nous prendrons, fera entre nous une annonce de paix, \& ne nous siftinguera au dehors que par une moderation propre à nous faire aimer. 


\section{a a NATURE. Bor}

Sans troubler perfonne dans le chois La D. de fes opinions, il ne faut que nous ré- MoN't?. foudre à ne pas établir les nôtres comme LVANGEL néceffaires. Voila le fûr moyen d'amener toures les Eglifes Réformées à une concorde univerfelle. Permis de croire JefusChrift préfent fur l'Autel: permis de ne lo pas croire. Permis de le confeffer préfent dans le Sacrement, \& de ne l'y pas adorer. Permis à plus forte raifon de l'y croire préfent, \& de l'y adorer.

Liberté de le croire Dieu \&r co-étemel au Pere: liberté de ne le croire Dieu que par une dénomination d’économie : liberté de confeffer la Diviniré, fa facisfaction, tous fes myfteres, comme urais \& révélés, fans croire tous les efprits obligés à plier leur raifon aux mêmes vérités.

En un mot on ne refufera le falue a aucun de ceux qui fe difent Chrétiens. Une telle conduice eft digne de la charicé que le Chriftianifme infpire : \& ce moyen fi dégagé des peticefles de l'amour-propre n'e1t-il pas faic pour operer l'unité?

Cette invention que l'Inftituteur du Chriltianifme n'avoit pas mile en ceuvre, n’a pas laiffé, par une apparence de générofité, \& par fa très-grande commodité, d'en impoler à bien des efprits. Le Tolé-

Erret de:nyiteme. 


\section{LE SPETACLE}

$\mathrm{L} \wedge$ DŚ-rantifime au premier afpeet femble né pour moxita. ralentir les haines. Il tourne les fectes Éancel. belligérantes, finon à la concorde des fentiments, du moins à la ceflation de toute hoftilité. Si c'eft une erreur, elle cft d'autant plus dangereufe qu'elle plaît, en prenant tes couleurs de la retenue $\&$ de la politeffe.

Protres Avant que d'en faire l'analyfe, difons sum Tone- un mot de fes progrès. Les Sociétés qui fe prútendent réformées font aujourd'hui Tolérantes. La plupart de ceux qui fo font féparés par choix, ou qui perféverent avec leurs familles dans la féparation d'avec l'Eglife Catholique, ne haifient plus qu'eile : \& comme c'eft d'elle qu'ils ont reçu ce qu'ils ont de bon, que c'eft dans cette Eglife que leurs Peres avoient trouvé la vie, ils la tolércroient elle-même, fi elle n'étoir intolérante. C'eft la fon crime. Ils ne parlent point d'elle tran. quillement, parce qu’à leur gré la défenfe de la Foi y eft trop enticre. Mais ils en ufent honorablement avec la multitude des fecies, fi divifées \& foudivifées qu'elles puiffent être, parce qu'ils y trouvent une condefcendance réciproque.

Iis embraffent très-communément dans la généralité de leur patience, j’ai prefque dit, de leur eftime, le Socinimifne 


\section{I A N A T UR E. 303}

méme pour qui Jefus-Chrift n'eft Dieu La Díqu'en figure. Plufieurs ne trouvent rien MoNstr. d'effentiellement mauvais dans le Maho. Évangeta métifme, où Jefus-Chrift eft honoré avec une rérerve encore plus grande. Ce qui furprend le plus, c'ent de les voir en bonne intelligence avec le Dćifme pour qui l'alliance Chrétienne eft une impofture, \& qui n'honore la Philofophie de Jefus- Chrift que jufqu’à la Croix exclufivement.

Cetre double difpofition de haine envers l'Eglife Catholique, \&i de ménagement pour toutes les fectes qui l'ont quittéc, fe déclare très-particuliérement par le choix des citations qui décorent les écrits des P. Réformés. D'une part ils évicent avec foin de citer les faints Peres, $\&$ fur-tout les Peres des quatrieme \& cinquieme fiecles: ou ils ne les citent que pour les critiquer. C'eft une réfolution prife de ne pas infpirer aux Leeteurs une vénéracion indifcrete pour des écrits dans lefquels la Foi actuelle de l'Eglife Catho. lique fe trouve énoncée à chaque page. D'une autre part ils citent, ils compilen avec complaifance les écrirs de Pope, de Bayle, \& de Montagne; dont la religion ne les incommode point, \& donz ils ne craignent point de fuire goûtcr les 


\section{LE SPE T T A LE}

Ln Thé principes. Je ne voudrois pas répondre sowrr. que le Tolérantifme nait fait des proféaraxcit. lyces jufques dans l'lighife Catholique. Comment le défendre d'un fyltême qui remet la raifon dans les dioits, \& qui femble concilier tous les partis?

Nature J'avoue que fi je u'étois pas Chrétien, gun Tale- je ierois Tolérant. Je le ferois même étant Il ruine ce Chrétien, fi le Chriftianifme étoit fans cue jerus- regle; fi l'on devenoit Chróien comme otwsts. on devient Philofophe, \& fi liduteur de la Foi n'avoic établi pour la fixer, lune Légiflation réguliérement autorifée félon les formes uficées par tout, ce qui ne lairfe licu à aucune difcuffion. Mais le Tolérancitine a un défaut : c'clt de renverfer ce que Jefus-Chrift a établi.

Le Sauveur regle \& captive le raifonnement humain par la Foi. Le Tolérantifme abandonne la Foi au raifonnement. Jefus-Chrift établit la Foi par un Miniftere immortel, qu'on ne peut rejetcer fans rejetter le Sauveur lui-même. Le Tolćrane fe paffe du Miniftere \& du culte extérieur. Il fait plus: il vous permet de vous paffer du Miniftere, ou de vous en donner un à votre gré. Jefus-Chrift avoit tiré les Nations des égarements de l'ofprit humain, en les amenant à la confeffion diftincte des mèmes vérités, par la pré- 


\section{DE IA NATURE. 303}

dication univerfelle de la même Foi, par IA Dsl'annonce d'une Doctrine à fuivre, non msstr. d'une Doctrine à examiner. Sans liver à T.Manusin Ia difpute fa Divinité, fon incarnation, fa réfurrection, fa médiation, il s'eft contencé de produire \& de perpétuer les témoignages qui doivent garantir l'A poftolat c la prédication jufqu'ta la fin. La Foi conduit ainfi la raion par des moyens conformes à fon état, \&z lui épargne les fuices de fa fragilité. La Réforme au contraire \& le Tolérantilme rejettent la raifon dans fon ancicnne incertitude, en la remettant fous fa propre conduite. Autant valoit-il être fans révélation.

Jefus-Chrift après avoir fixé pour toujours l'unité de la Foi par l'unité du Miniftere, vouloit q̨u'on s'attendit à confeffer hautement cetce Foi, au péril même de fa vie. (a) Le Tolérantilime n'oblige à rien; il ne blâme l'ignorance d'aucunes vérités: bien moins en demande-t-ill'uniforme confuffion. Il ne s'expofe à ricn, \& trouve chacun orthodoxe, à proportion qu'on fait taire fes lentiments, oules montrer avec indifférence. Les vues du Tolérandirme ne font donc point celles de jefus-Chrift.

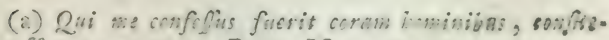
kor है ego cum coram Posre. Matt, 10:32. 


\section{LE SPECTACLE}

I. T Tó- Mais la célébrité \& le nombre de ceưz Moxstr. qui s'y rangent, ne font ils pas capables Évavioto. de compenfer ce défavantage? Ce font fouvent de très-beaux efprits.

$m_{n}$ pré. Les plus grands génies deviendroient funce de la la rifée de l'univers, s'ils vouloient reriun, 1's- faire ou interpréter à leur goré les Traités prit de de Rifwick \& de Munfter, méme en Thomme n'ultiti.n. laifane aux autres la liberté de les entendreà l'ancienne façon; ous'ils quintoient le Parlement pour fe donner à eux-mêmes une petice Magiftrature à part, faite exprès pour eux, mais fans ôter aux autres la liberté d’aller à la vieille Juftice.

Les hommes les plus célebres tombent dans un ridicule encore plus grand, quand ils s'ingerent de nous arranger un autre Chriftianifine plus raifonnable que le précédent; fans toucher néanmoins à la liberté d’autrui, \& en approuiant gracieufement tous les différents Chriftianifines nés \& à naître.

Ces inflitutions, conceffions, \& tranfactions, fur un Traité dont la Puiffance légiflative s'eft vifiblement réfervé la teneur \& la promulgation, font-elles des démarches qui faffent honneur à l'efprit humain? Elles font à peu près auffiférieufes \& auffi importantes que la Théologie de faint Evremond, qui décide quelqque 


\section{DE LA NATURE. 30 \%}

part avec plus de gravicé que le vin d'Ai LA D?. n'en infpire, qu'on réfurvera la vigueur Monstr. du gouvernement Epifcopal pour les Etats LVANGELo Mlonarchiques, \&i la modeltie du gouvermement Presbytérien pour les Ecats Populaires.

Le Chriftianifme eft-il donc un pays nouvellement découvert, abandonné at premier occupane, \&z où il foit libre à chaçue nouveau débarquué de s’arranger, comme il le jugera convenable? Rien ne décele mieux l'extrême pecitefle de ceux qui le donnent pour de grands efprits, que de vouloir être écoutés, quand il eft notoire que Dieu nous parle; \& de fe préfenter avec leurs fyttêmes, quand le fouverain Légiflateur nous adrefre le fien par une publication réguliere.

La pecitefre n'eft pas l'unique défaut de leur conduite. En fe difant Chrétiens, ils font profeffion de recevoir la L_oi \& la parole de Dieu : mais en grands raifonneurs ils fe réfervent la liberré d'en fixer le fens, Ce qui eft une vraie dérifion.

Il faut opter. S'il n'y a point de Miniftere, il n'y a point de Chriftianifme : \& c'elt une baffeffe de fe dire Chrétien. Mais fi le Miniftere \& les témoignages fe fon perpétués, nous favons les intentions du Légiflateur, puifque c'elt pour nous les 


\section{LE SPECT A C L E}

LA Dí- apprendre qu'il y a un Mllnifterc. Qu'eftMoNsrr. ce donc au jufte que cette liberté d'inter¿vaxulé préter l'Evangile par la raifon? qu'eft-ce que la proteftation que font les Tolérants en ramenant la révélation à leur fens, de laiffer aux autres la liberté d'une femblable interprétation, finon un aveu très-intelligible d'une commune infidéliée? C'eft une convention de pur intérêt entre gens qui n'ont rien de commun que le mépris de la regle, qui ménagent les termes par confidération pour eux-mêmes. C'eft une contenance telle quelle, qui fert à cacher le défordre de leurs penfées, \& la pitié qu'ils fe font les uns aux autres.

T. Tolé- Le Tolérantifme que nous venons de rantims voir fi plein de foibleffe $\&$ de dérguileD thitren- ment, commet une derniere injuftice en c: Cire- fe domnant les couleurs \& le nom de la Tolérnnce Chrétienne, qui eft une vertu très-aimable \&̊ très-néceffaire, mais qque le Tolérantifme détruit par une cruauté très-réelle.

Nous ne parlerons pas ici de la politique des Souverains qui étendent ou qui refferrent la liberté de profeffer différentes Religions dans leurs Etats. Il s'agit de régler notre propre conduite \& nos fentiments perfonnels à l'égard de ceux qui 


\section{DE L A NA TURE. 309}

fe font retirés des Aftemblées de l'Eglife LA D:

Catholique. N'y auroit-il pas un mérite monstr. réel à les tolérer tous, même à concevoir Kaxcki. qu'ils peuvene demeurer tranquilles dans la voie qu'ils ont choifie, \& qu'ils croient bomne? Pourquoi vouloir les allarmer fur leur état? Nous ne voudrions pas toucher à leurs biens. Mais la liberté de leurs penfees ne leur eft-elle pas aufi chere? Nous devrions les laiffer en paix en faifant comme eus profellion d'une tolérance univerfelle. N'eft-ce pas là où nous conduit la douceur Chrćtienue qui elt bienfaifante envers tous?

La dunceur Chrétienne \& ln tolérance Chrórienne, on également leur principe dans la charité : mais la charicé agit fort differcment, \& acquitce des devoirs qui fe diverfifien felon les lieux \& les perfonnes. Nous devons la douceur Chrétienne à tous les hommes, en quelque futution quils fe trouvent, $\&$ de quelque Religion quils foient. Nais nous ne leur devons pas indiftinctement la Tolérance. L'une n'eft point l'autre : \& il eft de la derniere conféquence de prendre à cet égard les vraies idées de l'Evangile. Commençons par la douceur Chrétienne. Une des intentions de l'ancienne Loi, \& de curche. la fevéricé Judaingue, étoit de conferver tiume. 


\section{L E S PECTACLE}

ร.A DL-à part le Peupie dépofitaire des promernonsrr. fes malgré fon éloignement pour la vraie íMNGel. juftice. C'étoit de le préferver de l'idolî̀trie, de l'ompêcher de fe confondre avec les Gentils par des alliances qui auroient rendu la poftérité d'lfaac \& la ligne de Juda méconnoiffables. De là les expulfions, les exhérédations, l'exacte tenue des Regiftres, les châtiments rigoureux contre les infracteurs de la Loi; maisfpécialement contre les I iraćlites convaincus d'idolâtrie.

Ceux qui crient contre la dureté de ces traitements, ne volent ni la profonde ingracicude de ce Peuple indomptable, ni la lugeffe des moyens qui confervoient efficacement le dépôt des promefles, \& en empêchoit la diffipation comme celle dil Pcuple même, malgré fon emportement pour les licences \& pour les luperftitions paiennes.

On a vu le châtiment final de leur obftination dans la ruine des dix Tribus perfévéramment infideles; \& la jufteffe des vues qui régloient le tour, par la confervation fpéciale de la tribu de Juda, qui avoit les promeffes.

Rappellons-nous de plus que dans l'infticution de la Rćpublique des Hébreux, le gouvernenent en écoit une 


\section{1) I L NATURE. 3 II}

vraie Théocratie. (a) L'arche portative LA Dén'éroit pas feulement le dépôt des Loix de monstr. la Nation: mais par la pofture d'adora- ÉVANGEZ. teurs qu'on avoit donnée aux deux fymboles qui accompagnoient les deux côtés du Propitiacoire, ou du couvercle de l'Arche, elle étoir le Trône du grand Roi, le 'Trône de l'Invifible qui y recevoit les hommages de fon Peuple \& lui fuiroi: connoître fes volontés. Les Hébreux pendant quatre cents ans n'eurent poinc d'autre Roi que Dieu même: \& l'acte d'idolâtrie étoit une véritable rébellion, qui ruinoit l'ordre public, donnoit confé. quemment lieu à une jufte rigueur, \& faifoit traiter un idolâtre comme un ennemi déclaré. Le zele de Phinéès reçut des éloges, \& fembloit même donner des armes aux particuliers contre ceux qui étoient publiquement ido'âtres.

Mais ni cette féparation d'avec le refte du genre-humain, ni cecte manicre de punir de mort les contraventionsà la Loi, ne font plus l'efpric du Chriftianifme, qui fait des adoraceurs par l'amour du devoir, non par la crainte des mauvais traitements. Les Chrtiens ont à virre avec tous les hommes; * \& fuffent-ils au mi- "T.Cor.s: lieu des loups, leur douceur doit être in-

(a) Le gouvernement de Dieu. 


\section{LE SPECTACLE}

L $D$. vincible : ils font une profeflion expreffe ansir. daimer les hommes, \& leurs ennemis s.anult. mêmes. Cet efprit eft l'ame ơ le grand objet de la nouvelle alliance. On ne tue point, on ne maltraite point ceux qu'on aime \& qu'on eft obligé d'aimer.

C'eft lans déroger au principe de cette bienveillance invariable; c'eft fans fe fourtraire aux fupports de la inciété, qu'ils évitent avec prudence le commerce de ceux de leurs freres dont les mours font fcandaleures, ou les liaifons nuifibles. L'activiré des fervices ne louflie aucune interruption par cette réferve: \& ce fond de bonne volonté qui les rend refpectrbles à leurs ennemis mèmes, ne les abandoone pas quand ils ont à vivre avec des freres ou avec des fupéricurs d'une conduite injufte ou irréguliere. Les bons oflices ne font pas toujours en leur pouvoir : mas ils ne feroient plus Chrétiens que de nom; ils feroient devenus Pharifiens, ou faux zólateurs, fi leurzele étoit meurtrier.

On vit defcendre fur Jefus-Chrift le fymbole de eet Efprit de la nouvelle alliance au moment qu'il en fit l'ouverture, cieft-à-dire à la prédicarion de fon Précurfeur. Depuis les jours de Jean-Baptilte, les Prophécies \& la Loi ont leur accomplifferment, 


\section{TE \& A NATUR}

plifement, puifque le Sauveur promiseft Is D: l'auteur de la grace \& de la vérité : il masta. apporte au genre-humain non l'efprit de źvancus. terreur, qui feul n'établit qu'une juftice extérieure; mais l'efprit de charité, qui érablic la douceur, la bienveillance, la paix, le regne de Dieu dansles coeurs. Il ne nous fera plus ordonné d'aucre violence que celle que nous nous ferons in nous-mẻmes pour muvir les vrais biens. Tout ce qui vient enfuite, foit dans les leçons du Sauveur, foit dans les exemples de res Difciples, inculque d'une façon conftante au Chrétien de ne fe porter à aucune violence à la vue des plus grands fcandales; de ne point invoquer le feu du ciel fur ceux mêmes (a) qui travero fent l'cuvre de Jefus-Chritt; \& fur-tous de ne point tirer l'épée pour la défenie de la Foi contre le Miniftere publio, (b) contre le gouvernement de l'Erat; mais de regarder comme indiffolubles les ferments qui attacheront les Chrétiens, ou à Tibere, quoique Puien; ou in Néron, quoique perfécuteur; ou à Julien, quoiqu'apoltac.

Ni la faufe religion, ni l'irréligion ne peut fervir de titre à un particulier qua elle

(a) Lutc. 9:54 E fuiv.

(b) Foan. $18: ' 11$.

Tone Fll. Part. II. 


\section{LE SPECTACLE}

La I)-aflige, pour attenter à la vie d'un autre mossin. particulier, moins encure à la vie d'un Ennuel. Supérieur. Quand les premiers Chréciens fe virent pourfuivis par des loix injuftes $\&$ inhumaines, leurs reffources furent la priere, la patience, la fuite; jamais le fchifme, jamais la rebellion, ni les poignards.

Mais cette donceur qui fe laiffe maltraicer plutôt que de maltraiter perfonne; cette douceur qui a rendule Chriftianifme vraiment grand aux yeux de toute la terre, \& qui doit rendre les vrais Chrétiens aimables à tout ce qui les environne, n'emporte point avec elle l'obligation de penfer que chacun pourra fe fauver dans fa fecte, \& de négliger la regle de la vérité pour avoir la paix.

- On doir tout facrifier à la paix hors la vérité, \& la regle quinous affure la vérité. Mais la regle de la vérité \& de l'alliance Chrétienne, regle à jamais juftifiée par la fage pratique de toutes les Sociétés, eft de reconnoître la légiflation par les pouvoirs des Envoyés, \& de s'affurer de la réalité de l'alliance par la perjécuité d'un feul \& même Miniftere. Sans cette regle, la feule propre à maintenir la certitude dans un Corps, l'Apoftolat étoit inucile; \& fans l'Apoftolat, l'annonce de 


\section{กEIA NATURE. SIJ}

l'Incarnation éroit une tentative fuperflue, LA D:puifqu'on annonceroit en vain ce qui ne moxst:. pourroit être certifié.

Il paroit cependant, difent les Toléraniftes, que S. Paul a propofé fur ce fujet des idées fort différentes de celles des Catholiques. Il ne veut pas quion trouve mauvais que chacun abonde en fon fens: * * Rom. It: c’eft déja nous accordor une grande libercé, \& nous prefcrire la loi de la condefcendance; mais il va beaucoup plus loin. Il n'exige qu'une chofe comme ab. folument néceffaire de la part de ceux qui enfeignent, * c'eft qu'ils fuppofent tous * I. Cor. 3 : l'Incarnation du Verbe divin, ou du moins ${ }^{10}$. . The. Ia médiation du Sauveur Jefus-Chrilt. 5 . Voilà le fondement fur lequel il faut que chacun bâtiffe. Il fouhaite enfuice qu'aulieu de pailles, de bois, de matériaux foibles \& comburtibles, on n'en ajoute que de bons à l'édifice commencé. Il avoue que Dicu fera la recherche \& le difcernement de tout ce que les Winiftres de la Parole auront enfeigné; que tout ce qu'il y aura de foible dans leur $\mathrm{Mi}$ niftere fera perdu \& mis au néant. Mais il n'en fera pas de même des auteurs de ces opinions. Leur perfonne fera fauvée, falvus erit. *Et fi Dieu les tolere jufqu’à les fauver, fa conduite ne devient-elle pas la ${ }^{*} I . C_{m}$ : :

$\mathrm{O}$ ij 
3T LE STECTACLE

CA DE - regle de la nôtre? Nous fommes done anstr. tenus les uns envers les autres à la loi śtaxGet.. d'une exacte tolérance.

La To- Javoue que S. Paul prefcrit ici la reIerance Clntitien. ne. gle de la tolérance Chrétienne: mais envers qui veut-il quion l'exerce? aflurément c'elt envers ceux qui honorent l'unite, non envers ceux qui la rompent, en rejetranc le Miniftere \& en multipliant les fectes. Il parle de ceux qui enfeignoient dans l'Eglife de Corinthe, \& qui à la prédicacion de l'Evangile ajoucoient deja quelques opinions ou explications différentes. Il leur avoue que Dieu en ćprouvant les imperfections de leurs fervices, pourra épargner leur perfonne, \& leur accorder le falut, parce quils n'ont ni quitté l'Eglife, ni rejetté fon Minittere. Nais il incimide cous les ouvriers négligents ou amis de leurs propres penfées, en leur failant bien comprendre que l'ouvre \& l'ouvrier même feront mis à l'epreuve, \& à une épreuve auffi terrible qu'eft celle du feu. De maurais matériaux tels que le bois, ou le chaume, employés au-lieu de pierres, employés pour les matieres folides, feront éprouvé \& emportés : l'ouvrier lui-même, loin d'en recevoir la récompeníe, courra un tres-grand rilque de ne pouvoir échapper. 


\section{I) $E_{E}$ LA NATURE. 3I?}

L'intention, l'intérêt, l'amour-propre, le LA DR. défaut de charité, tout fera jugé \& éva- Mowrm. lué. S'il te fauve, c'eft comme on fe fauve branchs, en paffant au travers du feu.

Sainc Paul eft fi éloigné d’autoriferces bûtifleurs d'Eglifes indépendantes, où chacun eft la regle à lui-même, qu'il fait trembler les ouvriers mêmes qui travart! lent dans l'unité, en infiltant fortement fur la néceffité de travailler de concert fur un feul fondement, \& à ù un même bâtiment; en infiftant avec chaleur fur le choix des matériaux les plus folides, \& fur la conformicé du fecond rravail avec le précédent, tout autre affortiment ne pouvant manquer d'être réprouvé \& anéanti.

L'Apôtre en ce même lieu foudroie également \& les attachements trop vifs, par lefquels les Difciples donnoient la préférence à certains maìres, \& la fauffe fageffe avec laquelle certains maîtres commençoien à joindre des penfées humaines à la doetrine révélée. Cetre philofophie l'allarmoic; \& les partialités des Fideles, comme la diverfité des opinions. lui paroiffoient des commencements de fchifme. Il ramere tout à l'unité, \& par l'unité à l'union.

Bieu loin done d'abandonner l'édifice

O iij 


\section{I8 Le SPECTACLE}

La DÉ comme font les Tolérants, à la multipliMoNsTr. cité des conducteurs \& à la difcrétion des Evaxget. travailleurs, il les rappelle févérement à Ia loi d'une feule architecture. "Si quel"qu’un, dit-il, dérruit le Temple de Dieu, " Dieu le détruira.

Nous devons fans doute à tous ceux de nos Freres qui fe font retirés de nos affemblées, ou qui perfiftent dans le fchifme de leurs Peres, la douceur \& ia bienveillance que nous ne refufons pas même aux Intiteles, ni aux Juifs, ni aux grands pécheurs. Mais quoique nous ne maltraicions ni les Infideles, ni les Juifs, ni les mauvais Chrétiens, quoique nous honorions dans le fehifine le plus confom. mé les talenss, la probité, \& fur-tour le refipet que pluticurs y confervent pour les premiers Conciles, nous ne tolérons pas pour cela le renverfement de la regle : \& en eft-il un plus grand que d'admetrre la prédication d'un Apoftolat immortel, fans croire les efprits obligés de s'y foumettre? eft-il un renverfement pareil à celui d'abandonner la révélacion à In diferétion des particuliers, \& de réprouver l'ancien Miniftere, dont la defftimation connue eft d'amener tous les efo Etbos. prits à une même Foi : In unitatem fidzi? 4 : 4s. On ne tolere ni dans un édifice la liberté 


\section{DE IA NATURE. 3 TP}

de bâtir fur deux deffeins, ni dans une La Ds. Légation la liberté de publier des Traicés mnNistr. qui fe contredifent.

La douceur Chrérienne s'exerce envers ceux qui font avec nous dans l'Eglife, \&x envers ceux qui font forcis d'avec nous. Cetce douceur n'excepte perfonne. Mais la Tolérance Chrétienne, que faine Paulautorite, \& que l'Riprit de Dieu commande, ne peut raitonnablement avoir lieu qu'envers ceux qui font dans la communion du Miniftere Apoltolique. Elle n'opere point l'unicé : mais elle l'entretient \& la fuppofe.

Comme la douceur eft l'exercice de la bicnvelllance que le Chrétien porce au genre-humain, la tolérance eft l'exercice de la modération avec laquelle nous de. vons fouffrir les défauts de la fraternité. Nous efpérons le falut des Prédicateurs \& des Fideles, qui ne fon qu'un feul corps, qui honorent l'unité, qui honorent le commun Miniltere es la prédication univerfelle. Mais quoique dans la même voie que celle où nous marchons tous enfemble, ce ront des hommes pleins d'infirmités qui peuvent avoir leurs icrupules, leurs ténebres, mềme des opinions erronées. Nous pouvons être plus ou moins allarmés fur les fuices de leurs dé-

$\mathrm{O}$ iv 


\section{LE S P E T A C E}

LA D)- fucts: mais nous avons la paix avec tous vossm. ceux que l'Eglife laife duns la CommuSTANGEL Dion.

Elle a le pouvoir de condamner toute errcur, $\&$ de fupprimer toute diverfiré d'opinionsdans la Doctrine de la Foi \& des mours. Mais nous ne fommes les juges ni de fes raifons, ni de fes délais. Sa patience eft le modele \& la mefure de la nôrre: \& c'eft cn elle une prudence pleine de charité de re contenter pendant un temps de montrer à ceux qui fe trompent le dépot de toute véricé, pour les ramener à l'uniformité de l'ancienne Doctrine, fans les condamner dybord avec éclat. De notre part quelle prudence \&zquelle autorité y auroit-il dans des particuliers à vouloir aller plus vite, ou plus loin qu'elle?

Tels font les fondements de la vraie \& neceflaire tolćrance. Elle eft effentiellement compofée des deux vertus dont l'Eglife nous ununtre l'exemple: je veux dire, d'une grande patience, \& d'une grande prudence. Mais quelle patience \& quelle réferve montrerons-nous crnvers ceux qui ne veulent plus bre ovec nous? \& quelle prudence y auroir-il a tunquillifer ceux qui étant hors de l'unite marchent à l'avencure fous la conduice 


\section{DE L A N A T URE. S2I}

de leur propre efprit? Rejetter l'annonce du Miniltere que Jefus-Chrift a adrefre

aे cous les Peuples \& d tous les fiecles, trasura. c'elt le rejecter lui-même : \& ne pas fuivre Jelus.Chrift, c'ett marcher dans les ténebres.

L.a colérance eft la vercu de ceux quí marchen enfemble dans la voie lumineufe \& connue de tour temps. Ils louffrenc mucuellement leurs défouts \& leurs légers écarts, parce qu'enlin ils ne quirtens poins In vole. Mais le Tolérancilme eft une illufion pleinể d'intumanice, puifquala-licus de troubler ceux qui ne peuvent manquer de s'égarer en prenane des roures difflrentes, il les raffure en leur perfunding que coutes routes font bonnes, \& aboutiffent au terme du falut.

Les efprits les plus fenfés \& les plus culcivés par l'urage des prócsutions quî re prennent dans la Société, peuvenc voir, indépendamment des fecours fans nome bre qu'ils crouvent dans les Livres \& dano les aucres monumenrs, que la grande certicude de l'ceuvre de notre faluc a sté acachée par une finguliere providence b des moyens immanquables. Ces moyens fonc lo perpétuicé d’un Apottolac toujours vifuble, \& la forme exterieure de l'ancien youvernement, qui, dans l'Lglile conzus

LA D:-

nowsy. 


\section{LE SPECTACLE}

I.a Dí-dans toute autre Sociécé, ferc à montrer moxim. les vrois pouvcirs, \& réprouve nettement Whaclat tour ce qui s'on démembre pour fe gollverner à parr. De même aufí que le bon ufage de la raifon n'eft pas d'ébranler par' des douces la réalité des établiffements notoires, mais d'y acquiefcer, \&z de nous en fervir; ce ne peut être que par le plus grand abus de la raifon humaine qu'on a ofé dire que l'Eglife n'étoit plus, tandis que nulle puifance ne pouvoit prévaloir contre elle. C'eft un égal travers d'avoir cru qu'on pouvoit ćcouter différents Minifteres, ou abfolument fe palfer de tout Miniftere, tandis que le Sauveur cn avoit envoyé un pour tous les licux ir pour tous les temps, n'en aroit envoyé qu'un, \& en avoit rendu l'unité toujours reconnoinable par la fubordination, par l'aggrégation, \& par la fucceffion.

Mais cette vifibilité que l'Egglife Catholique reçoit de fon Miniltere, eft-elle une vérité aufli acceffible pour les efprits bornés, ou peu culcivés, qui font la multirude?

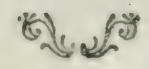


DE L N NAURE. 323

LA DÉ-

M1:5TR.

ÉVANGEL.

\section{H A P I T R E. IV.}

I a Démonftration évangélique, proportionnée à la capacité du Peuple.

T Es grands efprits peuvent envilager L la Religion Chrétienne fous fes différentes faces, \& en tirer des preuves dont lune fera plus d'impreffion fur un caractere, l'autre fera plus touchante pour un autre. Par-la ils fervent la Religion \& le prochain. Mais quelque reconnoiffants que nous devions être de leur travail, nous pourriọns excéder en le metrant au-deflus de fa jufte valeur. Gardonsnous de perdre de vue le principe important, que les prenves de lit Religion ne font point la communication de liallian$c 2, \&$ que ni les favants ni les fimples, ni les petits, niles grands, ne peuvent dans lordre commun avoir part aux biens révelés, que par le Miniftere porteur de Ia Parole \& des Sacrements : parce que te Clurittianifine n'eft pas feulement une Duettine qui puiffe être enfeignée dans des Livres, mais une Alliance qui doik

$\mathrm{O}$ yj 


\section{2: IES SPETACLE}

La Dh-être reçue de la bouchè \& des mains qué soverk. Dieu en a rendu dépofitaires.

B̀ ANGEl. Cette économic tient tous les efprits fur une même ligne. Nul d'cux, dans lordre de la révélation, ne ferạ à luimeme fa lumiere. Nul d'cux n'entreprendira de fe donner pour la lumicre des aucres. Tous puiferont la véricé \& les biens de l'alliance dans les moyens ćtablls pour la communiquer : \& quiconque ofera conduire aurrui dans les voies du Culut, doit avoir reçu fon ordre \& inonarer fa million. Si la million ell arbitraire, il égare au-lieu de conduire, parce que celui qui ne peut pas juftifies fon Ambaflade, n’a poinc de craité valide à prélenter.

Cecte premiere regle dont chacun fens Ia folidité il proportion de fa droirure d'efpric, a un autre avantage : c'eft de pouvoir devenir palpable \& acceffible au plus pecit Peuple. Efrayons de faire voir combicn il eft aife aux plus fimples, en furvant les ufages univeriellement reçus dans la fociété, de connoitre nertement les pouvoirs \& la perpécuité du Curps * s. cor a. d'Envoyé-quinous réconcilie *arec Dieu.

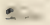
Ale promiere maxime, qui ett de jaer d'une Kegillacion par les témoignages rendus sux Linvoyés glo Sociéte joinc une 


\section{DE LA NATURE. 325}

feconde regle incelligible aux fimples, LA DÉcomme aux plus favants, qui eft que le Mosstr.

Deputé d'une Compugnie connue, met Lrakges, autant de cervinde dans les affirires qu'il tranjage, que fi le Corps intiar s'árois tranjporté fur les lieux.

L'ordre de la Providonce a éré vifible. menc de metre la démonftracion de for Evangile à la portée de cous, en l'attachanc à des moyens d'ulage, \& à l'exté. rieur meme de la Religion: mais n'approhendons-nous point que cette preuve ne saftoiblirfe comme lestericur?

Nous fommes accourumés a voir craíp rer la Religion avec un air de grandeur. Ls magnificence des Temples, leloquence des Prédicaceurs. un Clergé nombreus \& eclairé, la cancenance refpectucufe des Afremblées Chréciennes, tour faic fur nous desimpreffions touchances. Dépouillons la Religion de serte majefté exré. rieure, \& réduilions-la, fi lon veur, à ce quielle a de plus fimple. Allons la chercher dans les lieux les plus pauvres. C'elt? pour nous une mécelité de favoir como mont elle $y$ hit fes preuves, Ne rougilo Cons ni de l'extéricur, ni des motifs qui Cuffifenc dans les voles de Dieu pour amener ì fo Gaisceté les ames qui lui font sheres. 


\section{LE SPECT A C L E}

La Dó- Il n'clt plus queftion de Livres, parce moNsTR. que nous avons affaire à des gens qui ÉVArigl ne lifent tout au plus que leurs prieres. Mais ils écoutent comme nous la parole de Dieu, puifque la Foi, qui eft pour eux comme pour nous, leur vient de la Rom.10: prédication. Faifons done voir ici que les 17. droits du Miniftere qui leur parle, leur font aufi coninus que les établiffements humains dont ils font le mieux inftruits.

Un Prêtre Catholique fe prélente dans une Paroifre de campagne, compofée de plufieurs Hameaux : il en a raffemblé les habitants, pour être mis en poffeffion du gouvernement de cette Eglife peu diftinguée, \& où tout fe reffent de l'éloignement des Villes. Il adreffe la parole à ceux que fon Evêque lui a confiés, \& entreprend de les convaincre que fa miflion eft pour eux aufii falutaire \& aufi certaine que s'ils recevoient immédiatement les premiers Envoyés, \& Jefus-Chrilt lui-même.

Puilique c'eft la notre objet actuel, \&s qu'il refte à nous montrer, de mème qu'on va le faire voir ì ces bonnes gens, que les petits peuvent être auffi clairemont inftruits de la rénlité du Miniftere qui les fuuve, que les hubitants des Villes les plus opulentes; jectons-nous dans lis 


\section{DE I A N T UE E. $32 \%$}

foule des Audiceurs de cet homme qui La $D \leqslant$. fo dit Envoyé, \& fpécialement adrefté à moxstr. eux. Ecoutons comment il pourra leur ćrancec, perfuader que leur condition fe trouve préférable à celle des Socićtés léparćes. Entreprendra-t-il de les inftruire par des citations de Livres? Ils les entendent peu, ni n'en connoiffunt le mćrite ou l'autorité. Employera-c il une fuite de raifonnements? Elle n'a point de prife fur ces fortes d'efprits. Leur traitera-t-il le tout hiftoriquement? Mais fon récit ne portera pas les preuves avec lui. Je le vois feul. Il n'a rien à leur faire toucher au doigr \& à l'œil. Il n'a autour de lui ni témoins, ni répondants, ni monuments. Je tremble pour le troupeau dont le Pafteur eft fi dénué de tout fupport. Mais plus les circonftances oil nous le voyons font défavantageufes, plus fon Difcours devient intéreffant pour nous. Sachons en l'écoutant, fi la Religion Cacholique lui fournit des témoignages que les plus fimples puiffent comprendre, \& qui doivent raifonnablement les perfuader. 


\section{LESPECTACะ}

i. Dé-

HWN'STR.

a yadies.

D I S C O UR S

D'UN CURÉ DE CAMPAGNE

Au jour de fa prife de pofjegion.

$\sqrt{1 \text { Essiners, }}$

Il eft aifé de vous dire : Je fuis l'Am= baffindeur de Jefus-Chrift aupres de vous. Bien des gens font venusqui ont tenuce langage; mais on les a rejettés : \& fi plufieurs venoient à vous, vous ne les recevricz pas indiltinetement. Pourquoi done me recevez-vous aujourd'hui fans oppoficion comme vorre Pafteur, commel'Envoyé qui a droit de vous conduire dans les voies du falut?

Vous en favez les raifons. Mais il y a pour vous un grand profit à vousles rappeller dans un cerrain ordre, \&z ì vous entretenir du bonheur de votre condition. Car fi vous êtes fûrs d'avoir un Envoyé de Dieu qui loit expreflement dés pute pour vous, vous des hars d'avoir pare li lulliance des vrais bien-: \& comsne la furecé de vorre étac oft la penfée do glus coniolance que yous puidiez avois 


\section{DE L I NATURE. 329}

dans vos peines, c'eft aufil le plus grand LA Diczrélor que vous puiffiez laiffer à vos en- monst r. fants.

ÉVANGEL。

Vous avez même un jufte befoin d'enrendre quelquefois parler des vmis avantages de l'Eglife Catholique où Dicu vous a tait natre. Il ne fe trouve que trop fouvent des langues ennemies de vorre paix \& de tout bien, qui femblent prendre à tâche de vous jetter dans le découragement. Qu'avez-vous, difent-elles, qui vous releve au-deffus des autres Sociétés Chrétiennes? $\mathrm{Y}$ a-t-il mème aucune certicude quelque part que ce puiffe étre à l'égard de la vie à venir? Le Pafteur qui vient à vous dans vos folitudes, eft prefque toujours fans talent ou fans zele, \& vous n'êtes pas inftruits: ou enfin s'il acquitce les bienféances de fon ćat, ce n'eft toujours qu'un homme. Où a-t-il pris ce qu'il vous débire? Vous èces Chrétiens fur fa parole : \& ne pcut il pas fe tromper comme un autre? Cacholique ou Mahoméran, c'eft toujours mềme incerticude.

Non, Mes Fireres, votre foi n'eft pas incertaine. Vos efpérances ne font poinc fondées fur los promeffes d'un homme. Le Pofteur qui vous annonce la nouyclle du dalur, \& les recompentes promifes oे 


\section{LE SPECT A L E}

LA D:- la piéré, ne fe préfente pas à vous fans sionstr. pouvoir juftifier festires. Ce n'olt poine EVANGEL. Ion favoir qui vous répond de ce quiil vous annonce, comme ce n'eft point ion ignorance qui rendra votre état incertain : c'eft la mifion qui vous fauve, \&s vous coes fùrs que fa miffion vient de Dieu. Il en a les marques dans tout ce qui l'environne, \& dans tout ce qui s'eft préfenté ailleurs à vos youx. Il fait partie de l'Ambuffade que Jefus-Chrift a adrelfée au genre humain. Par ce Pafteur délégué pour votre Paroille, vous avez part à l'alliance. Par lui vous c̀ees vraiment unis à ceux quui vous l'ont envoyé: par cux vous êtes vraiment unis à Dieu même, de qui ils onc rcçu leurs pouvoirs Ex l'alliance qu'ils vous apportenc. Bien des gens fe perfuedent que ces chofes font bien éloignécs de leurs fens; elles font trì-réellement fous vos yeux $\&$ fous vos mains.

Il eft vrai que les biens qui vous font annoncés ne fe montrent pas encore. Dieu a créce des biens de différente nature. Il a créé le bled, l'or, \& les perles: mais il n'a établi perfonne pour fare in dittributiondubled, de l'or, \&x desperles à qui en voudroit recevoir. Le travail les peut obtenir : Couvent la cupidité les en- 


\section{DE LA NATURE. $33 \mathrm{I}$}

leve. Dieu nous détourne d'y attacher LA Dénotre cœur, parce que ces biens fon monstr. paffigers: \& il nous avercit qu'il nous évaligel. en réferve de plus parfaits.

C'eft de ces biens durables qu'il a établi l'annonce la plus pubique, \& l'acquifition la plus fùre. Ces biens font offerts à tous por une Ambaffade répandue d'un bout de la terre à l'autre, \& reconnoiffoble aux Petits comme aux Grands. Mais peut-être les marques de cette commiftion font-elles trop fpirituelles: elles font au contraire parfnitement fenfibles, elles vous font aumi familieres que les liaifons les plus ordinaires de votre vie.

Je fuppole qu'un Prince Etranger, pnr exemple, un Flecteur d'Allemagne, ou, fi vous voulez, un riche Marchand de Londres, fufte une eftime particuliere du vin qu'on recueille fur vos côceaux, ou du fafran que vos plaines produifent, ou de la liqueur quon tire de vos oliviers: vous appronez que cet homme puiffane veut vous engager par un Commifionnaire à lui réferver tous les ans ce que vous avez de meilleur. Ce Commillionnaire arrive, \& vous promet un prix tou. jours fupérieur à celui qui vous fers offere par d'autres. 


\section{LE SPECTACL}

L. DS- Si fon payement n'eft point prêt, vous sonstr. demanderez des répondants; \& lorfque .FAnGLl. vous ferez convaincus de l'arrangement qui regne dans les affaires de l'Etranger, comme de la réalité de la commifion \&e des garnats, vous vous porterez avec plaifir à faire fa provifion par préférence. Vous ferez flattés d'un débit für \& durable.

Mais s'il n'y avoit point de témoignages rendus à l'envoi du Commifionnaire; if, au-lieu d'un, il s'en préfentoit deus ou arois, qui, en s'attribunnt également la commilion, vouluffent être livrés fans argent \& fans répondants; vous ne feriez pas difpolés à écouter de tels aventuriers, moins encore à leur avancer vos mar. chandifes à crédit.

Vous commencez à voir comment, vous fuvez raifonner très-jufte, \& vous précaurionner à l'égard des ablents qui veulent être en correfpondance avec vous.

Choifffons des liens qui vous foient plus chers. Vous n'avez probablement famais vu le Ror. Pluficurs de vos démarches ont cependant rapport à lui. Vous vous réjouillez de fes profpérités, que vous regardez comme les vôtres. Vous pricz pour lui : vous cites fidieles ì acquirter les impúts, à obéir à fes Ordou- 


\section{BE L A NATURE. $\quad 333$}

nunces. Vous refpectez cout ce qui porte IA DE les marques de ion pouvoir, l'Elu, le monstr. Bailli, l'intendant, le premier Préfidenc. ávanger. Vous favez que c'eft le nom du Roi qui rend leurs commifions ou leurs jugements valides.

Pourquoi, je vous prie, les habitants de Normandie, dans leurs procès, appellentils à Rouen, non à Paris? Er pourquoi ceux du Forès ou du Berry portent-ils leurs caures a Paris non à Grenoble? Ils n'onc point vules Lettres patentes qui écablifrent les Tribunaux de Rouen, de Grenoble, \& de Paris : cependan: ils en diftinguent les départements fans méprife, $\&$ n'en on jamais regardé les pouvoirs comme donceux. Ces pouvoirs ne fe voient point. La volonté de nos Rois, qui ont établi \& maintenu ces Compagnies, ne fe voit point; mais leurs Lertres deétablifrement ontété vues, \&r enfuite, aulieu de ces Letres, leur lucceflion, leurs bâtiments, leurs Actes \& $\&$ les atteftations de la Province : voila des chofes qui fe voient : celles qui fe voient tiennent pour vous la place de celles qui ne fe peuvent voir : \& comme on ne peut s'y méprendre, elles font vorre fùrcté.

Allons plus loin. Tous les jours on voic vos attentions \& vos liaifons s’éten- 


\section{LE S P E C T A L E}

La Dé- dre à des événements tiès-éloignés de monstr. vous, à des hommes morts il y a pluLTANGEL. fieurs annécs, peut-ĉtre plufieurs fiecles. I.surs noms vous font connus : vous cxécutez avec connoiffunce leurs volontés; \& vous intenteriez procès à qui ne les exécuteroit pas.

Si quelqu'un vous contefte un bien de famille, ou un droit de pâcage, ou vos ufages dans la forêt, n'avez-vous pas foin de rappeller aufli-tôt les noms des auteurs \& des confervatcurs de vos titres? Vous connoiffez le Notaire qui en garde la minute : les armes du Roi qui font fur fa porte, vous font affez entendre qu'on peut lui confier toute forte d'Actes. Vous avez recours dans le befoin au Greffe où eft la copie de la tranfaction paffée entre vos anciens Seigneurs \&i les habitants du lieu. Vous n'ignorez point que c'eít Charles le Sage, ou faint Louis, qui en affurant à vos Seigneurs leur jufte poffeffion, y a mis une réferve en faveur de votre Communauté.

Vous tenez donc par des liens trèsréels à des hommes que vous voyez rarement : vous tenez à d'autres, que vous ne verrez jamais; \& favez ce qui vous attache à des bienfaiteurs morts il $\mathrm{y}$ a plufieurs centaines d'années. 


\section{E I A NATURE. 335}

Vous ne rous plaignez pas de ces LA Dímoyens d'arranger vos affaires. Ils vous mosstr. font connus : ils font très-commodes \& ÉFANGEL. très-capables de rous tranquillifer. Or ces moyens fi fimples font ccus dont Dieu a fait choir pour vous inftruire de votre falut, \& pour vous en facilicer l'acquifition. Iis font de la même notoriété. Ils font encore plus à vatre portée : ils funt plus nombreux \& plus vivants, plus touchants, plus immanquables.

Les Actes qu'on met dans le Greffe Inconve. d'une Juftice, \& les pieces qui compo- nients de\& fent le Secrétariat d'une Ambaffide, cou- font-le rent bien des rifques. L'eau, le feu, les fondement voleurs, les vers, \& la pouffiere y peu-faires. vent caufer bien du dégît. Si les papiers de l'Ambaffade de Hollande viennent à périr, l'Ambafudeur de Suede ne les remplacera pas. Si les Chartriers de Flandres avoient été pillés ou brûlés, la Provence \& le Languedoc ne les rétabliroient pas en y envoyant des copies de leurs propres Chartriers.

D'ailleurs ceux qui font chargés de la garde de ces Actes excrcent un Miniftere peu animé. Ils fe concentent d'en mettre le recueil en ordre \& hors d'infulie, puis de les montrer quand ils en font requis: mais ils naverifient perfonne de ce 


\section{$33^{6}$ LE SPECTACLE}

I. mL-qu'ils contiennent, ni de l'iniérêt quón Monra. y peut prendre; \& quoique ce foit en ¿vavur! cux une fage difcrétion de s'en taire, combien fe trouve-t-il de chofes dans ces Aetes dont on eft fouvent à plaindre de n'avoir pas été inftruit?

Enfin il elt arrivé plus d'une fois que des Actes qui paroiffoient en bonne forme, fe foient trouvés faux ou altérés. Voila les inconvénients qui accompagnent nos titres \& nos différents moyens de confervation.

Nus in- Dans l'affaire de votre falut, ce n'eft s onivopas de même : vous y trouvez tout ce qui fe trouve de commode $\&$ de certain dans les précautions que les hommes prennent enfemble. Mais les dangers qu'on peut courir dans les affires humaines, ne fe rencontrent pas dans les moyens préparés pour affurer votre falut. Si vous avez à craindre, c'eft de votre part: vos rifques font dans vos réfiftances \& dans votre mauvaife volonté. Les Porteurs \& les Actes de l'alliance que Dieu a faite avec vous, ne peuvent ni vous manquer, ni vous dire faux.

PenAcies D'abord les Actes de l'héritage qui te l'alliant vous cft refervé, font difperfés par-tout: ee lont ils font aurhentiques \& fi multipliés, qülils ne peuvent pas fe perdre ou tomber dans l'oubli. 


\section{DE L A N A TURE. 337}

I'oubli. Vous entendrez par-tout publier LA DÉ le même Evangile. Ce font les mêmes Mosirr. Symboles, les mêmes Prieres, les niêmes ĹNancal. Sacrements, les mêmes Fêtes, les miêmes leçons, les mêmes efpérances. Voilà vos titres, \& ils ne peuvent s'égarer : c'eftl'E. glife univerfelle qui en a le dépôt.

Ajoutuns que les articles de l'alliance, I.es dífa. \&x tous les Actes qui y ont rapport, n'ont fitaires des pas été confiés à des gordiens muets, ou Ačtes ne uniquenent chargés de la commiffion de toncher: les conferver. L'affaire de votre falur a nile: laifćté au contraire recommandée à des Mef- rers. fagers dont le premier devoir eft de vous l'annoncer, \& dont les fonctions font perpécuellementcette annonce, quand ils ne parieroient pas eux mêmes. Leur Miniftere eft toujours actif \& parlant. Les lieux où ils vous affemblent, la priere commune, \& les cérémonies ausquelles ils préfident, ne laiffent perfonne dans l'ignorance de la vérité. Les premiers d'entr'cux veillent de plus fur le travail des fubalternes: \& ceux-ci, quoique travaillant dans un efpace plus borné, ne laiffent rien échapper à leur activité. Les détails font leur département : ils vont porter la lumiere, \& gagner des cceurs, jufques dans les rectaites les plus faldvages.

Tome VIII, Part. II. $\mathrm{g}$ 


\section{LE SPECTACL}

IA Dé Ils y annoncent theureufe nouvelle, monstr. \& les voies du fulut dons l'enfarce, dans ENANGer. les principales circonitances de ha vie, \& dans la maladie. Que deviendroit, furtout, la raifon de vos enfants lans les foins du Peftur? Elle feroit brute, revêche, intraicable. Seroit-ce une raifon?

Vous trouvez au contiaire la docilité, In douceur des fervices, \& de nouverux progres d'incelligence à mefure que ros familles \& vos domeftiques appremment In Loi de Dieu, lesarticles de notre Foi, Jes prieres de l'Eglife, le Sermon de JefusChrift fur la montagne, fes autres dilcours, \& les plus beaux traits de la conduite de fes Saincs. Quelquefois de jeunes enfants deviennent vocre lumiere. En paroiftant vous réjouir, tantôt par la lecture \& tantût par le chant, ils deviennent nos Vicaires. Ils yous inftruifent : \& ce quils ont appris de leur Pafteur, devient en eus un frein qui regle l'cil, la main, \& cous les defirs. C'eft tour eniemble un continticl encouragement à tout bien.

Ces fecours ne font point paffagers, \& cependant on ne s'y borno pas. Les fètes du Seigneur que le Niniltere annonce, font outant d'intructions réicérées d'amnée cn annce, \& de femaine en fomaine, de manicre a perfécuter par- 


\section{DE la NatuRE. 3.39}

tout l'oubli \& l'indifférence. Chaque fète LA DGappelle les pauvres comme les riches. moxstr. Ceux qui ne jugent pas à propos de s'y KNaNgizo rendre, $c n$ ont du moins entendu le fignal. Ils en ont déja compris le fens : \& fi les cœurs déréglés ont pris nos affemblées en haine, c'eft parce qu'ils favent qu'elles font une école de vertu.

Mais ce que nous venons de voir, quoiqu'excellent, ne fuffic pns. Les Pafteurs rendent la Société douce \& bienfaifante par la prédication des bonnes mocurs, \& par tous les motifs de l'efpérance Chrétienne. C'eft un grand bien : mais il faut beaucoup plus; il faur qu'ils foient porteurs d'une Alliance vraiment fainte \& divine. Il faut qu'ils foient Envoyés, \& que vous en puifiez être convaincus. Leur annonce eft magnifique : mais eftelle certaine dans fon origine, \& votre Pafteur propre peut-il montrer qu'il ait été chargé par le Corps de l'uncienne Ambaflade, dune commiffion fpéciale qui vous l'adrefle en particulier?

De cette forte recevoir votre Pafteur, fera pour vous la même chofe que fi vous receviez les Chefs de l'Ambafíde; la même chore que fi vous écoutiez les Apôtres \& Jefus-Chrift lui-même. Vous ne vous offenfercz plus alors que les plus 


\section{LE SPECTACLE}

La De- éminents en favoir, que ceux qui ont de moxsm. beaux talents, \& de grandes qualicés pertvanibion fonnelles, tiennent les premiers rangs dans le corps des Ambaffadeurs, \& qu'ils exercent leurs fonctions dans les habitations les plas peuplées. La chofe eft dans l'ordre: \& fi de ce Corps il a été déenché un Député, revêtu de pouvoirs pour venir dans votre folitude vous faire part de l'Alliance Chrétienne, votre condition eft la même que celle des Paroiffes les plus diftinguées \& les plus inftruites.

Votre falut de la forte ne dépend ni des bonnes, ni des mauvaifes qualités du Pafteur, mais de la réaliré de fa miffion. Commencez feulement par voir d'où il vient, \& de quel Corps il fait partie. Nous verrons enfuite fi ceux qui l'ont détaché d'entr'eux, font eux-mêmes l'Ambaffade unique \& falutaire.

I.s urates Jufqu'ici, mes Freres, je n'ai eu avec ic l'Feitice vous d'autres liaifons que celles qui unifCatholique fent les cours Cacholiques difperfés dans Freuves de tout l'univers. Mais en ce jour, des homIn perpetuite de l'Amhatiade falutairc. mes dont vous refpectez le mérite \& le rang, vous ont fait connoître \& vous ont réguliérementpréfenté votre nouveau Pafteur, pour être mis en poffeffion de cette Eglife. La cérémonie ne tend pas feulement à le faire jouir de ce modique 


\section{DE LA NA T URE. 34 T}

revenu qui doit faire fa fubfiftance : cette $L_{A} D$ : réception eft pour vous-mêmes. Cet acte Monstn.

public, en inftallant le nouvel Envoyé, f́vanget. fair la liaifon de fon cuvre avec celle de fes Prédéceffeurs. Elle le conftieue dans l'exercice de la mème miffion. J'ai touché fucceflivement les divers infruments dus Miniftere public; jai reconnu les Liwres faints, les Prieres communes, le Ricuel des Sicrements \& des Fêres, les pratiques \& la créance de la Cathédrale de ce Diocefe, les pratiques \& la créance de tous les Diocefes Catholiques. Je me fuis engagé en préfentant les marques de mon envoi, à perpécuer lo méme culce \& la même Foi dont mon Evêuue, fon Clergé \& fon Peuple font avec vous une commune \& immortelle profeflion.

De vorre part, en recevant le nouvel Envoyé, vous refferrez les liens qui vous attachent à l'Evêque de qui vous l'avez reçu. Mlais vous ne pouvez être unis à votre Prélar, que par lui vous ne foyez unis à tout le Clergé de France, de qui il tiens fon Ordination. Par l'Eglife de France, dont vous faices partie, vous êtes unis ì toutes les Eiglifes Cacholiques difperfíes dans tous les Continents. Avec tous ces Clergús \& ces Eglifes vous êtes unis 2u premier de tous les Pufteurs, à celui

$\mathrm{P}$ ijj 


\section{LE SPECT A L E}

LA Dí-qui fait le lien commun des Eylifes, \& monstr. dont le Siege montre avec la Primauté śvangel. Ia fucceflion du Miniftere Apoltolique. Vous êtes dans l'unité, \& vous connoiffez très-bien cette unité.

Quiil fe préfente ici quatre hommes dont chacun fe dife Juge-Commillaire nommé pour régler, avec des Adjoints, les débats de votre Communauté, \& qui zous les quatre s'entre-condamnent. Vous demanderez à voir leur commiflion : \& celui qui produira la fienne fecllée du fceau du Parlement, vous le recevrez. Les trois autres auront beau dire: $I l n^{\prime} y$ a plus de Parlement; c'eft une Compat grie fans regle; c'eft un údinnent tombé en ruines. Il firfit que votre Communanté m'autorife, E j'amangerai zos affuires dans la plus parfaite équité.

Ces difcours ne peuvent contenter que des imprudents. Il n'y a de fùreté qu'à recevoir celui qui a des pouvoirs réguliers, \& qui eft avoué du Miniftere public. Il eft le feul des quatre dont les Actes fubfilleront, \& auront leur effet.

Il vous eft facile de faire tout d'un coup le difcernement de tous ceux quife font féparés de l'Eglife Cacholique, \& qui voudroicnt vous foumettre à un autre Miniltere, foit en fe donnant eux-mềnes 


\section{DE IA NA TURE. $3+3$}

leur miflion, foit en la recevant de vous. Its n'ont point de pouvoirs, \& yous n'en avez poine à leur donner.

Vous favez très-bien que ce n'eft pas à rous à infticuer vos Juges \& vos $\mathrm{Mh}$ giftracs. Ce n'cft pas non plus il des Parriculiers, ce n'elt pas même au Roi de France qu'il appartient de creer des Plénipocentiaires qui vimnent traiter avec nous de la part de l'Empcreur ou du Roi de Prufte. Que fi ce procédé vous paroit dévourvu de fens dans le réglement des allaires temporolles encre perionnos abfences; à plus force raifon ne recevrezvous la Parole de vie, les Sacremence, l'Alliance Chrétionne, que de ceux qui produifen les marques reconnoiflabies d'une feule \& même miffion qui vienne de Dieu. Je dis fur-tour d'une Ceule; car comment foutenir la penfée qu'il puilie y avoir quatre mifions ou plus, quand i) eft certain qu'il ne peut même y en avoir deux?

Vous confeffiz de bouche l'unité de ce Miniftere répandu par-tout. Vous la confeffez encore par votre conduice, lorfque dans vos voyages vous évitez d'alfilter aux Afremblées qui rejettent le Minittere Catholique, \& qui fe tiennent réparécs. Vous croiriez vous êure Téparés 


\section{LE SPECT ACL}

LA Dé-vous-mêmes en y prenant féance. Voưs monstr. les regardez comme autant de branches k vinger détachées de l'arbre, \& qui, ne participane plus a la leve, fe font defféchécs.

Ces Suciérés connoiffent leur fchifme: il Ios inquiete. Elles ne parient d'autre chole; \& croicnt a force de nous attribuer divers affuibliffements, pouvoir fe zranquilifer dans leurs féparations. Pour vous il tren eft pas de même : vous n'avez pas à vous defendre de perfévérer dans lancienne unité. Auff n'arive-t-il guères dans l'Eg glife Cacholique d'entre. tenir les Pideles de 1 a doctrine $\&$ de 13 conduite de ceux qui ont renoncé à l'Eglife. C'eft à ceur-ci à favoir pourquoi ils fe font jectés dans des routes fi différentes. Cuux qui fuivent le chemin qui a toujours été pratiqué, ne font point c1n peine de juftifier leur choix: \& il ne leur faut point d'exhortation pour les engager à y perfévérer. Quel repos pour vous, d'être dans la route qui a conduit vos Peres au falut, d'être dans la Société univerfellement répandue par-tout, \& oì l'on n'a jamais ceffé de dire: "Je crois "2 la fainte Eglife univerfelle. Je crois I'L-

"glife qui eft une, fainte, Carholique

"\& Apoftolique.

La vraie Eglife \& vorre Eggliee font he 


\section{DE L A NATUR E. 345}

mêtme, puifque la vôrre s'étend à tous les L.t Dún. lieus, n'ayant par toute cerre qu'un mê- mosstr. me Clergé, un même centre de réunion, Evaciçš. un même Chef, lien de tous les divers membres de ce grand Corps, \& marque toujours vifible d'une unicé qui n'eft interrompue ni par les trajets de mer, ni par la diverfité des Langues; j’ajoute, ni par la durée des temps.

La vraie Egdife \& votre Eglife fonc encore la même par une durée non interrompue, puifque la rôtre, avec tous les avancages précédents, a celui de remoncer jufquaux premiers Succeficurs des Apôtres, jufqu'à Jefus-Chrift, julqu“à Dieu lui-mệme, auteur de la bonne nouvelle.

Tour concourt en effei à vous convaincre que les $P$ afteurs $C$ atholiques, qui n'ont jamais ceffé de rravailler à l'édifice de votre Eglife, foni les Succelfeurs des Apôtres; que Jelus. Chrilt, qui a envoyé les Apôtres, elt l'héritier de tout, \& que Yous êtes appellés à être fes co-héritiers.

Ne vous figurez poine que je vous invite à feuillerer des Livres ${ }_{\gamma} \&$ à faire des recherches difficiles. Il ne vous faut point d'études ni de Livres pour connoitre l'unité, ou la correfpondance des Bailliages des environs svec le Parlement, ni pous 


\section{LE SPECTACLE}

IA Ds. favoir que le Parlement d'aujourd'hu? Mrosinc, eft celui qui fiégeoir les années précéEManget. dentes, celui-là même que nos Rois ont établi. Il ne vous faut ni Livres ni efforts, pour difecrner les Jurifdictions, \& les Juges en qui réfident les vrais pouvoirs. Si de faux Juges, de faux Notaires, ont quelquefois trompé le Public, ou les Particuliers, ç'a éré en contrefaifant quelgues-unes des formalités d'ufage. Mais ces faus Actes, ces entreprifes illégitimes, font promprement démentics, parce que ceux qui en font les auteurs ne font point connus. Ils n'ont pas éré reçus dans l'ancien Corps qui a les poutvoirs; ils n'ont pas l'aveu des autres perfonnes en charge : ils ne jouiffent pas de l'ufage des mêmes lieux \& des mêmes procédés. Thut eft contre eux.

N'eft-ce pas pour prévenir l'illufion \& les méprifes, que tout cet extérieura été prefcrit? C'eft donc cet extérieur même qui fait votre fürecé. C'eft ainfi que ce qui eft fpirituel, \& qui ne fe voit poini, a ćté rendu vifible \& certain, pour vous maniferter les volontés des Rois de la terre, \& les volontés de Dieu; pour vons affurer, foit les biens de cette vie, foit ceux de l'autre.

Vous lentez promptement \& nettement 


\section{1) E L A - N A T U R:E. 3\$?}

ce qui s'éloigne de cet extérieur connu. ILA D:

Celui qui concreferoit les Actes de la Ma- yowirk.

giftrature, pafferoit aufli-tôt dans voure Évaciuct efprit pour un fauffaire ou pour un féducteur. Celui qui condamneroit la forme de la Juftice, la Magiftrature érablie, \& lautorité publique, vous le regardericz comme un rebelle; parce que sill y avoit des plaintes à faire contre les Juges, ce n'eft pas à ce Parciculier qu'il appartient de les deftituer, ni de fe mettre en leur place. L'application de cette regle eft facile à faire au Minittere de l'Eglife univerfelle. Rien n'y eit livré aux réformes decelui-ci, ou de celui-lat : \& tour l'extérieur de l'Eglife Carholique doit fuire fur vous des impreffions encore plus touchantes, des improflions mille fois plus propres que les établiffements civils à vous procurer le repos d'une conduite prudente, quoique fans Livres \& fan fcience.

Dices-moi, je vous prie, des Peuples qui n’ontni la mêne langue, ni ics nêmes couruares, ni le même incérêt; des P'euples gui font diftants les uns des autres de trois $\mathbb{R}$ quntre cents lieues, de mille lienes, de plulieurs milliers de lieues, fe fonc ils'donné le moc pour avoir la même Foi, les mêmes Sacrements, le mêne 


\section{3 t. LE SPECTACL}

LA Di-gouvernement? Il faut donc qu'il fe for MoNstr. autrefois répandu parmi eux une Com. ásuivel. pagnie d'hommes qui leur aient porté la même Doctrine, \& qui aient amené ccs Peuples à penfer comme eux. Le Miniltere de ces Prédicateurs n'a en effee ceflé en aucum temps d'être préfent à la mémoire de toures les Eylifes qu'ils on réunies. Elles les nomment les Âpôtres, ou les Enroyés par excellence. Tours ont continué à célébrer leurs têtes \& leurs travous, à rendre témoignage aux écrits qu'elles avoient reçus d'eux, \& à lez lire de femaine en femaine dans leurs Affemblées.

Avant de vous montrer que ces homnes ont été autorifés de Dicu même ì faire ces ćtabliffements qui fe trouvent par-iout, affurez-vous encore micux de P'origine commune de toutes vos Eglifes, en vous rappellant non ce que vous avez lu, mais ce que vous avez pu voir.

Commencez par comparer cette Eglife Paroiffile avec les Paroiffes voifincs, \& zoutes ces Eglifiesavec les plus éloignées. Thappellez-vous les objets les plus communs qui fe voient dans les vôtres, \& daus couces celles done vous avez connoifance, Le premier objer qui fe montere dans les diehors d'une Pasoifie Cathow 


\section{If I A NATURE; 349}

Pique, c'eft la Tour \& la Croix. Cerce IA Des

Croix qui eft élevée au lieu le plus émi- monsir. nent, eft l'abrćgé de votre Foi, C'clt la sangero profeflion trés-publique de n'atcendre de falut que parle facrifice de Jufus-Chrift.

Le fignal de la Pricre qui fe faic fréquemmeni entendre dans la Tour, eft tout enfemble la convocation de courc la famille pour lover le Pere commun, \& Ia confulion du befoin concinuel où nous fommes cous de la grace du Sauveur. Les annonces \& les marque que l'Eglife Cacholique donne de fa Fui, font les mèmes dans le dehors de fes batiments, par-sout oì elle eft en libercé d'exercer fes ufages: même uniformiré dans l'intcrieur. Entrez dans vos Eiglifes Paroificles: $t$ ntrez dans les Abbayes anciennes, dans la premiere Eglife du Diocefe, ou dans d'autres Cathédrales; pous y trouverez les mêmes objers \& les nêmes in 6 truments, ici en pecir, ailleurs svec un air d'appareil \& de grandeur.

Sous les rours \& fuus les portiques fe voient très-communément d'anciennes fculptures qui repréfentent des Rois, des Seigneurs du lieu, des t'rinces bienfaiteurs, d'anciens Evêquesticonnoifrables à leur bonner \& à leus bícon paitoral. marque uniformas de leu r autorité \& d'un 


\section{$35^{\circ}$ LE S PECTACLE}

LA Tu-gouvernement toujours le même par. monstr. tout. Plufieurs de ces fculptures \& de Ĺvaset. ces tours remontent jufquaux premiers fiecles de notre Mionarchie, \&t font preuve d'onze \& de douze cents ans. On y moncre les fiulptures de nos premiers Rois à còté des tombeaux où repofoient les Saints du premier âge. Quand ces bitiments auroient ćté relevés, on fait lannée de leurs différentes dédicaces: on en célebre la mémoire, \&z l'on voit par la reffemblance générale de tous ces bàtiments, qu'ils n'êtoient que des imitations des Temples précédents qui périffoient de vieilleffe, \& qui approchoient des premiers fiecles.

- La même reffemblance \& les marques de la même Foi fe voient dans toutes les parties qui les compofent. Toute la Religion Carholique fe trouve nettement exprimiée dans tous les inftruments qui fervent aux fonctions du mème Miniftere, \&̊ à l'adminiftration des mêmes Sacre: ments. Vous en comprencz l'intention, vous en avez été fréguemment inftruits; auffi bien que des noms des Fères. Ces inftruments \& ces noms vous rappellent la vie de Jefus-Chritt, fes myfteres, ia doctrine, fa morr, fa réiurrection, is médiation. 


\section{DE LA NATURE, 351}

En fortant des Temples, où toute la LA D́s.

Religion fe retrace à vos ycux, même moxstr. fans livres \& fans peintures, vous trou- Évanglo vez une derniere leçon dans le lieu confacré à la fépulture de vos familles; c'eft le cimetiere, c'eft le dortoir: Voilà, ditesyous, où nos Peres fe font endormis. Leurs corps font là fans mouvement, mais leurs ames font vivantes; elles attendent en Dieu le grand jour de leur réunion avec un corps glorieux \& dégagé de fes foibleffes.

C'eft ainfi que tous les ufages de l'E. glife Catholique font pour nous, avecles figures peintes, un Livre touiours ouvert $\&$ dont le langæge eft le même en Portugal, en Hongrie, en Allemagne, en Po. logne, en Amérique, \& par-tout.

Nème reffemblance des trois Ordres du Miniftere. On ne dit point dans les Monarchies Catholiques : Nous avons befoin de conferver le gouvernement Epircopal, parce qu'il a plus de vigueur \& de dignité. On ne dit point dans les Républiques Catholiques : Supprimons le gouvernement des Evêques, \& confervons celui des Prètres, parce que ce dernier eft plus modefte. On ne délibere poine dans l'Eglife Catholique fur l'arrangement de ce qui a été réglé il y a 


\section{$353 \quad \mathrm{~L} \& \mathrm{SPECTACL}$}

La Dó-dix-fept fiecles. La huute eftime qu'orz Monstr. failoit dans toures les Eglifes du Miniftere ávangelóvangélique, a par-tout difporé le Peuple \& les Seigneurs à fixer des aumôneg perpétuelles pour l'entretien des mêmes bâtiments \& de la mêne ceuvre. Tunt fubfilte : tout fe retrouve. Ainfi tout ce que vous voyez dans l'Eglife Catholique vous annonce la même origine, la même Foi, \& le même efprit.

Telle eft la promiere prédication qui vous a inftruics dès l'enfance. Elle a été entendue par les Peres de vos Peres \& par leurs devanciers. Ceite prédication a précédé la mienne, \& je ne pourrai voss dire que ce que vous avez déja entendu.

Vous comprenez à préfent que ce n'eft point fur la parole d'un homme que vous êtes Chrétiens. Cette prédication univerfelle de tout l'extérieur de l'Erglife, vous inftruic indépendamment de moi, \& me fait la loi. Je pourrai par mes dificours, en vous remetrant chaque vérité, chaque myftere dovint les yeux, animer les bons. fentiments \& les bonnes mours. Mais je ne pourrai ni rien fupprimer, ni rien shanger dans ce qui vous a été appris. par le fimple extérieur de nos Eglifes.

Si j'ofois vous dire que la réfurrestion 


\section{ก E L NATURE。 353}

des morts n'eft ni concevable ni poffible; LA Défi jofois ne pas vous annoncer l'affem- MONSTR. blée du faint jour de Pâques; vous me Évastel. diriez que je fuis contraire à noi-même, puifque je me fuis engagé envers vous à perpétue: dans cette Parniffe les ufages de l'Eglife Catholique, \& confécuemmont à y célébrer la premiere de toutes fes fètes, la Réfurrection du Sauveur.

Si jolois dans mes inftructions vous difpenler de l'obligacion d'aimer Dieu, de l'obligation d'employer tout votre être à lui plaire; je ferois fur le champ réfuté par le premierdes Commandements que vous avez appris. Je ferois réfuté par la voix du perit Enfant qui vient à la porte de ce cheur publier à haute voix ces paroles: "Ecoure, ô mon Peuple: , je fuis le Seigneur ton Dieu, qui t'ai , affranchi de la fervitude. Tu n'auras , point d'autre Dicuque moi. Tu aime", ras le Seigneur ton Dieu de toute ton 9, ame, de tout ton cceur, \& de coutes " tes facultés.

Il en fera de même en tour. Je vous inftruirai : mais tout m'inftruit moi-même, Mon langage a été réglé avane que je fute avec veus, \& mes Succefluurs l's. drefferont à vos petits enfants.

Les mèmes vérités que j’ai trouvé ex: 


\section{LE S P C T A C L E}

LA Di-primées dans le fervice univerfel de i'Emoxta. glife, je ies ai trouvées peintes ou gravées inanute. fur les murailles \& fur les inftruments du fervice. Tuut ce que jai à vous apprendre ou à vous remettre devant les yeur, je l'ai trouvé dans les Collect:s ou Pricrescommunes que nous récitons tous les Dimanches avec toutes les liglifes, \& que les faints Cunciles nous enjoignent de vous expliquer pour exciter en vous de faintes atfections, \& pour laifler dans votre inceligence des mocif puiftunts de vous bien conduire.

On peut dans les grandes Villes entendre des difcours plus arrangés : mais on n'y enfuigne rien qui puife, mieux que l'Evangile \& l'Office de l'Egtife, donner de la droiture à l'efprit, $\&$ infpirer l'amour du bien.

Arrêtons-nous d'une façon plus particuliere fur l'annonce de l'Evangile, parce qu'il égale vorre condition à celle des Chrétiens les mieux inftruits, \& qu'il n'eft publié nulle part dans l'Eglife Catholique fans porter avec lui la preave de fa divinité.

Après que les Apôtres eurent converti les premiers Fideles parmi des Nations inconnues les unes aux autres, ils laifle. rent des hommes choifis pour continuer 


\section{E L A NA T URE. 355}

après eux la même prédication. Depuisce LA D'. temps elle n'a jamais été interrompue, \& Monstr. la parole de vie qui a d'abord formé l'E. ÉrANger. glile, continue à la former. Mais quoique touce véricé néceflaire le trouvât \& fe répétit dans cette prédication générale qui annonce le Chriftianifme, \& qui fait des Chrétiens; les premiers Fideles recucillirent avec foin tout ce qui avoic été écrit par les Evangéliftes ố par les faints $\Lambda$ pôtres. Les Egliles qui avoiont reçu, \& qui montroient ces écrics, fubittenc encore Ia plupart. Elles atcelterent aux autres qu'elles avoient recu celle \& telle inftruction fur leurs différents befoins. Les Apòtres écanc encore en rie, \& parcourant les Eglifes qui avoient reçu Jeurs écrits, elles ne pouvoient s'y méprendre. Lire ces Lettres, c'étoit entendre les Apôtres mêmes : aufî toutes les Egliles furent-elles attentives ì recueillir tout ce qui étoit fürement d'eux, \& en faifoient publiquement la lecture. De lá eft venue la coutume qui fe trouve par-tout de lire dans l'affemblée des Fideles une partie des Epitres \& des Evangiles, afin que cetre lecture venue des hommes Apoltoliques, fervit à jamais non-leulement d'inftruction à ious les Fideles, mais de regle à la prédication des Patteurs. De la forte 


\section{LE SPECTACLE}

La Dé-il ne leur a jamais été permis de $s^{7} \mathrm{c}$ ? Monstr. éloigner, ni pollible de le faire impunćs.avgrt. ment.

Quand des Docteurs trop livrés aux vains raifonnements de l'efprit humain, olerent dire que Jefus. Chrift avoic lareffemblance de Dieu, mais qu'il n'ćcoit qu'une excellente Créature, toutes les Eylifes oppoferent à ce blafphème leur créance commune. Leurs Députésaffemblés par les foins de l'Empereur Conftantin, réfuterent cetre vaine philofophie par deux moyens également fimples \& également furs. L'un étoit la prédication de leurs Egliles, ou Jefus-Chrift étoit appellé Dieu, honoré, adoré, \& invoqué comme le Pere. L'autre moyen écoit la lumiere des Ecritures Apoftoliques quife lifoient par-touc. Ils y trouverene que l'Apôtre S. Thomas avoit appellé Jefus-Chritt fon Seigneur \& fon Dieu. L'Bvangélitte fain Jean leur avoit appris que la Sagefle, le Verbe qui s'elt fait Homme, \& qui avoit fait le monde, éroit avant coutesles chofes crécés; que le Vorbe éroii en Dieu, \& qu'il éroit Dieu. Ainfi de la parole prèchée dans roures les Ezlifes, \& de la méne parole confervée dans les Ecrics Apoftoliques, fut formé le Symbole quo rous técitez tous les Dimanches. 


\section{E I A N T UR E. 35 ?}

Les Eglifes difperfées ont toujourseu La Dí. de la forte une roix infaillible pour con- Monstr. noître une vérité conteftee : c'étoit de rap. Érangel. procher ce qui étoit cru \& publié à cer égard dans chaque Eglile. Voilà la Tradition Apoftolique, \& celle-ci acquéroic une force invincible en fe trouvant d'accord avec les Ecricures Apoftoliques.

Voyez à préfent la fimplicité du moyen qui a été pris pour conferver cette Ecriture, qui devoit rendre à jamais notre prédication réguliere $\&$ invariable.

C'eft pour opérer ce grand bien; c'eft pour rendre cette divine Ecricure familiereaux Pafteurs, que lesaffemblées Chrétiennes ont toujours commencé \& commencent toujours par en faire entendre la decture. La preuve s'en trouve dans toute l'ítendue de la Société Catholique. Elle ne vous ouvrira aucune Eglife diftinguée oil vous ne trouviez une ou plufieurs Tribunes, élevées pour y faire à haute voix, vers le Peuple, la publication des Epîtres Apoftoliques, \& d'une partie de l'Evanzile. Ce font fur-tout les Eglifes les plus anciennes, où l'on a été le plus fidele à conferver la Tribune, d'où fe doit faire au Peuple l'annonce qui étoit inféparable des alfemblées des premiers fiecles.

Cetre partie des Fêres Chrétiennespa- 
$35^{8}$ LE SPECT A C LE

IA D.-roiffoit auffi néceflaire que la réception mox-rR. même des Sacrements de l'Eglife, parce imangr. que c'eft dans l'annonce de la parole qu'eft le germe \& l'accroiffement de la Foi. De là eft provenue par-tout la folemnité de cette annonce.

Ceux d'entre vous qui voyagent, l'ont quelquefois vu faire dans la premiere Eglife de la Ville Epifcopale ou ailleurs. Je la retracerai aux autres qui ne l'ont point vue; \& par une feule cérémonie, vous jugerez de l'utilité de toutes lesautres.

Le Diacre fe détache du Clergé qui Dimnite is environne l'Autel; \& ayant pris un Livre,
utilite de enve nos céré- diftingué parmi ceux qui fant de fervice, il demande au Préfident de l'Affemblée fa miffion, ou l'ordre d'annoncer au Peuple la parole de vie. Demande vraiment infructive pour vous! Cérémonie augufte, qui vous caractérife en petit la vigilance des Pafteurs fur le dépôt de la Foi! En permettant au Diacre de faire la publication de la parole évangélique, le Pafteur ou l'Officiant lui rappelle l'intention de l'Eglife \& du Corps des Pafteurs, dont il devient le Député. L'Officiant fait Ja même chofe que s'il lui diloit de leur part : L'Eglife ne confie fa prédicacion qu’à un homme für \& choifi. Servez-la 


\section{DE L A N A T URE. 359}

dignement \&ufitélement. Partez: \& en la D?́ ouvram la bouche pour porter aux File - monsth. les \& aux Infideles les paroles de l'Al- Érangli. liance, puifle votre cœur ĉtre plein de l'efprit de Dicu : Puiffe rotre annonce répandre la joie \& animer le goût de la vertu dans tous vos Auditeurs.

Le Diacre fe met en marche vers la Tribune, précédé d'un nouveau cortege. Il porte le Livre élevé, \& tous les Affitants s'inclinent profondément fur fon paffage.

Ce Livre ne reçoit pas les feuls témoignages du refpect des vivants; il c it cout couvert des préfents de ceux qui nous ont devancés. De riches bienfaiteurs l'onc orné de lames d'or. Des Reines ont détaché de leur tête les rubis \& les diamants dont nous le voyons briller. Cette marche eft annoncée en dehors par la mufique de la Tour. La mufique guerriere s'y joint dans les grandes cérémonies. C'eft ainfi qu'on annonce les Traicés de paix : \& le Peuple fidele fait que ce qu'on luj apporte eft l'heuretife nowrelle.

Au moment où le Diacre fait l'ouverture du Livre, toure l'A Tremblée fe tient debout, \& lui prêie un religieus filence.

Quand la publication cit faite, foit que le Diacre doive expliquer l'Evangile, 


\section{LE S P E C T A C L E}

IA Df. foit qu'il le laiffe expliquer à un autre; monstr. alors le Préfident de l'Afremblée, tout źvanger. le Clergé, \& quelạues Laïes repréfentanc le corps du Peuple, baifent le live tour-à-tour. Ils applaudillent à ce qui vient d'être lu, en difant: "J'y crois de cœur,

"E je le confeffe de bouche.

Intention A quoi ce cérémonial \& ces refpects fe rie noscé- rapportent-ils? S'il écoit accordé à chaque
rémonies. Fidele d'exprimer dans la priere publique les divers mouvements de fon cour, \& de faire entendre fes penfées par autant de paroles, nos Afremblées dégénéreroient en une horrible confufion. L'Eglife sy prend avec plus de prudence. Loin d"étouffer les fentiments de la piété, elle les excite tant qu'clle peur. Elle fouhaite même qu'ils fe produifent au dehors. Mais elle le faic avec ordire \& avec diğnicé.

Elle parle peu elle-même, \& nous fair enendre beaucoup plus de choles qu'elle n'en dit chaque jour. Elle nous fait concevoir \& médicer un grand nombre de vérités par les différentes parties de fon extérieur, où tout a un rens clair, \& un rapport net à fa Foi.

De même elle fe contente de la part des Fideles, d'un fimple figne de leur confolion, \& d'un gefic expreflif. Qui eft-ce

qui 
DE LA NATURE. $36 \mathrm{t}$ quî n'entend "pas ce que les Fideles dé- LA D'clarent par le baifer de paiz qui précede monstr. la Communion? Qui eft-ce qui n'eniend Évangal. pas l'aveu de leur confiance au facrifice unique du Sauveur, quand ils sabaiffent devant une Croix? Ont-ils une autre intention quand ils expriment la perfée de la Croix, par le mouvement de la main qui la figure? On parle à tout propos, même en fe taifant: \& comme on falue de la bouche, on falue du chapeau, on falue de la main.

On ne blâma jamais les Hébreux d'avoir orné de lames d'or l'Arche d'alliance. Les accufa-t-on jamais de fuperftition pour avoir été dans l'ufage, en quelque Pays qu'ils fuffent, defe toumer en priant vers le lieu où étoit l'Arche? Ce gefte les rappelloit à leurs obligations, en les occupant de l'Arche \& du Livre de la Loi qu'elle contenoit. Nos cérémonies de mêsme ne donnent pas la fainteré : mais elles font cour-à-tour l'avis \& l'expreffion des fentiments qui nous fanctifient. La vénération des Cacholiques ne va ni à l'or, ni aux pierreries qui couvrent la Croix oule Livre des Evangiles. Ils faven trèsbien que ce qui eft contenu dans ce Livre eft plus précieux que toutes !es richefles de la terre.

Tomie VIII. Part. II.

Q 


\section{Le SPECTACLE}

La Di- Ainfi dès avant que vos Pafteurs vous moxstr. aient fait aucune inftruction, l'cxtérieur strumb. de l'Eglife Catholique vous a déja appris très-uniformément les principales vérités. Ce que les Livres difent, le cérémonial le redit en cent façons; \& plus le tout fe répere, plus le fens en eft arrêté. Il n'y peut être touché par qui que ce foit, qu'on n'entende le cri de la Foi quui oppole l'ancienne prédication à la nouveauté.

Nais ce cérémonial fi bien entendu, ne vous donne pas feulement d'utiles leçons : il vous offre par-tout preuve fur preuve de la vérité de votre créance. Ces Livres des Epìtres, des Actes des Apôtres, \& des Evangiles, ont été en tout temps très-proprementécrits, \& confervés avec foin dans les ancicnnes Bibliotheques, ou dansle Tréfor des grandes Eglifes. L'écriture s'en trouve fouvent d'un carnctere plus ancien que l'Eglife rmềme où on les met en cuvre. Cependant en quelqque Pays qu'on trouve cctte Ecriture, en quelque langue qu'elle ait été mife, c'eft toujours exactement le même Livre. Il fe retrouve jufques dans ces Sociétés qui fe font très-anciennement dérachées de l'Églife univerfelle pour fe gouverner à leur mode, \& qui ont ofé 


\section{DE L A NA T URE. 363}

renoncer à la forme d'union done leurs LA D:Peres confeffoient la nécefficé, à cetce Monstr. union par laquelle les Difciples de Jejus. Ltancer. Chrift avoient faic de tous les Pafteurs un feul corps de Pafteurs, \& de tous les troupeaux un feul \& mème troupeau.

Ce troupeau avec fes Pafteurs fe perpécue jufqua la confommation des fiecles. Vous ètes fûrs d'être de cet ancien troupeau; vous en avez la preuve dans la fucceffion \& dans l'unité de vos Pafteurs, qui n'on ceffé de venir à vous avec la même Ecriture, avec les mêmes Sacrements, les mêmes inftruments, les mêmes fymboles, \&r les mêmes pratiques. Vorre Pafteur vous prête fon Miniftere; \& ce font réellement les Apôtres dont voús entendez la prédication. Mais leur parole eft-elle la parole de Jefus-Chrift \& de Dieu même? Il me refte donc à montrer que qui écoute les Apôtres \& JefusChrift, écoute le Pere qui a envoyé JefusChrift \& les Apôtres. La preuve en $\in \mathbb{f}$ devant vous.

Trois fiecles de perfécution fervirent ta minin à rendre le témoignage le plus unanime de Jefis\&r le plus extraordinaire nux merveilles divine, it de Jefus-Cbrift, \& aux ceuvres de fes en eft fone Apôtres, puis de leurs Succefleurs. Dieu fithle duns rendoit tómoignage a fon Fils par des thotince. 


\section{$36+\quad$ LE SPECTACL}

LA Dé miracles que toute la terre a vus, \& par masta. des évćnements aufi notcirement prédits Érangel. que fidélement exécutés. Les hommes ont enfuite attefté le tout, jufqu'à la perte de leur liberté, de lcur patrie, \& de lcur vie. Mais le temps a-t-il rendu pour vous ce témoignage incertain? \& votre Religion, qui eft fondée fur ce témoignage de Dieu, feroit-clle devenue incertaine?

Non, affurément, ni le témoignage que Dieu a rendu à fes Envoyés, ni les témoignages que les premiers fiecles ont rendus à l'Evangile, ne font perdus point pour vous: ces témoignages fubfittent: ils font fous ros yeux, \& l'Eglile Catholique vous les conferve.

Si vous aviez vécu dans les premiers cemps du Chriftianifme, vous auriez pu fans doute être témoins par vous-mêmes, ou inttruits par le rapport des aurres, de plufieurs faits capables de vous converir, ou de vous affermir. Mais la contrainte des temps, \& la vie cachée des Chrétiens auroit dérobé la plupart des événements à voure connoiffance. Vous auriez peut-être évitć d'en être inftruits, pour ne pas courir le rifque de devenir Chrétiens. Au-licu qu'aujourd'hui la confollion \& la mort courageufe de tous ces tímoins fe trouvent expofés fous les 


\section{DE L A N A T URE. 365}

yeux du genre-humain. C'eft un corps LA D:de témoignages qui fe trouvent par-tout, MoxsTR. \& qui ne peuvent ni fe détruire, ni śvanger. s'obfcurcir. On fic alors pour vous conferver l'Evangile \& fes preuves, ce qui n'a été fait pour conferver aucune hifroire, ni pour faire durer le fouvenir d'aucun homme, quelque célebre qu'i] fùt.

Les Fideles qui virent mourir fous le glaive les faints Apôtres, puis leurs Dif- Martyrs ciples, \& des Martyrs de toute condition, de tout åge, \& de tout Pays, re- fubfiftante cueillirent avec refpect leur fang, \& les ce la dividébris de leurs corps : puis fur le licu Religion. même où ils les avoient enterrés, ils pofoient la Table du Seigneur. Ils y célébroient au moins une fois dans l'année les faints myfteres, \& s'y affembloient quelquefois dansle filence de la nuit pour annoncer la mort du Seigneur, \& celle des témoins de la vérité. Ils glorifioienc Dieu de la force qu'il donnoit à la parole de l'Evangile, \& ils atteftoient par cette folemniré à tout l'avenir la conftance \& la conviction des Témoins.

Les Fideles n'érigeoient point d'Autels aux Martyrs. Vous le favez très-bien. Nais le tombeau d'un Confefleur du Chrift leur paroifloit l'Autel qui lui dût 


\section{LE S P E C T A C L E}

LA D)- Ĉtre le plus agréable, comme il étoit auffi moxstr. le plus propre à animer leurfoi. Ils conívancer. tinuerent à s'y affembler d'année en annéc au jour de leur féparation. Quand ils en aroient la liberté, ils bâtiffoient à cette intention une Chapelle ou une Salle c'Nffemblée, fur le tombeau même, ou ailleurs s'ils ne pouvoient faire autrement. Un mouchoir teint du fang des Nartyrs, un os furtivement fouftrait à la vigilance des perfécuteurs, devenoit un mémorial confolant pour les Fideles. Quelquefois dans les rues fouterraines où ils avoient, comme le petit Peuple, la liberté d'enterrer leurs morts, ils élargiffoient en maniere de falle les caveaux de leurs Martyrs. Tous ces lieux \& les fêtes qu'on y célébroit, prirent par-tout le nom célebre de Mémoires des Martyrs.

L'Evêque indiquoit chaque fête du Sauveur au tombeau d'un tel, ou d'une telle Martyre. Les Fideles y paffoient une partie de la nuit en prieres, pour s'entre. édifier par de grands exemples, ou s'y cachoient pour fe dérober à la perfécution. Ces mémoires \& ces veilles fe mulciplicrent comme les violences des perfécuteurs : elles fervirent à faire connoître la vérité en tous licux, \& dans tous les fiecles. 


\section{E I A N A T U R E. 36 ?}

Nous ne connoiffons pas, à beaucoup LA D:près, tous les noms de cesiliuftres Con- munstr. fefleurs, parce que les perfécuteurs pre- Ĺvasule. noient quelquefois la précatution de fupprimer les Actes juridiques de leur mort, \& empêchoient qu'on ne les communiquât aux Chrétiens qui les lifoient dans leurs Afemblées. Mais comme le fang des Martyrs a coulé par-tout, il eft devenu par-tout une femence de nouveaux Chrétions. Le Chriftianifme s'eft ainfi étendu \& perpétué par-tout avec fes preuves.

Les Fideles de la grande Ville d'Antioche s'affembloient au tombeau de leur Pafteur Ignace; ceux de Smyrne, fur les cendres du vénérable Polycarpe, qui avoic fouvent entendu raconter les auvres du Seigneur de la bouche de S. Jean \& des autres Difciples. On s'affembloit dans les dehors de Rome, fur les tombeaux de Pierre \& Paul, de Clément, de Sixte, de Laurent, \&t d'une infinicé d'autres de tout âge $\&$ de tout état. La Ville la plus illuitre a cu les témoignnges les plus nombreux.

Rien de fi célebre que les mémoires de Cyprien à Carthage, de Gervais \& de Promis à Milan, de Porin, de Blandine, d'Irence, \& de tane d'autres, à Vienne of 


\section{LE SPEC T A C L E}

LA I) -à Lyon: par-tout nous continuons à nous mostr. affembler auprès des Fondateurs de nos EVANoul. Eglifes. II n'y a rien fur la terre ni de fi univerfel que ces Mémoires, ni de fi finguliérement illuftré que ce Témoignage: \& tout ce qui fe fait dans l'Eglife Catholique en oft la fuite; ç'en eft la parfaite perpétuité.

Tout l'ex-

L'Aurel, en bien des lieux a la forme terieurnit d'un tombeau. Par-tout où l'on copie Marure fú fidélement la fimple antiquité, le corps comme le de cet Autel cft couvert d'un rideau par fait preatvedes wetvies ile lifpritSalits devant, ou d'un ornement auquel on conferve toujours la forme d'un rideau. On l'ouvroit au jour de la fête pour mettre à découvert l'urne du faint Martyr qui étoit placée fous l'Autel, \& qu'on y retrouve encore.

Cette coutume fi propre à encourager les Fideles à la conftance dans les approches de la perfécution, \& à foutenir la piécé dans tous les fiecles, a introduit une autre pratique; favoir, de ne plus ćriger d'Autels, fans y placer les reftes d'un faint Martyr, ou de quelque perfonnage diftingué par une éminence vertu. Lorfque l'Autel étoit pofé \& fervoit aux affenblées du Peuple fidele, les corps de ceux qu'on honoroit comme les vafes de l'Efprit-Saint, n'étoient plus rangés fous 


\section{DE LA NATURE. 369}

I'Autel, parce qu'il étoit occupé. Onlés La Dáplaçoit dans les environs \& à côté, ou MoNistr. dans le fond de l'abfide qui terminoit le ÁAATGL bâtiment. Ils vencient, quoique morts, publier leur confiance en cclui qui les reflufcitera. C'eft ainfi que l'humble Genevieve eft placée derriere l'Aurel. C"eft la fituation du Prclat qui a baptifé Clovis \&r les François. La plupart des Fondaceurs de toures les Eglifes fe recrouvent de même auprès de la Table oùils ont rompu le pain de vie. La plupart des noms diftingués dans chaque Diocele couronnent l'Autel, \& actirent tous les yeux dans le fond des anciennes Cathédrales.

Autour de ces Aurels \& $x$ de ces rombeaux fe voient encore les lampes \& les des lampes cierges qui éclairoient les veilles des pre- ges dans miers Chrétiens. Quand vous entrez dans catholimos Cours de Juftice, vous trouvez des ques. habits, des procédés, des manieres de faluer, des cours de langage qui vous rappellent aux temps éloignés où ces établiffements ont été hairs. De même quand nous entrons dans les Egliles Cathédrales de Puris, de Lyon, de Milan, de Rome, \& généralement dans nos Eglifes, il femble, eu égard à nos mours, que nous pafions dans un nouvenu monde. Nous 


\section{LE SPECT ACLE}

I.A D'- voyons en efiet les habits, \& nous enMoNsTr. tendons le langage de ceux dont lescenÉvangel- dres repofent fous l'Autel. Les formules de leurs prieres, les inftrurnents de leur liturgie, les reftes \& les marques de leur fupplice, conjointement avec l'œuvre publique où ils furent d'abord montrés aux Fideles, \& placés à demeure pour les édifier à jamais, tout eft venu jufqu'à nous de compagnie. Rien n'a été défuni : \& la vérité qu'ils atteftoient fi hautement, vous fentez qu'ils l'atteftent dans les derniers jours comme dans les premiers temps.

Continuez à fuivre avec une légere attention le caractere de la plupart de vos cérémonies : vous continuerez à y appercevoir que l'Eglife eft née en quelque forte, ou a pris fes premiers accroiffements dans les cimetieres des Martyrs, \& que tout ce qui frappe vos fens eft un monument de la vérité.

C'eft en fréquentant les Mémoires des Témoins, que l'extérieur de l'Eglife s'eft arrangé. C'eft là qu'elle trouvoit fes richeffes en s'y uniffant au Chef des Fideles morts, \& des Fideles vivants. Elle y fortifioir la foi de fes enfants par de grands modeles pour les rendre invincibles. Elle leur offroit les marques de leur confeffion, 


\section{D) E A NA TUR E. 37I}

\& le puifrant fecours de la conmunion LA D\% des Saints, dont la mort n'a pu éteindre la charité, ni difcontinuer les prieres.

L'Eglife a tranfmis à la poftérité, avec leurs cendres $\&$ avec leurs fêtes, le témoignage qu'ils ont rendu par l'effufion de leur fang, aux événements quils avoient vus. Le témoignage que l'Erprit-Saint a reudu à Jefus-Chrift, a done été perpétué à jamais par le témoignage des hommes; \& ce témoignage fi courageux \& fi univerfel, a été confervé par tout l'extérieur de l'Eglife.

Les hommes les plus fameux dans l'hiftoire \& dans la conduite des affaires temporelles, font pour vous comme s'ilsn'avoient jamais été. Que je vous parle des penfées de Platon \& de Confucius, ou des victoires d'Annibal \& de Tamerlan, vous ne connoillez point ces gens-là, \&r c'eft pour vous une trìs-petite perte. Mhis vous vous réjouiffez à la nailfance du faint Précurfeur : vous quittez votre travail pour venir chanter les victoires du Diacre Etienne, des faints Apôtres, \& de ceux qui ont confeffé dans les tourments les merveilles de la Prédication Aportolique. C'eft à quoi fe réduit le favoir des Campagnes, \&r c'eft dans la vérité le feul qui vous foit néceffirire, 


\section{LE SFECTACLE}

LA Dś-puifqu'il fait la fûreté de votre Etąo MoNsTr. Plus vous étendez vos voyages dans les śanger. Pays Catholiques, plus vous trouvez de monuments de la premiere Prédication, $\&$ de la conftance des Témoins. Ccux qui ne voyagent pas les retrouvent fuffiamment dans les cérémonies de l'Eglife, qui func les mêmes à la Campagne que dans les Villes.

Comme l'Eglife ancienne célébroit la plupart de fes fêtes au tombeau de quelque Martyr, les Paroiffes s'y tranfportoient proceffionnellement, fur l'indication que l'Evềque leur en avoit donnée.

Les Pro- Cette indication de l'Afremblée à telle, ecfions. ou à telle Mćmoirc, a fixé les noms des bitiments qui porterent ainfi le nom d'un Saint, quoiqu'on n'y adore que Dieu; \& certe marche des Paroiffes convoquées fo retrouve dans la Proccffion qui précede encore la célébration de l'EuchaLes Eten. riflie. Le befoin de diftinguer les troutards.

peaux dans ces lieux qui avec le temps derinrent d'un grand abord, introduific les éiendards qui marchent encore à votre tête.

i.es $\mathrm{Ky}$ - Le récit \&: le chant des Kyrielles étoit vile un exercice aifé dans la longueur de la soute vers des cimetieres, toujours placés hors des Villes. L'ufage qui en eft 


\section{DE L A NA T UR . 373}

venu d'Orient, a retenu parmi nous les $L_{A}$ D'premiers mots de la formule Grecque, monstr. qui eft, vous le favez, l'invocation réi- t́varigrto térée du fecours Divin, \& la demande des pricres des hommes de Dieu.

L'Eglife n'ignore pas l'avantage que les Fideles tirent de l'intelligence de fes prieres. Elle vous les faic entendre comme l'Evangile, en vous les expliquant par des traductions imprimées, \& par la bouche de fes Pafteurs, à qui elle recommande cet important devoir dans fes Conciles. Eile vous exhorte à croître tous en fcience, \& elle vous y aide: mais elle ne fe détermine pas à changer fon langage, ni fes courumes, à la premiere clameur de quelque critique, non pas même à la premiere apparence d'un bien qui pourroic réfulcer de fon changement. Ce bien feroit d'éclairer plus aifémentles Fideles: mais elley fupplée. C'eft la fonction perpétuelle de fes Pafteurs; \& l'avantage de parler le langage vulgaire, feroit tomber un autre bien dont elle ne veut pas vous priver.

Votre très-grand bien eft que vous foyez fúrs de la fainceté \& de l'apoftolicité de votre Eglife. Le trìs-grand bien que l'Eglife fe propofe, eft de vousconvaincre que votre Foi n'eft point fortie 


\section{L E S P E C T A C L E}

LA Dí-de la tête de quelque nouveau venu; moxstr. mais que vous avez part à l'Alliance proÉvaxgel. mife \& apportée fur la terre. Or c'clt le bien, c'eft l'affurance que l'Eglife Catholique vous procure par la fabilité \& par l'uniformité de fes ufages.

En vous tranfinettant de cette forta le langage des premiers Chrétiens, leurs habits, leurs monuments, leurs fètes, leurs prieres, leurs pratiques, elle vous a confervé toute l'antiquité, tout le dépôt, la créance \& les témoignages.

Ce n'étoit pas allez que les preuves de la Foi Cacholigive fuffent dans des Livres où les favants les peuvent trouver; il falloit des preuves populaires. Vous venez de les voir. L'Eglife vous les a confervées dans tout fon extérieur : \& elles ne convainquent pas feulement les petits; elles éclairent les favants même. Tel eft le fruit ineftimable de la perfévérance de l'Eglife Catholique dans tous fes ufages. Ses pratiques font toujours les mêmes. Quand clle s'eft relitchée de la rigueur ou de l'uniformité de certains réglements, ça été pour un befoin prellant; ç'a été par une indulgence prudente. Mais fes dogmes, fes inftuctions, fon efprit, font invariables. Si l'extérieur de l'Eglife Catholique ne change pas, vous 


\section{DE L A NA T URE. 375}

comprenez que la Foi qui eft exprimée La Dspar tout cet extérieur, \& qui eft publi- nonstr. quement profeflée chez tant de Peuples, change encore moins. Vous avez donc le bonheur d'ètre dans l'unité des Eglifes, d'avoir la fucceflion des Pafteurs Apoftoliques; \& par eux de tenir a Dieu, qui les a chargés de fon Alliance avec les hommes.

Ces avaurages reconnoifrables dans toute l'Eglife Catholique, \& dans cette petite Paroiffe, comme daus les plus grandes, font pour vous le plus précieux de tous les biens, \& le plus grand fujet d'une vive reconnoiffance. Ce n'eft pas, il eft vrai, cet extéricur qui vous fauve; mais il vous attelte la certicude des moyens de faire votre falut.

Le Pafteur qui a été envoyé pour vous fervir à cette fin, ne baptife, ni ne remet les péchés en fon nom. Les Martyrs qui repolent fous l'Autel ne font point morts pour vous. Jefus-Chrift feul eft vorre Sauveur : \& fi vous mourez fans tenir à lui par l'amour, les avantages extéricurs, que vous avez dans l'Eglife Catholique, feront perdus pour vous. Mais ces liens qui rous uniffent fenfiblement aux Fideles de tous les fiecles, font par eux-mêmes d'un grand mérite. 


\section{LE SPECTACLE}

L. D: Ils font les marques de la vrnie Eglife. moxitr. Les autres Sociétés qui ont rompu ces AnAsuel. liens, ont perdule droic de fe faire écouter. Il y auroit une extrême imprudence à ćcouter des Pafteurs qui n'ont reçu pour vous aucune commiffion, \& c'eft une conduite pleine de bon fens de recevoir ceux qui viennent à vous avec les preuves toujours fubfiftantes d'une miffion qui ne devoit jamais être réroquée.

Vous plaindrez-vous à préfent, M ES Freres, d’avoir été délaifrés à l'écart, \& de n'avoir ni connoiffance, ni certitude de rien. Vous favez vraiment, ou vous pouvez fans effurts favoir tourfle néceffaire. Il s'offre à vous de toute part, avant même que j’aie ouvert la bouche pour acquitter mon Miriftere. Avec la vérité vous trouvez la certitude dans tout ce qui vous environne, \& cette certitude y eft plus éclatante que dans les écabliffements humains, \& dans les alliances temporelles.

Pour paffer une grande partie de vos jours dans la folitude, vous n'en êtes ni plus méprifables, ni réellement plus méprifés. Peu vous imporce au refte l'eftime des hommes. Vous êtes chers à Dieu: que vours faur-il de plus? Vous êtes fûrs de n'êre ni doftitués du droir de Bour. 


\section{DE I A NATURE. 377}

geoifie dans la Cité cólefte, ni érrangers LA Déà l'Alliance? Mais vous êtes les Conci- muastr. toyens des Snints, \& les enfants de la évancilos Maifon de Dieu. Vous êres fûrs de faire partic de l'édifice bâti, non fur les fondements chancelants de l'efprit particulier; mais fur le fondement des Propheres \& des Apôtres, parce que vous ne faites qu'un corps avec leurs Succeffeurs. Vous êtes fûrs conféquemment d'être appuyés fur la maîtreffe pierre de l'angle, qui eft Jefus-Chrift.

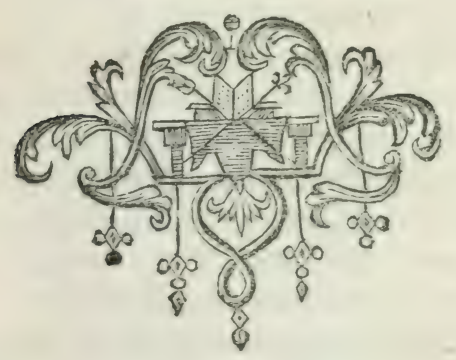




\section{LE SPECT ACLE}

$I_{A} \mathrm{~A} D E-$

MONSTR.

\&́VANGEL.

\section{O N C L US I O N D U TR A I T É}

D E L'H O M M E.

N voit par ce difcours, comme par tout ce qui a précédé, quà l'éçard du falut \& des moyens d'y parvenir, Dieu n'a rien laifée à la décemination de l'efprit particulier. Dans cette fociéré qu’il daigne faire avec nous, \& dans laquelle tous font invités d'entrer, il a voulu que la certitude du gouvernement, \& des biens offerts a la Foi, comme la certitude de l'ordre établi dans toute autre fociété, fût fondée fur dés preuves fenfibles, fubfiftantes, \& proportionnées à la capacité de tous. Il ne s'en eft point remis à la fupériorité du favoir de l'homme. Les talents peuvent fervir à l'annonce du falut, \& à la propagation de la Foi ; mais ils n'en feront point l'examen.

Soit en matiere de fcience, foit en matiere de fait, notre favoir n'eft urile que quand il eft en regle, \& la regle eft uni- verfolloment connue. Nous prenons dans nos raifunnements ce que Dieu a mis fous 


\section{DE, L A NATURE. $\quad 379$}

Le gonwernement de la raifon, Es à notre LA Déportée : mais ce qui dépend de la volonté atonstr. d'autrui, ce qui dépend de la yolonté des Évasigel. Légifateurs, E fur-tout du fupréme Légiflateur, nous l'apprendrons pur des Témoins, par des Envoyés, par un Minifsere chargé de nous en inftruire.

"Q Qui des hommes, en effer, peut fa- I. Cor. z: "voir ce qui eft dans l'homme, fi ce ${ }^{1 \mathrm{I}}$.

"n'eft l'efprit de l'homme qui eft en lui; ou celui à qui il confiera fa penfée? " $\mathrm{Nul}$ " ne connoì de même ce qui eft en Dieu, ", fi ce n'eft l'Efprit de Dieu; , ou celui à qui Dieu révélera fes intentions.

Aurant ce principe eft fimple \& conforme au fens commun, autant l'application en eft fimple \& intelligible à tous dans la caufe préfente. Les monuments des différents préparacifs de l'Evangile courrent la terre; \& toute la Société eft réguliérement inftruite, ou du moins avertie de la commifion du Miniltere qui nous annonce la Bonne Nouvelle: nous n'avons plus à délibérer fur le procédé qui nous convient. La part que la raifon humaine peut $\&$ doit prendre à l'Alliance qu'on nous apporte, eft de voir les preuves éclatantes qui environnent le Miniftere, \& d'entrer dans l'Alliance, non de la foumetre à fon jugcment. 


\section{LE S P E T T A L E}

LA Ds. Icice n'eft plus comme en Géomérrie, monsrr. comme dans les Mléchaniques, \& dans ¿nancal. les beaux Arts : il n'eft plus queftion d'examiner, de décider, de réformer : nous n'avons plus de Tribunal.

Tous tant que nous fommes, nous avons éprouvé les ténebres de notre raifon \& les bornes qui lui font prefcrites. C'eft fon bonheur d'avoir un fupplément à fa foibleffe, \& de trouver une regle fûre pour s'inftruire, fur-tout de ce qui dépend, non de fa volonté, mais d'une décifion étrangere. C'eft donc fon très-grand bonheur d'avoir à fuivre la même regle pour apprendre les dogmes révélés, bien loin d'en vouloir faire le difcernement par elle-même, \& de s'en arroger la vérification. L'Apoftolat ne prévient la raifon en lui annonçant tous les jours les intentions de Dieu dans la forme ufuelle de toutes les légiflations, que pour lui épargner des efforts fuperflus, \& de nouveaux égarements.

S'il eft donc forti de la bouche \& du cœur de l'homme des paroles dépourvues de fens, ce font celles-ci. (a) "Tout ", dogme qui n'a pas été homologué, ", pour ainfi dire, vérifié \& enrégiftré au ") Parlement fuprême de la raifon \& de (a) Bayle, Conment. Pbilofopbo 


\section{กE L A NA TURE. 381}

3 Ia lumiere naturelle, ne peut qu'être LA D'-

"d'une autorité chancelante \& fragile Monstr

" comme le verre.

Cette maxime eft commune aux Réformateurs \& aux Incrédules. Ils le cionnent tous, \& leurs difciples comme eux, pour autant de Juges fouverains. Ils ont tous un Tribunal fans appel: rous y monten tour-à-tour pour délibérer en regle, fi, la raifon ouie, ils toléreront ou fupprimeront l'Apoftolat de Jefus-Chrift; s'ils feront ou ne feront pas l'homologation de l'Evangile.

Quand nous marchons à la lumiere des témoignages de.la Foi, \& que nous con* formons nos fentiments à la paro!e de vie qui nous eft réguliérement annoncée; nous honorons Dieu par une confiance éclairée : rien de plus fenfé que de nous abandonner à fa conduite \& à fon plan, qui eft de nous exercer par la Foi, dans l'attente de la pleine manifeftation. Mais quand on nous voit fortir de notre peticeffe, \& procéder à la révifion de la Fol Chrétienne, ou à la fupprefition du Miniftere Catholique, nous montrons plus de fuffifance \& de ridicule que des avortons de Juges qui feroient un Code de Loix à leus gré, \& cafferoientl'ancienne Magiftrature. Si nous pouvons nous avilir encore 
382 LE SPECTACLE

LA D'. plus, c'eft de quitter les lumieres des téRTONSTR. moignages qui nous éclairent de toute źvanger. part, pour fuivre les bluettes de Pope, de Bayle, \& de Montagne. Ces difficultucux difcoureurs avouent qu'ils ne favent eux-mêmes où ils nous menent : \& nous les prenons pour guides. Non, ce ne font pas des guides que nous cherchons: nous fuyons la lumiere; nous nous plaifons dans la liberté des voies détournées, \& nous *nous croyons autorifés en nous rencontrant dans la même route avec des gens d'efprit. Mais que vient faire là leur cfprit? il cft hors de fa fphere. Ont-ils droit de parler fur ce qu'ils ne favent pas? L'Incarnation devient-elle impofible, parce qu'ils n'y peuvent atteindre? Et le Soleil eft-il ćteint, parce qu'ils ne peuvent comprendre ni la ftructure de cet aftre, ni la marche de la lumicre? Leurs téncbres nous rendront-elles clairvoyants? Et quand nous fommes déconcertés par leurs doutes, jufqu’à ne plus favoir où nous en formmes, n'eft-ce pas en nous le comble de l'imprudence de nous laiffer dire : $\Lambda$ vancez hardiment, vous n'avez rien à craindre.

Hors de l'Eglife, \& dans l'Eglife même, nous nous appauvriffons à mefure que nous mettons notre confiance dans 


\section{DE L A NATURE. 383}

les penféesd'un bel efprit, que nous épou- in DÉfons les vues de l'homme qui en impole monstr. par quelque brillant, ou par des fyftè- ÉMAages. mes hardis. Nul n'eft eftimable ou digne d'être écouté en fait de Traité public \&r de dogmes révélés, qu'autant qu'il s’abftient de prendre fa lumiere en lui-même. Prenons-la donc avec lui dans les archires de la Foi, dans la prédication des Pafteurs, \&r de tout le culte excérieur; prédication aufí perfévérante que les Chaires Epifcopales, aufi intelligible que les pratiques, \& auffi-bien juftifiée que la fuccellion des Miniftres; prédication aufi unique que ce Corps d'Eghiles qui n'ont ceflé d'être unies pour l'entendre.

Jefus-Chrift n'a jamais rien tant inculqué que le concert de fes Difciples, \& que la ftabilité de l'unité. Toutes fes exhortations \& tous fes établiffements nous ramenent là, parce que c'ct dans l'unité qu'il a mis nos fupports \& notre fùreté. Les faints Apôtres, fes confidents \& fes interpretes, n'ont rien tant condamné que les vues perfonnelles, que les interprétations de l'efprit particulier. * Ils ont *It.Pes: attaqué \& pourfuivi cat efprit comme le principe des erreurs * \& des fépara- *cof:a:

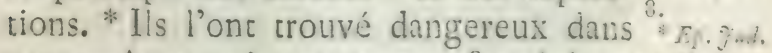
ceux-mêmes qui, cn recevant \& prếchant * iv. 


\section{LE S P E T T C L E}

LA Dé- l'Evangile, l'altéroient par le mêlange monstr. d'une vaine Philolophie.

Évangel. Cet efprit, dès le commencement* de *I. Cor.3. l'Eglife, introduiloit des partialités parmi les Fideles, \& flattoit quelques Miniftres de la Parole par la fatisfaction de voir applaudir à leur méthode \& à leurs penfées. S. Paul travailla promptement à étouffer ces premieres femences de divifion. "Il y a parmi vous des jaloufies \& des „, difpuces, dit-il aux Fideles de Corinthe: 2, l'un dit: Je fuisà Paul; l'autre: Je fuis à "Apollo. Mais qui eft Paul pour vousau", torifer à dire, je fuis à lui? Qui eft A poilo, ", pour dire, je m'attacheà fesfentiments? L'Apôtre choifit ainfi les noms les plus refpectés dans cette Eglife, pour ne point 2.Cr.4:6. nommer ceux qui étoient devenus l'objet d'une affection peu prudente : par-là il acquiert \& adoucit le droit de réprouver toutes ces préventions humaines pour les perfonnes, pour les méthodes, pour les opinions. Nul efpric particulier ne fera le bonheur des Chrétiens. Il n'y a qu'un langage \& qu'une conduite profitables; c'elt d'ètre à celui qui nous a acquis, \& de tcnir à lui, non par tel ou par tel, mais par la commune Prédication du Nhiniftere qu'il adreffe à tous, qui a tout reçu, \& qui nous livre tout. 
BE L.A. N $\triangle$ T URE. $\quad 385$

Bien loin donc de nous partialifer pour LA D: quelque homme que ce foit, nous n'artacherons pas notre falut à l'un des źvangetso moyens choifis de Dieu même, par exclufion aux autres. C'eft la totalité de ces moyens qui fait notre trúfor. Ce n'eft point Paul, ni même tous les Ecrivains ईacrés mis enfemble qui font notre unique regle, puifque la prédication du Miniftere qui a devancé ces faints Ecrits, n'a pas difcontinué. Ce n'eft point proprement la doctrine d'Apollo, ni la doctrine des Peres qui nous fuffit. Ce n'eft point Céphas ni fes Succefleurs qui operent en nous la juftice. Ils font tous, felon les différents de grés de leurs départements, les architectes de cet unique édifice que Dieu chérit. Tous leurs écrits, tous leurs travaux, tous leurs minifteres exercés \& tranfmis, toutes les graces perfonnelles fontenlemble devenus nos biens communs.

Ce qui affure notre écat, c'eft comme dans les Sociétés Civiles, le concours trèspublic \& très-indiffoluble de tous ces moyens qui s'entraident à jamais, \& fe juftifient mutuellement aux yeux de tout d'univers: nous les trouvons tour d'un coup \& uniquement dans l'Eglife Cacholique, dans la Communion des Saints, dans l'unité.

Tome VIII. Part. II. I 


\section{LE SPECT A C L E}

Lis D'. C'eft cette immortelle Communion des Monstr. Saints rendue fenfible pour nous fixer, Evanger. toujours vifible par les liens des Eglifes, $\&$ anéantie pour ceux qui les rompent; c'eft cette unité qui embraffe \& nous montre tous nos avantages, en nous donnane en propre la prédication Apoftolique qu'elle immortalife par l'Ordination; les Ecritures qu'elle a garanties depuis le premier fiecle par une publication journaliere; les Témoignages des Eglifes, qu'elle conjoint malgré leur difperfion; la Primauté par laquelle dans toute la durée des âges elle montre le corps de l'Eglife \& en unit les membres. C'eft en un mor l'unité qui nous met en mains l'Alliance avec les preuves, qui la notifient \& avec cous les profits qui en découlent : il ne s'en perd aucun, parce que l'unité lẹs recueille tous.

Les léçons d'A pollo n'ont pas été pout la feule Eglife-de Corinthe, ni celles de Cyptien pour la reule Eglife de Cartliage, ni celles de Boffuet pour la feule Eglife de NIeaux. C'eft pour l'unité que font lés Prédicateurs de Jefus-Chrift \& le Chef de la prédication. L'unité a tout difcerné, tour acquis, \& tout perpétué. C'eft donc par cette unité que tout nous appartient en commun : Omnia veftra funt, five Paulus, five Apollo, five Cephas. 
DE L A N.A T R E: 337

Hors de cette unité tout nous échappe, IA is:ou ce qui nous demeure eft fans profit, sionstr.

Hors de la communion des Saints le t́variger.

Chriftianifme n'eit plus que la Religion de celui-ci ou de celui-là. C'eft une ap. parence de fageffe; c'eft une préfomption fans réalicé; c'eft l'introduction d'une voie nouvelle; c'eft la condamnation de celle que Dieu avoit choifie pour toujours.

Dans l'unité, au contraire, nous ne nous attachons avec chaleur à aucun homme, ni même à aucune école, parce que nous $I$. C Cr. j: avons beaucoup mieux. Tout eft à nous: İ. nous avons l'Eglife entiere pour notre école, \& pour Mlaître celui qui a établi l'immortelle tranfmiffion de fes volontés une fois notifiées à un College de Minifrres. Nul établiffement plus fimple, plus fûr, \& plus humain. Ce College s'eft accru comme les befoins de l'Eglife : il fubfifte, \& par luil'Eglife eft toujours une.

Dans cer unique Temple du Seigneur, avec des imperfections paffageres \& prédites, fe trouvera à jamajs la parole de vie, la fainteté, \& l’immobilité égalemen prédites.

,C'eft donc là que la piéré faic un profit " durable du monde \& de la vie; des ", fcandales \& desépreuves; des maladies „\& de la mort : c'eft là que la piété ap. $\mathrm{R}$ ij 


\section{LE SPECTACLE, \&C.}

Ls D'-, , prend à ufer de ce qui paffe, \& à s'ap. MoxsTr. "proprier le falut à venir: Sive munErancel. "dus, five vita, five mors, five prafentia, five futura, omnia veftra funt.

Vous tous qui fentez vivement l'extrême înfuffifance des noms les plus célebres, vous ne comprenez pas moins la folidité des avantages de l'unité : pauvres parzout ailleurs, ici vous devenez héritiers de tout. L'unité vous fait part \& des lumieres précédentes, \& desfervicesactuels, \& des profits de tous les pouvoirs fpiricuels. Par votre tendre attachement à l'unité du Miniftere \&̊ du Dépôt, vous acquérez tout ce que l'Eglife poffede. "Vous " ne mettez plus votre gloire dans les

* Eid, "hommes. " "Par leurs raifonnements ils ne font devenus niles confidents du TrèsHaur, ni les difpenfateurs des vrais biens. Ni eux, ni vous, à l'égard du falut, vous ne découvrez en vous-même que le befoin d'être aidés : mais dans cette unité, fource de toute vérité \& de toute certizude, "Tout eft vraiment à vous, com", me vous y êtes vous-mêmes à Jefus"Chrift, \& Jefus-Chrift à Dieu. "O Omria onim veftra funt : vos auteris Chrifir, Chrifus autem Dei. 


\section{T A B L E}

DES M A TIERES。

(

U Uite ne la Démonstration EVANGÉLIQUE.

Chapitre I. Examen de l'Alliance Cluétienne par la preuve commune de tous les Traités,

Page I

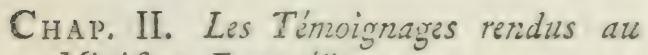
Miniftere Evangélique, I9

I. Le Témoignage de l'Esprit, - 22

II. Le Témoiznage du Baptéme, 92 III. Le Témoignage du Sang, $\quad 106$

OBJECTION,

I 2

Chap. III. La perpétuité des Témoignages rendus au Miniftere Evangélique,

I 8

I. La publicité du Miniftere Catholique, E de l'Eglife Catholique, $\quad$ I28

II. L'unité du Miniftere Catholique, E de l'Eglife Catholique, 238

De la Tolérsnce Chrétienne, $\quad 316$ 


\section{TABLE DES MATIERES.}

Cна p. IV. La Démonfration EvangéLique, proportionnée à la capacité du Peuple,

Discours d'un Curé de campagne au jour de fa prife de poffeffion,

328

Conclusion du TRAITÉ to L'HOMME,

$$
\text { FIN. }
$$


$A P P R O B A T I O N$.

J'A I lu, par ordre de Monfeigneur le Chancelier, le huitieme Tome du speciacle de la Narure, qui traite de l'Homme en $/ 0-$ ciété avec Dieu. Il m'a paru que la lećture en feroit utile \& agréable au Public. A Paris, ce 14 Juin 1749 .

MILLET。

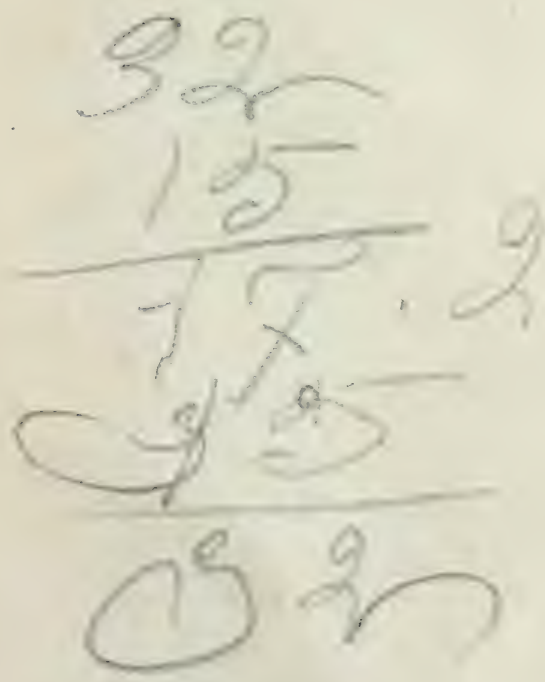







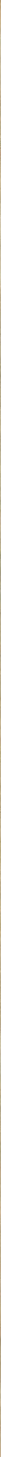




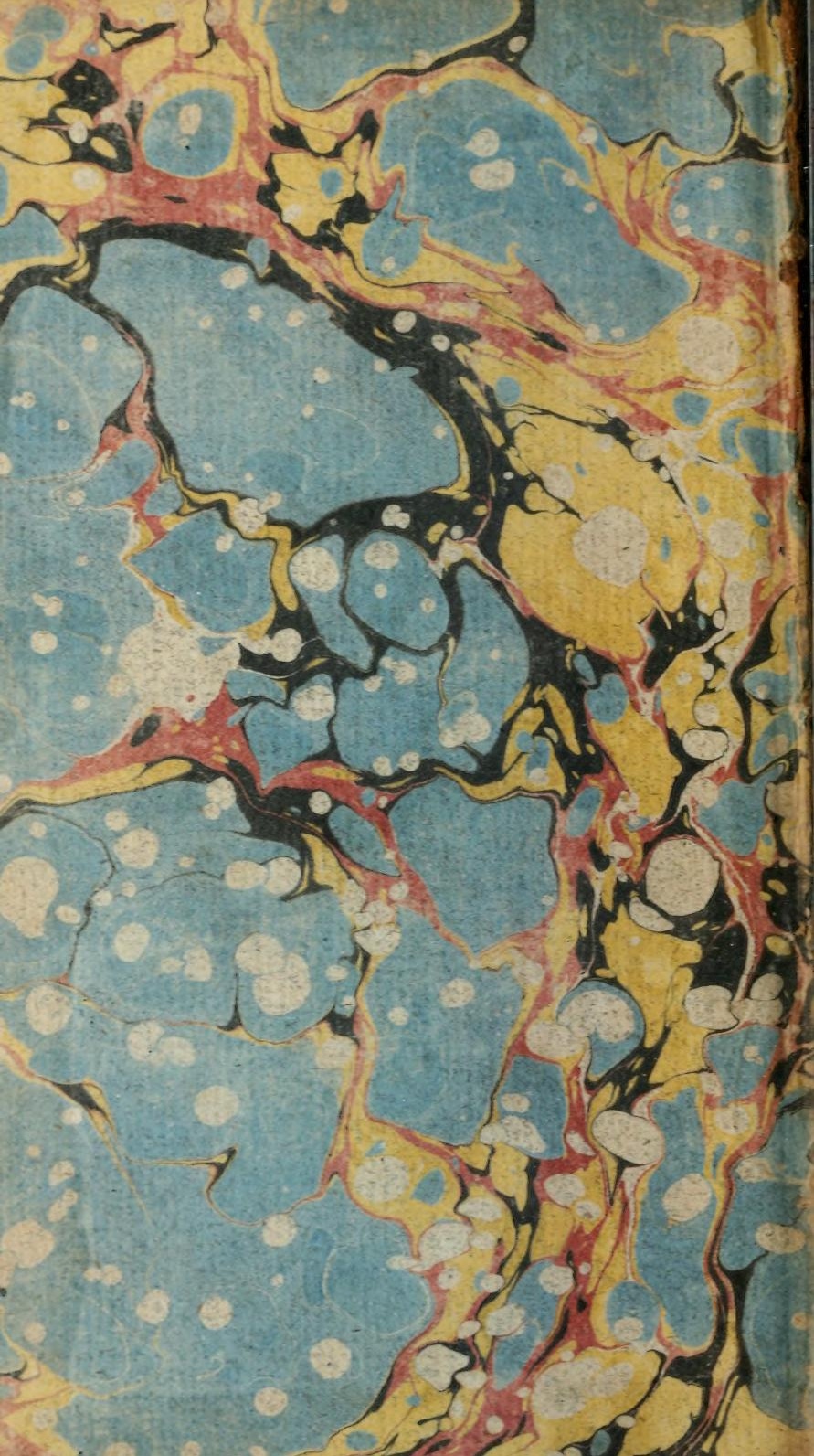




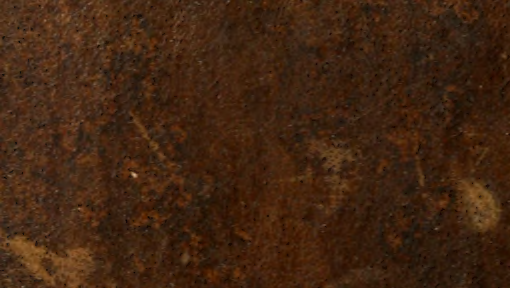

\section{bistion.}

\section{astion}

$6 x^{3}$

$\cos ^{2} \sin ^{2}$

(2)

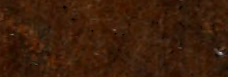

